INSTITUTO DE PESQUISAS ENERGÉTICAS E NUCLEARES

Autarquia Associada à Universidade de São Paulo

\title{
EFEITO DO MANEJO AGRÍCOLA, DA SAZONALIDADE E DOS ELEMENTOS \\ TRAÇO NA PRODUÇÃO DOS ÓLEOS VOLÁTEIS DE ERVA-CIDREIRA (MELISSA OFFICINALIS L.)
}

Fábio Vitório Sussa

Tese apresentada como parte dos requisitos para obtenção do Grau de Doutor em Ciências na Área de Tecnologia Nuclear - Aplicações.

Orientador:

Prof. Dr. Paulo Sergio Cardoso da Silva

Versão Corrigida

Versão Original disponível no IPEN

SÃO PAULO

2017 
Dedico esta pesquisa à minha família e especialmente à minha mãezinha que sempre me incentivou, me apoiou nas minhas escolhas e que me amou incondicionalmente. 


\section{AGRADECIMENTOS}

Agradeço a Deus por aproximar todas as pessoas que colaboraram comigo para a realização deste trabalho.

À minha família que sempre me motivou rumo à vida acadêmica.

Ao Rodrigo Mar, por todo convívio, apoio e compreensão.

Ao meu orientador, Prof. Dr. Paulo Sergio Cardoso da Silva, pelo voto de confiança e orientação desde a minha iniciação científica. Sinto-me privilegiado pela oportunidade de ter caminhado esses anos todos ao seu lado e ter aprendido muito mais do que apenas questões acadêmicas. Admiro seu profissionalismo e dedicação. Muito agradecido.

À farmacêutica Linete Mezenga Haraguchi que possibilitou a vivência no seu curso de plantas medicinais e fitoterapia e a realização deste trabalho.

Aos engenheiros agrônomos Adão Luiz Castanheiro Martins, Marcos Roberto Furlan e Marcos Victorino que compartilharam seus conhecimentos e contribuíram para a concretização desse trabalho.

Aos amigos do Departamento de Educação Ambiental - Universidade Aberta do Meio Ambiente e Cultura da Paz (DEA/UMAPAZ) que colaboraram com ensinamentos teóricos, práticos e cederam gentilmente o espaço para a instalação dos experimentos.

À Dra. Celina Lopes Duarte e à Luana Andrade pelos seus ensinamentos e colaboração com as análises cromatográficas realizadas no Centro de Tecnologia das Radiações do IPEN (CTR/IPEN).

Ao Dr. Rubens Cesar Lopes Figueira e ao Alexandre Barbosa Salaroli pela colaboração com as análises químicas realizadas no Instituto Oceanográfico da USP (IO/USP). 
Aos meus velhos e novos amigos do Centro do Reator de Pesquisa/IPEN (CRPq/IPEN).

Aos meus amigos e amigas de jornada.

Ao IPEN pela condução de programas de pós-graduação em nível de mestrado e doutorado, sem os quais não seria possível este trabalho de pesquisa.

Aos integrantes da banca pelas revisões e sugestões apresentadas no decorrer dessa pesquisa com o objetivo de aprimorar o trabalho.

Ao CNPq pelo apoio financeiro. 
No próximo milênio, os países que tiverem mais florestas e culturas primitivas preservadas serão beneficiados na pesquisa e na alimentação.

(Orlando Villas-Boas, 1998) 


\title{
EFEITO DO MANEJO AGRÍCOLA, DA SAZONALIDADE E DOS ELEMENTOS TRAÇO NA PRODUÇÃO DOS ÓLEOS VOLÁTEIS DE ERVA-CIDREIRA (MELISSA OFFICINALIS L.)
}

\author{
Fábio Vitório Sussa
}

\section{RESUMO}

Este trabalho é um estudo interdisciplinar envolvendo o cultivo de ervacidreira (Melissa officinalis L.) e sua caracterização química. O objetivo deste estudo foi fornecer informação sobre a adubação orgânica e convencional, a sazonalidade e os efeitos dos elementos traço na produção dos óleos voláteis de Melissa officinalis. O modelo experimental utilizado foi em canteiros com delineamento inteiramente casualizados (DIC) com quatro repetições. Melissa officinalis foi submetida a diferentes sistemas de adubação e época de colheita. A concentração elementar foi determinada pela análise por ativação neutrônica instrumental (INAA), espectrometria de absorção atômica por forno de grafite (GF AAS) e espectrometria de emissão óptica com fonte de plasma indutivamente acoplado (ICP-OES) nas folhas de Melissa officinalis e nos solos de cultivo. Os óleos voláteis de Melissa officinalis foram extraídos pela técnica de hidrodestilação, utilizando-se o aparelho de Clevenger e os principais metabólitos secundários (citronelal, neral, geranial, citronelol, nerol e geraniol) foram determinados por cromatografia gasosa acoplada ao espectrômetro de massas (GC-MS). Primavera e verão apresentaram os óleos de melhor qualidade por possuírem menores teores de citronelol, nerol e geraniol. A formação de neral e geranial foi favorecida no manejo convencional correlacionado com a presença dos elementos $\mathrm{Co}, \mathrm{Cr}$, Mg e Ni presentes no solo, enquanto que a formação do citronelal foi favorecida no manejo orgânico correlacionado com o elemento $\mathrm{Mn}$ presente nas folhas de Melissa officinalis. 


\title{
AGRICULTURAL MANAGEMENT, SEASON AND TRACE ELEMENTS EFFECT ON VOLATILE OIL PRODUCTION FROM LEMON BALM
}

(MELISSA OFFICINALIS L.)

\author{
Fábio Vitório Sussa
}

\begin{abstract}
This work is an interdisciplinary study of Lemon balm cultivation (Melissa officinalis L.) and its chemical characterization. The objective of this study was to provide information about organic and mineral fertilization, season and trace elements effects on volatile oil production by the species Melissa officinalis. The experimental design was completely randomized with four replications. Melissa officinalis was under different fertilization and harvest season. Instrumental neutron activation analysis (INAA), graphite furnace atomic absorption spectrometry (GF AAS) and inductively coupled plasma optical emission spectrometry (ICP-OES) were applied to determine the elemental concentration in the soil and plant samples. The volatile oil was extracted by hydrodistillation and the compounds citronelal, neral, geranial, citronelol, nerol and geraniol were analyzed by gas chromatography coupled to a mass spectrometer (GC-MS). The best quality of the oil was obtained in spring and summer because the lower content of citronellol, nerol and geraniol. Neral and geranial formation was favored in the conventional management correlated with the presence of $\mathrm{Co}, \mathrm{Cr}, \mathrm{Mg}$ and $\mathrm{Ni}$ elements present in the soil, whereas citronellal formation was favored in organic management correlated with $\mathrm{Mn}$ element present in the Melissa officinalis leaves.
\end{abstract}




\section{SUMÁRIO}

Página

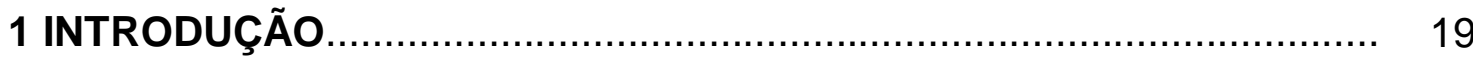

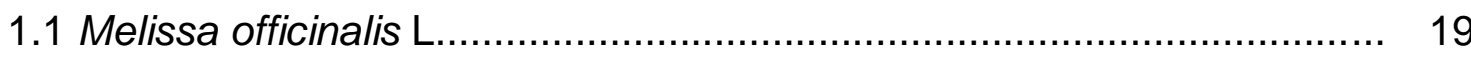

1.2 Princípios ativos....................................................................... 21

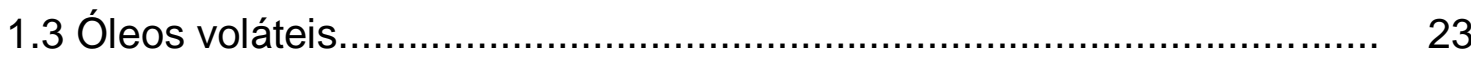

1.3.1 Biossíntese dos óleos voláteis....................................................... 23

1.4 Macronutrientes, micronutrientes e elementos traço .............................. 26

1.5 Adubação orgânica e mineral............................................................. 28

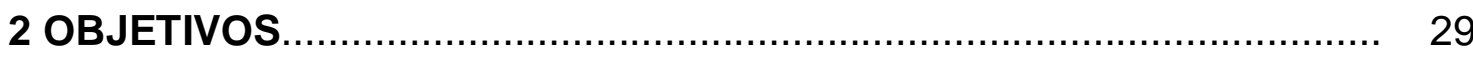

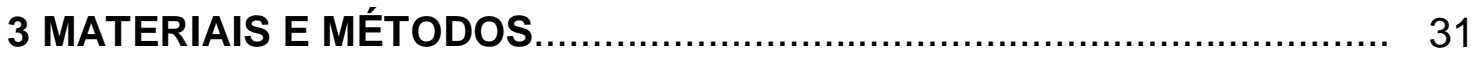

3.1 Local dos experimentos.................................................................... 31

3.2 Dados climáticos................................................................................ 32

3.3 Material botânico....................................................................... 33

3.4 Condições de cultivo...................................................................... 34

3.5 Coletas e preparo das amostras de solo............................................. 35

3.6 Coletas e preparo das amostras de planta.......................................... 40

3.7 Análise por ativação neutrônica instrumental (INAA)............................ 43

3.8 Preparação das amostras de solo para irradiação................................. 48

3.9 Preparação das amostras de planta para irradiação.............................. 49

3.10 Preparação dos materiais de referência e padrões sintéticos pipetados para irradiação..................................................................... 50

3.11 Irradiações e medidas....................................................................... 51

3.12 Espectrometria de absorção atômica por forno de grafite (GF AAS).... 52 
3.12.1 Procedimento experimental para as analise de $\mathrm{Cd}, \mathrm{Cu}$, $\mathrm{Ni}$ e $\mathrm{Pb} \ldots \ldots . .53$

3.13 Limite inferior de detecção (LID) e limite de quantificação (LQ)........... 58

3.14 Determinação dos óleos voláteis de Melissa officinalis...................... 61

3.14.1 Extração e caracterização dos óleos voláteis............................... 61

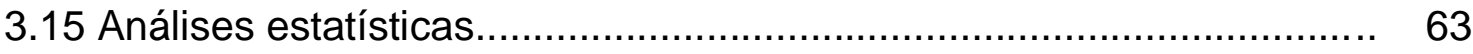

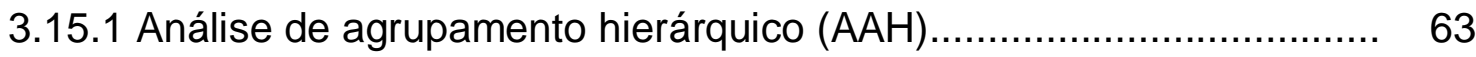

3.15.2 Análise de componentes principais (PCA) ................................... 64

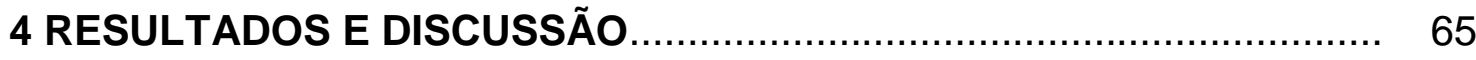

4.1 Caracterização elementar nas amostras de solo e de planta................ 65

4.1.1 Controle de qualidade dos procedimentos analíticos..................... 65

4.1.1.1 Precisão e exatidão dos resultados para INAA.......................... 65

4.1.1.2 Precisão e exatidão dos resultados para GF AAS e ICP-OES......... 68

4.2 Determinações das concentrações elementares............................. 70

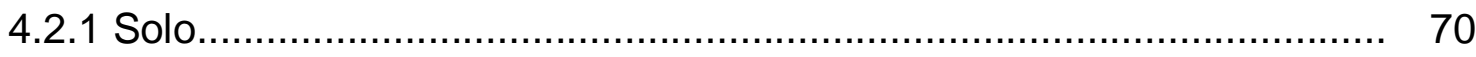

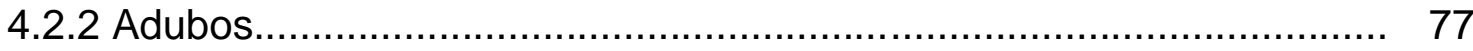

4.2.2.1 Composto orgânico, cama de frango e NPK............................ 77

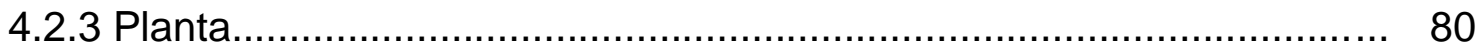

4.2.3.1 Análise de biomassa fresca de Melissa officinalis....................... 80

4.2.3.2 Análise da concentração dos elementos nas folhas de Melissa

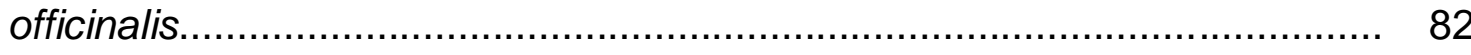

4.2.3.3 Análise dos teores dos óleos voláteis de Melissa officinalis............ 91

4.2.3.4 Análise dos óleos voláteis de Melissa officinalis por GC/MS........... 93

4.3 Análise de Correlação de Pearson............................................. 103

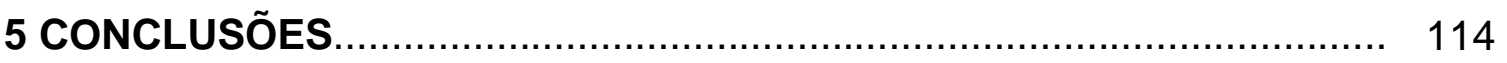

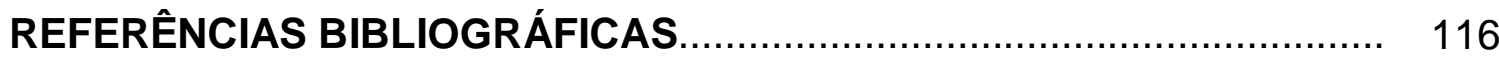




\section{LISTA DE TABELAS}

\section{Página}

TABELA 3.1 - Temperatura mensal média e precipitação mensal média nos períodos de janeiro de 2013 e janeiro de 2014

TABELA 3.2 - Análise química do solo utilizado como substrato no cultivo de Melissa officinalis.

TABELA 3.3 - Recomendação de adubação orgânica e convencional para melissa em função da análise do solo.

TABELA 3.4 - Recomendação de adubação orgânica utilizada para o plantio de Melissa officinalis baseada na adubação de hortelã (Boletim 100 - IAC).

TABELA 3.5 - Recomendação de adubação convencional utilizada para o plantio de Melissa officinalis baseada na adubação de hortelã (Boletim 100 - IAC)

TABELA 3.6 - Elementos analisados por ativação neutrônica, radioisótopo formado na ativação, energia dos raios gama utilizados na espectrometria gama e suas respectivas meias vidas.

TABELA 3.7 - Materiais de referência empregados para determinação elementar e garantia da qualidade analítica.

TABELA 3.8 - Elementos presentes e suas concentrações (conc. \pm incerteza) ou valor informativo, em $\mathrm{mg} \mathrm{kg}^{-1}$, nos materiais de referência IAEA-336, USGS STM-2, NIST 1646a e nos padrões pipetados (P.P) utilizados para INAA.

TABELA 3.9 - Elementos presentes e suas concentrações (conc. \pm incerteza), em $\mathrm{mg} \mathrm{kg}^{-1}$, nos materiais de referência Tomato Leaves, Peach Leaves e dos padrões pipetados (P.P), utilizados para INAA.

TABELA 3.10 - Parâmetros instrumentais na determinação de $\mathrm{Cu}, \mathrm{Cd}$ e Pb ajustados para análise 
TABELA 3.11 - Etapas de aquecimento do forno de grafite para determinação de $\mathrm{Cd}$, $\mathrm{Cu}$ e $\mathrm{Pb}$................................................ 55

TABELA 3.12 - Soluções utilizadas na construção da curva de calibração para determinação de $\mathrm{Cd}, \mathrm{Cu}, \mathrm{Ni}, \mathrm{Pb}^{1}$ e $\mathrm{Pb}^{2}$.......................... 56

TABELA 3.13 - Avaliação das premissas envolvidas no estudo de linearidade para as curvas analíticas de $\mathrm{Cd}, \mathrm{Cu}, \mathrm{Ni}$ e $\mathrm{Pb}$.........

TABELA 3.14 - Valores de Limite inferior de detecção (LID) e Limite de quantificação (LQ), em mg kg-1 , para as técnicas de INAA, GFAAS e IPC-OES obtidos para os elementos no material de referência IAEA-336, NIST 1646a e P.P

TABELA 4.1 - Resultados obtidos para o MR NIST 1646a utilizado para a verificação da qualidade dos resultados para a técnica de INAA, em mg kg-1 ${ }^{-1}(\mathrm{n}=6)$.

TABELA 4.2 - Resultados obtidos para o MR USGS STM-2 utilizado para a verificação da qualidade dos resultados para a técnica de INAA, em mg kg-1 ${ }^{-1}(\mathrm{n}=6)$

TABELA 4.3 - Resultados obtidos para o padrão sintético pipetado (PSP) utilizado para a verificação da qualidade dos resultados para a técnica de INAA, em $\mathrm{mg} \mathrm{kg}^{-1}$, $(\mathrm{n}=6)$......

TABELA 4.4 - Resultados obtidos para o MR IAEA-336 utilizado para a verificação da qualidade dos resultados para a técnica de INAA, em mg kg-1 ${ }^{-1}(n=4)$.

TABELA 4.5 - Resultados obtidos para os MR NIST 1547 (Peach leaves) e NIST 1573a (Tomato leaves) utilizado para a verificação da qualidade dos resultados para a técnica de INAA, em $\mathrm{mg} \mathrm{kg}^{-1},(\mathrm{n}=4)$.

TABELA 4.6 - Média das concentrações obtidas de $\mathrm{Cd}, \mathrm{Cu}, \mathrm{Ni}$ e Pb, em mg $\mathrm{Kg}^{-1}$, para os MR IAEA-336, NIST 1573a e NIST $1646 a$

TABELA 4.7 - Resultados das análises elementares para as amostras de solo, em mg kg-1

TABELA 4.8 - Concentrações médias para os 30 elementos determinados no solo. 
TABELA 4.9 - Concentração dos elementos nos adubos orgânicos aplicados nesta pesquisa e nos adubos químicos descritos na literatura, em $\mathrm{mg} \mathrm{kg}^{-1}$

TABELA 4.10 - Resultados da biomassa (BM) fresca de Melissa officinalis considerando os sistemas de cultivo e época de colheita, em gramas.

TABELA 4.11 - Análises descritivas das amostras de folhas considerando a média e coeficiente de variação para os sistemas de cultivo aplicados e sazonalidade, em $\mathrm{mg} \mathrm{kg}^{-1}$....

TABELA 4.12 - Resultados das análises elementares para as amostras de planta, $\mathrm{mg} \mathrm{kg}^{-1}$

TABELA 4.13 - Resultados dos teores dos óleos voláteis de Melissa officinalis sobre interação do manejo agrícola e época de colheita, em porcentagem.

TABELA 4.14 - Análise de variância, tendo como efeitos o manejo e a sazonalidade, aplicada ao teor de óleo volátil.

TABELA 4.15 - Análises descritivas dos óleos voláteis de Melissa officinalis considerando os sistemas de cultivo aplicados e sazonalidade, em porcentagem.

TABELA 4.16 - Porcentagem dos óleos voláteis de Melissa officinalis (média $\pm \mathrm{DP}$ ) considerando o manejo agrícola e época de colheita.

TABELA 4.17 - Matriz de correlação de Pearson entre os metais no solo e nas folhas de Melissa officinalis.

TABELA 4.18 - Matriz de correlação de Pearson entre os compostos do óleo volátil, teor, biomassa e os elementos inorgânicos presentes no solo.

TABELA 4.19 - Matriz de correlação de Pearson entre os compostos do óleo volátil, teor, biomassa e os elementos inorgânicos presentes nas folhas de Melissa officinalis. 


\section{LISTA DE FIGURAS}

Página

FIGURA 1.1 - Melissa officinalis L.................................................. 20

FIGURA 1.2 - Compostos majoritários dos óleos voláteis de Melissa officnalis.......................................................................... 23

FIGURA 1.3 - Rota biossintética proposta da função dos metais no metabolismo dos óleos voláteis em Melissa officinalis............ 25

FIGURA 3.1 - Local do experimento (Google Earth, 14/12/2008)............... 31

FIGURA 3.2 - Vista aérea do Parque Ibirapuera (Google Earth,

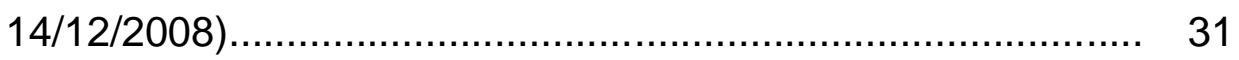

FIGURA 3.3 - Temperatura mensal média nos períodos de janeiro/2013 e janeiro/2014 .................................................................. 32

FIGURA 3.4 - Precipitação mensal média nos períodos de janeiro/2013 e janeiro/2014 ........................................................... 33

FIGURA 3.5 - Sementeiras em substrato convencional (a) e orgânico (b)... 33

FIGURA 3.6 - Transplante das mudas de melissa para os vasos plásticos......................................................................... 34

FIGURA 3.7 - Disposição dos sistemas de cultivo no campo

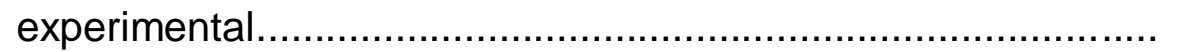

FIGURA 3.8 - Disposição dos vasos de plásticos no campo experimental.

FIGURA 3.9 - Boletim Técnico 100 - Recomendação para adubação de hortelã.

FIGURA 3.10 - llustração dos processos de preparação das amostras de solo: identificação (etapa I), coleta (etapa II), secagem das amostras (etapa III), quarteamento (etapa IV), pulverização (etapa V) e armazenamento (etapa VI).

FIGURA 3.11 - llustração dos processos de colheita das amostras de melissa: corte (etapa I) e armazenamento (etapa II) 
FIGURA 3.12 - llustração dos processos de preparação das amostras de melissa: recebimento das amostras no laboratório (etapa I), pesagem (etapa II), separação das folhas (etapa III) e separação das alíquotas (etapa IV)

FIGURA 3.13 - llustração dos processos para preparação das amostras para análise multielementar: secagem em estufa (etapa I), amostra seca (etapa II), pulverização (etapa III) e armazenamento (etapa IV).

FIGURA 3.14 - llustração da sequência de eventos para uma reação (n, y).

FIGURA 3.15 - llustração dos processos para preparação das amostras para irradiação: acondicionamento das amostras em saquinhos de polietileno (etapa I), invólucros selados, embalados em folha de alumínio e acondicionados em cápsula de alumínio para irradiação (etapa II).

FIGURA 3.16 - llustração dos processos para preparação das amostras para irradiação: acondicionamento das amostras em saquinhos de polietileno (etapa I), invólucros selados e embalados em papel de celulose (etapa II) e acondicionamento em cápsula de polietileno (etapa III)............

FIGURA 3.17 - llustração dos processos para preparação das amostras para irradiação: acondicionamento, selagem e embalagem para irradiação longa (a), embalagem em papel de celulose (b) e acondicionamento em cápsula de polietileno para irradiação curta (c)

FIGURA 3.18 - llustração dos processos para preparação das amostras para irradiação: transferência da solução para papel de filtro (etapa I), secagem dos papéis (etapa II) e acondicionamento em saquinhos de polietileno (etapa III).

FIGURA 3.19 - llustração do sistema com detector de Germânio Hiperpuro e eletrônica associada do Laboratório de Análise por Ativação Neutrônica. 
FIGURA 3.20 - llustração do processo de digestão das amostras para análise no GF AAS: amostra triturada e homogeneizada (etapa I), tratamento com ácidos em frasco de teflon (etapa II), digestão em micro-ondas (etapa III) e filtração e armazenamento em tubos plásticos (etapa IV).

FIGURA 3.21 - Equipamento de GF AAS modelo AAnalyst 800 da Perkin Elmer para determinação de $\mathrm{Cd}$, $\mathrm{Cu}$ e $\mathrm{Pb}$.

FIGURA 3.22 - Curva de calibração para Cd obtida por GF AAS. 56

FIGURA 3.23 - Curva de calibração para Cu obtida por GF AAS.................. 56

FIGURA 3.24 - Curva de calibração para Ni obtida por ICP-OES................. 57

FIGURA 3.25 - Curva de calibração para $\mathrm{Pb}^{1}$ obtida por GF AAS................. 57

FIGURA 3.26 - Curva de calibração para $\mathrm{Pb}^{2}$ obtida por GF AAS................ 57

FIGURA 3.27 - Aparelho de Clevenger................................................ 61

FIGURA 3.28 - Cromatógrafo gasoso acoplado ao espectrômetro de massas (GC/MS) ................................................. 62

FIGURA 4.1 - Valores de $E_{n}$-score obtidos na análise dos materiais de referência de matriz biológica.

FIGURA 4.2 - Valores de $E_{n}$-score obtidos na análise dos materiais de referência de matriz geológica e nos padrões sintéticos pipetados

FIGURA 4.3 - Resultado da Análise de Componentes Principais (PCA) mostrando as duas primeiras Componentes Principais para os dados do solo: (a) Gráfico dos "scores"; (b) Gráfico "Biplot".

FIGURA 4.4 - Concentração dos elementos nos adubos aplicados nos sistemas de cultivo: dados transformados. CO (composto orgânico) e CF (cama de frango)

FIGURA 4.5 - Biomassa fresca de Melissa officinalis considerando o manejo agrícola e época de colheita.

FIGURA 4.6 - Dendrograma da classificação das amostras de planta em três grupos, em função da biomassa fresca. 
FIGURA 4.7 - Teores dos óleos voláteis extraídos das folhas de Melissa officinalis considerando o manejo agrícola e época de colheita

FIGURA 4.8 - Cromatograma do padrão de citronelal em hexano com tempo de retenção nas análises de GC/MS.

FIGURA 4.9 - Cromatograma do padrão de citral em hexano com os tempos de retenção de neral e geranial, respectivamente, nas análises de GC/MS

FIGURA 4.10 - Sobreposição do cromatograma do ensaio em branco com os cromatogramas dos padrões comerciais na análise de citronelal, neral e geranial.

FIGURA 4.11 - Cromatograma dos óleos voláteis de Melissa officinalis.

FIGURA 4.12 - Porcentagem relativa média dos óleos voláteis de Melissa officinalis obtidos para a primeira coleta, outono (abril/2013)

FIGURA 4.13 - Porcentagem relativa média dos óleos voláteis de Melissa officinalis obtidos para a segunda coleta, inverno (julho/2013).

FIGURA 4.14 - Porcentagem relativa média dos óleos voláteis de Melissa officinalis obtidos para a terceira coleta, primavera (outubro/2013). 100

FIGURA 4.15 - Porcentagem relativa média dos óleos voláteis de Melissa officinalis obtidos para a quarta coleta, verão (janeiro/2014).

FIGURA 4.16 - Resultado da Análise de Componentes Principais (CP 1 e 2) mostrando o manejo agrícola (controle, orgânico e convencional), metais nos solos, metais nas folhas $\left({ }^{*}\right)$ e os óleos voláteis de Melissa officinalis.

FIGURA 4.17 - Dendrograma obtido entre os metais e os óleos voláteis de Melissa officinalis.

FIGURA 4.18 Correlações entre os metais no solo e nas folhas de Melissa officinalis. 
FIGURA 4.19 Correlações entre os óleos voláteis de Melissa officinalis e os metais presentes no solo..................................................... 110

FIGURA 4.20 Correlações entre os óleos voláteis e os metais presentes nas folhas de Melissa officinalis. 


\section{LISTA DE ABREVIATURAS/E OU SIGLAS}

AAH Análise de Agrupamento Hierárquico

ANVISA Agência Nacional de Vigilância Sanitária

ATP Adenosina trifosfato

CNEN Comissão Nacional de Energia Nuclear

DNA Ácido desoxirribonucléico

GC/MS Gas Cromatography Mass Spectrometry - Cromatografia gasosa acoplada à espectrometria de massas

GF AAS Graphite Furnace Atomic Absorption Spectroscopy - Espectrometria de absorção atômica com forno de grafite

IAC Instituto agronômico de Campinas

IAG Instituto de Astronomia, Geofísica e Ciências Atmosféricas

IAEA International Atomic Energy Agency - Agência Internacional de Energia Atômica

IEA-R1 Instituto de Energia Atômica-Reator 1

ICP-OES Inductively Coupled Plasma - Atomic Emission SpectrometryEspectrometria de emissão atômica com plasma indutivamente acoplado

INAA Instrumental Neutron Activation Analisys - Análise por ativação neutrônica instrumental

IPEN Instituto de Pesquisas Energéticas e Nucleares

L. Linneu

LAN Laboratório de Ativação Neutrônica

MR Material de referência

$\mathrm{NADH} \quad$ Nicotinamida-adenina-dinucleotídio

NADPH Nicotinamida-adenina dinucleótido-fosfato

NIST National Institute of Standards and Technology

P.P Padrão pipetado

PMSP Prefeitura Municipal de São Paulo

RDC Resolução da Diretoria Colegiada

RNA Ácido ribonucléico

SRM Standard Reference Material 


\section{INTRODUÇÃO}

A partir da Graduação em Farmácia, dos estudos e das pesquisas relacionadas com plantas medicinais e a vivência do curso de Plantas Medicinais e Fitoterapia realizado e coordenado pela farmacêutica Linete Maria Menzenga Haragushi, promovido pela Secretaria do Verde e do Meio Ambiente na Universidade Aberta do Meio Ambiente e da Cultura da Paz (UMAPAZ) em parceria com a Secretaria Municipal da Saúde de São Paulo, foi elaborada a presente Tese.

Durante o curso de capacitação em Plantas Medicinais e Fitoterapia para profissionais de saúde discutiu-se as questões relacionadas às Políticas Públicas na implantação do Programa de Fitoterápicos e Plantas Medicinais do Município de São Paulo e a implantação das Práticas Integrativas e Complementares (PICs) "Plantas Medicinais e Fitoterapia" no Sistema Único de Saúde (SUS).

Essa política traz, dentre suas diretrizes, a elaboração da Relação Nacional de Plantas Medicinais e de Fitoterápicos (Renafito) e o provimento do acesso a plantas medicinais e fitoterápicos aos usuários do SUS - através da Relação Nacional de Plantas Medicinais de interesse ao SUS (RENISUS).

Para garantir o acesso seguro e o uso racional de plantas medicinais e fitoterápicos é importante promover pesquisas, regulamentar o cultivo, identificar princípios ativos bem como investigar a correlação entre os fatores que afetam a formação, o crescimento e as características medicinais das plantas (Brasil, 2006).

Neste sentido, visando contribuir ao estudo de plantas medicinais, às discussões das Políticas Nacionais de implantação de Plantas Medicinais e Fitoterápicos, voltadas à implementação da Fitoterapia no Sistema Único de Saúde, realizou-se o estudo com a espécie Melissa officinalis L.

\subsection{Melissa officinalis $\mathrm{L}$.}

A espécie estudada foi escolhida entre aquelas presentes na resolução RDC № 10, de 9 de março de 2010, que dispõe sobre o uso de drogas vegetais 
junto à Agência Nacional de Vigilância Sanitária, ANVISA (ANVISA, 2010). Desta forma, o uso dessas plantas passa a ter a chancela oficial do órgão governamental regulador, e em consequência disso, ter sua demanda bastante aumentada. A obtenção dessas plantas adquire então uma grande importância, uma vez que haverá a necessidade do aumento de sua produção. A própria Política Nacional de Plantas Medicinais e Fitoterápicos (PNPMF) já indicava essa necessidade com o estabelecimento de diretrizes voltadas à parte agronômica das plantas medicinais (Ming et al., 2012).

Foi escolhida uma espécie popularmente utilizada para controlar estresse, insônia e ansiedade (May et al, 2008; Sodré et al, 2012). Estes sintomas aumentaram consideravelmente nos últimos anos, tornando-se uma doença prevalente que afetam uma grande porcentagem da população (Petenatti et al, 2011), a qual tem cada vez mais recorrido a plantas medicinais disponível que pode executar a mesma ação terapêutica com menos efeitos colaterais, dependência ou tolerância do que os medicamentos sintéticos (Cass, 2004).

Melissa officinalis L. (FIG. 1.1), conhecida popularmente como erva-cidreira verdadeira ou melissa, é uma espécie botânica de origem asiática e européia, e cultivada no Brasil por mais de um século.

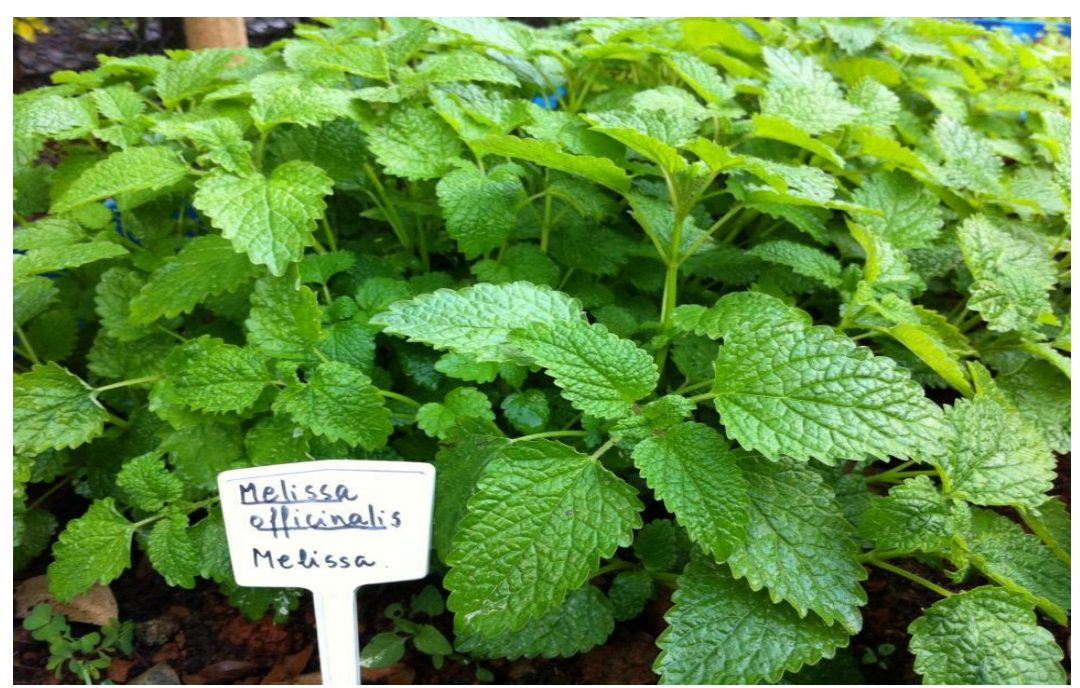

FIGURA 1.1 - Melissa officinalis L.

A espécie é uma erva de hábito perene, herbácea, rizomatosa, podendo variar de 30 a $100 \mathrm{~cm}$ de altura e de fácil cultivo. Suas folhas membranáceas são verde-escuras na parte superior e verde-clara na parte inferior atingindo de 3 a 6 
cm de comprimento, são grandes, pecioladas, opostas, lanceoladas, ovais e pilosas, serrilhadas e com nervuras bem salientes (Meira et al., 2011).

Pertence à família Lamiaceae, a qual compreende diversas espécies de importância na culinária, medicina, indústria farmacêutica e cosmética como o Rosmarinus officinalis L. (alecrim), Mentha piperita L. (hortelã-pimenta), Lavandula ssp. (lavanda), Ocimum basilicum L. (manjericão), Origanum vulgare L. (orégano), Salvia officinalis L. (sálvia), Thymus vulgaris L. (tomilho), Ocimum fratissimum L. (alfavaca) e Plectranthus barbatus (boldo-peludo).

Essa família apresenta distribuição cosmopolita, com cerca de 300 gêneros e aproximadamente 7500 espécies. No Brasil, ocorrem cerca de 350 espécies distribuídas em 26 gêneros (Aoyama et al., 2011).

A Melissa officinalis L. encontra-se numa posição de destaque no rol das plantas medicinais devido à sua importância fitoterapêutica. Esta espécie é utilizada popularmente para controlar crises nervosas, taquicardia, melancolia, histerismo e ansiedade (Meira et al., 2011).

As propriedades bioativas estudadas de $M$. officinalis incluem atividade sedativa (Blank et al., 2005), antiespamódicas, carminativas, estomáquicas, diaforéticas, antidrepressivas e vermífugas (Reis et al., 2009). Müzell (2006) ainda cita a ação antitumoral além de efeito na resposta imune humoral e celular de ratos. Estudos indicam a ação antivirótica contra o vírus do herpes (HSV) (Reis et al., 2009). As propriedades medicinais de Melissa officinalis estão relacionadas à ampla variedade química dos seus óleos voláteis ou essenciais (Colussi et al, 2011).

O cultivo de melissa tem crescido em importância econômica no setor produtivo de plantas medicinal, devido ao elevado valor econômico que os princípios ativos dessa planta têm alcançado no mercado (Freitas et al., 2002).

No Brasil, o interesse sobre a espécie tem se mostrado em trabalhos onde se analisa o crescimento, porém sem apreciação da produtividade propriamente dita (BLANK et al., 2005; MAY et al., 2008).

\subsection{Princípios ativos}

Os vegetais produzem uma grande variedade de compostos orgânicos que aparentemente não possuem função direta no seu crescimento e desenvolvimento, essas substâncias são conhecidas como metabólitos 
secundários. Sua produção é resultado de complexas interações entre biossíntese, transporte, estocagem e degradação, sendo cada um desses processos governado por genes e influenciado por três fatores principais: hereditariedade, estágio de desenvolvimento e ambiente (Castro et al., 2004; Santos, 2001).

Os metabólitos secundários estão relacionados à defesa vegetal protegendo as plantas da herbivoria, contra infecção por micro-organismos patogênicos, além de agirem como atrativos para os animais polinizadores, dispersores de sementes e como agentes na competição planta-planta (Taiz e Zeiger, 2006) e muitos são fitotóxicos, constituindo uma fonte relativamente inexplorada de novos herbicidas (Dias e Dias, 2004). Os metabólitos secundários são constituídos de diversos grupos: mucilagens, óleos essenciais, alcalóides, taninos, bioflavonoides, glicosidios, ácidos orgânicos, antraquinonas, compostos fenólicos, cumarinas e outros (Furlan, 2005).

O metabolismo secundário por sua vez pode ser influenciado por fatores climáticos, temperatura, intensidade de luz, efeito sazonal, etc. (Aguiar e Costa, 2005; Tavares et al., 2011). Gobbo-Neto e Lopes (2007) relacionam os principais fatores que podem coordenar ou alterar a taxa de produção de metabólitos secundários: sazonalidade, ritmo circadiano, temperatura, disponibilidade hídrica, radiação ultravioleta, estresse por nutrientes, altitude, poluição atmosférica e indução por estímulos mecânicos ou ataque de patógenos.

Informações sobre o efeito de condições ambientais no metabolismo secundário de plantas provêm principalmente de esforços da pesquisa para maximizar a produção de constituintes ativos de espécies medicinais e aromáticas. Avanços no sentido de compreender a influência dos fatores ambientais na regulação de biossíntese de metabólitos secundários, podem contribuir para um aumento na produção de compostos de interesse nestas espécies (Morais, 2009).

Diante ao exposto verifica-se que vários fatores influenciam nos teores dos elementos presentes em uma determinada parte da planta bem como no teor de metabólitos secundários produzidos. Este fato pode explicar porque as plantas provenientes de regiões distintas podem apresentar diferenças com relação à composição. 


\section{3 Óleos voláteis}

Os óleos voláteis de Melissa officinalis estão presentes nos tricomas secretores das folhas e apresentam o citral (geranial + neral - FIG. 1.2) como seu componente majoritário, sendo este o de maior interesse para a indústria farmacêutica devido às suas atividades antioxidativa, antimicótica, sedativa e antivirótica (Meira et al., 2011; Lorenzi \& Matos, 2002; Haber et al., 2005).

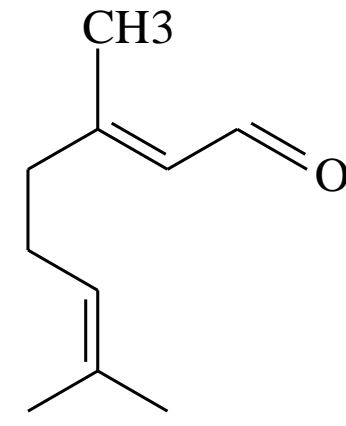

Geranial

(Citral A)

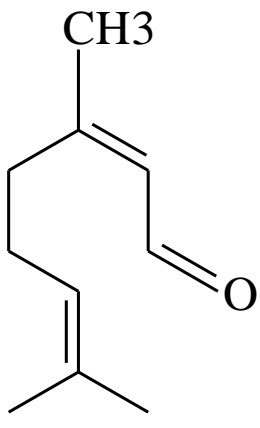

Neral

(Citral B)

FIGURA 1.2 - Compostos majoritários dos óleos voláteis de Melissa officinalis.

Seus óleos apresentam outros compostos em menor quantidade como o citronelal, metilcitronelal, citronelol, pineno, limoneno e linalol (Lorenzi e Matos, 2002; May et al., 2008).

Os teores totais de óleos voláteis de Melissa officinalis, obtidos por hidrodestilação são habitualmente muito baixos $(0,02$ a $0,40 \%)$ e tornam-se, assim, pertencente a uma das classes mais preciosas de óleo volátil, apresentando alto preço, comparado aos preços do óleo volátil de rosas e de flor de laranjeira (Sorensen, 2000). Outros fatores importantes a serem estudados, que podem influenciar na produção de óleo volátil, são a época de plantio (Silva, 2011) e a disponibilidade de nutrientes minerais (Brown et al., 2003).

\subsubsection{Biossíntese dos óleos voláteis}

Os metabólitos secundários das plantas provêm de três rotas biossintéticas conhecidas como via do acetato, mevalonato e do ácido chiquímico.

$\mathrm{Na}$ FIG. 1.3 é apresentada uma rota biossintética proposta para a biossíntese do citral elaborada a partir de dados coletados na literatura 
(Krishina et al., 2016; Kouachi et al., 2009; Mäki-Arvela et al., 2003; Mertens et al., 2007; Yilmaz et al., 2005, Didillon et al., 1992).

O citral vem da rota do acetato, derivado do acetil coenzima $A$, a qual, pela combinação de três moléculas de acetato, forma o intermediário ácido mevalônico (FIG. 1.3, etapa 1, item 1) com seis carbonos. O ácido mevalônico é então convertido no isopentenilpirofosfato (IPP) (FIG 1.3, etapa 1, item 2) e este, pela ação da enzima isopentenil pirofosfato isomerase sofre isomerização e forma 0 3,3-dimetilpirofosfato (DMAPP) (FIG. 1.3, etapa 1, item 3).

As enzimas que catalisam a união entre isoprenos, moléculas formadas por unidade de cinco carbonos, e que promovem o alongamento da cadeia terpênica são as prenil transferases, as quais são ativadas por $\mathrm{Mg}^{2+}$ e $\mathrm{Mn}^{2+}$ como cofatores.

Em seguida, os compostos IPP e DMAPP se unem e, através de uma reação catalisada pela enzima geranil pirofosfato sintetase (GDS), fornecem o primeiro monoterpeno $\left(\mathrm{C}_{10}\right)$ reconhecível que é o geranil pirofosfato (GPP), o precursor universal dos monoterpenóides (FIG. 1.3, etapa 2, item 4). A GDS prefere $\mathrm{Mg}^{2+}$ como cofator. Por fim, ocorre a perda da fração pirofosfato da molécula de GPP gerando produtos oxigenados, como o geraniol (FIG. 1.3, etapa 2, item 5) catalisado pela enzima geraniol sintetase (GES) que após oxidação origina enfim o citral (FIG. 1.3, etapa 2, item 6) (Cobos, 2015). lijima et al (2006) analisaram a atividade enzimática para a formação de citral, em manjericão (Ocimum basilicum), encontrando que a enzima geraniol deshidrogenase (GEDH), oxida geraniol para produzir geranial. Esta enzima pertence às álcool cinamil desidrogenases (CADs) que evoluíram das desidrogenases/reductases (MDR), sendo conformadas por duas unidades, cada uma com dois átomos de $\mathrm{Zn}$ como cofator (Arsenijević et al., 2013). A união do IPP com DMAPP até a formação do citral caracteriza-se como a etapa 2 da biossíntese.

A etapa 3 é caracterizada pela hidrogenação simples do citral e pela ação de um grupo de metais conhecidos como catalisadores para a conversão em citronelal, citronelol, geraniol e nerol.

Assim, a hidrogenação do citral para o citronelol, citronelal, geraniol e nerol ocorre com a presença de catalisadores à base de $\mathrm{Pd}, \mathrm{Ir}, \mathrm{Os}, \mathrm{Pt}, \mathrm{Rh}, \mathrm{Ru}$ e $\mathrm{Ni}$ (FIG. 1.3, etapa 3, item 7), Pd, Co e Ni (FIG. 1.3, etapa 3, item 8) e Zn, Pb e Ru (FIG. 1.3, etapa 3, itens 9 e 10), respectivamente. 
ETAPA 1

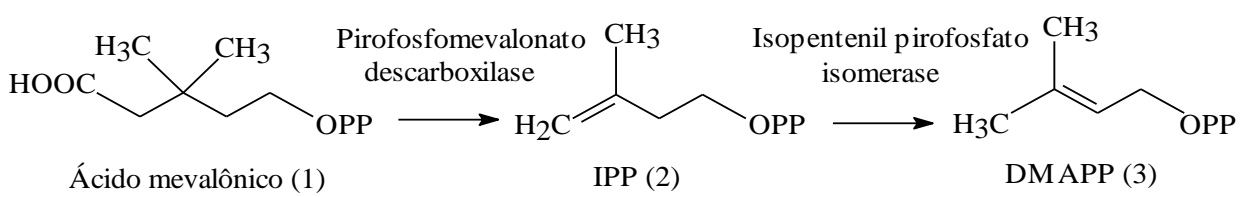

ETAPA 2

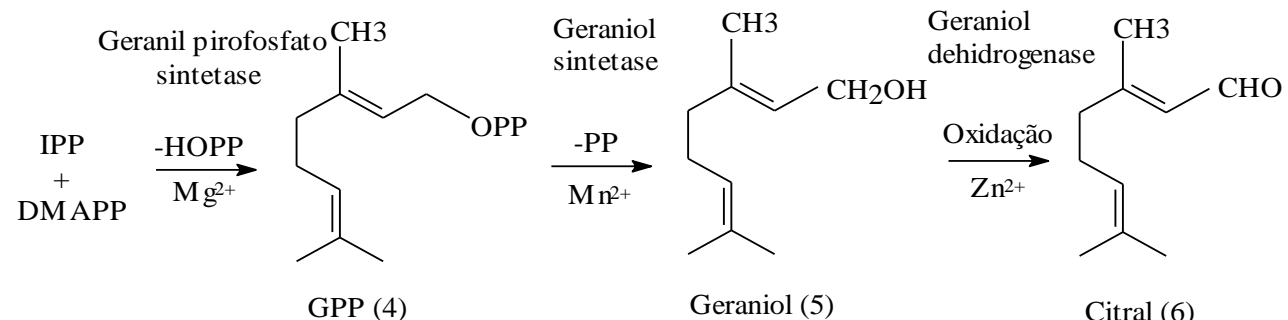

ETAPA 3<smiles>CC(C)=CCCC(C)CCO</smiles>

Citronelol (7)<smiles>[R10]O[R10](=O)NCC</smiles>

$$
\text { Citral (6) }
$$<smiles>CC(C)=CCCC(C)=CC=O</smiles>

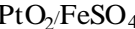
$\mathrm{Zn} / \mathrm{Pb} / \mathrm{Ru}$<smiles>CCCC</smiles><smiles>CC(C)=CCCC(C)=CCO</smiles><smiles>[Y]C(=O)OC(=O)OCC</smiles><smiles>CC(C)=CCCC(C)CC=O</smiles>

Citronelal (8)

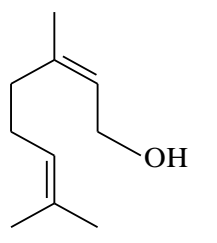

Nerol (10)

FIGURA 1.3 - Rota biossintética proposta da função dos metais no metabolismo dos óleos voláteis em Melissa officinalis.

O conhecimento das vias biossintéticas dos componentes majoritários do óleo volátil de melissa disponibiliza uma visão da importância de cada componente presente nas reações e torna possível o planejamento de estratégias que inibam ou ativem as enzimas presentes no caminho metabólico. Isto demonstra que o conhecimento de enzimas e cofatores que participam do 
metabolismo do citral é essencial para que a espécie apresente uma maior concentração deste metabólito.

\subsection{Macronutrientes, micronutrientes e elementos traço}

Os elementos químicos têm papel fundamental em todos os sistemas biológicos, pois participam de processos metabólicos, como componentes de diferentes enzimas (Ivyengar et al., 1970; Carvalho et al., 2007) e podem afetar a produção de monoterpenos e óleos voláteis (Cobos, 2015).

Os elementos com funções específicas e essenciais no metabolismo das plantas são geralmente classificados em dois grupos, os macronutrientes e os micronutrientes, em relação às suas concentrações na planta, conforme são requeridos para crescimento e reprodução adequados (Kirkiby \& Römheld, 2007).

Com a evolução das pesquisas na área de nutrição mineral de plantas, foram identificados alguns elementos que podem ser considerados essenciais para algumas espécies ou mesmo substituir parcialmente a função de elementos essenciais. Outros, quando em concentrações muito baixas, estimulam o crescimento de plantas, porém sua essencialidade não é demonstrada ou apenas demonstrada sob determinadas condições especiais. Esses elementos têm sido classificados como elementos benéficos (Malavolta, 1980).

São considerados macronutrientes primários os elementos nitrogênio $(N)$, fósforo $(\mathrm{P})$ e potássio $(\mathrm{K})$ por serem requeridos pelas plantas em grandes quantidades. Assim como os macronutrientes secundários cálcio $(\mathrm{Ca})$, magnésio $(\mathrm{Mg})$ e enxofre (S). Estes elementos fazem parte de moléculas essenciais e possuem função estrutural (Alvarenga et al., 1998; Hewitt e Smith, 1975).

O nitrogênio é considerado elemento essencial por estar presente em cerca de $1-5 \%$ da biomassa seca total, conformando biomoléculas importantes, tais como ATP, NADH, NADPH, clorofila, proteínas e inúmeras enzimas que fazem biossíntese de metabolitos secundários (Cobos, 2015).

O fósforo, na forma de fosfato, é um componente integral do material genético (DNA e RNA), dos principais compostos energéticos bioquímicos (ATP, creatina-fosfato e fosfoenolpiruvato), dos compostos intermediários de síntese e degradação, bem como dos fosfolipídios que compõem as membranas celulares (Deon, 2007). 
O potássio é o nutriente mais abundante nos tecidos das plantas, não faz parte de nenhum composto orgânico, porém interfere em vários processos fisiológicos tais como: ativação enzimática de aproximadamente sessenta enzimas, síntese de amido e de proteínas, abertura e fechamento dos estômatos, fotossíntese, extensão celular, translocação de fotossintatos para partes em crescimento, resistência a doenças e melhor eficiência no uso da água (Garlet et al., 2007).

O cálcio promove o fortalecimento de todos os órgãos das plantas, principalmente raízes e folhas. É um componente da parede celular vegetal, sendo necessário para a manutenção da estrutura vegetal (Prado e Natale, 2004).

O magnésio é componente essencial da clorofila, pigmento responsável pela fotossíntese e coloração verde das plantas.

O enxofre é nutriente-chave para o desenvolvimento da cultura juntamente com os elementos N, P e K. É exigido para a formação de aminoácidos e de proteínas.

Os micronutrientes são geralmente representados por B (boro), $\mathrm{Cl}$ (cloro), $\mathrm{Cu}$ (cobre), Fe (ferro), Mo (molibdênio), Mn (manganês) e Zn (zinco). São considerados elementos benéficos Al (alumínio), Co (cobalto), Ni (níquel), Se (selênio), Si (silício), $\mathrm{Na}$ (sódio) e V (vanádio).

São fundamentais para o crescimento e o desenvolvimento das plantas, agindo como constituintes das paredes celulares (B) e das membranas celulares $(\mathrm{B}, \mathrm{Zn})$, como constituintes de enzimas ( $\mathrm{Fe}, \mathrm{Mn}, \mathrm{Cu}, \mathrm{Ni}$ ), como ativadores de enzimas (Mn, Zn) e na fotossíntese (Fe, Cu, Mn, Cl) (Kirkby e Römheld, 2007).

O termo "elemento traço" tem sido usado para definir metais que normalmente estão presentes em baixas concentrações no ambiente, usualmente menor que $1000 \mathrm{mg} \mathrm{kg}^{-1}$, muito embora ferro $(\mathrm{Fe})$ e titânio (Ti) ocorram em altas concentrações são considerados elementos traço por alguns autores. A absorção, o transporte e a redistribuição dos elementos traço, micronutrientes ou não, tem muita semelhança ao que se conhece com respeito aos macronutrientes (Malavolta, 1994). Embora alguns elementos apresentem importantes funções para as plantas, os elementos cádmio $(\mathrm{Cd})$, cromo $(\mathrm{Cr})$, níquel $(\mathrm{Ni})$, chumbo $(\mathrm{Pb})$, cobre $(\mathrm{Cu})$, ferro $(\mathrm{Fe})$, manganês $(\mathrm{Mn})$ e zinco $(\mathrm{Zn})$ são exemplos de elementos traço que podem apresentar potencial tóxico, devido a solubilidade, absorção e concentração adequada para as plantas (Silva, 2006). 


\subsection{Adubação orgânica e mineral}

O manejo adequado do solo fornece os macro e micronutrientes necessários ao desenvolvimento das plantas, função esta atribuídas aos adubos (Novaes, 2007).

A adubação é um fator de grande importância na produção de plantas medicinais. Uma adubação equilibrada é essencial para a obtenção de plantas mais resistentes às pragas e doenças, com maiores teores de princípios ativos, sem comprometer a produção de massa verde (Carvalho, 2005).

Para o plantio de plantas medicinais é recomendado que elas recebam adubação orgânica, como esterco de aves ou curral curtidos e composto orgânico (Martins e Figueiredo, 2009). Por outro lado, os adubos orgânicos por si só não resolvem o problema de garantir ou aumentar a fertilidade do solo, sendo necessário praticar sempre a adubação orgânica e a mineral, pois nenhuma delas, aplicadas isoladamente, satisfaz as exigências do solo e as duas, aplicadas em conjunto, se completam. Dessa forma, os fertilizantes orgânicos e inorgânicos podem ser utilizados juntos para alcançar a máxima produtividade (Ernani, 2008).

A utilização do adubo orgânico em relação ao adubo mineral é significativa, principalmente pela liberação gradual dos nutrientes na medida em que são demandados para o crescimento das plantas. Se os nutrientes forem imediatamente disponibilizados no solo, como ocorre com os adubos minerais, podem ser perdidos por volatilização (nitrogênio), fixação (fósforo) ou lixiviação (principalmente o potássio) (Severino et al., 2004).

Diversos estudos agronômicos pesquisam a influência da adubação orgânica e mineral sobre o desenvolvimento de espécies medicinais, como a melissa (Fluck, 1954; Gershenzon, 1984; Martins et al., 1995, Silva, 2011; Luz et al., 2014). Porém poucos avaliam a correlação entre os nutrientes presentes nos cultivos com a produtividade dos óleos voláteis. Suas ações nas plantas medicinais ainda são pouco estudadas no Brasil, mas com certeza são imprescindíveis para melhorar a qualidade da produção (Furlan, 2005). Neste sentido, esta pesquisa tem como caráter inédito, estudar a correlação dos metais na biossíntese dos óleos voláteis majoritários produzidos pela espécie Melissa officinalis. 


\section{OBJETIVOS}

O estudo teve como objetivo avaliar os efeitos dos elementos traço, micronutrientes ou não, na composição dos óleos voláteis da espécie Melissa officinalis, para os quais foi levantada a hipótese de que a deficiência ou excesso desses metais pode promover maior ou menor produção de compostos ativos na planta. Procurou-se testar a hipótese de que a produção dos constituintes majoritários, presentes nos óleos voláteis de melissa, está correlacionada com a sua composição elementar.

\section{Objetivos específicos}

- Determinar a composição elementar do solo;

- Determinar a composição elementar nas folhas de Melissa officinalis;

- Determinar os teores dos metabólitos majoritários produzidos pela espécie Melissa officinalis;

- Correlacionar os teores dos constituintes inorgânicos nos solos e nas folhas com os constituintes orgânicos majoritários dos óleos voláteis de Melissa officinalis com a finalidade de avaliar a influência da composição elementar na produção dos metabólitos.

Para alcançar o objetivo foram aplicadas as técnicas analíticas com os seguintes objetivos:

- Análise por ativação neutrônica instrumental (INAA): determinação da concentração dos elementos traço essenciais e não essenciais (As, $\mathrm{Ba}, \mathrm{Br}$, $\mathrm{Ce}, \mathrm{Cl}, \mathrm{Co}, \mathrm{Cr}, \mathrm{Cs}$, Eu, Fe, Hf, La, Lu, Mn, Na, Rb, Sb, Sc, Sm, Ta, Th, Ti, $\mathrm{U}, \mathrm{V}, \mathrm{Yb}, \mathrm{Zn}$ e $\mathrm{Zr}$ ) e adicionalmente determinação dos macronutrientes $(\mathrm{Ca}$, $\mathrm{K}$ e $\mathrm{Mg}$ ) nas amostras de solo e nas amostras das folhas da espécie Melissa officinalis;

- Espectrometria de absorção atômica com forno de grafite (GF AAS): determinação dos elementos $\mathrm{Cu}, \mathrm{Cd}$ e $\mathrm{Pb}$ nas amostras de solo e nas amostras das folhas da espécie Melissa officinalis; 
- Espectrometria de Emissão Óptica com Fonte de Plasma Indutivamente Acoplado (ICP-OES): determinação do elemento $\mathrm{Ni}$ nas amostras de solo e nas amostras das folhas da espécie Melissa officinalis;

- Arraste a vapor e cromatografia gasosa acoplada ao espectrômetro de massas (GC/MS): determinação dos constituintes químicos majoritários neral, geranial e citronelal, presentes nos óleos voláteis da espécie Melissa officinalis, assim como os constituintes em menores quantidades nerol, geraniol e citronelol.

- Análise estatística. 


\section{MATERIAIS E MÉTODOS}

\subsection{Local dos experimentos}

Os experimentos foram conduzidos na Escola Municipal de Jardinagem (FIG. 3.1), cujas coordenadas geográficas são S23 $35^{\prime} 26,57^{\prime \prime}$ e O46³9'19,03", a qual pertence ao Departamento de Educação Ambiental e Cultura de Paz / Universidade Aberta do Meio Ambiente e Cultura de Paz (DEA/UMAPAZ) localizados no Parque Ibirapuera (FIG. 3.2), na cidade de São Paulo, Brasil.

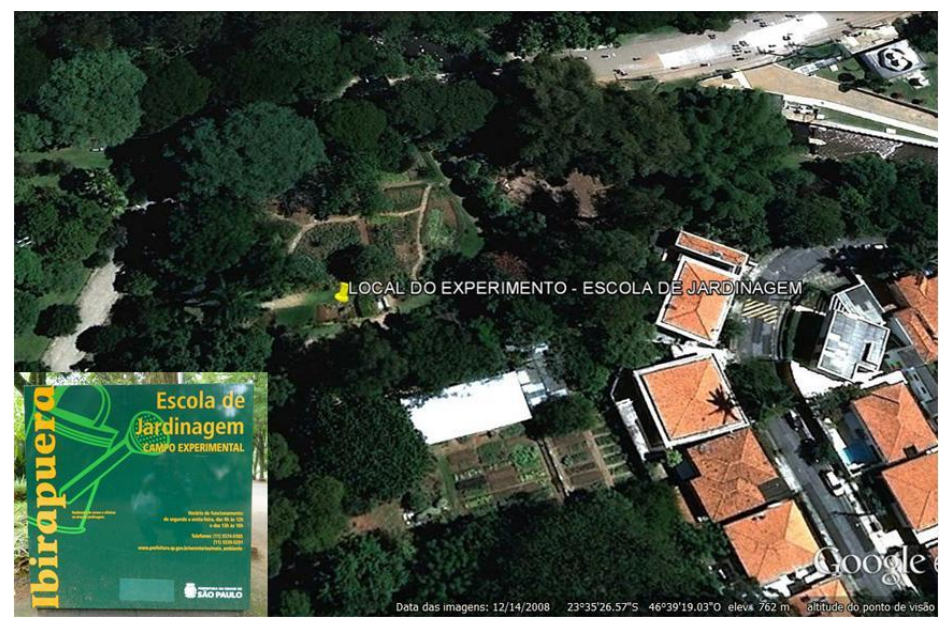

FIGURA 3.1 - Local do experimento (Google Earth, em 14/12/2008).

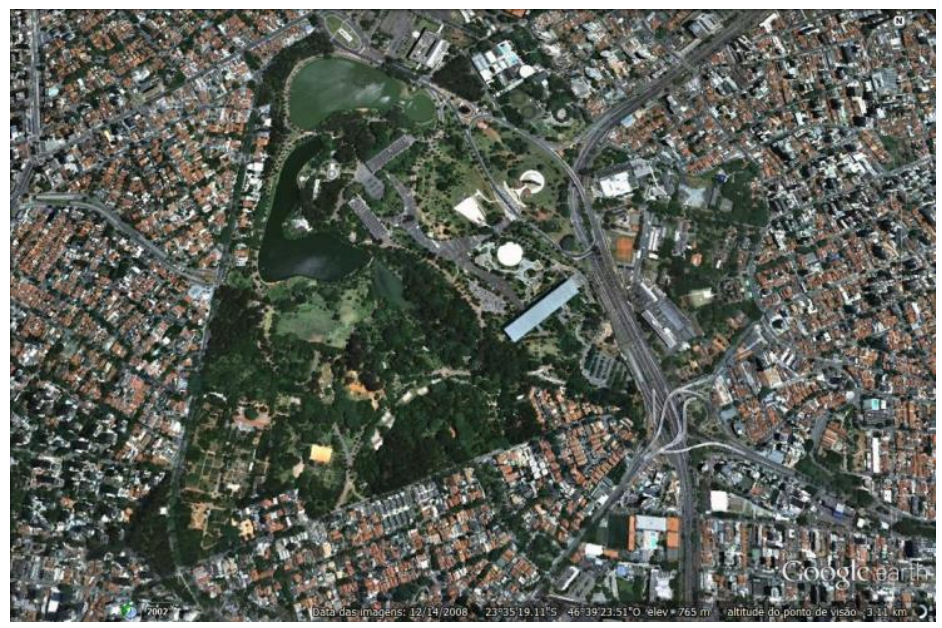

FIGURA 3.2 - Vista aérea do Parque Ibirapuera (Google Earth, em 14/12/2008). 


\subsection{Dados climáticos}

A coleta dos dados climáticos (TAB. 3.1; FIG. 3.3 e 3.4) foi realizada através do site oficial do Instituto de Astronomia, Geofísica e Ciências Atmosféricas da USP (Boletim, 2013; Boletim, 2014).

A Estação Meteorológica do IAG/USP está localizada no Parque Estadual das Fontes do Ipiranga (antigo Parque do Estado), Bairro da Água Funda, Capital, $\mathrm{SP}$, latitude $\mathrm{S} 23,6512^{\circ}$ e longitude $046,6224^{\circ}$ e altitude de 799,2 metros.

TABELA 3.1 - Temperatura mensal média e precipitação mensal média no período de janeiro de 2013 a janeiro de 2014.

\begin{tabular}{lcc}
\hline \multicolumn{1}{c}{ Períodos } & Temperatura média $\left({ }^{\circ} \mathrm{C}\right)$ & Precipitação mensal total $(\mathrm{mm})$ \\
\hline JAN. 2013 & 21,2 & 187,7 \\
FEV. 2013 & 22,7 & 281,4 \\
MAR. 2013 & 21,4 & 191,1 \\
ABR. 2013 & 19,3 & 91,8 \\
MAl. 2013 & 17,8 & 40,1 \\
JUN. 2013 & 17,5 & 130,3 \\
JUL. 2013 & 15,4 & 82,5 \\
AGO. 2013 & 16,5 & 10,1 \\
SET. 2013 & 18,0 & 103,9 \\
OUT. 2013 2013 & 108,8 \\
NOV. 2013 & 18,9 & 201,7 \\
DEZ. 2013 & 20,7 & 72,1 \\
JAN. 2014 & 22,3 & 199,3 \\
\hline
\end{tabular}

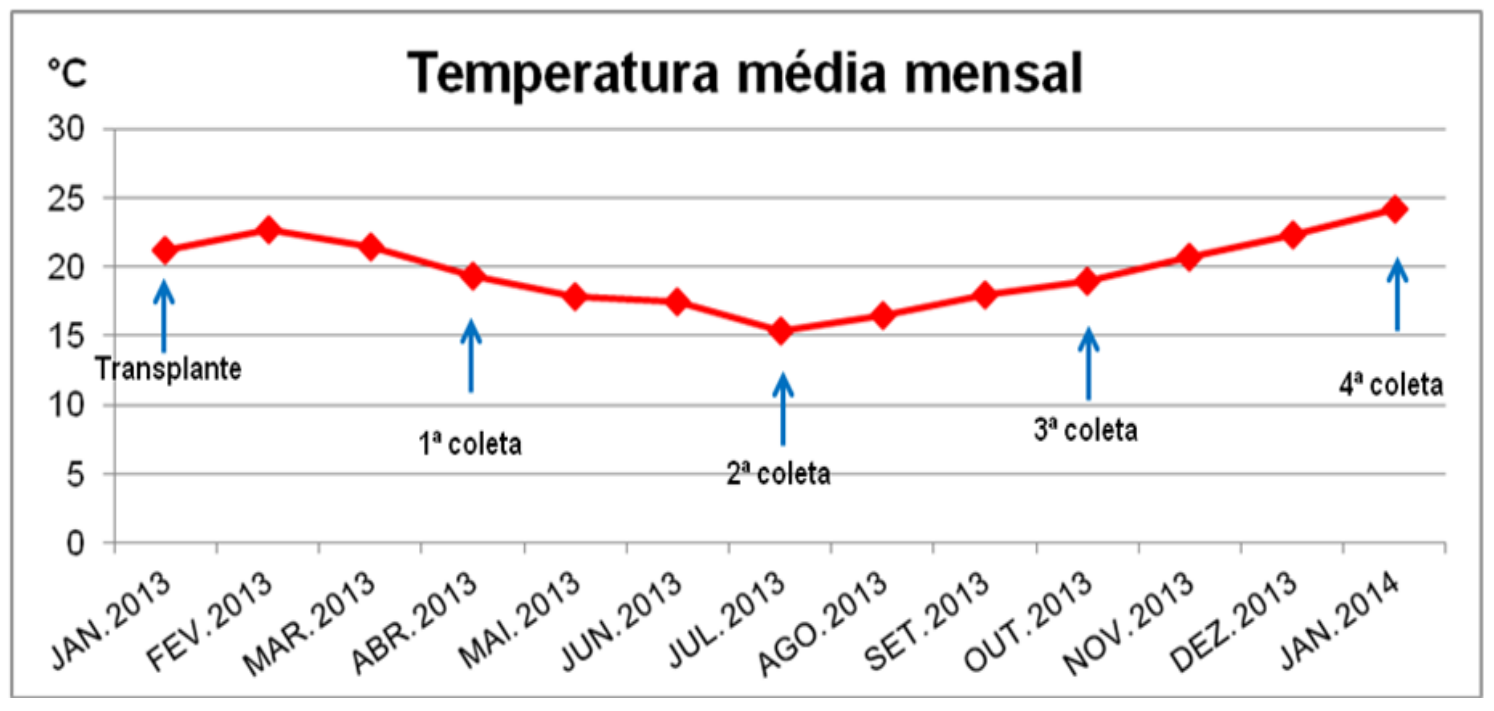

FIGURA 3.3 - Temperatura mensal média nos períodos de janeiro/2013 e janeiro/2014. 


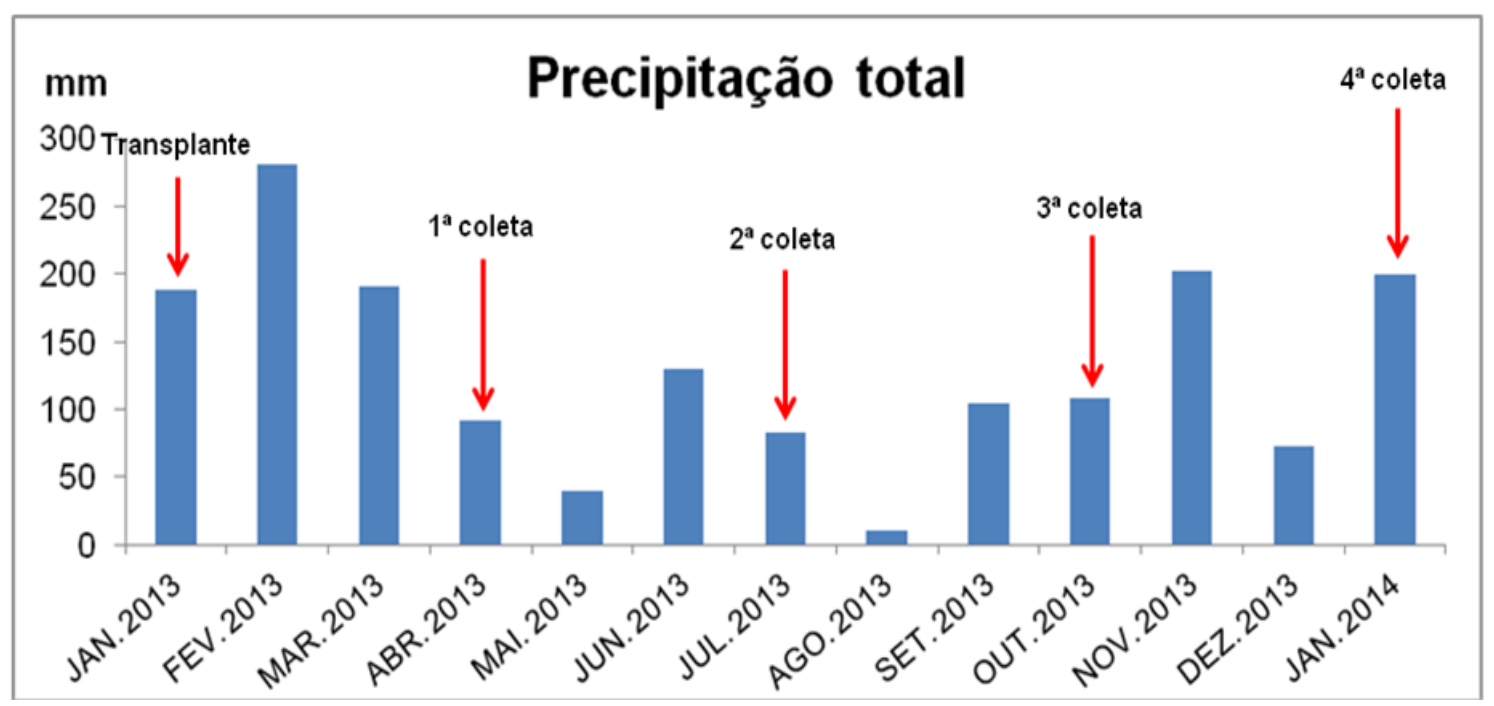

FIGURA 3.4 - Precipitação mensal média nos períodos de janeiro/2013 e janeiro/2014.

\subsection{Material botânico}

A espécie Melissa officinalis foi obtida a partir da propagação por sementes. A produção das mudas foi conduzida numa estufa, na Fazenda Experimental da Faculdade Integrada Cantareira - FIC, na Serra da Cantareira, Mairiporã, SP, no período de outubro a dezembro de 2012. As mudas foram produzidas e condicionadas em bandejas, preenchidas com substratos comerciais, orgânico e convencional (FIG. 3.5).
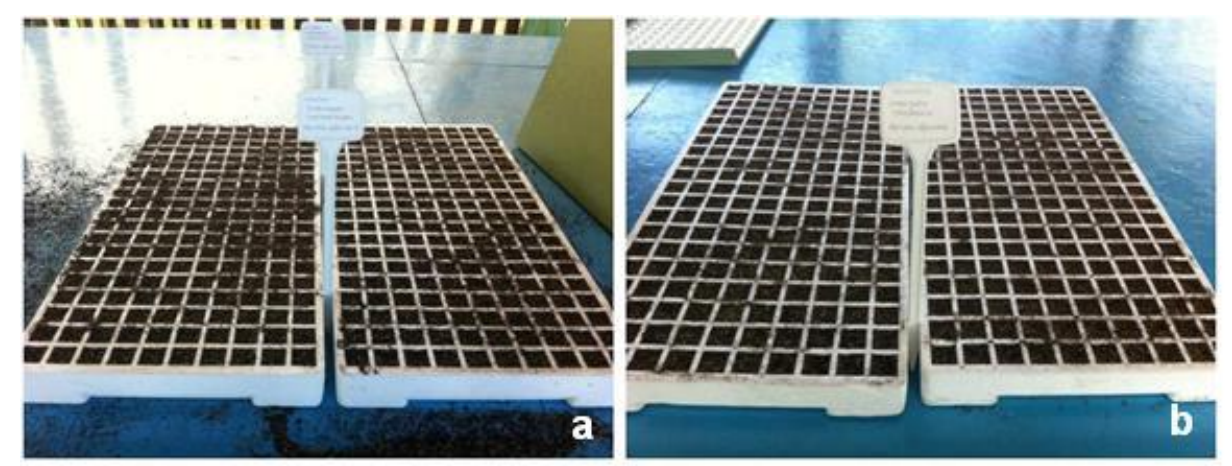

FIGURA 3.5 - Sementeiras em substrato convencional (a) e orgânico (b).

No condicionamento orgânico, o substrato comercial utilizado foi o Biomix ${ }^{\circledR}$, composto por turfa, casca de pinus moída e compostada, vermiculita, composto orgânico (esterco cama de equino e de galinha) e aditivos minerais e no condicionamento convencional, o substrato comercial utilizado foi o Tropstrato®, composto por casca de pinus, turfa, vermiculita expandida, enriquecido com 
macro e micronutrientes. Os substratos fornecem as condições químicas e físicas favoráveis à germinação das sementes e ao seu desenvolvimento, dando sustentação às plântulas (Andreoli, 2006). Em janeiro de 2013, quando as mudas apresentavam de 4-6 folhas, foram transplantadas para vasos plásticos, com capacidade de $0,1 \mathrm{~m}^{3}$. Os espaçamentos utilizados foram $22,5 \mathrm{~cm}$ entre plantas. Em cada vaso foram plantadas três mudas em uma linha central com $90 \mathrm{~cm}$ de comprimento (FIG. 3.6).
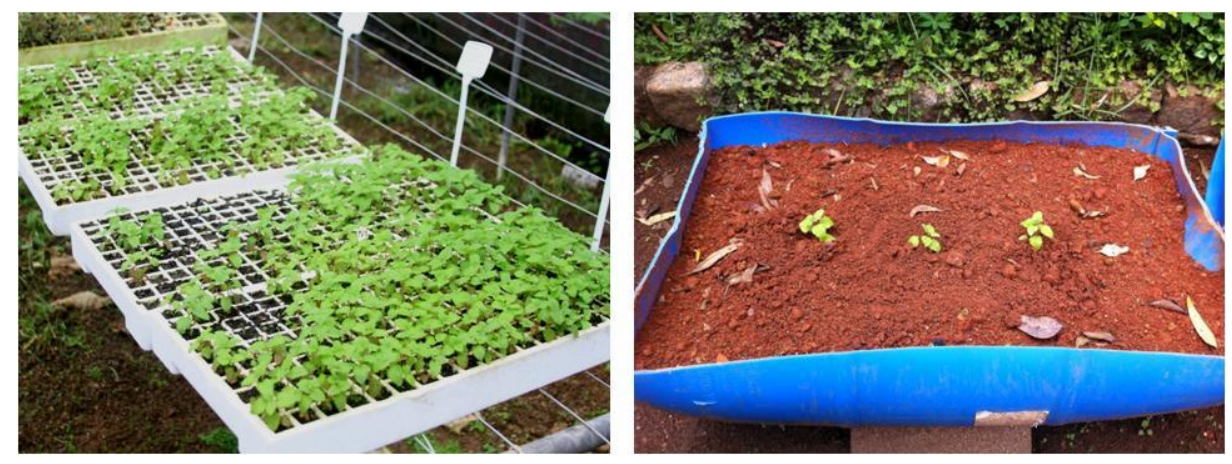

FIGURA 3.6 - Transplante das mudas de melissa para os vasos plásticos.

\subsection{Condições de cultivo}

O modelo experimental utilizado foi em canteiros com delineamento inteiramente casualizados (DIC), segundo Costa (2003) e com quatro repetições (FIG. 3.7). Foram alocados nas parcelas seis sistemas de adubação: solo controle com as mudas do condicionamento orgânico e do condicionamento convencional (SL-1 e SL-2, respectivamente); solo com adubação orgânica (2 $\mathrm{t}$ ha-1 de cama de frango) com e sem adição de microelementos: B, Cu, Mn, Zn, Mo, (SL-3 e SL-4, respectivamente); e solo com adubação convencional (30 $t \mathrm{ha}^{-1}$ de NPK, 6:14:8) com e sem adição microelementos: B, Cu, Mn, Zn, Mo (SL-5 e SL-6, respectivamente).

\begin{tabular}{|c|c|c|c|c|c|c|c|}
\hline SL-1A & SL-4D & SL-4A & SL-5A & SL-1C & SL-2C & SL-1B & SL-5C \\
\hline SL-4B & SL-6A & SL-3C & SL-3A & SL-6C & SL-2B & SL-6B & SL-6D \\
\hline SL-3D & SL-3B & SL-2D & SL-1D & SL-4C & SL-5D & SL-2A & SL-5B \\
\hline
\end{tabular}

FIGURA 3.7 - Disposição dos sistemas de cultivo no campo experimental. 
Os canteiros foram posicionados de forma que todos tivessem os mesmos períodos de exposição ao sol, sombra e chuva (FIG. 3.8). A irrigação foi feita com aspersor giratório tipo espiga e a capina foi feita de forma manual sempre que necessária.

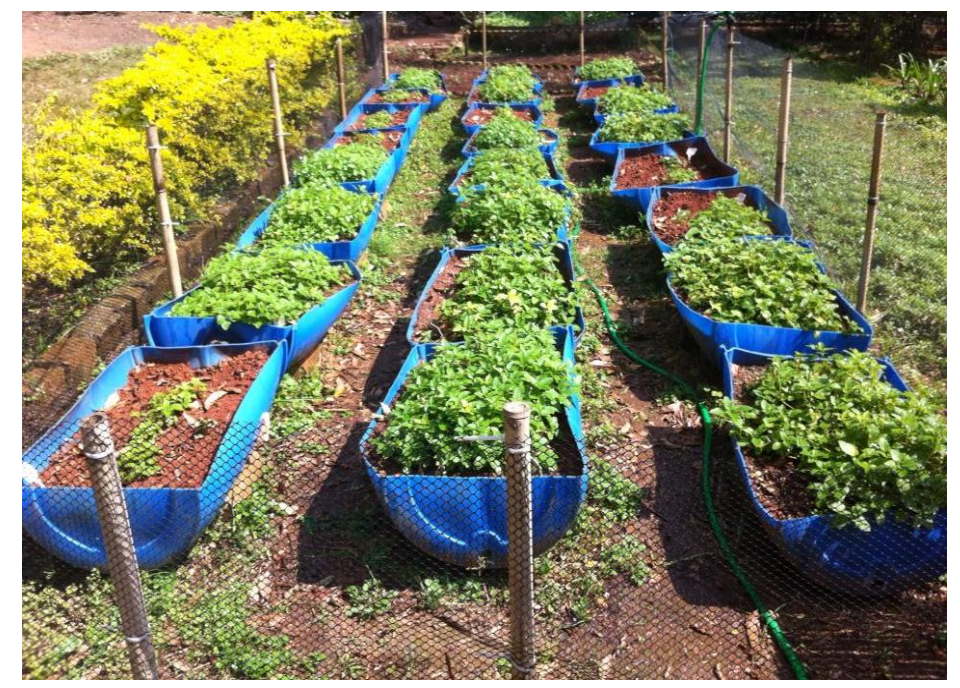

FIGURA 3.8 - Disposição dos vasos de plásticos no campo experimental.

\subsection{Coletas e preparo das amostras de solo}

A amostragem é a primeira e principal etapa de um programa de avaliação da fertilidade do solo, pois é com base na análise química destas amostras que se realiza a interpretação e que são definidas as doses de corretivos e de adubos. Uma amostragem de solo foi realizada antes da instalação dos experimentos na faixa de $0-20 \mathrm{~cm}$ de profundidade, segundo metodologia da Embrapa, 1997. A amostra coletada foi encaminhada para análises no laboratório do Centro de Apoio Tecnológico Cantareira - CEATEC, cujas características químicas encontram-se apresentadas na TAB. 3.2.

TABELA 3.2 - Análise química do solo utilizado como substrato no cultivo de Melissa officinalis.

\begin{tabular}{|c|c|c|c|c|c|c|c|}
\hline $\begin{array}{l}\mathbf{p H}^{(1)} \\
\mathrm{CaCl}_{2}\end{array}$ & $\begin{array}{l}\mathrm{MO}^{(2)} \\
\mathrm{g} / \mathrm{dm}^{3}\end{array}$ & $\begin{array}{c}\text { Fósforo } \\
\mathrm{mg} / \mathrm{dm}^{3}\end{array}$ & $\begin{array}{c}\mathbf{H}+\mathbf{A} \mathbf{l}^{(3)} \\
\mathrm{mmolc} / \mathrm{dm}^{3}\end{array}$ & $\begin{array}{l}\text { Potássio } \\
\mathrm{mmolc} / \mathrm{dm}^{3}\end{array}$ & $\begin{array}{c}\text { Cálcio } \\
\mathrm{mmolc} / \mathrm{dm}^{3}\end{array}$ & $\begin{array}{l}\text { Magnésio } \\
\mathrm{mmolc} / \mathrm{dm}^{3}\end{array}$ & $\begin{array}{c}\mathbf{S B}^{(4)} \\
\mathrm{mmolc} / \mathrm{dm}^{3}\end{array}$ \\
\hline 7,4 & 15 & 1 & 15 & 3,5 & 64 & 8 & 76 \\
\hline $\begin{array}{c}\text { CTCC(5) }^{(5)} \\
\mathrm{mmolc} / \mathrm{dm}^{3}\end{array}$ & $\begin{array}{c}\text { V\%(6) } \\
\%\end{array}$ & $\begin{array}{c}\text { Enxofree } \\
\mathrm{mg} / \mathrm{dm}^{3}\end{array}$ & $\begin{array}{l}\text { Boro } \\
\mathrm{mg} / \mathrm{dm}^{3}\end{array}$ & $\begin{array}{l}\text { Cobre } \\
\mathrm{mg} / \mathrm{dm}^{3}\end{array}$ & $\begin{array}{l}\text { Ferro } \\
\mathrm{mg} / \mathrm{dm}^{3}\end{array}$ & $\underset{\mathrm{mg} / \mathrm{dm}^{3}}{\text { Mangâs }}$ & $\begin{array}{l}\text { Zinco } \\
\mathrm{mg} / \mathrm{dm}^{3}\end{array}$ \\
\hline 91 & 83 & 30 & 0,1 & 0,1 & 8 & 1 & 2,1 \\
\hline
\end{tabular}


A recomendação de adubação foi definida em conjunto com o Prof. Dr. Marcos Roberto Furlan e Prof. MSc. Helcio de Abreu Júnior, com base na análise do solo, utilizando o programa para Cálculo de Equilíbrio de Base, segundo Albrecht (1967).

$\mathrm{Na}$ TAB. 3.3 são apresentados os valores calculados para adubação recomendada. Para os elementos $\mathrm{Ca}, \mathrm{Mg}$ e $\mathrm{K}$ os teores recomendados foram calculados com base no resultado obtido para a capacidade de troca cationica do solo e foram estimados de acordo com sua contribuição percentual para a CTC.

TABELA 3.3 - Recomendação de adubação em função da análise do solo.

\begin{tabular}{cccccccccccc}
\hline Área & \multicolumn{3}{c}{ \% da CTC } & \multicolumn{1}{c}{$\mathrm{mg} / \mathrm{dm}^{3}$} \\
\hline & $\mathbf{C a}$ & $\mathbf{M g}$ & $\mathbf{K}$ & $\mathbf{P}$ & $\mathbf{S}$ & $\mathbf{B}$ & $\mathbf{C u}$ & $\mathbf{F e}$ & $\mathbf{M n}$ & $\mathbf{Z n}$ & $\mathbf{M . O}$ \\
Calculado & 70,3 & 8,79 & 3,85 & 1 & 30 & 0,1 & 0,1 & 8 & 1 & 2,1 & 1,5 \\
Ideal & 70 & 10 & 3,5 & 20 & 15 & 1 & 2 & 20 & 20 & 4 & 2,5 \\
\hline Recomendação & 0 & 44,4 & 0 & 38 & 0 & 1,8 & 3,8 & 24 & 38 & 3,8 & 20 \\
(kg/ha) & $\mathbf{C a O}$ & $\mathbf{M g O}$ & $\mathbf{K}_{\mathbf{2}} \mathbf{O}$ & $\mathbf{P}$ & $\mathbf{S}$ & $\mathbf{B}$ & $\mathbf{C u}$ & $\mathbf{F e}$ & $\mathbf{M n}$ & $\mathbf{Z n}$ & $\mathbf{t} / \mathbf{h a}$ \\
\hline
\end{tabular}

O cálcio contribui com $70 \%$ da capacidade de troca de cátions (CTC), 0 magnésio com 8,8 \% e o potássio com $4 \%$. Para a maioria das plantas estes valores são ideais, porém para melissa, semelhante à hortelã, foi necessário adequar todos os nutrientes na faixa mínima segundo Albrech (1967). O magnésio apresentou concentração um pouco abaixo do valor ideal, porém como o fósforo também apresentou concentração baixa foram recomendadas fontes de fósforo que também possuam magnésio, como os Termofosfatos (TAB. 3.4).

O enxofre apresentou nível adequado, assegurando que as plantas terão baixo ou nenhum ataque de ácaros (Abreu Jr., 1998).

Como os micronutrientes ( $\mathrm{B}, \mathrm{Cu}, \mathrm{Mn}, \mathrm{Zn})$ apresentaram uma baixa disponibilidade, também foram recomendadas fontes para adequá-los na faixa mínima (TAB. 3.3).

Nas TAB. 3.4 e 3.5 são apresentadas as quantidades recomendadas utilizadas para o plantio de melissa para os tratamentos orgânicos (SL-3 e SL-4) e convencional (SL-5 e SL-6), respectivamente. Como não existe recomendação de adubação para a espécie Melissa officinalis no Estado de São Paulo, o modelo da 
recomendação seguiu os padrões do Boletim Técnico 100 do Instituto Agronômico de Campinas (IAC) para adubação da hortelã (Raij et al., 1997) (FIG. 3.9).

TABELA 3.4 - Recomendação de adubação orgânica utilizada para o plantio de Melissa officinalis baseada na adubação de hortelã (Boletim 100 IAC).

\begin{tabular}{lcc}
\hline \multicolumn{2}{c}{ Adubação orgânica com micronutrientes (SL-3) } \\
\hline $\begin{array}{lcc}\text { Constituintes químicos } \\
\text { Macro e micronutrientes }\end{array}$ & FONTES & $\begin{array}{c}\text { Quantidade } \\
\left(\mathbf{m g} / \mathbf{d m}^{\mathbf{3}}\right)\end{array}$ \\
\hline NPK & Cama de frango (2 t/ha) & 1000 \\
& Composto (30 t/ha) & 15000 \\
Fósforo (P) & Termofosfato Yoorin & 100 \\
Boro (B) & Ácido bórico & 5,25 \\
Cobre (Cu) & Sulfato de cobre & 7,5 \\
Manganês (Mn) & Sulfato de manganês & 25 \\
Zinco (Zn) & Sulfato de zinco & 9,5 \\
Molibdênio (Mo) & Molibdato de sódio & 0,125 \\
\hline \multicolumn{3}{c}{ Adubação orgânica sem micronutrientes (SL-4) } \\
\hline NPK & Cama de frango (2 t/ha) \\
Fósforo (P) & Composto (30 t/ha) & 1000 \\
\hline
\end{tabular}

TABELA 3.5 - Recomendação de adubação convencional utilizada para o plantio de Melissa officinalis baseada na adubação de hortelã (Boletim $100-I A C)$.

\begin{tabular}{|c|c|c|}
\hline \multicolumn{3}{|c|}{ Adubação convencional com micronutrientes (SL-5) } \\
\hline $\begin{array}{l}\text { Constituintes químicos } \\
\text { Macro e micronutrientes }\end{array}$ & FONTES & $\begin{array}{c}\text { Quantidade } \\
\left(\mathrm{mg} / \mathrm{dm}^{3}\right)\end{array}$ \\
\hline NPK & $\begin{array}{c}\text { NPK }(4: 14: 8) \\
\text { Composto }(30 \text { t/ha })\end{array}$ & $\begin{array}{c}430 \\
10000\end{array}$ \\
\hline $\mathrm{N}(30 \mathrm{~kg} / \mathrm{ha})$ & Uréia $(45 \%$ de $\mathrm{N})$ & 33 \\
\hline $\mathrm{K}(30 \mathrm{~kg} / \mathrm{ha})$ & $\mathrm{KCl}$ & 25 \\
\hline Boro (B) & Ácido bórico & 5,25 \\
\hline Cobre (Cu) & Sulfato de cobre & 7,5 \\
\hline Manganês (Mn) & Sulfato de manganês & 25 \\
\hline Zinco (Zn) & Sulfato de zinco & 9,5 \\
\hline Molibdênio (Mo) & Molibdato de sódio & 0,125 \\
\hline \multicolumn{3}{|c|}{ Adubação convencional sem micronutrientes (SL-6) } \\
\hline & NPK $(4: 14: 8)$ & 430 \\
\hline NPK & Composto (30 t/ha) & 10000 \\
\hline $\mathrm{N}(30 \mathrm{~kg} / \mathrm{ha})$ & Uréia $(45 \%$ de N) & 33 \\
\hline $\mathrm{K}(30 \mathrm{~kg} / \mathrm{ha})$ & $\mathrm{KCl}$ & 25 \\
\hline
\end{tabular}




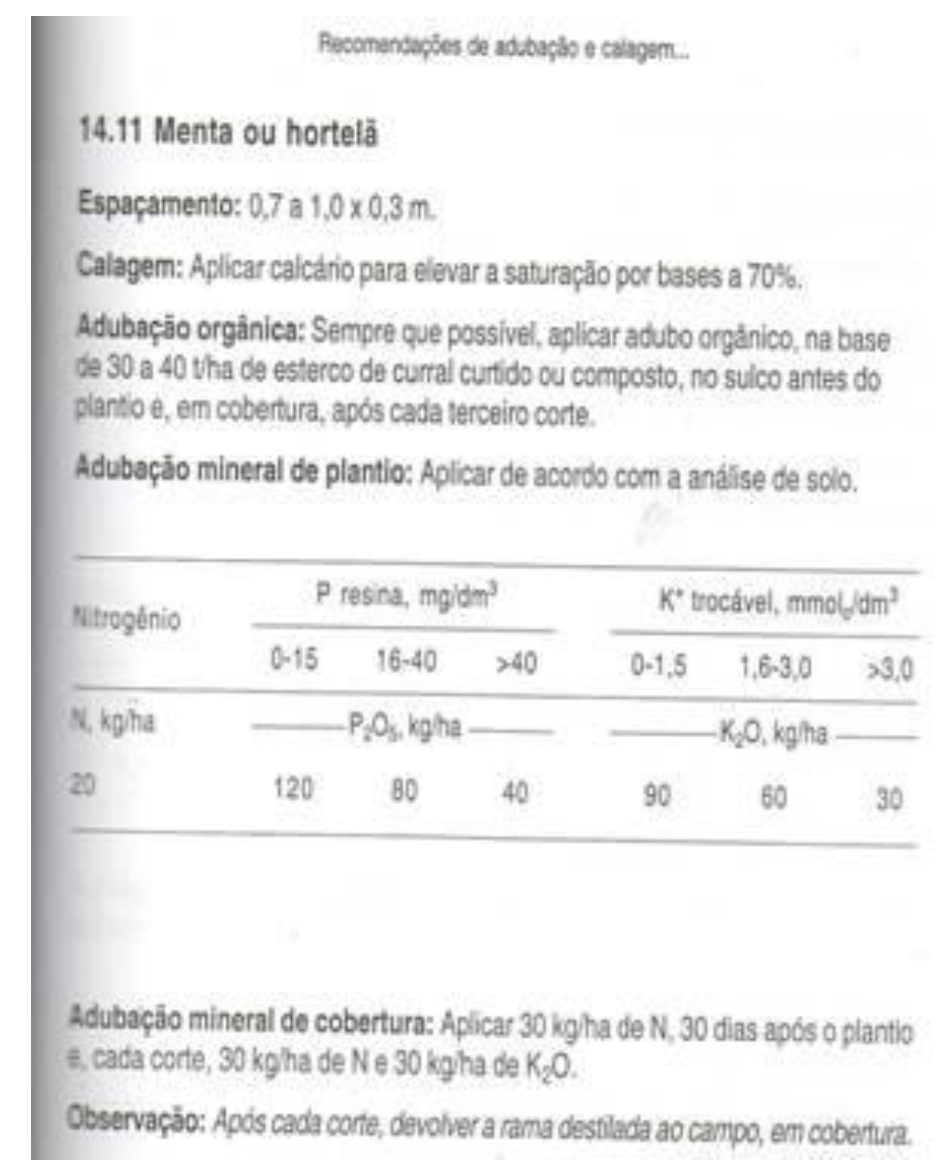

FIGURA 3.9 - Boletim Técnico 100 - Recomendação para adubação de hortelã.

O solo em que as plantas foram cultivadas foi alterado em função do manejo agrícola requerido para o desenvolvimento da espécie, tanto no sistema orgânico quanto no sistema convencional. Esta prática contribui para a descaracterização superficial do solo (Ferrari, 2008).

Devido ao manejo diferenciado entre os sistemas de produção orgânico e convencional, foram coletadas amostras de solo após a instalação dos experimentos, sob as plantas amostradas, para avaliação da composição química de modo a verificar se há diferença entre os manejos aplicados e estudar a correlação entre as concentrações dos elementos químicos presentes no solo e nas plantas.

As amostras foram coletadas nos períodos de abril de 2013 (outono), julho de 2013 (inverno), outubro de 2013 (primavera) e janeiro de 2014 (verão). A amostragem foi feita com uma pá estreita de jardinagem na profundidade de 0 $20 \mathrm{~cm}$ e acondicionadas em sacos plásticos. Depois de retiradas, as amostras foram conduzidas ao Laboratório de Ativação Neutrônica (LAN). 
As amostras foram secas à temperatura ambiente e, posteriormente, retirou-se, por quarteamento, uma alíquota de cerca de $20 \mathrm{~g}$. Para obtenção de material fino e homogêneo, com tamanho de partículas apropriado à análise, as amostras foram moídas manualmente a uma granulometria de 115 mesh, homogeneizada e armazenadas em frascos de polietileno (FIG. 3.10).

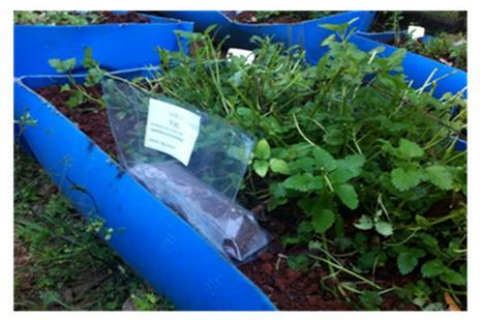

ETAPA I

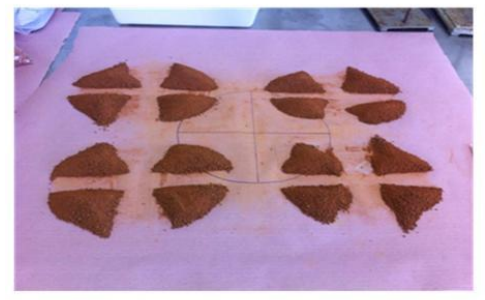

ETAPA IV

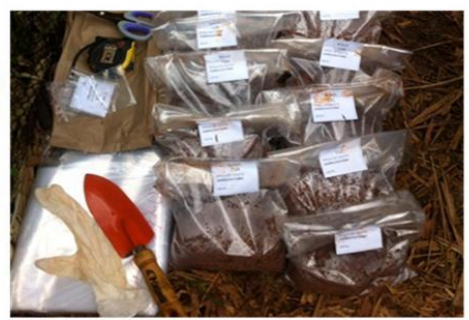

ETAPA II

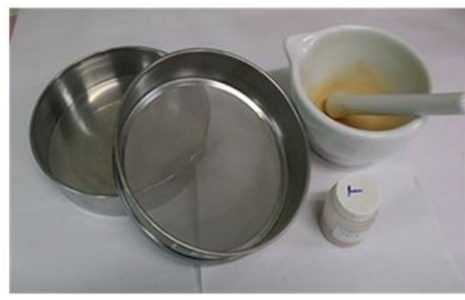

ETAPA V

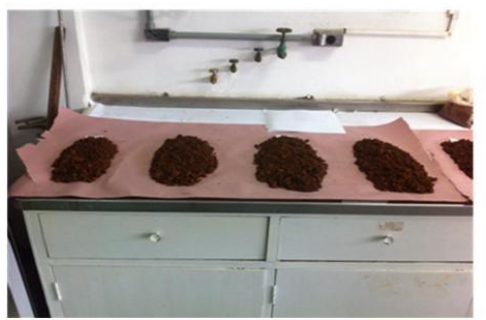

ETAPA III

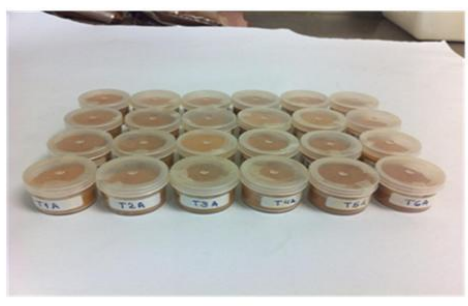

ETAPA VI

FIGURA 3.10 - llustração dos processos de preparação das amostras de solo: identificação (etapa I), coleta (etapa II), secagem das amostras (etapa III), quarteamento (etapa IV), pulverização (etapa V) e armazenamento (etapa VI).

As amostras de solo foram identificadas da seguinte maneira: SL (solo); O, I, P e V (correspondem as épocas de coletas: outono, inverno, primavera e verão, respectivamente); 1, 2, 3, 4, 5 e 6 (corresponde ao manejo aplicado: controle com mudas do condicionamento orgânico, controle com mudas do condicionamento convencional, orgânico com micronutrientes, orgânico sem micronutrientes, convencional com micronutrientes e convencional sem micronutrientes, respectivamente).

Por exemplo:

SLO-1 significa solo (SL) coletado no outono (O) no sistema de manejo controle com mudas do condicionamento orgânico (1).

SLI-3 significa solo (SL) coletado no inverno (I) no sistema de manejo orgânico com micronutrientes (3). 


\subsection{Coletas e preparo das amostras de planta}

O cultivo de Melissa officinalis foi iniciado em janeiro de 2013 e finalizado em janeiro de 2014. A exsicata ${ }^{1}$ da espécie encontra-se depositada no Herbário Municipal de São Paulo, SP sob numeração, PMSP 15923.

Foram realizadas quatro colheitas durante o ano de cultivo. As amostras foram cortadas a $10 \mathrm{~cm}$ do solo com uma tesoura de titânio para não contaminálas. Todas as amostras foram colhidas às 17 horas.

A primeira colheita foi realizada em abril de 2013, compreendendo a transição da estação do verão para o outono.

A segunda colheita foi realizada em julho de 2013, compreendendo a transição da estação do outono para o inverno.

A terceira colheita foi feita em outubro de 2013, compreendendo a transição da estação do inverno para a primavera.

A quarta colheita foi feita em janeiro de 2014, compreendendo a transição da estação da primavera para o verão.

Após a colheita, as amostras de melissa foram acondicionadas em sacos plásticos e armazenadas em caixa térmica (FIG. 3.11).

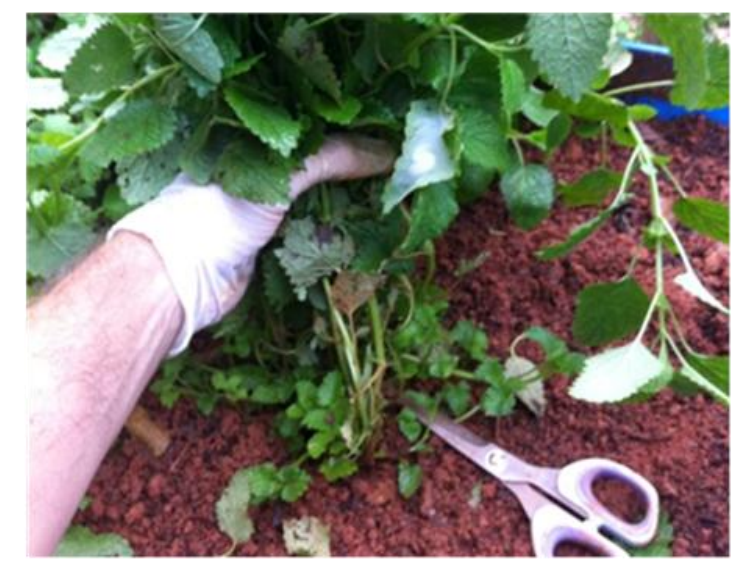

ETAPA I

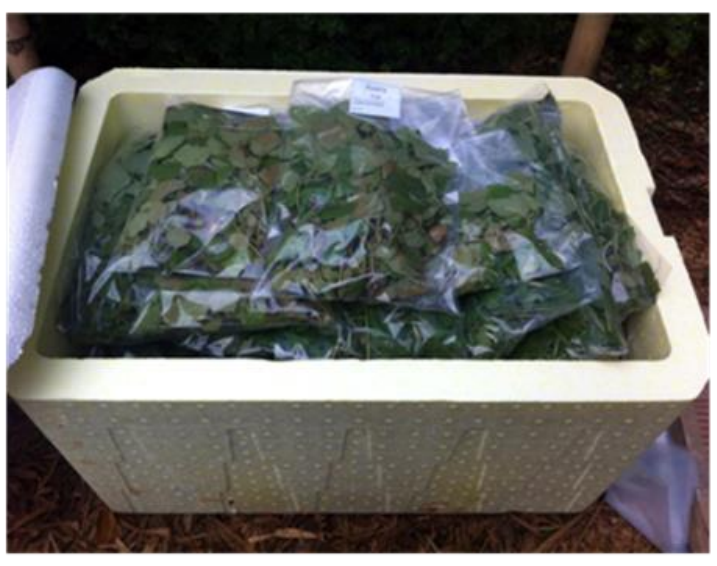

ETAPA II

FIGURA 3.11 - llustração dos processos de colheita das amostras de melissa: corte (etapa I) e armazenamento (etapa II).

$\overline{{ }^{1} \text { Exsicata é uma amostra de planta prensada e em seguida seca numa estufa, fixada em uma }}$ cartolina de tamanho padrão acompanhada de uma etiqueta ou rótulo contendo informações sobre o vegetal e o local de coleta, para fins de estudos botânicos. 
No laboratório, as amostras foram pesadas para determinação do cálculo de biomassa fresca e, em seguida, as folhas foram separadas do caule. Uma alíquota das amostras de folhas foi separada para determinação multielementar e outra alíquota para extração dos óleos voláteis (FIG. 3.12).

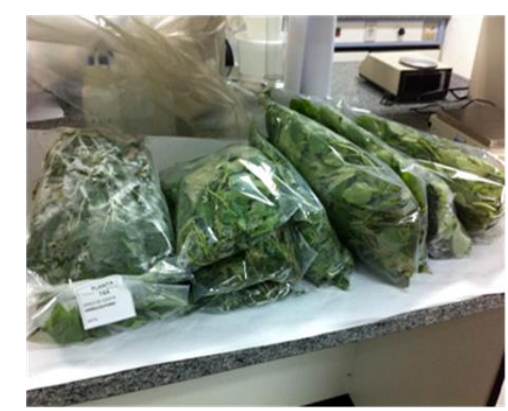

ETAPA I

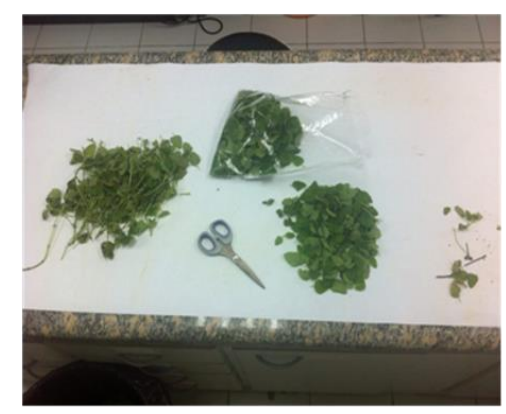

ETAPA III

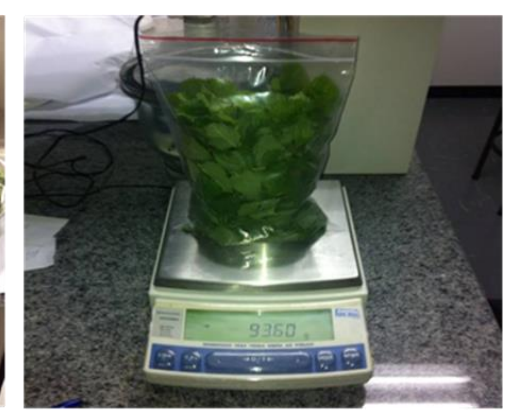

ETAPA II

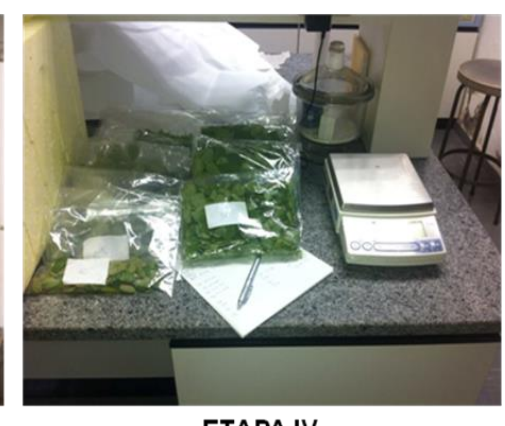

ETAPA IV

FIGURA 3.12 - llustração dos processos de preparação das amostras de melissa: recebimento das amostras no laboratório (etapa I), pesagem (etapa II), separação das folhas (etapa III) e separação das alíquotas (etapa IV).

Foram coletadas no total $16483 \mathrm{~g}$ de plantas ao longo do experimento. Após a separação das folhas, a massa fresca correspondente foi de $3461 \mathrm{~g}$ (21\%). Desta massa, uma alíquota de $620 \mathrm{~g}$ folhas de melissa foi separada para determinação multielementar. As amostras foram lavadas para retirada de impurezas, como terra; e, seca em estufa a uma temperatura de $60{ }^{\circ} \mathrm{C}$ por 24 horas, temperatura e tempo suficiente para total eliminação de umidade e peso constante. Para obtenção de material fino e homogêneo, com tamanho de partículas apropriado à análise, a alíquota foi pulverizada manualmente em almofariz de porcelana a uma granulometria de 100 mesh, utilizando-se peneiras de aço inoxidável com malha de nylon, homogeneizada e armazenada em tubos de polietileno (FIG. 3.13). 
Uma alíquota de $2841 \mathrm{~g}$ de folhas de melissa foi separada para extração dos óleos voláteis, acondicionada em sacos plásticos e mantida sob refrigeração de aproximadamente $-5^{\circ} \mathrm{C}$, para posterior extração dos óleos voláteis.
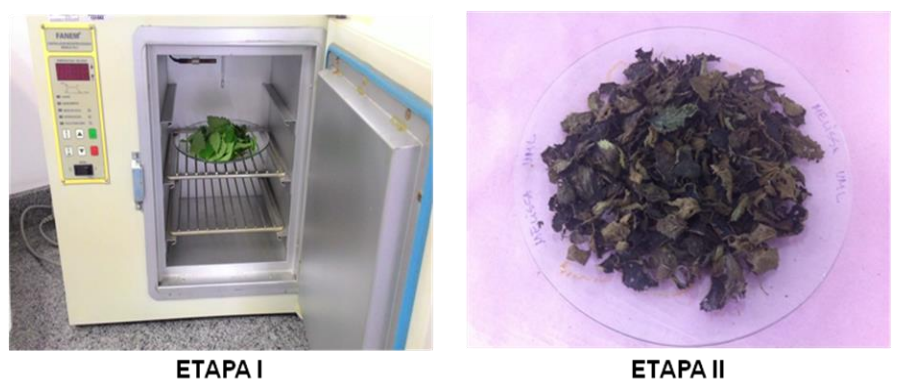

ETAPA II
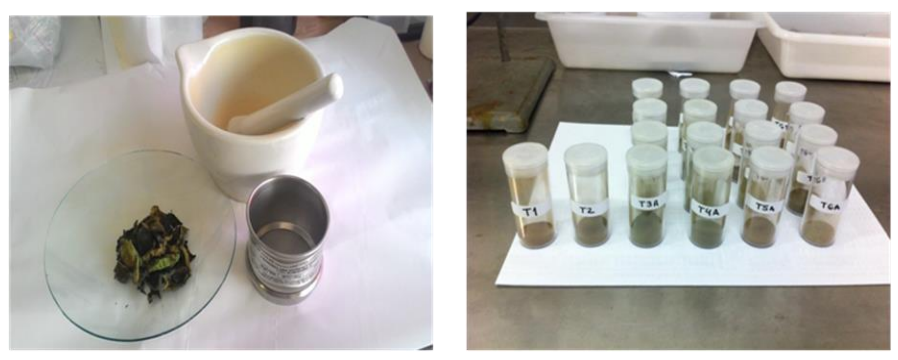

ETAPA IV

FIGURA 3.13 - llustração dos processos para preparação das amostras para análise multielementar: secagem em estufa (etapa I), mostra seca (etapa II), pulverização (etapa III) e armazenamento (etapa IV).

As amostras de plantas foram identificadas da seguinte maneira: BM (biomassa), FL (folhas) e OV (óleos voláteis); O, I, P e V (correspondem as épocas de colheitas: outono, inverno, primavera e verão, respectivamente); 1, 2, $3,4,5$ e 6 (corresponde ao cultivo aplicado: controle com mudas do condicionamento orgânico, controle com mudas do condicionamento convencional, orgânico com micronutrientes, orgânico sem micronutrientes, convencional com micronutrientes e convencional sem micronutrientes, respectivamente).

Por exemplo:

BMO-1 significa biomassa (BM) coletada no outono $(\mathrm{O})$ no sistema de cultivo controle com mudas do condicionamento orgânico.

FLI-2 significa folha (FL) coletada no inverno (I) no sistema de cultivo controle com mudas do condicionamento convencional (2).

OVP-5 significa óleo volátil (OV) extraído da coleta da primavera $(\mathrm{P})$ do sistema de cultivo convencional com micronutrientes (5). 


\subsection{Análise por ativação neutrônica instrumental (INAA)}

Esta técnica consiste no bombardeamento de um dado material, por nêutrons, formando radionuclídeos artificiais, seguido da medida da radioatividade induzida. O método baseia-se em uma reação nuclear resultante da interação de um nêutron com um núcleo alvo produzindo um núcleo composto, em estado excitado, que irá decair de acordo com a meia vida do nuclídeo formado, através da emissão de um ou mais raios gama ( $\mathrm{Y}$ ) característicos (FIG. 3.14).

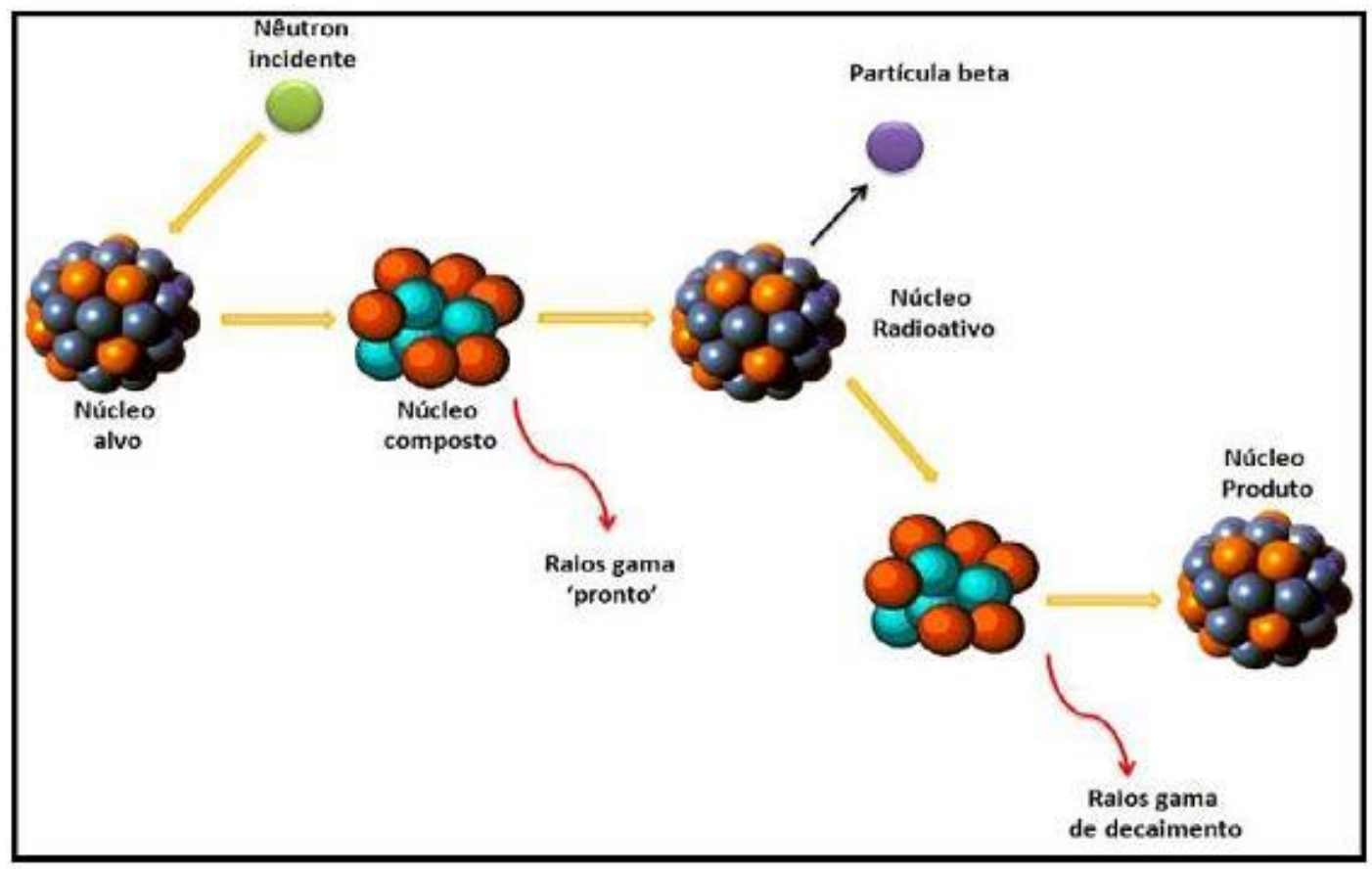

FIGURA 3.14 - llustração da sequência de eventos para uma reação (n, y).

A intensidade da radiação emitida é proporcional à concentração do elemento na amostra e, uma vez que, cada radioisótopo, produzido no processo de ativação, possui características próprias de emissão (meia-vida e energia das partículas ou radiação gama), é possível efetuar determinações por meio da comparação com a concentração em padrões certificados.

$\mathrm{Na}$ TAB. 3.6 são apresentados os elementos determinados, os radioisótopos formados na ativação usados na medida, suas meias-vidas e energias dos raios gama utilizadas na determinação de suas concentrações. 
TABELA 3.6 - Elementos analisados por ativação neutrônica, radioisótopo formado na ativação, energia dos raios gama utilizados na espectrometria gama e suas respectivas meias-vidas.

\begin{tabular}{|c|c|c|c|}
\hline Elemento & Radioisótopo & $E(k e V)^{1}$ & Meia Vida $^{2}$ \\
\hline As & ${ }^{76} \mathrm{As}$ & 559 & $26,32 \mathrm{~h}$ \\
\hline $\mathrm{Ba}$ & ${ }^{131} \mathrm{Ba}$ & 496 & $11,8 d$ \\
\hline $\mathrm{Br}$ & ${ }^{82} \mathrm{Br}$ & 554 e 776 & $35,3 \mathrm{~h}$ \\
\hline $\mathrm{Ca}$ & ${ }^{47} \mathrm{Sc}$ & 158 & $3,35 d$ \\
\hline $\mathrm{Ce}$ & ${ }^{141} \mathrm{Ce}$ & 145 & $32,5 d$ \\
\hline $\mathrm{Cl}$ & ${ }^{38} \mathrm{Cl}$ & 1642,7 & $37,24 \mathrm{~min}$ \\
\hline Co & ${ }^{60} \mathrm{Co}$ & 1173 e 1332 & $5,72 \mathrm{a}$ \\
\hline $\mathrm{Cr}$ & ${ }^{51} \mathrm{Cr}$ & 320 & $27,7 d$ \\
\hline Cs & ${ }^{134} \mathrm{Cs}$ & 795,85 & $2,06 \mathrm{a}$ \\
\hline Eu & ${ }^{152} \mathrm{Eu}$ & 121 e 344 & $13,33 a$ \\
\hline $\mathbf{F e}$ & ${ }^{59} \mathrm{Fe}$ & 1099 e 1291,6 & $44,5 d$ \\
\hline $\mathrm{Hf}$ & ${ }^{181} \mathrm{Hf}$ & 482,18 & $742,39 d$ \\
\hline K & ${ }^{42} \mathrm{~K}$ & 1524,58 & $12,36 \mathrm{~h}$ \\
\hline $\mathrm{La}$ & ${ }^{140} \mathrm{La}$ & 328 e 1596,21 & $40,27 \mathrm{~h}$ \\
\hline Lu & ${ }^{177} \mathrm{Lu}$ & 208,36 & $6,71 \mathrm{~d}$ \\
\hline Mg & ${ }^{27} \mathrm{Mg}$ & 844 e 1014 & $9,45 \mathrm{~min}$ \\
\hline Mn & ${ }^{56} \mathrm{Mn}$ & 847 e 1811 & $2,58 \mathrm{~h}$ \\
\hline $\mathrm{Na}$ & ${ }^{24} \mathrm{Na}$ & 1368,68 & $14,96 \mathrm{~h}$ \\
\hline Nd & ${ }^{174} \mathrm{Nd}$ & 91,1 e 531,01 & $10,98 d$ \\
\hline $\mathbf{R b}$ & ${ }^{86} \mathrm{Rb}$ & 1076 & $18,66 \mathrm{~d}$ \\
\hline Sb & ${ }^{122} \mathrm{Sb}$ & 564 e 692 & $2,7 d$ \\
\hline Sc & ${ }^{46} \mathrm{Sc}$ & 889 & $83,81 d$ \\
\hline Se & ${ }^{75} \mathrm{Se}$ & 264 & $119,77 \mathrm{~d}$ \\
\hline Sm & ${ }^{153} \mathrm{Sm}$ & 103,18 & $46,27 \mathrm{~h}$ \\
\hline Ta & ${ }^{182} \mathrm{Ta}$ & 1221 e 1231 & $114,5 d$ \\
\hline Tb & ${ }^{160} \mathrm{~Tb}$ & 879,38 & $72,3 d$ \\
\hline Th & ${ }^{233} \mathrm{~Pa}$ & 312,01 & $27 d$ \\
\hline $\mathrm{Ti}$ & ${ }^{51} \mathrm{Ti}$ & 320 & $5,76 \mathrm{~min}$ \\
\hline $\mathbf{U}$ & ${ }^{239} \mathrm{~Np}$ & 228,18 e 277,6 & $2,36 d$ \\
\hline V & ${ }^{52} \mathrm{~V}$ & 1434 & $3,74 \min$ \\
\hline $\mathrm{Yb}$ & ${ }^{169} \mathrm{Yb}$ & 177,21 e 197,98 & $32,02 d$ \\
\hline $\mathrm{Zn}$ & ${ }^{65} \mathrm{Zn}$ & 1115,6 & $243,9 d$ \\
\hline $\mathrm{Zr}$ & ${ }^{95} \mathrm{Zr}$ & 724,2 e 756,7 & $64,02 d$ \\
\hline
\end{tabular}

${ }^{1} \mathrm{E}(\mathrm{keV})$ - energia mil elétrons-volts $=10^{3}$ elétrons-volt.

${ }^{2}$ min(minutos), h(horas), d(dias), a(anos).

A análise por ativação com nêutrons foi proposta em 1936, sendo bastante utilizada para análises multielementares em diferentes áreas, como produtos agrícolas, plantas medicinais, arqueologia, biomedicina, toxicologia, bioquímica, análises ambientais, produtos industriais, geologia e análises de solo em geral (Sussa et al., 2016; Ferrari, 2008; Francisconi, 2014; Yamashita et al, 2006; 
Sussa et al., 2009; Glascock, 2010; Hazenfratz-Marks, 2014; Silva, 1998; Fei et al., 2010; Moreira et al., 2007).

A INAA é um dos métodos mais importantes dentre os disponíveis para a análise de elementos-traço. Tem a capacidade de determinação simultânea de muitos elementos com alta sensibilidade, sendo possível a determinação em níveis de $\mathrm{ng} \mathrm{g}^{-1}$ até $\%$, com exatidão e precisão. Possui também alta especificidade (habilidade de correlacionar diretamente e de forma não ambígua o sinal obtido com o elemento analisado) e seletividade (possibilidade de medir o elemento em questão na presença de outros elementos que emitem sinais da mesma natureza) (Greenberg et al., 2011).

$\mathrm{Na}$ INAA, a amostra é irradiada juntamente com um padrão, cuja composição é a mais similar possível, nas mesmas condições. Após a irradiação, a radioatividade das amostras e dos padrões é medida no mesmo detector, o que permite que as massas desconhecidas dos elementos de interesse possam ser diretamente calculadas a partir das taxas de contagens da amostra e do padrão, conhecendo-se as massas de ambos (Glascock, 2010; Bostelmann, 2006).

A equação 3.1 utilizada para calcular a concentração de um elemento desconhecido na amostra em relação ao padrão de comparação é a seguinte:

$$
C_{a i}=\frac{\left(A_{a i} m_{p} C_{p i}\right) e^{\lambda\left(\mathrm{t}_{\mathrm{a}}-\mathrm{t}_{\mathrm{p}}\right)}}{A_{p i} m_{a}}
$$

onde:

$\mathrm{C}_{\mathrm{ai}}=$ concentração do elemento i na amostra $\left(\mathrm{mg} \mathrm{kg}^{-1}\right)$

$\mathrm{C}_{\mathrm{pi}}=$ Concentração do elemento i no padrão $\left(\mathrm{mg} \mathrm{kg}^{-1}\right)$

$A_{\mathrm{ai}}=$ Atividade do elemento i na amostra (cps)

$A_{p i}=$ Atividade do elemento i no padrão (cps)

$\mathrm{m}_{\mathrm{a}}$ e $\mathrm{m}_{\mathrm{p}}=$ massas da amostra e do padrão, respectivamente $(\mathrm{g})$

$\lambda=$ Constante de decaimento do radioisótopo

$t_{a}-t_{p}=$ diferença de tempo (min.) entre as contagens da amostra e padrão. 
Como padrões, foram utilizados materiais de referência (MR) de matrizes de origem vegetal e geológica; e também padrões sintéticos provenientes de soluções-padrão pipetadas em papel de filtro para determinação das concentrações dos elementos nas amostras e para o controle da qualidade analítica, conforme descrito na TAB. 3.7.

TABELA 3.7 - Materiais de referência empregados para determinação elementar e garantia da qualidade analítica.

\begin{tabular}{|c|c|c|}
\hline Matriz & Material & Fabricante \\
\hline \multirow{3}{*}{ Vegetal } & Líquen-336 & IAEA $^{1}$ \\
\cline { 2 - 3 } & $\begin{array}{c}\text { Tomato Leaves } \\
(1573 a)\end{array}$ & NIST $^{2}$ \\
\cline { 2 - 3 } Geológica & $\begin{array}{c}\text { Peach Leaves } \\
(1547)\end{array}$ & NIST \\
\cline { 2 - 3 } & $\begin{array}{c}\text { Syenite, Table Mountain } \\
(\text { STM-2) }\end{array}$ & USGS $^{3}$ \\
\hline \multirow{2}{*}{ Sintético } & Solução monoelementar & NIST \\
\hline
\end{tabular}

${ }^{1}$ IAEA - International Atomic Energy Agency, Áustria.

${ }^{2}$ NIST - National Institute of Standards and Technology, EUA.

${ }^{3}$ USGS - United States Geological Survey, EUA.

${ }^{4}$ SPEX CERTIPREP - Inorganic and Organic Certified Reference Materials, EUA.

$\mathrm{Na}$ TAB. 3.8 são apresentadas as concentrações dos elementos nos materiais de referência (IAEA-336, USGS STM-2, NIST 1646a) e o do padrão pipetado utilizados para INAA. 
TABELA 3.8 - Elementos presentes e suas concentrações (conc. \pm incerteza) ou valor informativo, em $\mathrm{mg} \mathrm{kg}^{-1}$, nos materiais de referência IAEA-336, USGS STM-2, NIST 1646a e nos padrões pipetados (P.P) utilizados para INAA.

\begin{tabular}{|c|c|c|c|c|c|c|c|}
\hline \multirow{2}{*}{ Elementos } & \multicolumn{2}{|c|}{ IAEA-336 } & \multicolumn{2}{|c|}{ USGS STM-2 } & NIST 1646a & \multicolumn{2}{|r|}{ P.P } \\
\hline & conc. & \pm incert. & conc. & \pm incert. & conc. \pm incert. & conc. & \pm incert $^{1}$ \\
\hline As & 0,6 & $\pm 0,2$ & & - & $6,23 \pm 2,1$ & 50 & \pm 5 \\
\hline $\mathrm{Ba}$ & 6 & \pm 2 & 639 & \pm 61 & $210^{+}$ & 400 & \pm 40 \\
\hline $\mathrm{Br}$ & 13 & \pm 3 & & - & - & 50 & \pm 5 \\
\hline $\mathrm{Ca}$ & & - & 7800 & \pm 300 & $5190 \pm 200$ & 2000 & \pm 200 \\
\hline $\mathrm{Ce}$ & 1,3 & $\pm 0,3$ & 256 & \pm 23 & 34 & 20 & \pm 2 \\
\hline Co & 0,3 & $\pm 0,1$ & & - & 5 & 10 & \pm 1 \\
\hline $\mathrm{Cr}$ & 1,1 & $\pm 0,4$ & & - & $40,9 \pm 1,9$ & 20 & \pm 2 \\
\hline Cs & 0,11 & $\pm 0,02$ & 1,52 & $\pm 0,06$ & - & 10 & \pm 1 \\
\hline Eu & 0,023 & $\pm 0,005$ & 3,45 & $\pm 0,25$ & - & 5 & $\pm 0,5$ \\
\hline $\mathrm{Fe}$ & 0,04 & $\pm 0,02$ & 37700 & \pm 900 & $20080 \pm 390$ & 1000 & \pm 100 \\
\hline $\mathrm{Hf}$ & & - & 27 & $\pm 0,8$ & - & 5 & $\pm 0,5$ \\
\hline K & 0,18 & $\pm 0,05$ & 33800 & \pm 1700 & $8460 \pm 160$ & 500 & \pm 50 \\
\hline La & 0,7 & $\pm 0,2$ & 154 & \pm 11 & 17 & 25 & $\pm 2,5$ \\
\hline Lu & 0,007 & $\pm 0,002$ & 0,6 & $\pm 0,04$ & - & 5 & $\pm 0,5$ \\
\hline $\mathrm{Na}$ & 320 & \pm 85 & 66100 & \pm 3800 & $7410 \pm 170$ & 1000 & \pm 100 \\
\hline Nd & & - & 81 & $\pm 4,8$ & 15 & 100 & \pm 10 \\
\hline $\mathbf{R b}$ & 1,8 & $\pm 0,4$ & 114 & \pm 11 & 38 & 50 & \pm 5 \\
\hline Sb & 0,07 & $\pm 0,02$ & & - & 0,3 & 20 & \pm 2 \\
\hline Sc & 0,17 & $\pm 0,03$ & & - & 5 & & $\pm 0,5$ \\
\hline Se & & - & & - & $0,193 \pm 0,028$ & 50 & \pm 5 \\
\hline Sm & 0,11 & $\pm 0,03$ & 12 & $\pm 0,9$ & - & 50 & \pm 5 \\
\hline Ta & & - & 16 & $\pm 1,1$ & - & 20 & \pm 2 \\
\hline Tb & 0,014 & $\pm 0,002$ & & 1,38 & - & 10 & \pm 1 \\
\hline Th & 0,14 & $\pm 0,04$ & 27 & \pm 5 & 5,8 & & $\pm 0,5$ \\
\hline $\mathbf{U}$ & & - & & 7,6 & 2 & 20 & \pm 2 \\
\hline $\mathrm{Yb}$ & 0,04 & $\pm 0,01$ & 4,2 & $\pm 0,8$ & - & 20 & \pm 2 \\
\hline Zn & 30 & \pm 10 & 223 & \pm 19 & $48,9 \pm 1,6$ & 100 & \pm 10 \\
\hline $\mathrm{Zr}$ & & - & 1280 & \pm 62 & - & 2000 & \pm 200 \\
\hline
\end{tabular}

Para os elementos determinados pela irradiação curta, como o $\mathrm{Cl}, \mathrm{Mg}, \mathrm{Mn}$, Ti e V, foram utilizados os materiais de referência NIST 1573a (Tomato Leaves) e NIST 1547 (Peach Leaves) e também padrões sintéticos provenientes de 
soluções-padrão (SPEX CERTIPREP) com concentrações conhecidas dos mesmos elementos pipetados em papel de filtro.

$\mathrm{Na}$ TAB. 3.9 são apresentadas as concentrações, em $\mathrm{mg} \mathrm{kg}^{-1}$, dos elementos nos materiais de referência Tomato Leaves, Peach Leaves e o do padrão pipetado.

TABELA 3.9 - Elementos presentes e suas concentrações (conc. \pm incerteza), em $\mathrm{mg} \mathrm{kg}{ }^{-1}$, nos materiais de referência Tomato Leaves, Peach Leaves e dos padrões pipetados (P.P), utilizados para INAA.

\begin{tabular}{|c|c|c|c|c|}
\hline \multirow{2}{*}{ Elementos } & \multirow{2}{*}{$\begin{array}{c}\text { Tomato Leaves } \\
\text { conc + incert }\end{array}$} & Peach Leaves & \multicolumn{2}{|c|}{ P.P } \\
\hline & & conc. \pm incert. & conc. & \pm incert. \\
\hline $\mathrm{Cl}$ & $6600^{\dagger}$ & $360 \pm 19$ & 1000 & \pm 100 \\
\hline $\mathrm{Mg}$ & $12000^{\dagger}$ & $4320 \pm 8$ & 500 & \pm 50 \\
\hline$M n$ & $246 \pm 8$ & $89 \pm 3$ & 50 & \pm 5 \\
\hline $\mathrm{Ti}$ & - & & 100 & \pm 10 \\
\hline V & $0,835 \pm 0,01$ & $0,37 \pm 0,03$ & 1 & $\pm 0,1$ \\
\hline
\end{tabular}

${ }^{\dagger}$ Valor de informação.

\subsection{Preparação das amostras de solo para irradiação}

Para a irradiação longa (8 horas) foram pesadas, numa balança analítica Shimadzu (modelo AUW 220D), aproximadamente $150 \mathrm{mg}$ das amostras de solo em saquinhos de polietileno, previamente limpos com acetona. Em seguida, os invólucros foram selados e embalados em folha de alumínio. As amostras foram acondicionadas em cápsula de alumínio, denominadas "coelhos", fabricadas especialmente para irradiação com nêutrons. (FIG. 3.15).

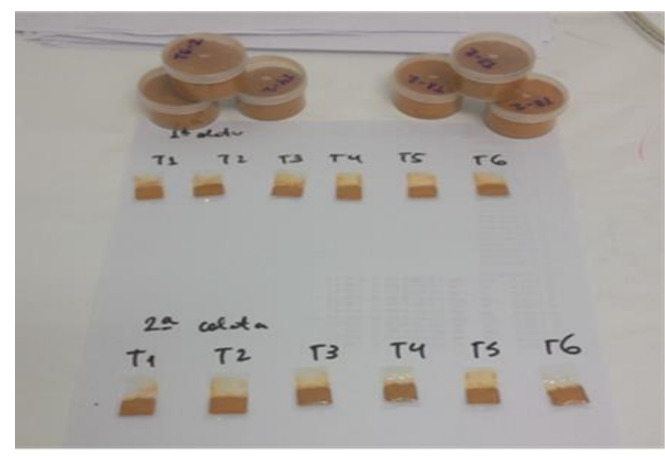

ETAPA I

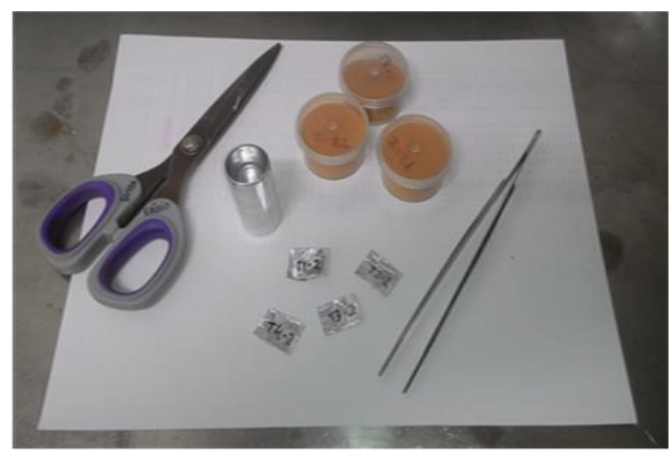

ETAPA II

FIGURA 3.15 - llustração dos processos para preparação das amostras para irradiação: acondicionamento das amostras em saquinhos de polietileno (etapa I), invólucros selados, embalados em folha de alumínio e acondicionados em cápsula de alumínio para irradiação (etapa II). 
Para irradiação curta foram pesadas cerca de $30 \mathrm{mg}$ de amostras de solo em saquinhos de polietileno, os invólucros foram selados e embalados em papel fino de celulose. As amostras foram acondicionadas em cápsula de polietileno de elevada pureza, "coelhos", fabricadas especialmente para irradiação com nêutrons (FIG. 3.16). As amostras foram submetidas à irradiação por 20 segundos, tempo estabelecido em estudos preliminares para determinação dos elementos de interesse.

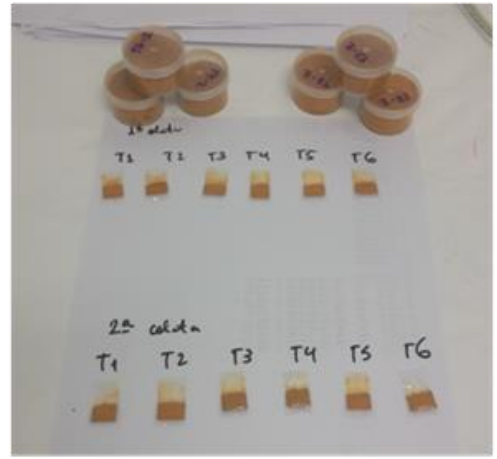

ETAPA I

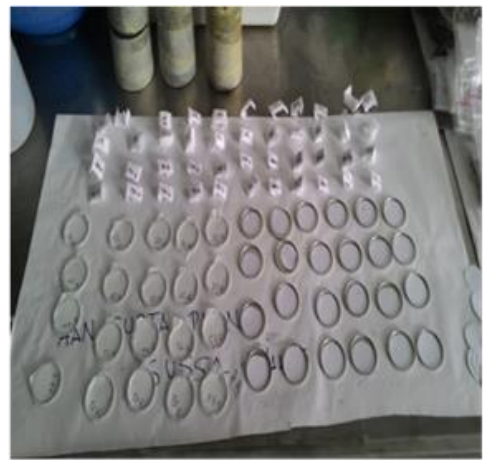

ETAPA II

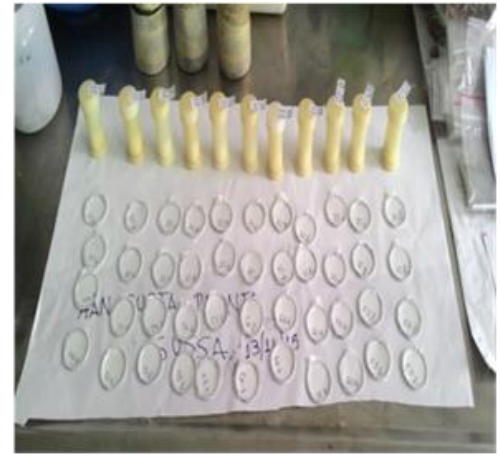

ETAPA III

FIGURA 3.16 - Ilustração dos processos para preparação das amostras para irradiação: acondicionamento das amostras em saquinhos de polietileno (etapa I), invólucros selados e embalados em papel de celulose (etapa II) e acondicionamento em cápsula de polietileno (etapa III).

\subsection{Preparação das amostras de planta para irradiação}

Para a irradiação longa (8 horas) foram pesadas aproximadamente $150 \mathrm{mg}$ das amostras de planta em saquinhos de polietileno, com auxílio de balança analítica Shimadzu (modelo AUW 220D) e os invólucros foram selados e embalados em folha de alumínio. As amostras foram acondicionadas em cápsula de alumínio "coelhos", fabricadas especialmente para irradiação com nêutrons (FIG. 3.17, etapa I).

Para irradiação curta (20 segundos) foram pesadas cerca de $70 \mathrm{mg}$ de amostras de planta em saquinhos de polietileno, os invólucros foram selados e embalados em papel fino de celulose. As amostras foram acondicionadas em cápsula de polietileno de elevada pureza, "coelhos", fabricadas especialmente para irradiação com nêutrons (FIG. 3.17, etapas II e III). 


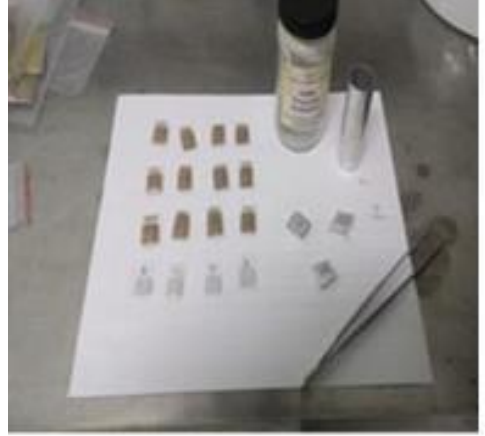

ETAPA I

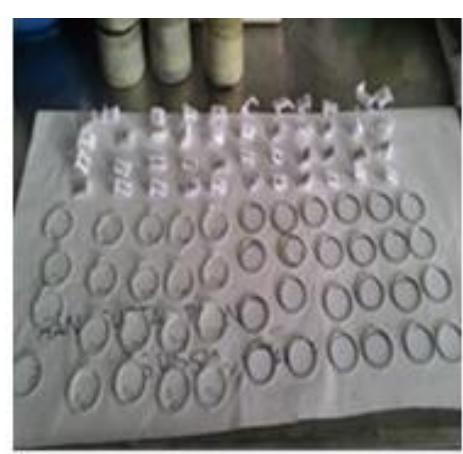

ETAPA II

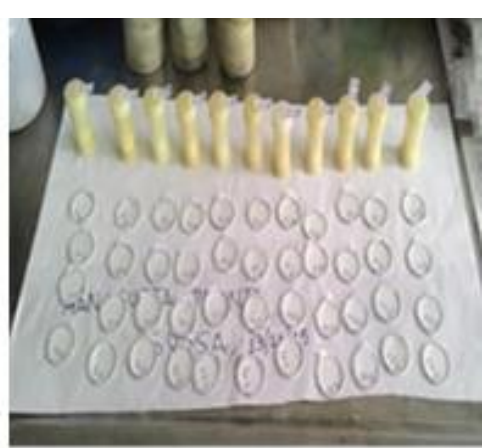

ETAPA III

FIGURA 3.17 - Ilustração dos processos para preparação das amostras para irradiação: acondicionamento, selagem e embalagem para irradiação longa (etapa I), embalagem em papel de celulose (etapa II) e acondicionamento em cápsula de polietileno para irradiação curta (etapa III).

\subsection{Preparação dos materiais de referência e padrões sintéticos pipetados} para irradiação

Para irradiação dos materiais de referência foram pesados aproximadamente $100 \mathrm{mg}$ para irradiação longa e aproximadamente $50 \mathrm{mg}$ para irradiação curta. Os MR foram preparados conforme descrito nos itens 3.8 e 3.9.

Os padrões sintéticos foram pipetados em papel de filtro e deixados para secar com luz artificial. Após a secagem dos papéis, estes foram cuidadosamente dobrados e embalados em saquinhos de polietileno (FIG. 3.18). Para irradiação longa e curta, foram seguidos os mesmos procedimentos descritos nos itens 3.8 e 3.9.

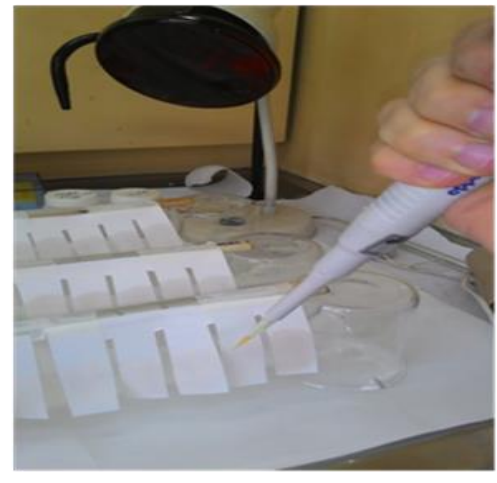

ETAPA I

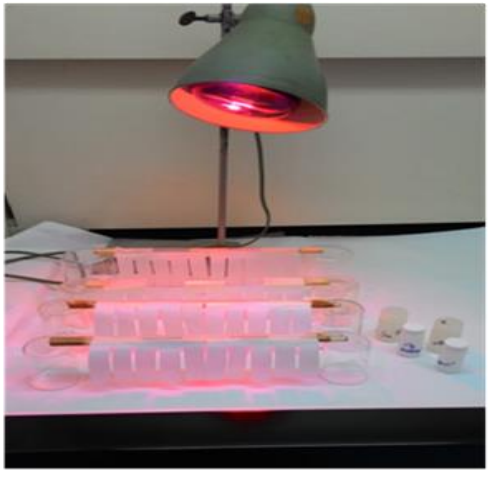

ETAPA II

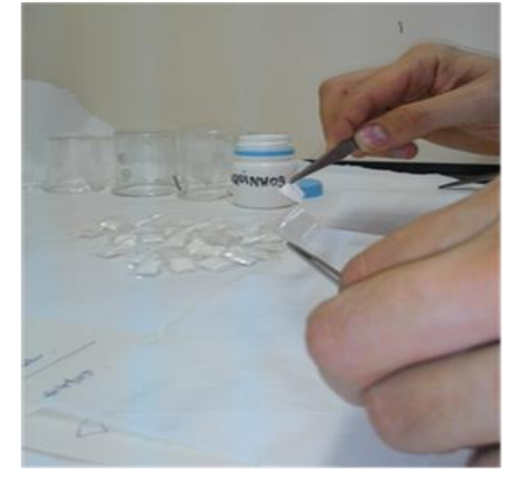

ETAPA III

FIGURA 3.18 - Ilustração dos processos para preparação das amostras para irradiação: transferência da solução para papel de filtro (etapa I), secagem dos papéis (etapa II) e acondicionamento em saquinhos de polietileno (etapa III). 


\subsection{Irradiações e medidas}

Todas as amostras e padrões foram irradiados no Reator Nuclear de Pesquisa IAE-R1 do IPEN/CNEN-SP sob um fluxo de nêutrons térmicos (energia média de $0,025 \mathrm{eV}$ ) de 1 a $5 \times 10^{12} \mathrm{~cm}^{-2} \mathrm{~s}^{-1}$. Foram realizadas duas séries de irradiação de acordo com o tempo de decaimento de cada radionuclídeo de interesse formado na amostra, conhecido como irradiação longa e irradiação curta.

A irradiação longa é empregada para determinação das concentrações dos radionuclídeos de meia-vida longa e intermediária ( $\mathrm{As}, \mathrm{Ba}, \mathrm{Br}, \mathrm{Ce}, \mathrm{Co}, \mathrm{Cr}, \mathrm{Cs}$, Eu, $\mathrm{Fe}, \mathrm{Hf}, \mathrm{K}$, La, Lu, Na, Nd, Rb, Sb, Sc, Se, Sm, Ta, Tb, Th, U, Yb, Zn e Zr). Para esta irradiação, as amostras, os materiais de referência e os padrões sintéticos, acondicionados nos coelhos, foram completamente vedados e posicionados próximos ao núcleo de reator e expostos ao fluxo de nêutrons especificado por um período de oito horas.

Nesta irradiação foram realizadas duas séries de medidas da radioatividade. A primeira foi feita após sete dias de decaimento, para determinação dos elementos $\mathrm{As}, \mathrm{Br}, \mathrm{K}, \mathrm{La}, \mathrm{Na}, \mathrm{Nd}, \mathrm{Sb}, \mathrm{Sm}, \mathrm{Tb}, \mathrm{U}$ e Yb. A segunda, foi feita após 15 dias de decaimento para determinação dos elementos $\mathrm{Ba}, \mathrm{Ca}, \mathrm{Ce}, \mathrm{Co}, \mathrm{Cr}, \mathrm{Cs}$, Eu, Fe, Hf, Lu, Rb, Sb, Sc, Se, Ta, Tb, Th, Zn e Zr.

A irradiação curta foi empregada para determinar os radionuclídeos de meias-vidas curtas (da ordem de alguns minutos a poucas horas) e neste trabalho foi utilizado para determinação das concentrações dos elementos $\mathrm{Cl}, \mathrm{Mn}, \mathrm{Mg}$, Ti e V. Para sua realização, as amostras, os materiais de referência e os padrões sintéticos pipetados, foram acondicionados em tubos de polietileno (coelhos) completamente vedados e irradiados por 20 segundos sob fluxo da ordem de $10^{12} \mathrm{n} \mathrm{cm}^{-2} \mathrm{~s}^{-1}$. O tempo de decaimento na irradiação curta variou de 2 a 20 minutos.

A medida da atividade gama induzida nas amostras, nos materiais de referência e dos padrões sintéticos, foi feita utilizando um detector de GeHiperpuro, EG\&G Ortec e equipamentos eletrônicos associados, com largura do pico a meia altura de 0,88 e 2,09 keV para os picos de 122 e $1332 \mathrm{keV}$ emitidos pelos radioisótopos ${ }^{57} \mathrm{Co} \mathrm{e}{ }^{60} \mathrm{Co}$, respectivamente (FIG. 3.19). 


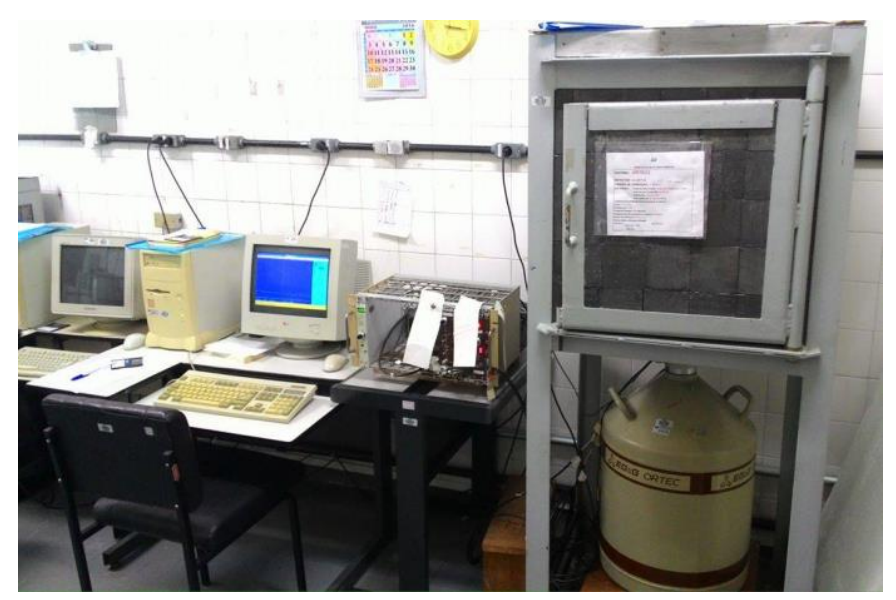

FIGURA 3.19 - llustração do sistema com detector de Germânio Hiperpuro e eletrônica associada do Laboratório de Análise por Ativação Neutrônica.

Para as irradiações longas, após 7 e 15 dias de decaimento, o tempo de contagem foi de 60 minutos para as amostras de solo e de 120 minutos para as amostras de planta. E para os materiais de referência e os padrões pipetados sintéticos, o tempo de contagem foi de 60 minutos.

Para as irradiações curtas, as contagens foram feitas durante 3 minutos para as amostras de solo e de planta e 2 minutos para os materiais de referência e para os padrões sintéticos.

A análise dos espectros foi feita utilizando-se o programa VISPECT2 (Neto, 2014) e os cálculos foram feitos em planilha de Microsoft Excel®.

\subsection{Espectrometria de Absorção Atômica por Forno de Grafite (GF AAS)}

A análise pela técnica de espectrometria de absorção atômica por forno de grafite teve por objetivo a determinação da concentração de $\mathrm{Cd}$, $\mathrm{Cu}$ e $\mathrm{Pb}$ nas amostras de solo e de folhas de Melissa officinalis.

A espectrometria de absorção atômica é um método sensível para a determinação quantitativa de mais de 60 elementos, a partir da medida da intensidade da radiação transmitida convertida em um sinal analítico por um detector. Os limites de detecção para AAS são da ordem de ppm a ppb (Skoog et al., 1998).

Na Espectrometria de Absorção Atômica, a amostra é exposta à radiação emitida por uma lâmpada com comprimentos de onda específicos, cujas energias dos fótons são exatamente as mesmas que podem ser absorvidas pelos átomos livres do elemento de interesse. Existe uma lâmpada para cada elemento que se 
deseja determinar. A luz dirigida através da nuvem do elemento atomizado em uma chama ou cubeta de forno de grafite passa por um monocromador até atingir o detector. A quantidade de energia absorvida naquele comprimento de onda específico é diretamente proporcional à concentração do elemento na amostra (Shriver et al, 2006).

Existem diferentes técnicas empregadas para a quantificação de qualquer elemento metálico usando-se as absorções características dos átomos.

As principais diferenças entre as técnicas se originam dos processos de atomização, capazes de converter $\mathrm{o}$ analito em átomos livres. O tipo de atomizador utilizado neste estudo foi 0 forno de grafite (aquecimento eletrotérmico), que apresenta alta sensibilidade, podendo determinar metais ao nível de ppb e ppt (Correia et al, 2003; Shriver et al, 2006). A alta sensibilidade é devida à capacidade de gerar átomos rapidamente e mantê-los no caminho óptico por mais tempo. As temperaturas no forno de grafite por indução atingem de 2000 a $3000^{\circ} \mathrm{C}$, proporcionando a atomização da amostra (Skoog et al., 1998).

\subsubsection{Procedimento experimental para as analise de $\mathrm{Cd}, \mathrm{Cu}, \mathrm{Ni}$ e $\mathrm{Pb}$}

Para determinação da concentração dos elementos $\mathrm{Cd}, \mathrm{Cu}$ e $\mathrm{Pb}$ por espectrometria de absorção atômica por forno de grafite (GF AAS) e, da concentração de Ni por espectrometria de emissão óptica com fonte de plasma indutivamente acoplado (IPC-OES ${ }^{1}$ ), as amostras necessitam de digestão prévia. As amostras foram digeridas em micro-ondas, por sua eficiência, rapidez e baixa contaminação (FIG. 3.20).

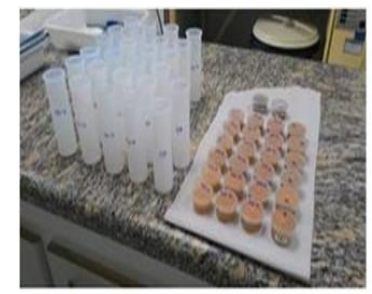

ETAPA I

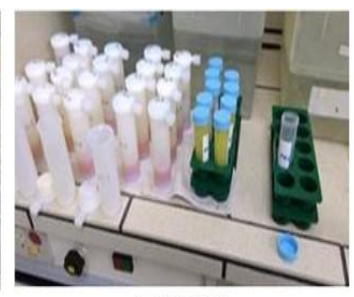

ETAPA II

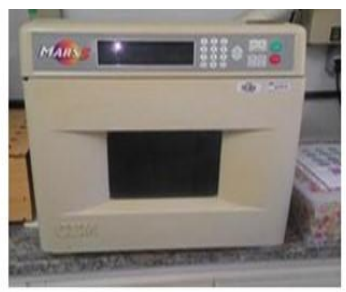

ETAPA III

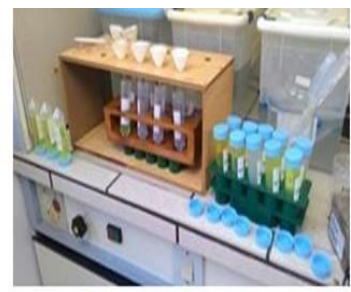

ETAPAIV

FIGURA 3.20 - llustração do processo de digestão das amostras para análise no GF AAS: amostra triturada e homogeneizada (etapa I), tratamento com ácidos em frasco de teflon (etapa II), digestão em micro-ondas (etapa III) e filtração e armazenamento em tubos plásticos (etapa IV).

${ }^{1}$ Espectrometria de Emissão Óptica com Fonte de Plasma Indutivamente Acoplado (ICP-OES), segundo metodologia Francisconi, 2014. 
Para esta análise foram pesadas alíquotas de cerca de $300 \mathrm{mg}$ das amostras de planta, solo e de cada material certificado (NIST 1573a - Tomato Leaves, NIST 1547 - Peach Leaves e NIST 1646a - Estuarine Sediment) em tubos de Teflon. Em seguida foram adicionados $4 \mathrm{ml}$ de ácido nítrico concentrado ( $\mathrm{HNO}_{3}$ conc.) e $1 \mathrm{ml}$ de $\mathrm{H}_{2} \mathrm{O}_{2} 20 \%$ (v/v).

Posteriormente, as amostras foram submetidas à digestão a frio, durante 1 dia e em seguida colocadas em forno de micro-ondas modelo MARS 5 da CEM. O programa de digestão utilizado foi feito em duas fases: na primeira empregou-se uma potência de $300 \mathrm{~W}$ a 100\%, durante 5 minutos, para elevar a temperatura da amostra à $80{ }^{\circ} \mathrm{C}$ e em seguida, permanecer neste valor por 55 minutos. $\mathrm{Na}$ segunda fase empregou-se uma potência de $300 \mathrm{~W}$ a $100 \%$, durante 5 minutos para elevar a temperatura à $100^{\circ} \mathrm{C}$ e em seguida permanecer neste valor por mais 55 minutos.

Após a digestão e resfriamento dos tubos, as amostras e os materiais de referência foram filtrados em papel de filtro Vetec (filtração media), com auxílio de funil de vidro, diretamente em balão volumétrico de $50 \mathrm{~mL}$ e o volume dos balões foi completado com água ultrapura Milli-Q®.

As amostras digeridas, juntamente com os materiais de referência foram analisadas no equipamento de GF AAS modelo AAnalyst 800 da Perkin Elmer (FIG. 3.21) no Laboratório de Absorção Atômica do LAN/IPEN-SP para determinação de $\mathrm{Cd}$, $\mathrm{Cu}$ e $\mathrm{Pb}$ e para determinação de $\mathrm{Ni}$, as amostras foram analisadas no Instituto Oceanográfico/USP.

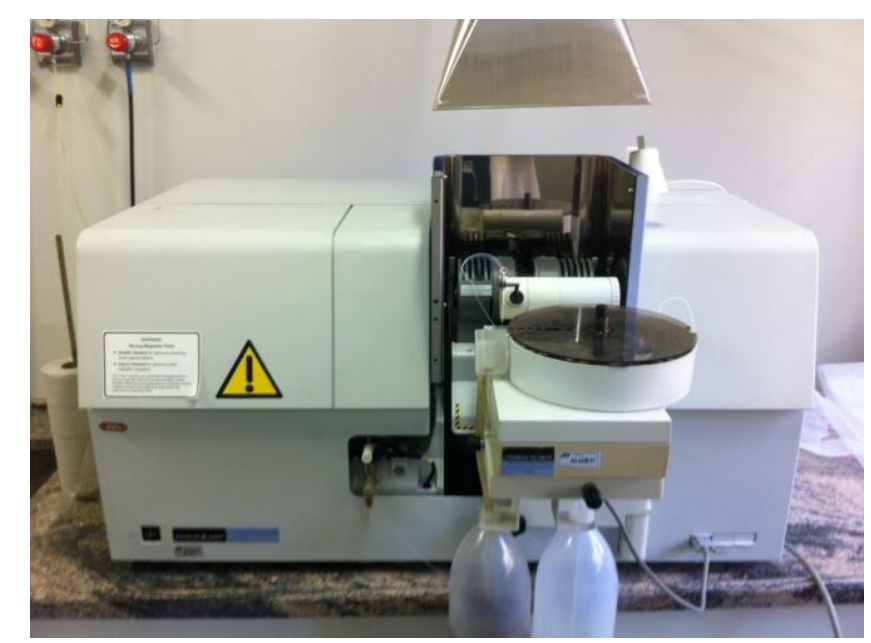

FIGURA 3.21 - Equipamento de GF AAS modelo AAnalyst 800 da Perkin Elmer para determinação de $\mathrm{Cd}$, $\mathrm{Cu}$ e $\mathrm{Pb}$. 
Os parâmetros instrumentais usados na determinação de $\mathrm{Cd}$, $\mathrm{Cu}$ e $\mathrm{Pb}$ nas amostras por GF AAS são apresentados na TAB.

TABELA 3.10 - Parâmetros instrumentais da determinação de $\mathrm{Cu}$, Cd e Pb ajustados para análise.

\begin{tabular}{lccc}
\hline Parâmetros & $\mathbf{C d}$ & $\mathbf{C u}$ & $\mathbf{P b}$ \\
\hline Lâmpada & $\mathrm{EDL}$ & $\mathrm{LCO}$ & $\mathrm{EDL}$ \\
Comprimento de onda $(\mathrm{nm})$ & 228,8 & 324,8 & 283,3 \\
Corrente da lâmpada $(\mathrm{mA})$ & 230 & 10 & 440 \\
Fenda espectral $(\mathbf{n m})$ & 0,7 & 0,5 & 0,7 \\
Volume de injeção da amostra $(\boldsymbol{\mu L})$ & 20 & 20 & 20 \\
Volume de injeção do modificador químico $(\boldsymbol{\mu L})$ & 10 & 10 & 10 \\
\hline
\end{tabular}

A medida de absorbância da amostra no equipamento de GF AAS é feita quando ocorre a etapa de atomização, devido ao aquecimento eletrotérmico do forno de grafite. Na TAB. 3.11 são apresentadas as etapas de aquecimento do forno de grafite para cada leitura efetuada no equipamento.

TABELA 3.11 - Etapas de aquecimento do forno de grafite para determinação de $\mathrm{Cd}, \mathrm{Cu}$ e $\mathrm{Pb}$.

\begin{tabular}{|c|c|c|c|c|c|c|c|c|c|c|c|c|}
\hline \multirow[t]{2}{*}{ Etapa } & \multicolumn{3}{|c|}{$\begin{array}{c}\text { Temperatura } \\
\left({ }^{\circ} \mathrm{C}\right)\end{array}$} & \multicolumn{3}{|c|}{$\begin{array}{c}\text { Rampa de } \\
\text { Aquecimento } \\
\qquad\left({ }^{\circ} \mathrm{C} \mathrm{s}^{-1}\right)\end{array}$} & \multicolumn{3}{|c|}{ Patamar (s) } & \multicolumn{3}{|c|}{$\begin{array}{c}\text { Fluxo interno } \\
\text { de argônio } \\
\left(\mathrm{mL} \mathrm{min}{ }^{-1}\right)\end{array}$} \\
\hline & $\mathrm{Cd}$ & $\mathrm{Cu}$ & $\mathrm{Pb}$ & $\mathrm{Cd}$ & $\mathrm{Cu}$ & $\mathrm{Pb}$ & $\mathrm{Cd}$ & $\mathrm{Cu}$ & $\mathrm{Pb}$ & $\mathrm{Cd}$ & $\mathrm{Cu}$ & $\mathrm{Pb}$ \\
\hline Secagem 1 & 110 & 110 & 110 & 1 & 1 & 1 & 30 & 30 & 30 & 250 & 250 & 250 \\
\hline Secagem 2 & 130 & 130 & 130 & 15 & 15 & 15 & 30 & 30 & 30 & 250 & 250 & 250 \\
\hline Pirólise & 500 & 500 & 500 & 10 & 10 & 10 & 20 & 20 & 20 & 250 & 250 & 250 \\
\hline Atomização & 1500 & 1500 & 1500 & 0 & 0 & 0 & 5 & 5 & 5 & 0 & 0 & 0 \\
\hline Limpeza & 2450 & 2450 & 2450 & 1 & 1 & 1 & 3 & 3 & 3 & 250 & 250 & 250 \\
\hline
\end{tabular}

Antes da determinação de $\mathrm{Cd}, \mathrm{Cu}, \mathrm{Ni}$ e $\mathrm{Pb}$ nas amostras foram preparadas soluções destes elementos a partir de soluções estoque (SE) e de solução de $\mathrm{HNO}_{3}$ 0,2\% (v/v) (Merck), usado como diluente, para construção da curva de calibração do equipamento. 
Na TAB. 3.12 são apresentadas as concentrações das soluções padrão que foram preparadas e as curvas de calibração para $\mathrm{Cd}, \mathrm{Cu}, \mathrm{Ni}$ e $\mathrm{Pb}^{1}$ e $\mathrm{Pb}^{2}$ são apresentadas nas FIG. 3.22, 3.23, 3.24, 3.25 e 3.26, respectivamente.

TABELA 3.12 - Concentração das soluções utilizadas na construção da curva de calibração para determinação de $\mathrm{Cd}, \mathrm{Cu}, \mathrm{Ni}, \mathrm{Pb}^{1} \mathrm{e} \mathrm{Pb}^{2}$.

\begin{tabular}{lccccc}
\hline Soluções de & \multicolumn{5}{c}{ Concentração $\left(\mu \mathbf{g ~ L}^{-1}\right)$} \\
\cline { 2 - 6 } calibração & $\mathrm{Cd}$ & $\mathrm{Cu}$ & $\mathrm{Ni}$ & $\mathrm{Pb}^{1}$ & $\mathrm{~Pb}^{2}$ \\
\hline Branco & 0 & 0 & 0 & 0 & 0 \\
SE-1 & 1,4 & 40 & 0,01 & 5 & 24 \\
SE-2 & 2,8 & 85 & 0,05 & 10 & 48 \\
SE-3 & 4,2 & 132 & 0,1 & 15 & 71 \\
SE-4 & 5,6 & 167 & 0,5 & 20 & 95 \\
SE-5 & 7,0 & 198 & 1 & 25 & 119 \\
SE-6 & - & - & 5 & - & - \\
SE-7 & - & - & 10 & - & - \\
\hline
\end{tabular}

$\mathrm{Pb}^{1}$ curva de calibração para análise das plantas.

$\mathrm{Pb}^{2}$ curva de calibração para análise dos solos.

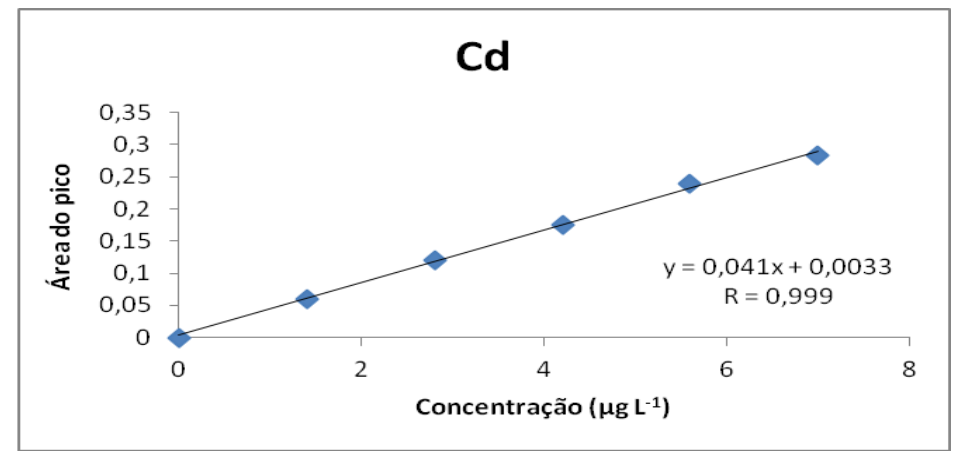

FIGURA 3.22 - Curva de calibração para Cd obtida por GF AAS.

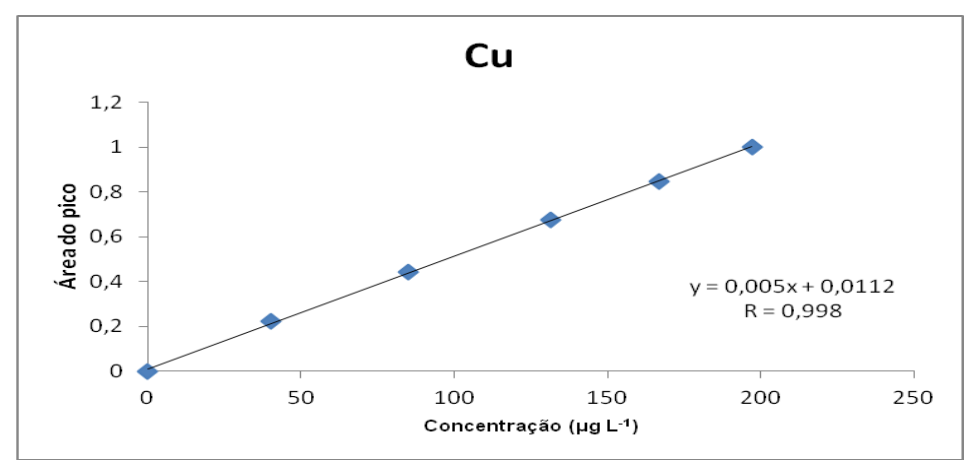

FIGURA 3.23 - Curva de calibração para Cu obtida por GF AAS. 


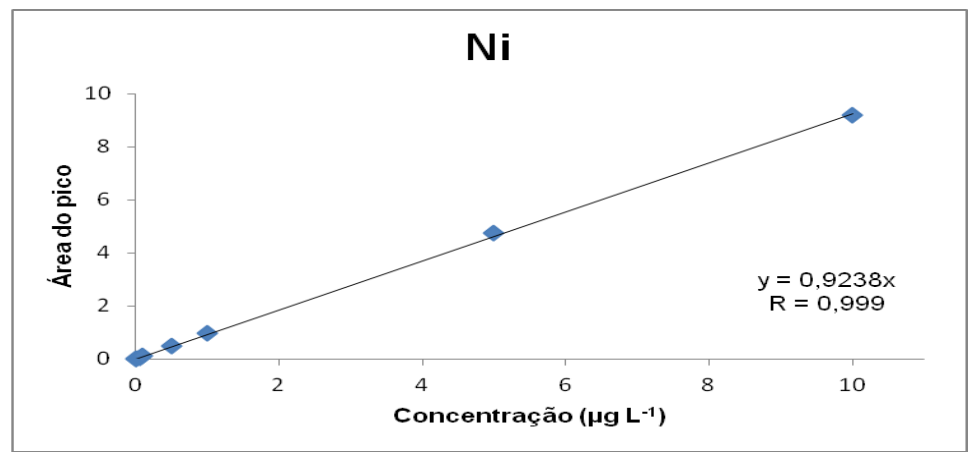

FIGURA 3.24 - Curva de calibração para Ni obtida por ICP-OES.

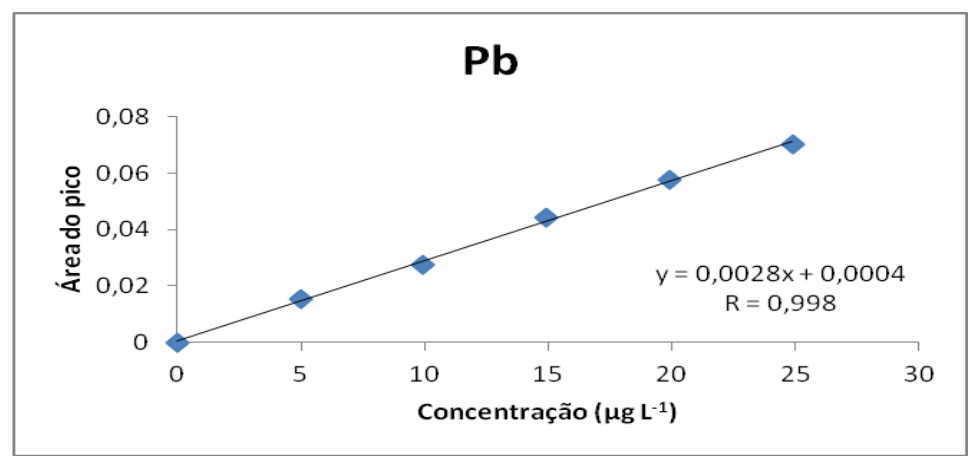

FIGURA 3.25 - Curva de calibração para $\mathrm{Pb}^{1}$ obtida por GF AAS.

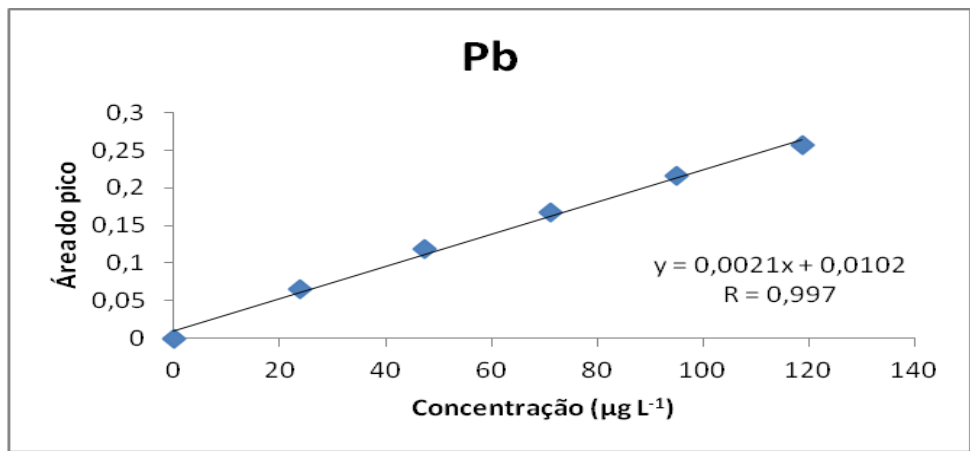

FIGURA 3.26 - Curva de calibração para $\mathrm{Pb}^{2}$ obtida por GF AAS.

O sinal analítico foi determinado a partir da área do pico de absorção e utilizou-se o modo de regressão linear para o ajuste da curva. Foram realizados ensaios relacionados à avaliação da linearidade. A determinação da equação de calibração é muito importante tanto em análises de rotina quanto em procedimentos de validação de métodos (Souza, 2014).

A linearidade das curvas de calibração foi checada tanto de forma visual do gráfico da curva de calibração no momento das medidas, como também pelo coeficiente de correlação linear das curvas, $R(r>0,99)$, distribuição dos resíduos, 
homocedasticidade e independência dos resíduos (Souza, 2014). Dessa forma, as retas obtidas poderam ser consideradas um modelo matemático adequado para o estudo, onde o sinal do equipamento é diretamente proporcional à concentração dos analitos.

A TAB. 3.13 apresenta a avaliação das demais premissas que devem ser checadas para se estabelecer a linearidade. Os cálculos foram realizados de acordo com as recomendações de Souza e Junqueira, 2005.

TABELA 3.13 - Avaliação das premissas envolvidas no estudo de linearidade para as curvas analíticas de $\mathrm{Cd}, \mathrm{Cu}, \mathrm{Ni}$ e $\mathrm{Pb}$.

\begin{tabular}{lcccccc}
\hline Premissa avaliada & Estatística & $\mathbf{C d}$ & $\mathbf{C u}$ & $\mathbf{N i}$ & $\mathbf{P b}^{\mathbf{1}}$ & $\mathbf{P b}^{\mathbf{2}}$ \\
\hline Normalidade & & 0,97 & 0,99 & 0,88 & 0,93 & 0,44 \\
Homocedasticidade & $p$-valor & 0,14 & 0,11 & 0,10 & 0,85 & 0,42 \\
Independência & & 0,43 & 0,15 & 0,24 & 0,77 & 0,07 \\
\hline
\end{tabular}

$\mathrm{Pb}^{1}$ curva de calibração para análise das plantas.

$\mathrm{Pb}^{2}$ curva de calibração para análise dos solos.

A distribuição normal dos resíduos $(p>0,10)$, que é requisito para aplicação de estatísticas paramétricas, foi confirmada através do teste de Shapiro-Wilk. Como mostrado na TAB. 3.13, os $p$-valores foram maiores que 10\%, não rejeitamos a hipótese de normalidade dos dados.

Para avaliação da homocedasticidade foi usado o teste de Breusch Pagan assumindo um nível de confiança de 0,05 . Todos os valores ficaram maiores que o nível de significância, assim os dados podem ser considerados homocedásticos.

Para confirmação de independência dos resíduos foi realizado o teste de Durbin-Watson. Adotando um nível de significância de $5 \%$ temos que pelo teste os resíduos são independentes.

\subsection{Limite inferior de detecção (LID) e limite de quantificação (LQ)}

Quando são realizadas medidas em amostras com baixos níveis do analito, como por exemplo, análise de traços, é importante saber qual o menor valor de concentração do analito que pode ser detectado pelo método. Para a validação de um método analítico, é normalmente suficiente fornecer uma indicação do nível em que a detecção do analito pode ser distinguida do sinal do branco/ruído. 
O limite de detecção também é considerado como a menor concentração do analito que um procedimento analítico específico pode detectar com segurança. Sendo também definido como a concentração mínima na qual uma substância pode ser medida e declarada, a um determinado grau de confiança, de que a concentração do analito é maior que zero.

O limite inferior de detecção (LID) e o limite de quantificação (LQ) para INAA, GF AAS e ICP-OES, sob as condições em que foram realizadas as medidas neste trabalho para as análises das amostras de folhas de Melissa officinalis e amostras de solo, foram calculados utilizando o material de referência IAEA-336 (Líquen), NIST 1646a e P.P (padrão pipetado), a equação 3.2 (Keith et al., 1983) e equação 3.3 (Guimarães, 2011).

$$
L I D=\frac{3 V S b}{T C}
$$

onde:

$\mathrm{Sb}$ = desvio padrão da contagem da radiação de fundo;

$\mathrm{V}=$ valor certificado $\left(\mathrm{mg} \mathrm{kg}^{-1}\right)$

$\mathrm{T}=$ tempo de contagem (s);

$\mathrm{C}=$ contagem do fotopico do elemento de interesse.

$$
L Q=3 L I D
$$

Foram analisadas 10 amostras do material de referência para determinação do LID e LQ. Na TAB. 3.14 são apresentadas as médias dos valores de Limite inferior de detecção e Limite de quantificação, calculados para os elementos presentes nos materiais de referência IAEA-336, NIST 1646a e P.P. 
TABELA 3.14 - Valores de Limite inferior de detecção (LID) e Limite de quantificação (LQ), em $\mathrm{mg} \mathrm{kg}^{-1}$, para as técnicas de INAA, GF AAS e IPC-OES obtidos para os elementos no material de referência IAEA-336, NIST 1646a e P.P.

\begin{tabular}{|c|c|c|c|c|c|c|}
\hline \multirow[t]{2}{*}{ Elemento } & \multicolumn{2}{|c|}{ IAEA-336 } & \multicolumn{2}{|c|}{ NIST 1646a } & \multicolumn{2}{|c|}{ P.P } \\
\hline & LID & LQ & LID & LQ & LID & LQ \\
\hline As & 0,11 & 0,32 & 2,21 & 6,64 & - & - \\
\hline $\mathrm{Ba}$ & 11,65 & 34,95 & 1,83 & 5,49 & - & - \\
\hline $\mathrm{Br}$ & 0,1 & 0,4 & 1,8 & 5,5 & - & - \\
\hline $\mathrm{Ca}$ & 831 & 2492 & 671 & 2013 & - & - \\
\hline $\mathrm{Cd}^{*}$ & 0,004 & 0,013 & - & - & - & - \\
\hline $\mathrm{Ce}$ & 0,33 & 0,99 & 1,72 & 5,16 & - & - \\
\hline $\mathrm{Cl}$ & & & & & 147 & 441 \\
\hline Co & 0,04 & 0,11 & 0,26 & 0,78 & - & - \\
\hline $\mathrm{Cr}$ & 0,37 & 1,12 & 0,51 & 1,53 & - & - \\
\hline Cs & 0,07 & 0,22 & 0,70 & 2,09 & - & - \\
\hline $\mathrm{Cu}^{*}$ & 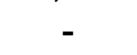 & - & 0,035 & 0,21 & - & - \\
\hline $\mathrm{Eu}$ & 0,01 & 0,03 & 0,08 & 0,23 & - & - \\
\hline $\mathrm{Fe}$ & 27 & 80 & 264 & 792 & - & - \\
\hline $\mathrm{Hf}$ & 0,06 & 0,17 & 0,4 & 1,25 & - & - \\
\hline K & - & - & - & - & 165 & 496 \\
\hline La & 0,09 & 0,28 & 0,51 & 1,53 & - & - \\
\hline Lu & 0,01 & 0,03 & 0,05 & 0,16 & - & 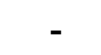 \\
\hline Mg & - & - & & - & 37 & 110 \\
\hline$M n$ & - & - & - & - & 0,3 & 1,0 \\
\hline $\mathrm{Na}$ & 1,2 & 3,6 & 59 & 178 & - & - \\
\hline Nd & 1,95 & 5,86 & 11 & 33 & - & - \\
\hline $\mathrm{Ni}^{* *}$ & & , & 0,025 & 0,075 & - & - \\
\hline $\mathrm{Pb}^{*}$ & 0,005 & 0,014 & & & - & - \\
\hline $\mathbf{R b}$ & 1,3 & 3,8 & 7,7 & 23,2 & - & - \\
\hline $\mathrm{Sb}$ & 0,02 & 0,07 & 0,25 & 0,75 & - & - \\
\hline Sc & 0,01 & 0,02 & 0,05 & 0,16 & - & - \\
\hline $\mathrm{Se}$ & 0,18 & 0,55 & 1,75 & 5,26 & - & - \\
\hline Sm & 0,01 & 0,03 & 0,07 & 0,22 & - & - \\
\hline Ta & 0,04 & 0,11 & 0,35 & 1,04 & - & - \\
\hline Tb & 0,04 & 0,11 & 0,35 & 1,05 & - & - \\
\hline Th & 0,05 & 0,15 & 0,41 & 1,23 & - & - \\
\hline $\mathrm{Ti}$ & & 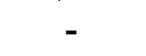 & & & 4,9 & 14,6 \\
\hline $\mathbf{U}$ & 0,13 & 0,39 & 1,55 & 4,66 & - & - \\
\hline V & - & - & - & - & 0,03 & 0,08 \\
\hline Yb & 0,06 & 0,19 & 0,50 & 1,50 & - & - \\
\hline $\mathrm{Zn}$ & 1,4 & 4,1 & 12,6 & 37,7 & - & - \\
\hline $\mathrm{Zr}$ & . & . & & & 27 & 82 \\
\hline
\end{tabular}




\subsection{Determinação dos óleos voláteis de Melissa oficinalis}

\subsubsection{Extração e caracterização dos óleos voláteis}

A extração do óleo foi realizada em laboratório do IPEN pelo método da hidrodestilação com o uso de aparelho tipo Clevenger modificado (FIG. 3.27). Os tecidos vegetais foram cortados em pequenos pedaços e colocados em balão de fundo redondo de capacidade de $1000 \mathrm{ml}$ e foram adicionados $500 \mathrm{ml}$ de água destilada. O período de extração dos óleos voláteis foi de 4 horas, assim que as primeiras gotas de óleo condensaram, segundo a Farmacopéia Brasileira (Brasil, 2010).

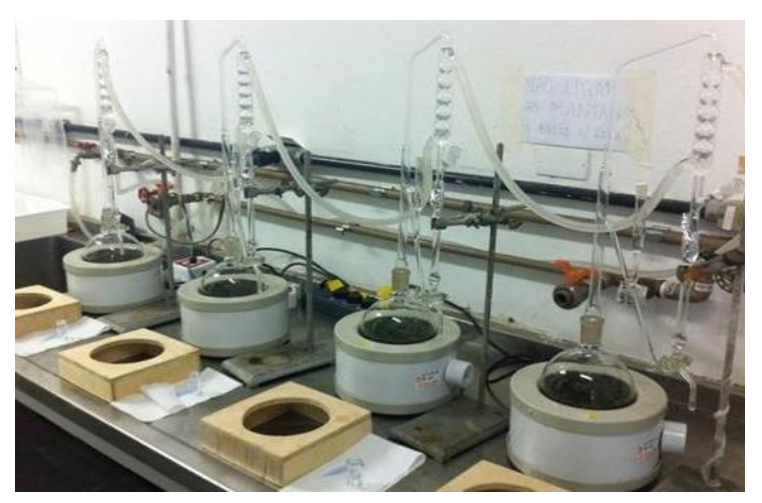

FIGURA 3.27 - Aparelho de Clevenger.

Ao final da extração, foram adicionados $500 \mu \mathrm{l}$ de hexano pelo tubo em T do aparelho de Clevenger, a fim de solubilizar o óleo na fração hexânica e separálo da fração aquosa. As amostras de óleo foram coletadas com micropipeta, armazenadas em frascos e acondicionada em caixa de isopor para evaporação total do hexano. Ao término desses procedimentos, os óleos voláteis extraídos foram quantificados quanto ao seu teor ( $\mathrm{g} / \mathrm{g}$ de folha) e armazenados em freezer até análise da composição química.

O perfil cromatográfico foi conduzido em cromatógrafo a gás acoplado ao espectrômetro de massas (GC/MS, Shimadzu, QP-5000), dotado de coluna capilar de sílica fundida OV - 5 (30 m x 0,25 mm x 0,25 $\mu \mathrm{m}$ Ohio Valley Specialty Chemical, Inc.). Operando sob condições de temperatura de $60^{\circ} \mathrm{C}$ a $120^{\circ} \mathrm{C}$ em $3{ }^{\circ} \mathrm{C} \mathrm{min}{ }^{-1}$, temperatura de injeção e do detector de $240{ }^{\circ} \mathrm{C}$ e $230{ }^{\circ} \mathrm{C}$, respectivamente a $70 \mathrm{eV}$. O gás utilizado foi o hélio com uma vazão constante de 
1,7 $\mathrm{mL} \mathrm{min}^{-1}$, split 1/20 (FIG. 3.28). Essas análises foram realizadas em laboratório do CTR/IPEN.

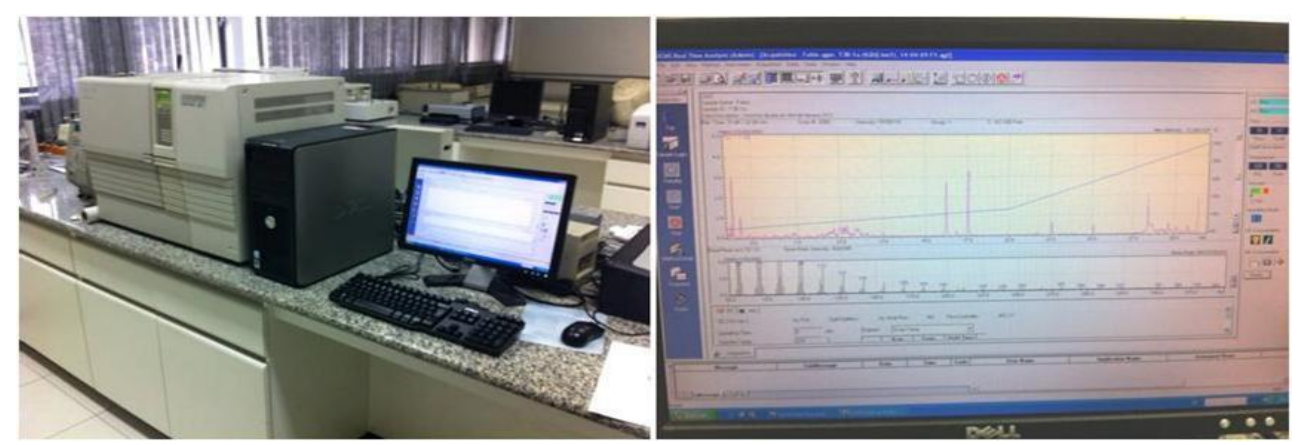

FIGURA 3.28 - Cromatógrafo gasoso acoplado ao espectrômetro de massas (GC/MS).

O citronelal, neral e geranial foram identificados a partir da avaliação dos tempos de retenção dos componentes das soluções padrão (citronelal e citral, $95 \%$ - Sigma Aldrish $\AA$ ), bem como dos fragmentos de massa gerados pelo GC/MS e posteriormente comparados com os dados de espectro de massa da literatura e por base de dados computadorizada da biblioteca NIST.

A identificação dos constituintes minoritários nerol, geraniol e citronelol foi feita por comparação dos índices de retenção linear calculados com a equação 3.4 obtidos por meio da injeção de uma mistura padrão de n-alcanos $\left(\mathrm{C}_{7} \mathrm{H}_{16}\right.$ $\mathrm{C}_{40} \mathrm{H}_{82}$ Sigma Aldrich $\AA$, 98\%) comparados com dados da literatura (McLafferty e Stanffer, 1989; Adams, 2001; Viegas e Bassoli, 2007).

$$
I_{k}=100 n+100\left[\frac{t_{R X}-t_{R n}}{t_{R N}-t_{R n}}\right]
$$

onde:

$\mathbf{I}_{\boldsymbol{k}}=$ índice de retenção do composto de interesse;

$t_{\mathrm{RX}}=$ tempo de retenção do composto de interesse;

$\mathbf{n}=$ número de átomos de carbono do n-alcano eluído antes do composto de interesse;

$t_{\mathrm{Rn}}=$ tempo de retenção do $\mathrm{n}$-alcano eluído antes;

$\mathbf{N}=$ número de átomos de carbono do $\mathrm{n}$-alcano eluído depois do composto de interesse;

$\mathbf{t}_{\mathrm{RN}}=$ tempo de retenção do n-alcano eluído depois. 


\subsection{Análises estatísticas}

Análises estatísticas de caráter univariado foram realizadas para cada variável considerada independente, e multivariado considerando as variáveis simultaneamente.

A análise de variância foi empregada com realização de teste de comparação múltipla entre médias pelos testes ANOVA e de Tukey. A análise foi realizada para cada variável independente, para testar a hipótese de igualdade dos tratamentos do solo, a biomassa fresca, teor de óleo volátil e composição química dos óleos voláteis analisados nos diferentes tratamentos e épocas de colheita. A Análise de Variância é uma ferramenta estatística que estuda medidas dependentes de vários tipos de efeitos simultâneos, com o objetivo de decidir quais destes efeitos são realmente significativos (Parreira, 2003).

Neste trabalho foi utilizada a Análise de Correlação de Pearson, Análise de Agrupamento Hierárquico (AAH) e Análise de Componentes Principais (PCA). Estas técnicas estão entre os procedimentos que fornecem uma abordagem mais interessante e promissora para o objetivo proposto (Arumugam et al, 2012).

A fim de evitar interferências das unidades de medida nas análises de componentes principais e de agrupamento, os dados foram padronizados, obtendo-se média $=0$ e variância $=1$. Para realização dos testes foram empregados o software STATISTICA 13 e o Action Pro 3.1.

\subsubsection{Análise de Agrupamento Hierárquico (AAH)}

As técnicas de agrupamento são utilizadas com o objetivo de investigar as relações existentes dentro de um conjunto multivariado no qual, a priori, nenhuma caracterização é conhecida (Parreira, 2003). A análise de agrupamento foi utilizada para explorar as similaridades entre as amostras e/ou variáveis, definindo-as em grupos, ou clusters. Para a AAH, adotou-se a distância euclidiana como medida de similaridade e o método de Ward para ligar os casos entre si. Esse método possui a tendência de formar grupos com alto grau de homogeneidade interna, ou seja, dentro dos agrupamentos e também elevada heterogeneidade externa entre os agrupamentos. Com isso, se bem sucedida a análise, estes agrupamentos estarão graficamente apresentando os objetos de dentro dos agrupamentos próximos enquanto que os agrupamentos externos estarão distantes (Ferreira, 2015). Para representar o agrupamento hierárquico foi 
utilizado o dendrograma, que é a forma gráfica mais comumente empregada (Paye et al., 2012; Sena, 1999; Freitas et al., 2011)

\subsubsection{Análise de Componentes Principais (PCA)}

A análise de componentes principais é uma técnica multivariada que examina relações entre certo número de variáveis quantitativas. A PCA tem por objetivo reduzir a dimensão original de um conjunto de dados buscando preservar sua estrutura e facilitar a interpretação das análises realizadas (Ferrari, 2008). A redução dimensional obtida por essa técnica é realizada pela transformação das variáveis originais em um novo conjunto de variáveis, que são as componentes principais, não correlacionadas, e ordenadas de modo que um número reduzido de componentes retenha a maior parte das informações presentes na matriz original (Hazenfratz-Marks, 2014).

A PCA é um método exploratório porque ajuda na elaboração de hipóteses gerais a partir dos dados coletados, contrastando com estudos direcionados nos quais hipóteses prévias são testadas. Ela é capaz de separar a informação importante da redundante. Para a análise exploratória é de fundamental importância entender que os "scores" fornecem a composição das CPs em relação aos objetos (amostras) enquanto os "loadings" fornecem essa mesma composição em relação às variáveis. Como as CPs são ortogonais, é possível examinar as relações entre os objetos através dos gráficos dos "scores" projetados nas primeiras CPs, e entre as variáveis através dos gráficos dos "loadings". Esses gráficos apresentam informações úteis sobre tendências subjacentes e características da estrutura dos dados, tais como, agrupamentos de objetos ou variáveis e caracterização dos chamados "outliers" (amostras malcomportadas, que não se encaixam no modelo). O estudo conjunto de "scores" e "loadings" permite estimar a influência de cada variável em cada objeto (Sena, 1999). 


\section{RESULTADOS E DISCUSSÃO}

\subsection{Caracterização elementar nas amostras de solo e de planta}

\subsubsection{Controle de qualidade dos procedimentos analíticos}

\subsubsection{Precisão e exatidão dos resultados para INAA}

Os materiais de referência $(M R)$ de matrizes de origem biológica e geológica, descritos no item 3.1 e os padrões pipetados foram irradiados juntamente com as amostras para a verificação da metodologia empregada para determinação multielementar pela INAA.

Como matrizes geológicas, foram utilizados os MR NIST 1646a (Estuarine Sediment) e USGS STM-2 (Syenite Table Mountain) para irradiação longa e curta; e como matrizes biológicas, o IAEA-336 (Líquen) e o NIST 1573a (Tomato Leaves) foram utilizados para irradiação longa e os MR NIST 1547 (Peach Leaves) e o NIST 1573a (Tomato Leaves) para irradiação curta. Os padrões sintéticos pipetados (PSP) foram utilizados em ambas as irradiações.

A avaliação da exatidão alcançada na determinação da concentração dos elementos químicos nas amostras de solo e planta foi realizada a partir do critério de En-score (Konieczka e Namieśnik, 2009; INMETRO, 2010), conforme a equação 4.1:

$$
\text { En }- \text { score }=\frac{\text { Xlab }- \text { Xref }}{\sqrt{u_{(\text {Xlab })}^{2}+u_{(\text {Xref })}^{2}}}
$$

(Equação 4.1)

onde:

$X_{l a b}=$ resultado obtido $\left(\mathrm{mg} \mathrm{kg}^{-1}\right)$

$X_{r e f}=$ valor de referência descrito no certificado $\left(\mathrm{mg} \mathrm{kg}^{-1}\right)$

$u_{(X l a b)}=$ incerteza combinada do resultado obtido.

$u_{(X r e f)}=$ incerteza combinada do valor de referência.

Considera-se para a técnica de AAN que um resultado é satisfatório quando os valores de $E_{n}$ estão entre -1 e 1 (Konieczka e Namieśnik, 2009; 
INMETRO, 2010). Esta condição garante que um resultado individual da amostra controle (material de referência) está dentro do intervalo de confiança de $95 \%$ do valor verdadeiro ou aceito.

Os valores de concentração obtidos nos MR e nos padrões sintéticos pipetados, desvio padrão relativo (DPR\%), erro relativo (ER\%) e $E_{n \text {-score estão }}$ apresentados nas TAB. 4.1, 4.2, 4.3, 4.4 e 4.5.

TABELA 4.1 - Resultados obtidos para o MR NIST 1646a utilizado para a verificação da qualidade dos resultados para a técnica de INAA, em $\mathrm{mg} \mathrm{kg}^{-1},(\mathrm{n}=6)$.

\begin{tabular}{lcrccc}
\hline \multirow{2}{*}{ Elementos } & \multicolumn{5}{c}{ NIST 1646a } \\
\cline { 2 - 6 } & Valor certificado & Valor encontrado & DPR(\%) & ER(\%) & $E_{n}$-score \\
\hline $\mathbf{B a}$ & $210^{\dagger}$ & $226 \pm 22$ & 9,5 & $-7,8$ & - \\
$\mathbf{C a}$ & $5190 \pm 200$ & $5852 \pm 1535$ & 26,2 & $-12,8$ & $-0,4$ \\
$\mathbf{C e}$ & $34^{\dagger}$ & $35 \pm 2$ & 4,7 & $-3,6$ & - \\
$\mathbf{F e}$ & $20080 \pm 390$ & $20208 \pm 238$ & 1,2 & $-1,0$ & $-0,4$ \\
$\mathbf{K}$ & $8640 \pm 160$ & $9860 \pm 1672$ & 17,0 & -14 & $-0,7$ \\
$\mathbf{L a}$ & $17^{\dagger}$ & $18 \pm 1$ & 3,7 & $-5,5$ & - \\
$\mathbf{N a}$ & $7410 \pm 170$ & $7521 \pm 221$ & 2,9 & $-1,5$ & $-0,4$ \\
$\mathbf{M g}$ & $3880 \pm 90$ & $4741 \pm 896$ & 19 & 22 & 0,95 \\
$\mathbf{M n}$ & $235 \pm 3$ & $233 \pm 4$ & 2 & $-0,63$ & $-0,3$ \\
$\mathbf{N d}$ & $15^{\dagger}$ & $14 \pm 3$ & 24,3 & 6,8 & - \\
$\mathbf{R b}$ & $38^{\dagger}$ & $37 \pm 3$ & 9,3 & 1,7 & - \\
$\mathbf{T h}$ & $5,8^{\dagger}$ & $5,3 \pm 0,7$ & 13,2 & 7,8 & - \\
$\mathbf{U}$ & $2^{\dagger}$ & $2,2 \pm 0,4$ & 17,7 & -10 & - \\
$\mathbf{T i}$ & $4560 \pm 210$ & $4076 \pm 690$ & 17 & -10 & $-0,67$ \\
$\mathbf{V}$ & $44,8 \pm 0,8$ & $43 \pm 4$ & 10 & $-4,4$ & $-0,48$ \\
$\mathbf{Z n}$ & $48,9 \pm 1,6$ & $49 \pm 7$ & 14,8 & $-0,2$ & $-0,01$ \\
\hline
\end{tabular}

†Valor de informação. DPR (desvio padrão relativo). ER (erro relativo).

TABELA 4.2 - Resultados obtidos para o MR USGS STM-2 utilizado para a verificação da qualidade dos resultados para a técnica de INAA, em $\mathrm{mg} \mathrm{kg}^{-1},(\mathrm{n}=6)$.

\begin{tabular}{lrrrcc}
\hline \multirow{2}{*}{ Elementos } & \multicolumn{7}{c}{ USGS STM-2 } \\
\cline { 2 - 6 } & Valor certificado & \multicolumn{1}{c}{ Valor encontrado } & DPR(\%) & ER(\%) & $E_{n}$-Score \\
\hline Ba & $639 \pm 61$ & $638 \pm 55$ & 8,7 & 0,1 & 0,01 \\
$\mathbf{C e}$ & $256 \pm 23$ & $239 \pm 3$ & 1,2 & 6,5 & 0,7 \\
$\mathbf{F e}$ & $37700 \pm 900$ & $37794 \pm 328$ & 0,86 & $-0,24$ & $-0,09$ \\
$\mathbf{K}$ & $33800 \pm 1700$ & $29617 \pm 4829$ & 16,3 & 12,4 & 0,8 \\
$\mathbf{L a}$ & $154 \pm 11$ & $146 \pm 1$ & 0,7 & 5,4 & 0,8 \\
$\mathbf{N a}$ & $66100 \pm 3800$ & $64508 \pm 804$ & 1,2 & 2,4 & 0,4 \\
$\mathbf{N d}$ & $81 \pm 4,8$ & $72 \pm 11$ & 15,6 & 11,0 & 0,7 \\
$\mathbf{R b}$ & $114 \pm 11$ & $119 \pm 8$ & 6,5 & $-4,2$ & $-0,4$ \\
$\mathbf{T h}$ & $27 \pm 5$ & $31,2 \pm 0,4$ & 1,3 & $-15,6$ & $-0,8$ \\
$\mathbf{Z n}$ & $223 \pm 19$ & $223 \pm 28$ & 12,5 & 0,2 & 0,01 \\
$\mathbf{Z r}$ & $1280 \pm 62$ & $1373 \pm 186$ & 14 & -7 & $-0,47$ \\
\hline
\end{tabular}


TABELA 4.3 - Resultados obtidos para o padrão sintético pipetado (PSP) utilizado para a verificação da qualidade dos resultados para a técnica de INAA, em mg kg ${ }^{1},(n=6)$

\begin{tabular}{lrcccc}
\hline \multirow{2}{*}{ Elementos } & \multicolumn{5}{c}{ Padrão Sintético Pipetado } \\
\cline { 2 - 6 } & Valor pipetado & Valor encontrado & DPR(\%) & ER(\%) & $E_{n}$-Score \\
\hline As & $50 \pm 5$ & $48 \pm 3$ & 5,9 & 3,7 & 0,3 \\
Ba & $400 \pm 40$ & $363 \pm 29$ & 7,9 & 9,2 & 0,7 \\
Ce & $20 \pm 2$ & $20,4 \pm 0,3$ & 1,6 & $-2,0$ & $-0,2$ \\
Co & $10 \pm 1$ & $10,2 \pm 0,2$ & 2,1 & $-2,2$ & $-0,2$ \\
Cr & $20 \pm 2$ & $19,5 \pm 0,6$ & 3,0 & 2,7 & 0,3 \\
Fe & $1000 \pm 100$ & $960 \pm 14$ & 1,4 & 4 & 0,4 \\
K & $500 \pm 50$ & $310 \pm 74$ & 23,9 & 37,9 & 2,1 \\
La & $25 \pm 2,5$ & $22,9 \pm 0,1$ & 0,6 & 8,2 & 0,8 \\
Na & $1000 \pm 100$ & $1004 \pm 6$ & 0,6 & $-0,4$ & $-0,04$ \\
Nd & $100 \pm 10$ & $98 \pm 14$ & 14,2 & 1,7 & 0,1 \\
Rb & $50 \pm 5$ & $52 \pm 4$ & 7,0 & $-3,6$ & $-0,3$ \\
Sb & $20 \pm 2$ & $18 \pm 3$ & 18,6 & 11,2 & 0,6 \\
Sc & $5 \pm 0,5$ & $5,42 \pm 0,02$ & 0,4 & $-8,4$ & $-0,8$ \\
Th & $5 \pm 0,5$ & $5,4 \pm 0,1$ & 1,5 & $-7,3$ & $-0,7$ \\
U & $20 \pm 2$ & $19 \pm 2$ & 10 & 3,5 & 0,25 \\
Zn & $100 \pm 10$ & $93 \pm 11$ & 12,3 & 6,6 & 0,4 \\
\hline
\end{tabular}

TABELA 4.4 - Resultados obtidos para o MR IAEA-336 utilizado para a verificação da qualidade dos resultados para a técnica de INAA, em $\mathrm{mg} \mathrm{kg}^{-1},(\mathrm{n}=4)$.

\begin{tabular}{lrrrrr}
\hline \multirow{2}{*}{ Elemento } & \multicolumn{5}{c}{ IAEA-336 } \\
\cline { 2 - 6 } & \multicolumn{7}{c}{ Valor certificado } & Valor encontrado & DPR(\%) & ER(\%) & $E_{n}$-Score \\
\hline As & $0,6 \pm 0,2$ & $0,7 \pm 0,1$ & 10,7 & -5 & $-0,15$ \\
Ba & $6 \pm 2$ & $7 \pm 3$ & 38,5 & -7 & $-0,14$ \\
Br & $12,9 \pm 2,9$ & $16,4 \pm 0,2$ & 1,1 & -27 & $-1,19$ \\
Ce & $1,3 \pm 0,3$ & $1,27 \pm 0,04$ & 3,5 & 1 & 0,04 \\
Co & $0,29 \pm 0,10$ & $0,33 \pm 0,02$ & 4,7 & -15 & $-0,43$ \\
Cr & $1,1 \pm 0,4$ & $1,0 \pm 0,1$ & 6,9 & 5 & 0,13 \\
Cs & $0,11 \pm 0,02$ & $0,14 \pm 0,02$ & 15 & -27 & $-1,01$ \\
Eu & $0,023 \pm 0,005$ & $0,022 \pm 0,002$ & 8,2 & 4 & 0,16 \\
Fe & $430 \pm 145$ & $399 \pm 6$ & 1,4 & 7 & 0,21 \\
La & $0,7 \pm 0,2$ & $0,54 \pm 0,01$ & 2,7 & 23 & 0,80 \\
Lu & $0,007 \pm 0,002$ & $0,004 \pm 0,001$ & 31,4 & 39 & 1,14 \\
Na & $320 \pm 85$ & $282 \pm 7$ & 2,6 & 12 & 0,45 \\
Sc & $0,170 \pm 0,030$ & $0,174 \pm 0,002$ & 0,9 & -3 & $-0,15$ \\
Se & $0,22 \pm 0,06$ & $0,28 \pm 0,10$ & 35,7 & -26 & $-0,49$ \\
Sm & $0,11 \pm 0,03$ & $0,103 \pm 0,003$ & 3,1 & 7 & 0,24 \\
Tb & $0,014 \pm 0,002$ & $0,023 \pm 0,008$ & 33,7 & -61 & $-1,09$ \\
Th & $0,14 \pm 0,04$ & $0,14 \pm 0,01$ & 5,2 & -1 & $-0,03$ \\
Yb & $0,04 \pm 0,01$ & $0,04 \pm 0,01$ & 23,8 & -8 & $-0,20$ \\
Zn & $30 \pm 10$ & $27 \pm 1$ & 3,2 & 13 & 0,37 \\
\hline
\end{tabular}


TABELA 4.5 - Resultados obtidos para os MR NIST 1547 (Peach leaves) e NIST 1573a (Tomato leaves) utilizado para a verificação da qualidade dos resultados para a técnica de INAA, em $\mathrm{mg} \mathrm{kg}^{-1}$, $(n=4)$.

\begin{tabular}{lccccc}
\hline \multirow{2}{*}{ Elementos } & \multicolumn{5}{c}{ NIST 1547 } \\
\cline { 2 - 6 } & Valor certificado & Valor encontrado & DPR $(\%)$ & ER(\%) & $E_{n}$-score \\
\hline $\mathbf{M g}$ & $4320 \pm 80$ & $4198 \pm 233$ & 6 & -3 & $-0,50$ \\
$\mathbf{M n}$ & $98 \pm 3$ & $97 \pm 1$ & 1 & -1 & $-0,46$ \\
$\mathbf{K}$ & $24300 \pm 300$ & $23981 \pm 618$ & 3 & -1 & $-0,46$ \\
\hline \multirow{2}{*}{ Elemento } & \multicolumn{5}{c}{ NIST 1573a } \\
\cline { 2 - 6 } & Valor certificado & Valor encontrado & DPR $(\%)$ & ER(\%) & $E_{n}$-score \\
\hline $\mathbf{C a}$ & $50500 \pm 900$ & $55716 \pm 7172$ & 12,9 & -10 & $-0,72$ \\
$\mathbf{H f}$ & $0,14^{\dagger}$ & $0,15 \pm 0,01$ & 7,2 & -10 & - \\
$\mathbf{C l}$ & $6600^{\dagger}$ & $5986 \pm 491$ & 8,2 & $-9,3$ & - \\
$\mathbf{R b}$ & $14,9 \pm 0,3$ & $15,1 \pm 0,6$ & 4,1 & -2 & $-0,34$ \\
$\mathbf{V}$ & $0,835 \pm 0,01$ & $0,96 \pm 0,21$ & 22,1 & -15 & $-0,60$ \\
\hline
\end{tabular}

†Valor de informação

\subsubsection{Precisão e exatidão dos resultados para GF AAS e ICP-OES}

Para verificação da confiabilidade dos resultados obtidos por GF AAS foram utilizados os materiais de referência IAEA-336 (Líquen) e NIST 1573a (Tomato leaves). Para verificação do Ni, por ICP-OES, foi utilizado o MR NIST 1646a (Estuarine Sediment).

Na TAB. 4.6 são apresentados os valores médios obtidos para o desvio padrão relativo (DPR\%), erro relativo (ER\%) e $E_{n}$-score da metodologia na análise dos materiais de referência.

TABELA 4.6 - Média das concentrações obtidas de $\mathrm{Cd}$, $\mathrm{Cu}$, $\mathrm{Ni}$ e Pb, em mg Kg${ }^{-1}$, para os MR IAEA-336, NIST 1573a e NIST 1646a.

\begin{tabular}{ccrlccc}
\hline Elementos & Valor certificado & Valor encontrado & DPR(\%) & ER(\%) & $\boldsymbol{E}_{\boldsymbol{n}}$-score \\
\hline $\mathbf{C d}^{1}$ & $0,12 \pm 0,02$ & 0,15 & $\pm 0,01$ & 7,0 & -32 & $-1,86$ \\
$\mathbf{C u}^{2}$ & $4,70 \pm 0,14$ & 4,86 & $\pm 0,09$ & 1,9 & -3 & $-0,95$ \\
$\mathbf{N i}^{3}$ & 23 & 20,714 & $\pm 0,002$ & 1,1 & $-9,9$ & - \\
$\mathbf{P b}^{1}$ & $4,90 \pm 1,39$ & 3,32 & $\pm 0,07$ & 2,1 & 32 & 1,14 \\
\hline
\end{tabular}

${ }^{1}$ MR IAEA-336 (Líquen).

${ }^{2}$ MR NIST 1573a (Tomato leaves).

${ }^{3}$ MR NIST 1646a (Estuarine Sediment).

Pode-se notar uma boa precisão (DPR\%) e exatidão (ER\%) com valores inferiores a $15 \%$ para a maioria dos elementos determinados nos materiais de referência utilizados para verificação das metodologias aplicadas. 
Nas FIG. 4.1 e 4.2 estão apresentados os resultados de En-score, em forma de gráfico, para os materiais de referência IAEA-336, NIST 1573a, NIST 1547, NIST 1646, USGS STM-2 e padrão sintético pipetado.

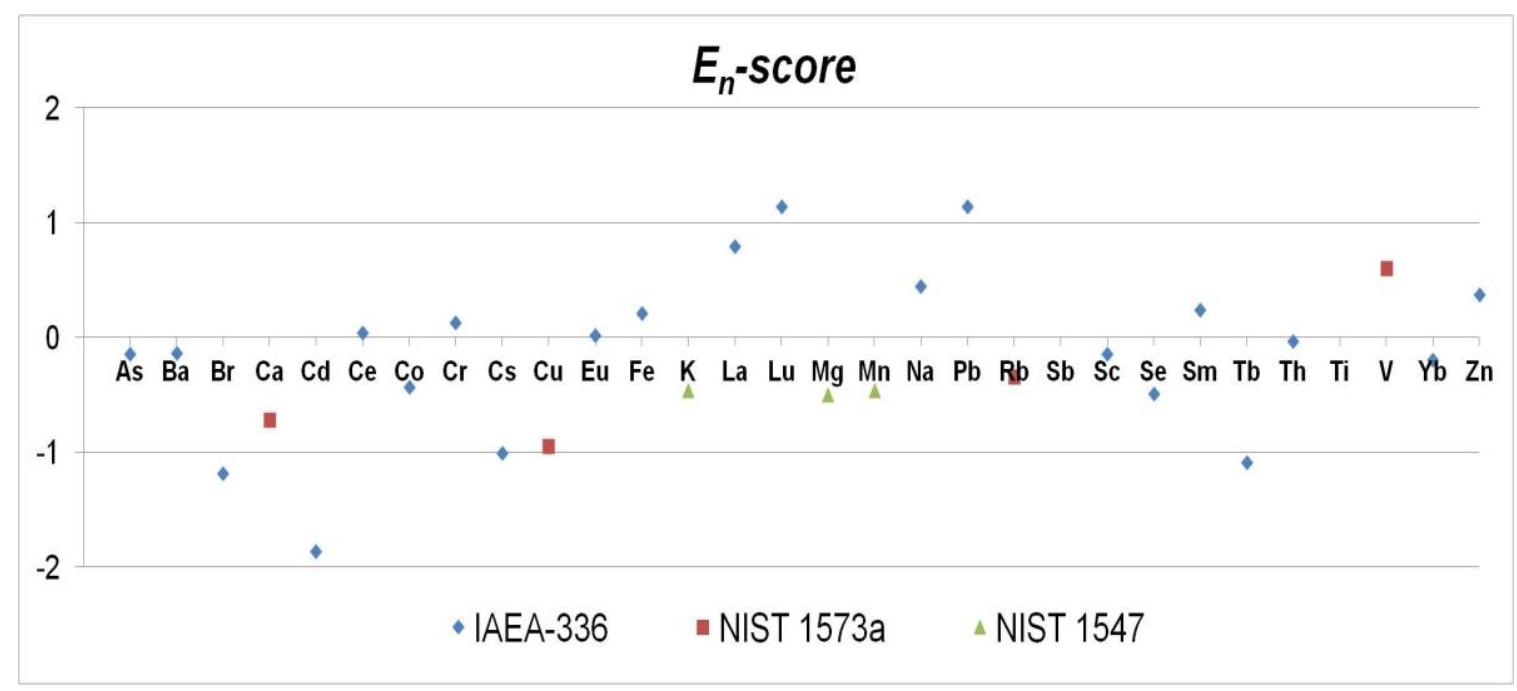

FIGURA 4.1 - Valores de $E_{n}$-score obtidos na análise dos materiais de referência de matriz biológica.

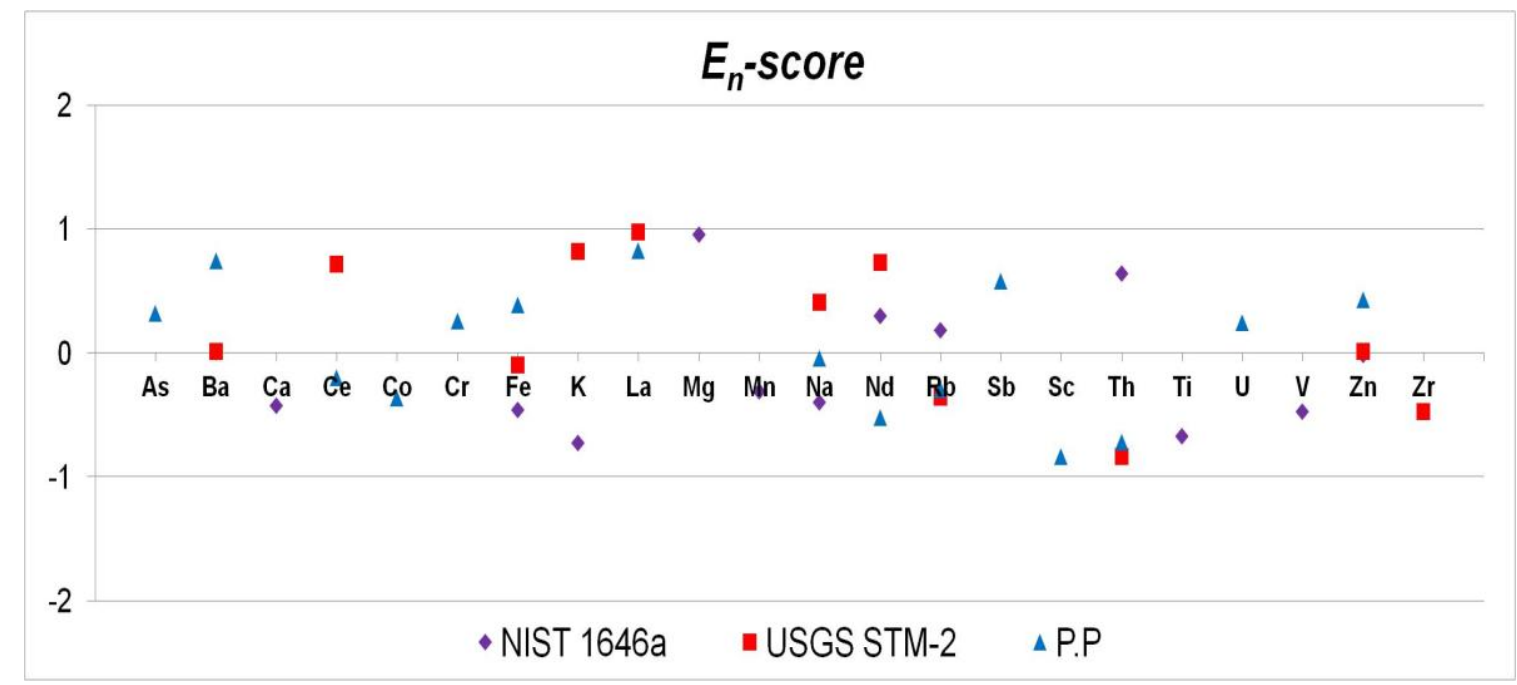

FIGURA 4.2 - Valores de $E_{n}$-score obtidos na análise dos materiais de referência de matriz geológica e nos padrões sintéticos pipetados.

Os resultados de $E_{n}$-score apresentados foram satisfatórios para a maioria dos elementos, uma vez que os valores se encontram dentro do intervalo admissível entre -1 e 1 . Entre os materiais de matrizes biológicas (FIG. 4.1), observou-se que os valores de En para elementos $\mathrm{Br}, \mathrm{Cd}$, $\mathrm{Lu}, \mathrm{Pb}$ e $\mathrm{Tb}$ apresentaram-se fora do intervalo de -1 e 1 , sendo que estes elementos foram tratados com maior atenção nas suas interpretações. 


\subsection{Determinações das concentrações elementares}

\subsubsection{Solo}

$\mathrm{Na}$ TAB. 4.7 estão apresentados os resultados das médias das concentrações dos elementos no solo (SL), os valores de incertezas expandidas para os elementos determinados pela AAN e os desvios padrão para os elementos determinados por GF AAS e ICP-OES nos diferentes manejos agrícola: controle com mudas do condicionamento orgânico (1), controle com mudas do condicionamento convencional (2), orgânico com micronutrientes (3), orgânico sem micronutrientes (4), convencional com micronutrientes (5) e convencional sem micronutrientes (6); e nas diferentes épocas do ano: outono (O), inverno (I), primavera $(\mathrm{P})$ e verão $(\mathrm{V})$.

A Análise de Componentes Principais (PCA) foi realizada com a finalidade de verificar se os manejos aplicados no solo foram satisfatórios, ou seja, resultaram em solos com características suficientemente distintas do solo controle.

As variáveis $\mathrm{Nd}$, $\mathrm{Rb}$, Se e $\mathrm{Tb}$ apresentaram mais de $80 \%$ dos resultados analíticos abaixo do LQ e, as variáveis Ba e Zn apresentaram menos de $40 \%$ de valores determinados nas amostras, por isso, não foram incluídas nas análises multivariadas. As 24 amostras de solo foram classificadas, levando em consideração a contribuição conjunta das variáveis $\mathrm{As}, \mathrm{Br}, \mathrm{Ca}, \mathrm{Cd}, \mathrm{Ce}, \mathrm{Co}, \mathrm{Cr}$, Cs, Cu, Eu, Fe, Hf, K, La, Lu, Mg, Mn, Na, Ni, Pb, Sb, Sc, Sm, Ta, Th, Ti, U, V, Yb e Zr. A PCA foi realizada com base nas concentrações dos elementos nas amostras de solo (FIG. 4.3). Foi tratada uma matriz 6 × 30 (6 sistemas de cultivo $x$ 30 variáveis) sendo obtido um modelo que com duas Componentes Principais (CPs) explica $40 \%$ da variância dos dados originais. Os dados foram normalizados para assegurar que todas as variáveis contribuam igualmente para o modelo. O comprimento dos vetores, que representam os elementos no solo, é proporcional a sua importância (Duarte, 2012). 
TABELA 4.7 - Resultados das análises elementares para as amostras de solo, em mg kg-1.

\begin{tabular}{|c|c|c|c|c|c|c|c|c|c|c|c|c|c|c|c|c|c|}
\hline \multirow[t]{2}{*}{ Amostras } & \multicolumn{2}{|c|}{ As } & $\mathrm{Ba}$ & \multicolumn{2}{|c|}{$\mathrm{Br}$} & \multicolumn{2}{|c|}{$\mathbf{C a}$} & \multicolumn{2}{|c|}{ Cd } & \multicolumn{2}{|c|}{$\mathrm{Ce}$} & \multicolumn{2}{|c|}{ Co } & \multicolumn{2}{|c|}{$\mathrm{Cr}$} & \multicolumn{2}{|c|}{ Cs } \\
\hline & média $^{n}$ & $\pm 1 \delta$ & média $\pm 1 \delta$ & média & $\pm 1 \delta$ & média & $\pm 1 \delta$ & média & $\pm 1 \delta$ & média & $\pm 1 \delta$ & média & $\pm 1 \delta$ & média & $\pm 1 \delta$ & média & $\pm 1 \delta$ \\
\hline SLO-1 & 36 & \pm 2 & - & 25,9 & $\pm 0,5$ & 6094 & \pm 1041 & 0,045 & $\pm 0,003$ & 42 & \pm 2 & 3,4 & $\pm 0,1$ & 105 & \pm 4 & 2,9 & $\pm 0,5$ \\
\hline SLO-2 & 38 & \pm 2 & $68 \pm 21$ & 26,0 & $\pm 0,5$ & 5866 & \pm 997 & 0,038 & $\pm 0,002$ & 40 & \pm 2 & 3,1 & $\pm 0,1$ & 102 & \pm 4 & 3,1 & $\pm 0,5$ \\
\hline SLO-3 & 27,4 & $\pm 0,8$ & - & 21,8 & $\pm 0,3$ & 6505 & \pm 759 & 0,041 & $\pm 0,002$ & 57 & \pm 2 & 3,60 & $\pm 0,08$ & 133 & \pm 4 & 2,4 & $\pm 0,2$ \\
\hline SLO-4 & 27,0 & $\pm 0,8$ & - & 22,7 & $\pm 0,3$ & 6945 & \pm 896 & 0,056 & $\pm 0,016$ & 45 & \pm 2 & 3,21 & $\pm 0,08$ & 107 & \pm 3 & 2,5 & $\pm 0,2$ \\
\hline SLO-5 & 30,6 & $\pm 0,9$ & - & 23,3 & $\pm 0,3$ & 6682 & \pm 736 & 0,037 & $\pm 0,007$ & 44 & \pm 1 & 3,01 & $\pm 0,08$ & 104 & \pm 3 & 2,4 & $\pm 0,2$ \\
\hline SLO-6 & 30,2 & $\pm 0,8$ & $140 \pm 39$ & 22,7 & $\pm 0,3$ & 6872 & \pm 764 & 0,037 & $\pm 0,005$ & 42 & \pm 1 & 3,10 & $\pm 0,07$ & 97 & \pm 3 & 2,2 & $\pm 0,2$ \\
\hline LI-1 & 38 & \pm 2 & $83 \pm 22$ & 24,5 & $\pm 0,5$ & 7346 & \pm 1179 & 0,034 & $\pm 0,0$ & 43 & \pm 2 & 3,7 & $\pm 0,1$ & 107 & \pm 4 & 2,8 & $\pm 0,5$ \\
\hline SLI-2 & 35 & \pm 2 & - & 24,3 & $\pm 0,5$ & 5460 & \pm 971 & 0,0453 & $\pm 0,0002$ & 39 & \pm 1 & 3,1 & $\pm 0,1$ & 101 & \pm 4 & 3,0 & $\pm 0,5$ \\
\hline SLI-3 & 29,8 & $\pm 0,8$ & $76 \pm 15$ & 22,6 & $\pm 0,2$ & 8474 & \pm 924 & 0,038 & $\pm 0,004$ & 46 & \pm 1 & 3,10 & $\pm 0,07$ & 84 & \pm 3 & 2,7 & $\pm 0,2$ \\
\hline SLI-4 & 29,5 & $\pm 0,8$ & $102 \pm 17$ & 22,0 & $\pm 0,2$ & 9203 & \pm 1010 & 0,04 & $\pm 0,01$ & 43 & \pm 1 & 2,86 & $\pm 0,07$ & 86 & \pm 3 & 3,4 & $\pm 0,3$ \\
\hline LII-5 & 31,7 & $\pm 0,8$ & $82 \pm 16$ & 23,9 & $\pm 0,2$ & 11481 & \pm 1185 & 0,050 & $\pm 0,002$ & 46 & \pm 1 & 3,25 & $\pm 0,07$ & 97 & \pm 3 & 2,7 & $\pm 0,3$ \\
\hline SLI-6 & 33,0 & $\pm 0,8$ & $135 \pm 19$ & 24,2 & $\pm 0,2$ & 12346 & \pm 1251 & 0,046 & $\pm 0,003$ & 46 & \pm 1 & 3,35 & $\pm 0,07$ & 90 & \pm 3 & 3,3 & $\pm 0,3$ \\
\hline LP-1 & 31 & \pm 1 & - & 22,1 & $\pm 0,4$ & 7843 & \pm 1210 & 0,041 & $\pm 0,007$ & 41 & \pm 1 & 2,90 & $\pm 0,09$ & 96 & \pm 4 & 2,4 & $\pm 0,3$ \\
\hline SLP-2 & 31 & \pm 1 & - & 23,1 & $\pm 0,5$ & 12244 & \pm 2596 & 0,041 & $\pm 0,002$ & 46 & \pm 2 & 3,0 & $\pm 0,1$ & 101 & \pm 4 & 1,7 & $\pm 0,3$ \\
\hline LP-3 & 30 & \pm 1 & - & 21,7 & $\pm 0,4$ & 8205 & \pm 1611 & 0,045 & $\pm 0,002$ & 42 & \pm 1 & 3,03 & $\pm 0,09$ & 98 & \pm 3 & 3,5 & $\pm 0,5$ \\
\hline SLP-4 & 30 & \pm 1 & $196 \pm 28$ & 23,0 & $\pm 0,4$ & 6552 & \pm 1335 & 0,046 & $\pm 0,002$ & 44 & \pm 2 & 3,16 & $\pm 0,09$ & 93 & \pm 3 & 3,5 & $\pm 0,5$ \\
\hline SLP-5 & 31 & \pm 1 & - & 23,8 & $\pm 0,4$ & 7226 & \pm 1460 & 0,062 & $\pm 0,004$ & 50 & \pm 2 & 3,13 & $\pm 0,09$ & 91 & \pm 3 & 3,2 & $\pm 0,4$ \\
\hline SLP-6 & 20 & \pm 1 & - & 22,5 & $\pm 0,4$ & 8570 & \pm 1645 & & - & 40 & \pm 1 & 2,95 & $\pm 0,09$ & 96 & \pm 3 & 3,2 & $\pm 0,4$ \\
\hline LV-1 & 32 & \pm 2 & - & 23,9 & $\pm 0,5$ & 8437 & \pm 1 & 0,047 & \pm 0 & 40 & \pm 1 & 3,7 & $\pm 0,1$ & 107 & \pm 4 & 3,1 & $\pm 0,4$ \\
\hline SLV-2 & 34 & \pm 2 & - & 24,4 & $\pm 0,5$ & 11100 & \pm 2576 & 0,048 & $\pm 0,004$ & 45 & \pm 2 & 3,5 & $\pm 0,1$ & 115 & \pm 4 & 3,0 & $\pm 0,4$ \\
\hline SLV-3 & 35 & \pm 3 & - & 20,1 & $\pm 0,4$ & 11058 & \pm 1723 & 0,069 & $\pm 0,002$ & 44 & \pm 2 & 3,3 & $\pm 0,1$ & 91 & \pm 3 & 3,3 & $\pm 0,7$ \\
\hline SLV-4 & 40 & \pm 4 & - & 22,5 & $\pm 0,5$ & 10623 & \pm 1698 & 0,0623 & $\pm 0,0004$ & 43 & \pm 2 & 3,5 & $\pm 0,1$ & 100 & \pm 4 & 3,1 & $\pm 0,7$ \\
\hline SLV-5 & 37 & \pm 3 & - & 23,4 & $\pm 0,5$ & & 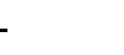 & 0,0698 & $\pm 0,0003$ & 48 & \pm 2 & 3,4 & $\pm 0,1$ & 93 & \pm 3 & 3,5 & $\pm 0,8$ \\
\hline SLV-6 & 40 & \pm 4 & - & 25,4 & $\pm 0,5$ & 10196 & \pm 1662 & 0,069 & $\pm 0,006$ & 54 & \pm 2 & 3,6 & $\pm 0,1$ & 100 & \pm 4 & 4,2 & $\pm 0,9$ \\
\hline
\end{tabular}




\begin{tabular}{|c|c|c|c|c|c|c|c|c|c|c|c|c|c|c|}
\hline Amostras & $\mathrm{Cu}$ & $\mathrm{Eu}$ & $\mathrm{Fe}$ & & $\mathbf{H}$ & & & $\mathbf{K}$ & Le & & L & u & $\mathrm{Mg}$ & Mn \\
\hline SLO-1 & $13,8 \pm 0,3$ & $0,45 \pm 0,02$ & 69172 & \pm 781 & 19,1 & $\pm 0,3$ & 2036 & \pm 483 & 21,9 & $\pm 0,4$ & 0,71 & $\pm 0,03$ & $32238 \pm 2361$ & $144 \pm 3$ \\
\hline SLO-2 & $15,1 \pm 0,1$ & $0,48 \pm 0,02$ & 67274 & \pm 829 & 17,6 & $\pm 0,2$ & 1445 & \pm 458 & 20,0 & $\pm 0,4$ & 0,76 & $\pm 0,03$ & $31626 \pm 2284$ & $142 \pm 3$ \\
\hline SLO-3 & $16,8 \pm 0,6$ & $0,41 \pm 0,02$ & 68572 & \pm 803 & 17,8 & $\pm 0,2$ & & 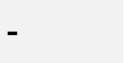 & 30,6 & $\pm 0,5$ & 0,77 & $\pm 0,03$ & $177900 \pm 25673$ & $169 \pm 2$ \\
\hline SLO-4 & $20,4 \pm 0,2$ & $0,46 \pm 0,02$ & 66291 & \pm 776 & 17,2 & $\pm 0,2$ & & - & 18,5 & $\pm 0,3$ & 0,92 & $\pm 0,03$ & $174289 \pm 23426$ & $160 \pm 3$ \\
\hline SLO-5 & $14,2 \pm 0,2$ & $0,53 \pm 0,02$ & 63100 & \pm 779 & 17,3 & $\pm 0,2$ & & - & 23,0 & $\pm 0,4$ & 0,80 & $\pm 0,03$ & $28046 \pm 2400$ & $142 \pm 2$ \\
\hline SLO-6 & $18,9 \pm 0,3$ & $0,43 \pm 0,02$ & 61760 & \pm 763 & 17,9 & $\pm 0,2$ & & - & 21,4 & $\pm 0,4$ & 0,81 & $\pm 0,03$ & $25813 \pm 2023$ & $119 \pm 2$ \\
\hline SLI-1 & $14,4 \pm 0,5$ & $0,51 \pm 0,03$ & 70323 & \pm 944 & 19,7 & $\pm 0,3$ & 2429 & \pm 668 & 22,5 & $\pm 0,4$ & 0,67 & & $25200 \pm 4047$ & $161 \pm 3$ \\
\hline SLI-2 & $11,49 \pm 0,05$ & $0,47 \pm 0,02$ & 68003 & \pm 911 & 18,0 & $\pm 0,2$ & 1924 & \pm 463 & 19,8 & $\pm 0,4$ & 0,71 & $\pm 0,03$ & $22751 \pm 2580$ & $134 \pm 3$ \\
\hline SLI-3 & $27,7 \pm 1,1$ & $0,48 \pm 0,02$ & 60805 & \pm 680 & 16,0 & $\pm 0,2$ & & - & 25,1 & $\pm 0,6$ & 0,62 & $\pm 0,02$ & $22099 \pm 1836$ & $200 \pm 4$ \\
\hline SLI-4 & $23,5 \pm 0,1$ & $0,46 \pm 0,02$ & 62421 & \pm 700 & 17,0 & $\pm 0,2$ & 3221 & \pm 729 & 22,6 & $\pm 0,4$ & 0,56 & $\pm 0,02$ & $22511 \pm 1774$ & $171 \pm 4$ \\
\hline SLI-5 & $19,7 \pm 0,4$ & $0,47 \pm 0,02$ & 65401 & \pm 731 & 17,6 & $\pm 0,2$ & & - & 24,0 & $\pm 0,4$ & 0,70 & $\pm 0,03$ & $19413 \pm 1207$ & $117 \pm 2$ \\
\hline SLI-6 & $20,30 \pm 0,06$ & $0,45 \pm 0,02$ & 68714 & \pm 765 & 19,0 & $\pm 0,2$ & & - & 23,6 & $\pm 0,4$ & 0,68 & $\pm 0,03$ & $22059 \pm 2862$ & $201 \pm 4$ \\
\hline SLLr=I & $11,9 \pm 0,2$ & $0,49 \pm 0,02$ & 63959 & \pm 666 & 17,2 & $\pm 0,2$ & 3244 & \pm 485 & 21,5 & $\pm 0,4$ & 0,82 & $\pm 0,03$ & $22097 \pm 2199$ & $151 \pm 3$ \\
\hline SLP-2 & $11,39 \pm 0,08$ & $0,31 \pm 0,02$ & 64877 & \pm 683 & 18,2 & $\pm 0,2$ & 2863 & \pm 438 & 23,1 & $\pm 0,4$ & 0,80 & $\pm 0,03$ & $23887 \pm 2058$ & $140 \pm 2$ \\
\hline SLP-3 & $17,22 \pm 0,08$ & $0,43 \pm 0,02$ & 66897 & \pm 792 & 17,0 & $\pm 0,2$ & 2253 & \pm 335 & 21,4 & $\pm 0,4$ & 0,64 & $\pm 0,03$ & $34477 \pm 8060$ & $172 \pm 2$ \\
\hline SLP-4 & $17,49 \pm 0,06$ & $0,42 \pm 0,02$ & 65977 & \pm 780 & 17,5 & $\pm 0,2$ & 1790 & \pm 359 & 21,7 & $\pm 0,4$ & 0,84 & $\pm 0,03$ & $28556 \pm 4902$ & $163 \pm 2$ \\
\hline SLP-5 & $13,6 \pm 0,6$ & $0,50 \pm 0,02$ & 66758 & \pm 794 & 17,4 & $\pm 0,2$ & 2977 & \pm 401 & 26,5 & $\pm 0,5$ & 0,65 & $\pm 0,03$ & $24508 \pm 2469$ & $173 \pm 3$ \\
\hline SLP-6 & $17,9 \pm 0,4$ & $0,51 \pm 0,02$ & 64489 & \pm 763 & 16,2 & $\pm 0,2$ & 2558 & \pm 414 & 21,7 & $\pm 0,4$ & 0,62 & $\pm 0,03$ & $25487 \pm 1913$ & $161 \pm 3$ \\
\hline SLV-1 & - & $0,53 \pm 0,02$ & 67561 & \pm 704 & 12,1 & $\pm 0,2$ & 2150 & \pm 483 & 21,0 & $\pm 0,4$ & 0,76 & $\pm 0,03$ & $25466 \pm 1615$ & $169 \pm 3$ \\
\hline SLV-2 & $12,8 \pm 0,2$ & $0,41 \pm 0,02$ & 72201 & \pm 859 & 12,7 & $\pm 0,2$ & 1996 & \pm 421 & 23,7 & $\pm 0,4$ & 0,78 & $\pm 0,03$ & $21493 \pm 2080$ & $154 \pm 2$ \\
\hline SLV-3 & $21,58 \pm 0,04$ & $0,49 \pm 0,02$ & 57799 & \pm 622 & 15,1 & $\pm 0,3$ & 3218 & \pm 575 & 22,1 & $\pm 0,4$ & 0,57 & $\pm 0,03$ & $21807 \pm 1362$ & $219 \pm 4$ \\
\hline SLV-4 & $20,7 \pm 0,6$ & $0,55 \pm 0,03$ & 62948 & \pm 678 & 18,0 & $\pm 0,2$ & 2849 & \pm 545 & 22,1 & $\pm 0,4$ & 0,71 & $\pm 0,03$ & $20481 \pm 1196$ & $223 \pm 4$ \\
\hline SLV-5 & $16,9 \pm 0,6$ & $0,57 \pm 0,03$ & 62887 & \pm 677 & 17,3 & $\pm 0,2$ & 2319 & \pm 403 & 25,9 & $\pm 0,5$ & 0,75 & $\pm 0,03$ & $23313 \pm 2046$ & $146 \pm 2$ \\
\hline SLV-6 & $19,29 \pm 0,07$ & $0,59 \pm 0,03$ & 67090 & \pm 810 & 19,6 & $\pm 0,3$ & 2622 & \pm 340 & 29,7 & $\pm 0,5$ & 0,77 & $\pm 0,03$ & $21641 \pm 1521$ & $109 \pm 2$ \\
\hline
\end{tabular}




\begin{tabular}{|c|c|c|c|c|c|c|c|c|c|c|c|}
\hline Amostras & $\mathrm{Na}$ & Nd & $\mathbf{N i}$ & $\mathbf{P b}$ & $\mathbf{R b}$ & & b & Sc & Se & $\mathrm{Sr}$ & \\
\hline SLO-1 & $350 \pm 11$ & $<L Q$ & $12,677 \pm 0,002$ & $14,3 \pm 0,4$ & - & 3,1 & $\pm 0,4$ & $18,6 \pm 0,1$ & $<\mathrm{LQ}$ & - & \\
\hline SLO-2 & $335 \pm 11$ & $<L Q$ & $15,370 \pm 0,003$ & 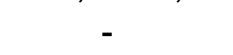 & $<L Q$ & & - & $18,1 \pm 0,1$ & $<L Q$ & - & \\
\hline SLO-3 & $409 \pm 9$ & $<L Q$ & $13,767 \pm 0,003$ & $14,52 \pm 0,04$ & $<\mathrm{LQ}$ & 2,8 & $\pm 0,5$ & $18,5 \pm 0,1$ & $<\mathrm{LQ}$ & 5,2 & $\pm 0,2$ \\
\hline SLO-4 & - & $36 \pm 2$ & $11,928 \pm 0,002$ & $15,88 \pm 0,01$ & $<L Q$ & 3,9 & $\pm 0,7$ & $18,3 \pm 0,1$ & $<L Q$ & 3,1 & $\pm 0,1$ \\
\hline SLO-5 & $354 \pm 8$ & $<L Q$ & $10,187 \pm 0,001$ & $11,9 \pm 0,1$ & $<L Q$ & 3,5 & $\pm 0,6$ & $17,89 \pm 0,09$ & - & 3,2 & $\pm 0,1$ \\
\hline SLO-6 & $361 \pm 8$ & $<L Q$ & $14,900 \pm 0,002$ & 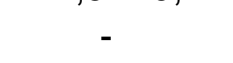 & $<L Q$ & 2,8 & $\pm 0,5$ & $17,62 \pm 0,09$ & - & 2,9 & $\pm 0,1$ \\
\hline SLI-1 & $343 \pm 12$ & $45 \pm 3$ & $12,600 \pm 0,001$ & $13,35 \pm 0,02$ & - & 1,1 & $\pm 0,4$ & $18,9 \pm 0,1$ & $<\mathrm{LQ}$ & 3,60 & $\pm 0,04$ \\
\hline SLI-2 & $357 \pm 12$ & - & $7,344 \pm 0,001$ & $11,11 \pm 0,01$ & - & 1,3 & $\pm 0,4$ & $17,8 \pm 0,1$ & - & 3,26 & $\pm 0,03$ \\
\hline SLI-3 & - & - & $8,078 \pm 0,002$ & $12,5 \pm 0,3$ & $<\mathrm{LQ}$ & 1,4 & $\pm 0,4$ & $16,15 \pm 0,09$ & $<\mathrm{LQ}$ & 2,61 & $\pm 0,02$ \\
\hline SLI-4 & $374 \pm 8$ & $46 \pm 2$ & $9,885 \pm 0,002$ & $14,1 \pm 0,3$ & - & 1,2 & $\pm 0,3$ & $16,63 \pm 0,09$ & $<\mathrm{LQ}$ & 2,81 & $\pm 0,02$ \\
\hline SLI-5 & $387 \pm 9$ & $33 \pm 2$ & $6,964 \pm 0,001$ & $11,29 \pm 0,03$ & $<L Q$ & 1,4 & $\pm 0,4$ & $17,59 \pm 0,09$ & $<\mathrm{LQ}$ & 3,24 & $\pm 0,02$ \\
\hline SLI-6 & $396 \pm 9$ & $<L Q$ & $8,601 \pm 0,001$ & $11,42 \pm 0,05$ & $<L Q$ & 1,3 & $\pm 0,3$ & $18,21 \pm 0,09$ & $<L Q$ & 2,99 & $\pm 0,02$ \\
\hline SLP-1 & $415 \pm 12$ & - & $8,241 \pm 0,001$ & $10,71 \pm 0,06$ & - & & - & $17,2 \pm 0,1$ & - & 2,49 & $\pm 0,09$ \\
\hline SLP-2 & $402 \pm 12$ & $<L Q$ & $8,910 \pm 0,002$ & $12,1 \pm 0,2$ & - & & - & $17,6 \pm 0,1$ & - & 2,8 & $\pm 0,1$ \\
\hline SLP-3 & $381 \pm 11$ & $<L Q$ & $8,427 \pm 0,001$ & $9,98 \pm 0,03$ & $<L Q$ & 0,9 & $\pm 0,2$ & $17,3 \pm 0,1$ & $<L Q$ & 3,1 & $\pm 0,1$ \\
\hline SLP-4 & $388 \pm 11$ & $<L Q$ & $12,183 \pm 0,003$ & $12,39 \pm 0,06$ & - & 0,9 & $\pm 0,2$ & $17,9 \pm 0,1$ & $<L Q$ & 3,7 & $\pm 0,1$ \\
\hline SLP-5 & $444 \pm 12$ & - & $9,389 \pm 0,001$ & $11,78 \pm 0,06$ & - & 1,2 & $\pm 0,3$ & $17,9 \pm 0,1$ & $<\mathrm{LQ}$ & 3,8 & $\pm 0,1$ \\
\hline SLP-6 & $386 \pm 11$ & $<L Q$ & $10,362 \pm 0,002$ & & $<L Q$ & 0,7 & $\pm 0,2$ & $17,4 \pm 0,1$ & - & 3,4 & $\pm 0,1$ \\
\hline SLV-1 & $403 \pm 12$ & $<L Q$ & $11,585 \pm 0,001$ & $10,8 \pm 0,1$ & - & & - & $18,4 \pm 0,1$ & $<\mathrm{LQ}$ & 2,32 & $\pm 0,09$ \\
\hline SLV-2 & $389 \pm 13$ & $<L Q$ & $14,611 \pm 0,001$ & $12,69 \pm 0,09$ & - & & - & $19,3 \pm 0,1$ & $<\mathrm{LQ}$ & 2,8 & $\pm 0,1$ \\
\hline SLV-3 & $482 \pm 14$ & $<L Q$ & $10,641 \pm 0,003$ & $11,86 \pm 0,06$ & - & & - & $15,7 \pm 0,1$ & - & 2,9 & $\pm 0,1$ \\
\hline SLV-4 & $424 \pm 12$ & $<L Q$ & $12,440 \pm 0,001$ & $13,3 \pm 0,2$ & - & 1,2 & $\pm 0,3$ & $16,9 \pm 0,1$ & - & 2,9 & $\pm 0,1$ \\
\hline SLV-5 & $496 \pm 14$ & $40 \pm 3$ & $13,059 \pm 0,002$ & $13,21 \pm 0,06$ & - & 2,7 & $\pm 0,4$ & $16,9 \pm 0,1$ & - & 3,5 & $\pm 0,1$ \\
\hline SLV-6 & $538 \pm 15$ & $<L Q$ & $9,539 \pm 0,002$ & & - & 3,0 & $\pm 0,4$ & $18,3 \pm 0,1$ & - & 3,6 & $\pm 0,1$ \\
\hline
\end{tabular}




\begin{tabular}{|c|c|c|c|c|c|c|c|c|c|c|}
\hline Amostras & Ta & $\mathrm{Tb}$ & Th & $\mathrm{Ti}$ & $\mathbf{U}$ & $\mathbf{V}$ & $\mathrm{Yb}$ & \multicolumn{2}{|c|}{$\mathrm{Zn}$} & $\mathrm{Zr}$ \\
\hline SLO-1 & $2,8 \pm 0,1$ & - & $33 \pm 2$ & - & $5,3 \pm 0,4$ & $224 \pm 11$ & $4,1 \pm 0,5$ & - & 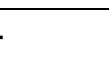 & $657 \pm 64$ \\
\hline SLO-2 & $2,7 \pm 0,1$ & $<L Q$ & $31 \pm 2$ & - & $<L Q$ & $222 \pm 12$ & $3,7 \pm 0,4$ & 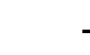 & - & $513 \pm 76$ \\
\hline SLO-3 & $2,9 \pm 0,1$ & $<L Q$ & $33 \pm 2$ & $10863 \pm 601$ & $5,2 \pm 0,3$ & $186 \pm 8$ & $3,4 \pm 0,2$ & 95 & \pm 6 & $433 \pm 54$ \\
\hline SLO-4 & $3,8 \pm 0,1$ & $<L Q$ & - & $6456 \pm 397$ & $5,2 \pm 0,3$ & $96 \pm 5$ & $4,7 \pm 0,2$ & 78 & \pm 6 & $465 \pm 43$ \\
\hline SLO-5 & $3,5 \pm 0,1$ & $<L Q$ & $30 \pm 2$ & $8767 \pm 1283$ & $4,7 \pm 0,2$ & $210 \pm 13$ & $4,9 \pm 0,2$ & 82 & \pm 6 & $563 \pm 51$ \\
\hline SLO-6 & $2,1 \pm 0,1$ & - & $29 \pm 2$ & $8381 \pm 1238$ & $<L Q$ & $163 \pm 13$ & $4,0 \pm 0,2$ & 72 & \pm 6 & $490 \pm 47$ \\
\hline SLI-1 & $2,9 \pm 0,1$ & $<L Q$ & $34 \pm 2$ & - & $<L Q$ & $178 \pm 11$ & $4,4 \pm 0,6$ & . & . & $720 \pm 75$ \\
\hline SLI-2 & $2,8 \pm 0,1$ & $<L Q$ & $32 \pm 2$ & - & $5,0 \pm 0,4$ & $162 \pm 13$ & $3,0 \pm 0,3$ & - & . & $444 \pm 89$ \\
\hline SLI-3 & $2,36 \pm 0,09$ & $<L Q$ & $28 \pm 2$ & - & $5,5 \pm 0,3$ & $192 \pm 12$ & $3,5 \pm 0,3$ & - & . & $641 \pm 55$ \\
\hline SLI-4 & $2,46 \pm 0,09$ & - & $29 \pm 2$ & - & $5,5 \pm 0,3$ & $194 \pm 13$ & $3,2 \pm 0,2$ & - & . & $557 \pm 56$ \\
\hline SLI-5 & $2,51 \pm 0,09$ & - & $30 \pm 2$ & - & $6,5 \pm 0,4$ & $178 \pm 11$ & $3,6 \pm 0,3$ & . & . & $622 \pm 40$ \\
\hline SLI-6 & $3,3 \pm 0,1$ & $<L Q$ & $30 \pm 2$ & $8784 \pm 828$ & $6,1 \pm 0,3$ & $138 \pm 14$ & $3,3 \pm 0,3$ & 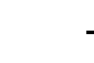 & 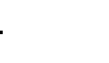 & $784 \pm 45$ \\
\hline SLP-1 & $2,6 \pm 0,1$ & $1,05 \pm 0,13$ & $32 \pm 2$ & $13594 \pm 1433$ & $8,0 \pm 0,7$ & $203 \pm 17$ & $4,0 \pm 0,3$ & & . & $562 \pm 48$ \\
\hline SLP-2 & $3,2 \pm 0,1$ & $<\mathrm{LQ}$ & $33 \pm 2$ & $10258 \pm 1237$ & $5,1 \pm 0,5$ & $154 \pm 19$ & $4,0 \pm 0,3$ & & . & $646 \pm 81$ \\
\hline SLP-3 & $2,8 \pm 0,1$ & $<L Q$ & $28 \pm 2$ & $10818 \pm 1100$ & $7,0 \pm 0,5$ & $206 \pm 14$ & $3,1 \pm 0,2$ & & - & $726 \pm 73$ \\
\hline SLP-4 & $3,0 \pm 0,1$ & - & $30 \pm 2$ & $9646 \pm 1076$ & $7,1 \pm 0,4$ & $246 \pm 17$ & $3,8 \pm 0,3$ & & . & $893 \pm 78$ \\
\hline SLP-5 & $2,4 \pm 0,1$ & $<L Q$ & $31 \pm 2$ & $8537 \pm 665$ & $6,3 \pm 0,4$ & $173 \pm 10$ & $3,5 \pm 0,2$ & 332 & \pm 22 & $681 \pm 68$ \\
\hline SLP-6 & $2,5 \pm 0,1$ & $<L Q$ & $30 \pm 2$ & $8814 \pm 719$ & $4,9 \pm 0,3$ & $175 \pm 12$ & $3,6 \pm 0,2$ & & & $582 \pm 42$ \\
\hline SLV-1 & $2,8 \pm 0,1$ & - & $33 \pm 2$ & $8823 \pm 727$ & $<L Q$ & $195 \pm 11$ & $4,0 \pm 0,3$ & & 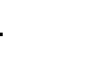 & $285 \pm 42$ \\
\hline SLV-2 & $3,3 \pm 0,1$ & $<L Q$ & $35 \pm 2$ & $9204 \pm 750$ & $4,9 \pm 0,7$ & $173 \pm 12$ & $4,7 \pm 0,4$ & 53 & \pm 5 & $380 \pm 47$ \\
\hline SLV-3 & $2,0 \pm 0,1$ & $<\mathrm{LQ}$ & $27 \pm 2$ & $6819 \pm 704$ & $5,1 \pm 0,5$ & $176 \pm 10$ & $2,8 \pm 0,2$ & & 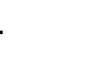 & $305 \pm 58$ \\
\hline SLV-4 & $2,2 \pm 0,1$ & - & $30 \pm 2$ & $8656 \pm 801$ & $<L Q$ & $186 \pm 11$ & $4,0 \pm 0,4$ & & . & $438 \pm 50$ \\
\hline SLV-5 & $2,8 \pm 0,1$ & - & $30 \pm 2$ & $9189 \pm 751$ & $4,7 \pm 0,5$ & $155 \pm 9$ & $3,7 \pm 0,2$ & & . & $564 \pm 54$ \\
\hline SLV-6 & $2,8 \pm 0,2$ & $<L Q$ & $32 \pm 2$ & $7771 \pm 757$ & $6,3 \pm 0,5$ & $143 \pm 11$ & $4,2 \pm 0,3$ & 66 & \pm 6 & $515 \pm 72$ \\
\hline
\end{tabular}

Continuação TAB. 4.7 

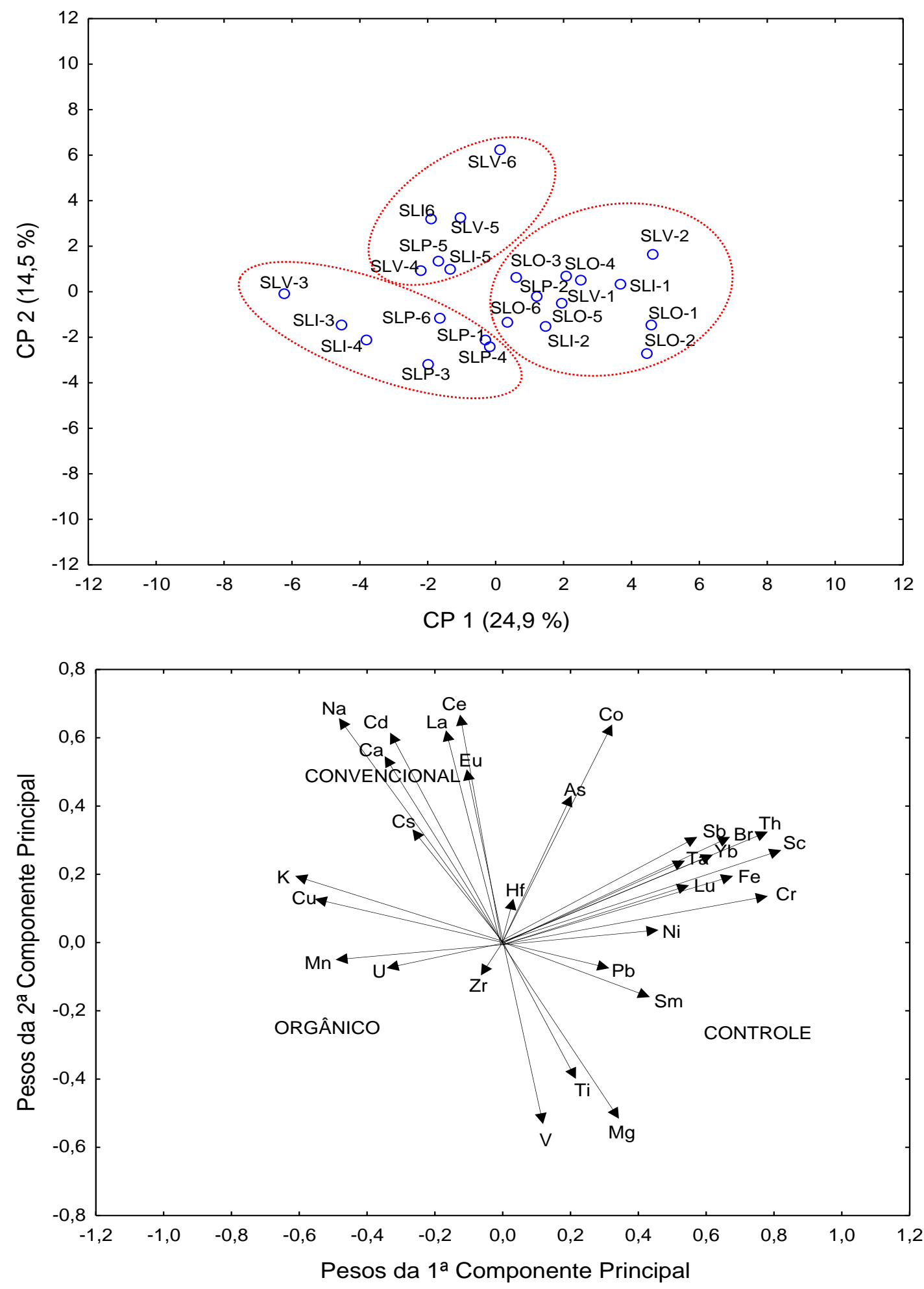

FIGURA 4.3 - Resultado da Análise de Componentes Principais (PCA) mostrando as duas primeiras Componentes Principais para os dados do solo: (a) Gráfico dos "scores"; (b) Gráfico "Biplot"

Na FIG. 4.3 são mostrados os gráficos das duas primeiras CPs. O gráfico de "scores" (FIG. 4.3a) permite a caracterização de tendências entre os manejos. 
A primeira CP $(24,9 \%)$ é responsável pela diferenciação entre o sistema de cultivo controle e os sistemas de cultivos adubados.

A segunda CP (14,5 \%) separa os sistemas de cultivos orgânicos e convencionais.

$\mathrm{Na}$ CP1, a maioria dos solos dos sistemas de cultivos controle (SLO-1, SLO-2, SLI-1, SLI-2, SLP-2, SLV-1 e SLV-2) apresenta valores de fator de carregamento positivos, contrastando com os sistemas de cultivos adubados (SLI3, SLI-4, SLI-5, SLI-6, SLP-3, SLP-4, SLP-5, SLP-6, SLV-3, SLV-4 e SLV-5) que apresentam resultados de fatores de carregamento negativos. A CP2 possui valores de fator de carregamento positivos para a maioria das amostras do cultivo convencional (SLI-5, SLI-6, SLP-5, SLV-5 e SLV-6) e negativos para as amostras do cultivo orgânico (SLI-3, SLI-4, SLP-3, SLP-4, SLV-3).

Através do gráfico "Biplot" (FIG. 4.3b) é possível visualizar conjuntamente as relações entre as CPs, os sistemas de cultivos e as variáveis. Observando-se ao longo do eixo da CP1, os pesos das variáveis que mais influenciam e separam o solo controle, são os teores de Sc, Cr, Th, Fe, Br, Yb, Sb, Lu, Ta, Ni, Sm, Pb (nesta ordem) que apresentam, em média, os teores mais elevados destes elementos-traço. Por outro lado, os sistemas adubados apresentaram maiores teores, em média, dos macronutrientes $\mathrm{Ca}$ e $\mathrm{K}$ e dos micronutrientes essenciais $\mathrm{Cu}, \mathrm{Mn}$ e $\mathrm{Na}$ (TAB. 4.8).

Pode-se notar, ao longo do eixo da CP2, que as variáveis que mais contribuem para a diferenciação do sistema de cultivo convencional (valores de fator de carregamento positivos) são $\mathrm{Ce}, \mathrm{Na}, \mathrm{La}, \mathrm{Ca}$, Eu e Cs. Ainda, esse grupo respondeu pelos maiores valores, em média, para estes elementos-traço. E no sistema de cultivo orgânico (valores de fator de carregamento negativos) as variáveis $\mathrm{K}, \mathrm{Cu}, \mathrm{Mn}$ e $\mathrm{U}$ contribuíram para a diferenciação, sendo que o $\mathrm{K}, \mathrm{Cu}$ e Mn apresentaram valores, em média, maiores para estes elementos e $U$ apresentou valor médio intermediário.

A PCA permitiu distinguir a separação entre amostras de solos submetidas a diferentes tipos de manejo e quais as variáveis influenciaram nesta separação.

Na TAB. 4.8 são apresentadas as médias das concentrações para os 30 elementos determinados e o teste de Tukey para a comparação das médias.

Entre os elementos determinados no solo, a maioria apresenta coeficiente de variação (CV) menor do que $25 \%$. Os elementos $\mathrm{Ca}, \mathrm{U}$, e $\mathrm{Zr}$ apresentaram 
coeficiente de variação entre 30 e 66 \%. Esta variação pode estar relacionada com o manejo agrícola (Silveira e Cunha, 2002) e também, com a sensibilidade da técnica empregada.

TABELA 4.8 - Concentrações médias para os 30 elementos determinados no solo.

\begin{tabular}{|c|c|c|c|c|c|c|c|c|c|c|}
\hline \multirow{2}{*}{ Manejo } & \multicolumn{2}{|c|}{ As } & \multicolumn{2}{|c|}{$\mathrm{Br}$} & \multicolumn{2}{|c|}{$\mathrm{Ca}$} & \multicolumn{2}{|c|}{ Cd } & \multicolumn{2}{|c|}{$\mathrm{Ce}$} \\
\hline & médian $^{n}$ & $\mathrm{CV}(\%)^{1}$ & média & $\mathrm{CV}(\%)$ & média & $\mathrm{CV}(\%)$ & média & $\mathrm{CV}(\%)$ & média & $\mathrm{CV}(\%)$ \\
\hline Controle & $34,4^{\mathrm{a}}$ & 9 & $24,3^{\mathrm{a}}$ & 5 & $8071^{a}$ & 30 & $0,04^{\mathrm{a}}$ & 11 & $42,1^{\mathrm{a}}$ & 6 \\
\hline Orgâ & $31,0^{\mathrm{a}}$ & 14 & $22,1^{a}$ & 4 & $8446^{a}$ & 21 & $0,05^{\underline{a}}$ & 22 & $45,5^{\mathrm{a}}$ & 10 \\
\hline \multirow[t]{2}{*}{ Convencional } & $32,8^{\mathrm{a}}$ & 11 & $23,6^{b}$ & 4 & $9053^{a}$ & 26 & $0,05^{a}$ & 27 & $46,4^{a}$ & 10 \\
\hline & \multicolumn{2}{|c|}{ Co } & \multicolumn{2}{|c|}{$\mathrm{Cr}$} & \multicolumn{2}{|c|}{ Cs } & \multicolumn{2}{|c|}{$\mathrm{Cu}$} & \multicolumn{2}{|c|}{ Eu } \\
\hline ontrole & $3,3^{\mathrm{a}}$ & 10 & $104^{a}$ & 5 & $2,8^{\mathrm{a}}$ & 18 & $13,6^{c}$ & 11 & $0,48^{\mathrm{a}}$ & 9 \\
\hline Orgâr & $3,2^{\mathrm{a}}$ & 7 & $94^{b}$ & 8 & $3,0^{\mathrm{a}}$ & 15 & $21,9^{\mathrm{a}}$ & 18 & $0,46^{a}$ & 10 \\
\hline \multirow[t]{2}{*}{ Convencional } & $3,2^{\mathrm{a}}$ & 7 & $96^{b}$ & 5 & $3,1^{\underline{a}}$ & 20 & $17,6^{b}$ & 14 & $0,51^{\mathrm{a}}$ & 11 \\
\hline & \multicolumn{2}{|c|}{$F$} & \multicolumn{2}{|c|}{$\mathrm{Hf}$} & \multicolumn{2}{|c|}{$\mathrm{K}$} & \multicolumn{2}{|c|}{ La } & \multicolumn{2}{|l|}{$\mathbf{L}$} \\
\hline Controle & $921^{\underline{a}}$ & 4 & $16,8^{\mathrm{a}}$ & 17 & $261^{\mathrm{a}}$ & 25 & $21,7^{\mathrm{a}}$ & 6 & $0,75^{\mathrm{a}}$ & 7 \\
\hline Orgân & $63964^{b}$ & 6 & $16,9^{\mathrm{a}}$ & 6 & $2666^{a}$ & 24 & $23,0^{\mathbf{a}}$ & 15 & $0,71^{a}$ & 18 \\
\hline \multirow[t]{2}{*}{ Convencional } & $65025^{\mathrm{ab}}$ & 4 & $17,8^{\mathrm{a}}$ & 6 & $2619^{a}$ & 10 & $24,5^{a}$ & 11 & $0,72^{a}$ & 10 \\
\hline & \multicolumn{2}{|c|}{ Mg } & \multicolumn{2}{|c|}{ Mn } & \multicolumn{2}{|c|}{ 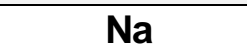 } & & \multicolumn{2}{|l|}{ 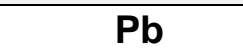 } \\
\hline Con & $25595^{a}$ & 16 & $149^{b}$ & 8 & $374^{\mathrm{a}}$ & 8 & $11,4^{\mathrm{a}}$ & 26 & $11,8^{\mathrm{a}}$ & 12 \\
\hline Orgân & $24326^{a}$ & 20 & $185^{a}$ & 14 & $409^{a}$ & 10 & $10,9^{\mathrm{a}}$ & 18 & $13,1^{\mathrm{a}}$ & 13 \\
\hline \multirow[t]{2}{*}{ Convencional } & $23785^{a}$ & 12 & $146^{b}$ & 21 & $420^{\mathrm{a}}$ & 16 & $10,4^{a}$ & 24 & $12,4^{a}$ & 9 \\
\hline & \multicolumn{2}{|c|}{$\mathbf{S b}$} & \multicolumn{2}{|c|}{ Sc } & \multicolumn{2}{|c|}{ Sm } & \multicolumn{2}{|c|}{$\mathrm{Ta}$} & \multicolumn{2}{|c|}{ Th } \\
\hline Cont & $1,8^{\mathrm{a}}$ & 58 & $18,3^{\mathrm{a}}$ & 4 & $2,9^{\mathrm{a}}$ & 17 & $2,9^{a}$ & 9 & $32,9^{\mathrm{a}}$ & 4 \\
\hline Orgânico & $1,8^{a}$ & 66 & $17,2^{b}$ & 6 & $3,3^{a}$ & 26 & $2,7^{a}$ & 21 & $29,4^{b}$ & 7 \\
\hline \multirow[t]{2}{*}{ Convencional } & $2,1^{a}$ & 49 & $17,7^{\mathrm{a} b}$ & 3 & $3,3^{a}$ & 0 & $2,8^{a}$ & 17 & $30,4^{b}$ & 3 \\
\hline & & & & & 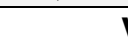 & V & & & $\bar{Z}$ & \\
\hline & $470^{\mathrm{a}}$ & 2 & $4,9^{\mathrm{a}}$ & 31 & $189^{\mathrm{a}}$ & 14 & $3,9^{\underline{a}}$ & 12 & $526^{\mathrm{a}}$ & 28 \\
\hline 0 & $8876^{a}$ & 22 & & 17 & $185^{a}$ & 23 & 3 , & 17 & $557^{\mathrm{a}}$ & 34 \\
\hline Convencional & $8606^{a}$ & 5 & $5,5^{\mathrm{a}}$ & 16 & $167^{\mathrm{a}}$ & 14 & $3,9^{\mathrm{a}}$ & 13 & $600^{\mathrm{a}}$ & 16 \\
\hline
\end{tabular}

Médias seguidas por letras distintas diferem entre si pelo teste de Tukey, a 0,05 de significância.

${ }^{1}$ Coeficiente de variação. $\mathrm{n}=8$.

\subsubsection{Adubos}

\subsubsection{Composto orgânico, cama de frango e NPK}

Na TAB. 4.9 são apresentados os resultados obtidos, neste estudo, da concentração dos elementos no adubo orgânico e na cama de frango, aplicado no manejo orgânico (3 e 4); no composto orgânico, aplicado tanto no manejo orgânico (3 e 4) quanto no manejo convencional (5 e 6) e; no adubo químico, 
aplicado no manejo convencional (5 e 6), presente em insumos globais na literatura.

TABELA 4.9 - Concentração dos elementos nos adubos orgânicos aplicados nesta pesquisa e nos adubos químicos descritos na literatura, em $\mathrm{mg} \mathrm{kg}^{-1}$.

\begin{tabular}{|c|c|c|c|}
\hline \multirow{2}{*}{ Elementos } & Composto orgânico & Cama de frango & \multirow[t]{2}{*}{ NPK ${ }^{\text {lit.1 }}$} \\
\hline & média $^{n} \pm \mathrm{DP}$ & média $\pm \mathrm{DP}$ & \\
\hline As & $10,9 \pm 0,4$ & $0,48 \pm 0,04$ & $2-1200^{b}$ \\
\hline $\mathbf{B a}$ & $301 \pm 13$ & $44 \pm 3$ & $200^{c}$ \\
\hline $\mathrm{Br}$ & $14,5 \pm 0,2$ & $10,9 \pm 0,1$ & $3-716^{e}$ \\
\hline $\mathrm{Ca}$ & $8823 \pm 1348$ & $33379 \pm 6947$ & $1,4-15000^{d}$ \\
\hline Cd & $0,405 \pm 0,001$ & $0,014 \pm 0,001$ & $0,05-170^{b}$ \\
\hline $\mathrm{Ce}$ & $59 \pm 2$ & $1,7 \pm 0,1$ & - \\
\hline Co & $3,13 \pm 0,07$ & $1,36 \pm 0,03$ & $0,41-385^{a}$ \\
\hline $\mathrm{Cr}$ & $51 \pm 1$ & $9,4 \pm 0,2$ & $70,5^{\mathrm{a}} ; 3-245^{\mathrm{b}}$ \\
\hline Cs & $2,62 \pm 0,33$ & $0,15 \pm 0,03$ & - \\
\hline $\mathrm{Cu}$ & $20,12 \pm 0,03$ & $140 \pm 3$ & $97^{a} ; 1-300^{c}$ \\
\hline $\mathrm{Cl}$ & nd & $74890 \pm 5316$ & - \\
\hline Eu & $0,66 \pm 0,03$ & $0,022 \pm 0,004$ & - \\
\hline $\mathrm{Fe}$ & $25517 \pm 196$ & $1367 \pm 13$ & $309-1529^{e}$ \\
\hline Hf & $195,8 \pm 0,1$ & $13,17 \pm 0,02$ & - \\
\hline $\mathbf{K}$ & $7541 \pm 68$ & $17388 \pm 812$ & $0-20000^{d}$ \\
\hline La & $30,1 \pm 0,5$ & $0,81 \pm 0,02$ & - \\
\hline Lu & $0,431 \pm 0,023$ & $<$ LID & - \\
\hline $\mathrm{Mg}$ & $13812 \pm 1223$ & nd & $7410-12240^{a}$ \\
\hline Mn & $184 \pm 27$ & $180 \pm 1$ & $149-5716^{a}$ \\
\hline $\mathrm{Na}$ & $885 \pm 35$ & $2441 \pm 47$ & $1,15-10324^{a}$ \\
\hline $\mathrm{Ni}$ & $11,137 \pm 0,003$ & $5,273 \pm 0,001$ & $116^{a} ; 7-38^{b}$ \\
\hline $\mathrm{Pb}$ & $28,4 \pm 0,3$ & $13,38 \pm 0,03$ & $44,5^{a} ; 2-1450^{b}$ \\
\hline $\mathbf{R b}$ & $45 \pm 2$ & $18,8 \pm 0,7$ & - \\
\hline $\mathrm{Sb}$ & $2,15 \pm 0,07$ & $<$ LID & - \\
\hline Sc & $8,2 \pm 0,1$ & $0,422 \pm 0,004$ & - \\
\hline $\mathrm{Se}$ & $1,1 \pm 0,3$ & $0,6 \pm 0,2$ & $0,5-25^{b}$ \\
\hline Sm & $4,3 \pm 0,1$ & $0,140 \pm 0,006$ & - \\
\hline $\mathrm{Ta}$ & $3,54 \pm 0,08$ & nd & - \\
\hline $\mathrm{Tb}$ & $0,8 \pm 0,1$ & nd & - \\
\hline Th & $15 \pm 1$ & $<$ LID & $1,7-103^{9}$ \\
\hline Ti & $4497 \pm 312$ & nd & - \\
\hline $\mathbf{U}$ & $4,9 \pm 0,3$ & nd & $5,17-54,3^{f}$ \\
\hline V & $69 \pm 3$ & nd & $2-1600^{e}$ \\
\hline Yb & $2,8 \pm 0,3$ & nd & - \\
\hline $\mathrm{Zn}$ & $170 \pm 5$ & $222 \pm 6$ & 299a; 50-1450c \\
\hline $\mathrm{Zr}$ & $380 \pm 14$ & nd & - \\
\hline
\end{tabular}


Na FIG. 4.4 está apresentado, na forma gráfica, o logaritmo das concentrações dos elementos nos adubos orgânicos. A transformação logarítmica foi aplicada para reduzir a variabilidade e a assimetria das ordens de grandeza dos resultados.

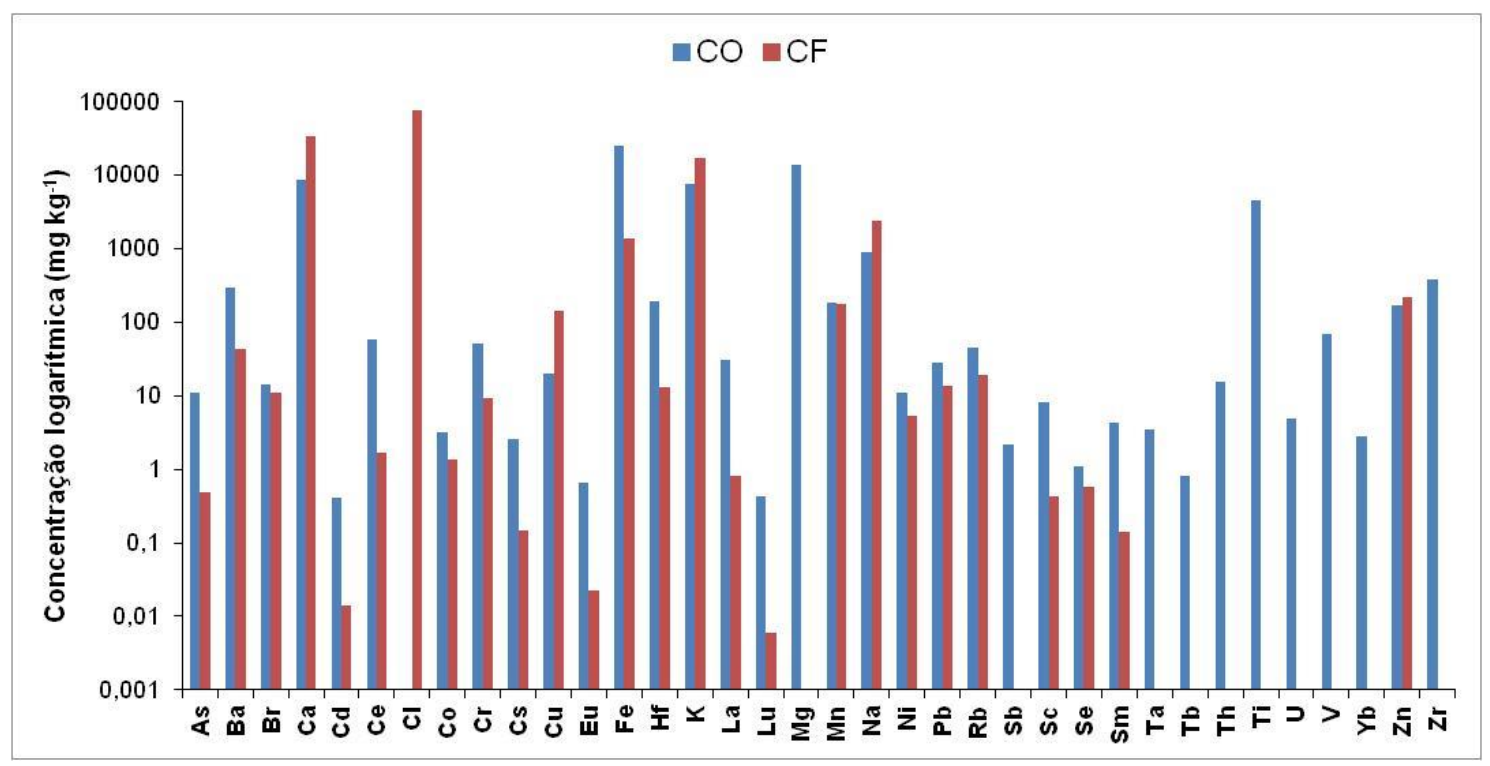

FIGURA 4.4 - Concentração dos elementos nos adubos aplicados nos sistemas de cultivo: dados transformados. CO (composto orgânico) e CF (cama de frango).

De acordo com a TAB. 4.9 os resultados das análises dos adubos aplicados demonstram que o composto orgânico e a cama de frango são fontes de macro e micronutrientes, como K, Ca, Mg, Mn, Na, Cl, Co, Cr, Cu, Fe e Zn. Quando se comparam os dois tipos de adubação (FIG. 4.4), a cama de frango apresentou maiores concentrações para os elementos $\mathrm{Ca}, \mathrm{Cl}, \mathrm{Cu}, \mathrm{K}, \mathrm{Na}$ e $\mathrm{Zn}$. Assim, como os adubos químicos (NPK), também são fontes de micronutrientes.

Os fertilizantes são fontes de macronutrientes, micronutrientes e elementos traço que contribuem para a melhoria das propriedades físicas, químicas e biológicas do solo (Ourives et al., 2010).

Para os parâmetros de fertilidade do solo, os adubos promovem benefícios favorecendo a elevação do $\mathrm{pH}$, da soma de bases (SB), da capacidade de troca catiônica $(T)$ e da saturação por bases (V\%), além de diminuição da acidez potencial $(\mathrm{H}+\mathrm{Al})$ (Santos et al., 2008). 


\subsubsection{Planta}

\subsubsection{Análise de biomassa fresca de Melissa officinalis}

$\mathrm{Na}$ TAB. 4.10 são apresentadas as médias, desvio padrão (DP) e o teste de Tukey dos resultados obtidos para biomassa (BM) fresca de Melissa officinalis considerando os sistemas de cultivo: controle com mudas do condicionamento orgânico (BM-1), controle com mudas do condicionamento convencional (BM-2), orgânico com micronutrientes (BM-3), orgânico sem micronutrientes (BM-4), convencional com micronutrientes (BM-5) e convencional sem micronutrientes (BM-6); e as épocas de colheita: outono $(\mathrm{O})$, inverno $(\mathrm{I})$, primavera $(\mathrm{P})$ e verão (V). E para melhor visualização os resultados são apresentados na FIG. 4.5 na forma de gráfico.

TABELA 4.10 - Resultados da biomassa (BM) fresca de Melissa officinalis considerando os sistemas de cultivo e época de colheita, em gramas.

\begin{tabular}{|c|c|c|c|c|}
\hline \multirow{2}{*}{ Amostras } & Outono & Inverno & Primavera & Verão \\
\hline & média $^{n} \pm \mathrm{DP}$ & média $\pm \mathrm{DP}$ & média $\pm \mathrm{DP}$ & média $\pm \mathrm{DP}$ \\
\hline BM-1 & $25^{\mathrm{cA}} \pm 5$ & $19^{\mathrm{cA}} \pm 1$ & $32^{\mathrm{CA}} \pm 4$ & $47^{\mathrm{CA}} \pm 15$ \\
\hline BM-2 & $26^{c A} \pm 5$ & $40^{\mathrm{cA}} \pm 37$ & $40^{\mathrm{CA}} \pm 13$ & $53^{\mathrm{cA}} \pm 30$ \\
\hline BM-3 & $460^{\mathrm{a} A} \pm 60$ & $321^{\mathrm{a} B} \pm 70$ & $252^{\mathrm{a} B} \pm 41$ & $275^{\mathrm{aB}} \pm 125$ \\
\hline BM-4 & $428^{a A} \pm 10$ & $308^{\mathrm{a} B} \pm 21$ & $264^{\mathrm{a} B} \pm 28$ & $221^{\mathrm{a} B} \pm 46$ \\
\hline BM-5 & $94^{\mathrm{bB}} \pm 19$ & $201^{\mathrm{bA}} \pm 18$ & $192^{\mathrm{bA}} \pm 28$ & $174^{\mathrm{bA}} \pm 27$ \\
\hline BM-6 & $92^{\mathrm{bB}} \pm 9$ & $172^{\mathrm{bA}} \pm 23$ & $133^{\mathrm{bA}} \pm 22$ & $186^{\mathrm{bA}} \pm 62$ \\
\hline
\end{tabular}

Médias seguidas por letras distintas, minúsculas na coluna e maiúsculas na linha, diferem entre si pelo teste de Tukey, a 0,05 de significância. $n=4$.

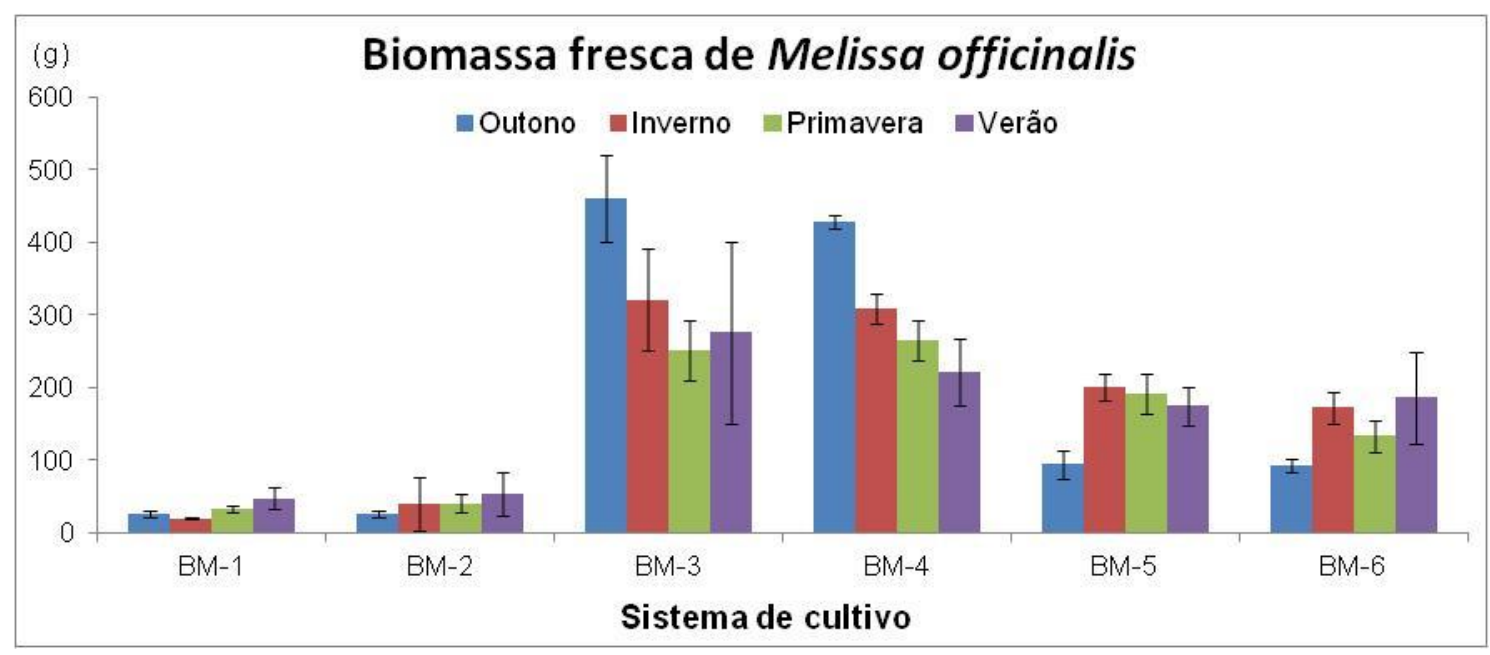

FIGURA 4.5 - Biomassa fresca de Melissa officinalis considerando o manejo agrícola e época de colheita. 
Os resultados analíticos foram avaliados pela análise de agrupamento hierárquico (AAH). O dendrograma foi aplicado aos valores médios das quatro amostras de cada tratamento. As 24 amostras de planta foram classificadas, levando em consideração os valores de biomassa fresca. Atribuindo-se o valor 20 para a distância de ligação (Dlig) no dendrograma, obtido a partir da análise de agrupamento, foi possível identificar três grupos de plantas (FIG. 4.6).

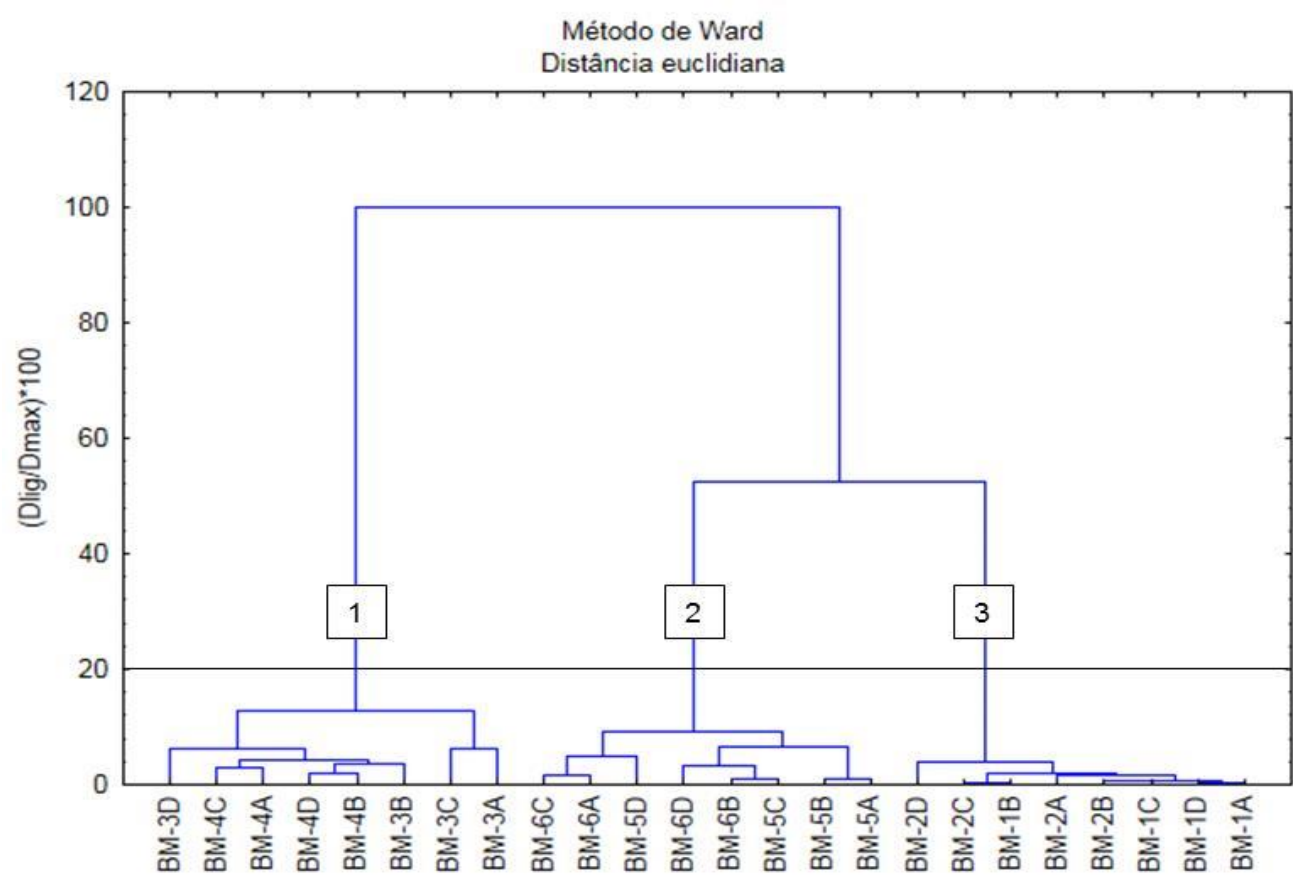

FIGURA 4.6 - Dendrograma da classificação das amostras de planta em três grupos, em função da biomassa fresca.

O grupo 1 é formado pelas amostras coletadas no solo com adubação orgânica, o grupo 2 é formado pelas amostras coletadas no solo com adubação convencional e o grupo 3 é formado pelas amostras coletadas no solo controle.

Os dados apresentados na TAB. 4.10 e o resultado da análise de agrupamento mostram que o manejo agrícola influenciou na produção de biomassa fresca de Melissa officinalis.

As biomassas frescas dos sistemas orgânicos com presença (BM-3) e ausência (BM-4) de micronutrientes e convencionais com presença (BM-5) e ausência (BM-6) de micronutrientes apresentaram maiores valores, significativos, comparados com a biomassa dos sistemas controles para condicionamento orgânico (BM-1) e convencional (BM-2). Isso foi devido à aplicação de matéria orgânica, pois aumenta a capacidade de retenção de água, promove à redução 
da densidade aparente, o aumento da porosidade total, forma agregados capazes de reduzir a erosão e aumenta a capacidade de absorção do solo; aumenta, ainda, os teores de nitrogênio, fósforo e enxofre a partir da decomposição e da mineralização da matéria orgânica e promove a redução da fixação do fósforo, pelos óxidos de ferro e alumínio, bloqueando os sítios de fixação com os radicais orgânicos. Forma, também, quelatos solúveis de ferro, manganês, zinco e cobre, disponibilizando-os às raízes, e favorece a atividade microbiológica e adição de novos micro-organismos, diversificando a flora e a microflora do solo. Tudo isso, reagindo no solo, forma húmus, que proporciona um excelente ambiente radicular, o que aumenta a absorção de nutrientes pelas plantas (Alleoni e Beauclair, 1995).

As biomassas frescas para os sistemas orgânicos (BM-3 e BM-4) apresentaram valores maiores, significativos $(p<0,05)$ quando comparados aos sistemas convencionais (BM-5 e BM-6). Segundo Kiehl (1985), os adubos orgânicos aplicados ao solo sempre proporcionam resposta positiva sobre a produção das culturas, igualando ou superando o efeito de fertilizantes químicos.

\subsubsection{Análise da concentração dos elementos nas folhas de Melissa officinalis}

$\mathrm{Na}$ TAB. 4.11 estão apresentados os resultados da análise descritiva nas folhas de Melissa officinalis obtidos pelas técnicas analíticas INAA, GF AAS e ICP-OES determinados nos diferentes sistemas de cultivo (controle, orgânico e convencional) e nas diferentes épocas de colheita (outono, inverno, primavera e verão) e o teste de Tukey para a comparação das médias. Os dados completos estão apresentados na TAB. 4.12.

Dentre os macronutrientes presentes nas folhas, estão: potássio $(\mathrm{K})$, cálcio (Ca) e magnésio $(\mathrm{Mg})$. Estes elementos apresentaram a seguinte ordem decrescente nas amostras analisadas: $\mathrm{K}>\mathrm{Ca}>\mathrm{Mg}$.

Eles foram encontrados em concentrações mais elevadas, seguindo uma variação média entre os sistemas de cultivos e as épocas de colheita. Sendo que estes elementos apresentaram maiores concentrações, em média, no sistema de cultivo orgânico (TAB. 4.11), o que representou alta demanda por nutrientes, devido a uma maior produção de biomassa (TAB 4.10).

A absorção de micronutrientes pela espécie Melissa officinalis apresentou a seguinte ordem decrescente: $\mathrm{Cl}>\mathrm{Fe}>\mathrm{Na}>\mathrm{Cr}>\mathrm{Zn}>\mathrm{Mn}>\mathrm{Cu}>\mathrm{Co}$. 
O cloro $(\mathrm{Cl})$ e o ferro $(\mathrm{Fe})$ foram os micronutrientes de maior concentração encontrado nas folhas de melissa, variando entre 1047 e $4785 \mathrm{mg} \mathrm{kg}^{-1}$, para o Cl e entre 433 e $4138 \mathrm{mg} \mathrm{kg}^{-1}$, para o Fe. O cloro apresentou um valor médio entre os sistemas de cultivo e época de colheita, exceto para a época do inverno, que apresentou menor concentração média. O nutriente ferro (Fe) apresentou menor concentração no sistema orgânico e maior variação para a estação do outono.

O sódio $(\mathrm{Na})$ apresentou concentrações menores nas plantas coletadas no sistema orgânico e o período do outono apresentou índices mais elevados, entre 120 e $266 \mathrm{mg} \mathrm{kg}^{-1}$.

A concentração do nutriente zinco $(Z n)$ não apresentou uma diferença significativa entre os sistemas de cultivo e a sazonalidade; e apresentou uma variação menor que $30 \%$. O Zn é considerado um elemento de fitotoxidez baixa a moderada (Kabata-Pendias e Pendias, 2001). A maioria das espécies estudadas é afetada por concentrações no tecido que variam de 100 a $400 \mathrm{mg} \mathrm{kg}^{-1}$. No entanto, os teores de $\mathrm{Zn}$ encontram-se abaixo da baixa adequada.

O manganês $(\mathrm{Mn})$ apresentou menores índices no sistema orgânico, entre 12,4 e $18,1 \mathrm{mg} \mathrm{kg}^{-1}$ e uma variação menor que $38 \%$ entre as épocas de colheita.

O nutriente cobre $(\mathrm{Cu})$ apresentou variação de 7,32 a 16,66 mg kg-1 entre as amostras coletadas em ambos os sistemas de cultivo e épocas do ano.

O cobalto (Co) apresentou maiores concentrações médias entre os sistemas adubados e menor concentração na época do outono.

Os elementos As, Ba, $\mathrm{Cd}, \mathrm{Cs}, \mathrm{Ni}, \mathrm{Pb}, \mathrm{Sb}$, Th e U, dependendo da sua concentração, podem ser considerados contaminantes.

Para o arsênio (As), que foi quantificado apenas nas amostras da coleta do outono, a concentração encontrada variou de 0,99 a $1,33 \mathrm{mg} \mathrm{kg-1}$. O limite máximo estabelecido para arsênio é de $0,6 \mathrm{mg} \mathrm{kg}^{-1}$ em vegetais para chá, segundo a RDC $\mathrm{n} \cong 42$ (ANVISA, 2002). Portanto, estas amostras ficaram acima do limite permitido pela ANVISA.

A concentração do elemento bário (Ba) variou entre 58 e $78 \mathrm{mg} \mathrm{kg}^{-1}$, sendo menor nos sistemas adubados em relação ao sistema controle e apresentou, entre as épocas de colheita, um coeficiente de variação de $34 \%$ na época do outono.

A concentração média de cádmio (Cd) foi de $0,05 \mathrm{mg} \mathrm{kg}^{-1}$ e apresentou variação maior na época do inverno (45 \%) e menor no sistema orgânico (37 \%). 
A RDC citada acima determina um limite máximo para cádmio de 0,4 $\mathrm{mg} \mathrm{kg}^{-1} \mathrm{em}$ folhas para preparos de infusões, logo as amostras analisadas apresentaram concentrações bem abaixo do limite estabelecido.

O elemento césio (Cs) apresentou concentrações abaixo do limite de quantificação para a metodologia aplicada.

As concentrações de níquel ( $\mathrm{Ni}$ ) variaram entre 4 e $31 \mathrm{mg} \mathrm{kg}^{-1}$. Os sistemas adubados apresentaram concentrações médias relativamente maiores em relação ao sistema controle e as amostras do outono apresentaram menores índices.

O chumbo $(\mathrm{Pb})$ apresentou uma concentração média de $3 \mathrm{mg} \mathrm{kg}^{-1}$, menor coeficiente de variação no sistema orgânico (39 \%) e maior na época do inverno (58\%) (TAB. 4.11). O limite máximo permitido pela ANVISA (BRASIL, 2013b) para este elemento em chá, erva mate e vegetais para infusão é de $0,6 \mathrm{mg} \mathrm{kg}^{-1}$, e conforme a Organização Mundial de Saúde, OMS (Saidelles et al., 2010; Vulcano et al., 2008), o limite máximo permitido em ervas medicinais é de $10 \mathrm{mg} \mathrm{kg}^{-1}$. Nos resultados obtidos são mostrados que as amostras analisadas excedem o limite máximo permitido pela ANVISA, porém, estão abaixo do limite permitido pela OMS.

O Antimônio ( $\mathrm{Sb}$ ) foi determinado em pouco mais da metade das amostras analisadas. Sua concentração média foi de $0,22 \mathrm{mg} \mathrm{kg}^{-1}$, sendo que, os sistemas adubados apresentaram as maiores concentrações. O limite de ingestão diária tolerável (IDT) de antimônio é de $0,006 \mathrm{mg} \mathrm{kg}^{-1}$ de peso corporal (Committee on Toxicity of Chemicals in Food, 2006). Considerando um indivíduo com $70 \mathrm{~kg}$ de peso corpóreo, o limite de ingestão diária de Sb é de 0,42 mg. De acordo com Francisconi (2013), o fator de transferência deste elemento da planta para o extrato, na forma de chá, foi de $100 \%$. Caso o indivíduo consuma o chá dessa planta como indicado pela ANVISA, três vezes ao dia, ele estará ingerindo uma quantidade superior ao limite estabelecido.

A concentração do elemento tório (Th) variou entre 0,17 e 1,95 $\mathrm{mg} \mathrm{kg}^{-1}$, sendo maior no sistema controle em relação aos sistemas adubados e apresentou maiores variações nas plantas coletadas nas épocas de outono e inverno.

O elemento urânio (U) apresentou concentrações abaixo do limite de quantificação para a metodologia aplicada. 
TABELA 4.11 - Análises descritivas das amostras de folhas considerando a média e coeficiente de variação para os sistemas de cultivo aplicados e sazonalidade, em $\mathrm{mg} \mathrm{kg}^{-1}$.

\begin{tabular}{|c|c|c|c|c|c|c|c|c|c|c|c|c|c|c|c|c|c|c|}
\hline \multirow{2}{*}{ Cultivo } & \multicolumn{2}{|c|}{ As } & \multicolumn{2}{|c|}{$\mathbf{B a}$} & \multicolumn{2}{|c|}{$\mathrm{Br}$} & \multicolumn{2}{|c|}{$\mathbf{C a}$} & \multicolumn{2}{|c|}{ Cd } & \multicolumn{2}{|c|}{$\mathrm{Ce}$} & \multicolumn{2}{|c|}{$\mathrm{Cl}$} & \multicolumn{2}{|c|}{ Co } & \multicolumn{2}{|c|}{$\mathrm{Cr}$} \\
\hline & média ${ }^{1}$ & $\mathrm{CV}(\%)^{3}$ & média & $\mathrm{CV}(\%)$ & média & $\mathrm{CV}(\%)$ & média & $\mathrm{CV}(\%)$ & média & $\mathrm{CV}(\%)$ & média & $\mathrm{CV}(\%)$ & Média & $\mathrm{CV}(\%)$ & $\begin{array}{c}\text { médi } \\
\text { a }\end{array}$ & CV(\%) & média & $\mathrm{CV}(\%)$ \\
\hline Controle & $1,52^{\mathrm{a}}$ & 71 & $78^{a}$ & 16 & $42^{\mathrm{a}}$ & 40 & $12004^{\mathrm{a}}$ & 15 & $0,05^{\mathrm{a}}$ & 51 & $1,49^{a}$ & 72 & $2363^{a}$ & 2 & $0,60^{\mathrm{a}}$ & 78 & $46^{a}$ & 113 \\
\hline Orgânico & $0,33^{\mathrm{a}}$ & 4 & $61^{b}$ & 15 & $10^{b}$ & 28 & $14421^{a}$ & 37 & $0,05^{\mathrm{a}}$ & 37 & $0,65^{\underline{a}}$ & 18 & $2549^{a}$ & 49 & $0,88^{\underline{a}}$ & 102 & $82^{a}$ & 113 \\
\hline Convencional & $1,65^{\mathrm{a}}$ & 59 & $58^{b}$ & 13 & $21^{b}$ & 93 & $12276^{\mathrm{a}}$ & 24 & $0,06^{a}$ & 52 & $0,98^{a}$ & 71 & $2582^{a}$ & 46 & $0,92^{\mathrm{a}}$ & 66 & $68^{a}$ & 68 \\
\hline Sazonalidade & média $^{2}$ & $\mathrm{CV}(\%)$ & média & $\mathrm{CV}(\%)$ & média & $\mathrm{CV}(\%)$ & média & $\mathrm{CV}(\%)$ & média & $\mathrm{CV}(\%)$ & média & $\mathrm{CV}(\%)$ & média & $\mathrm{CV}(\%)$ & média & $\mathrm{CV}(\%)$ & média & $\mathrm{CV}(\%)$ \\
\hline Outono & $1,37^{a}$ & 69 & $66^{a}$ & 34 & $37^{a}$ & 69 & $11311^{a}$ & 32 & $0,07^{a}$ & 25 & $2,0^{a}$ & 54 & $2747^{a}$ & 51 & $0,3^{\underline{a}}$ & 34 & $9,0^{b}$ & 39 \\
\hline Inverno & $0,28^{\mathrm{a}}$ & - & $68^{\underline{a}}$ & 19 & $26^{a}$ & 95 & $13579^{a}$ & 41 & $0,07^{a}$ & 45 & $0,7^{b}$ & 18 & $1556^{\underline{a}}$ & 30 & $1,0^{\mathrm{a}}$ & 68 & $76,2^{\mathrm{a}}$ & 70 \\
\hline Primavera & - & - & $62^{a}$ & 9 & $20^{a}$ & 71 & $12727^{a}$ & 10 & $0,04^{\mathrm{ab}}$ & 25 & $0,9^{b}$ & 38 & $3049^{a}$ & 51 & $0,9^{a}$ & 47 & $82,1^{\mathrm{a}}$ & 52 \\
\hline Verão & - & - & $66^{\underline{a}}$ & 12 & $15^{\mathrm{a}}$ & 36 & $13985^{a}$ & 25 & $0,03^{b}$ & 20 & $0,5^{\mathrm{b}}$ & 30 & $2640^{\mathrm{a}}$ & 9 & $1,1^{\mathrm{a}}$ & 86 & $57,6^{\mathbf{a}}$ & 59 \\
\hline Média total & & 21 & & 6 & & 24 & 12 & 01 & 0 , & 05 & 1,0 & & & 98 & 0 & 8 & 6 & 5 \\
\hline \multirow[b]{2}{*}{ Cultivo } & \multicolumn{2}{|c|}{ Cs } & \multicolumn{2}{|c|}{$\mathrm{Cu}$} & \multicolumn{2}{|c|}{ Eu } & \multicolumn{2}{|c|}{$\mathrm{Fe}$} & \multicolumn{2}{|c|}{ Hf } & \multicolumn{2}{|c|}{$\mathbf{K}$} & \multicolumn{2}{|c|}{ La } & \multicolumn{2}{|c|}{ Lu } & \multicolumn{2}{|c|}{ Mg } \\
\hline & média & $\mathrm{CV}(\%)$ & média & $\mathrm{CV}(\%)$ & média & $\mathrm{CV}(\%)$ & média & $\mathrm{CV}(\%)$ & média & $\mathrm{CV}(\%)$ & média & $\mathrm{CV}(\%)$ & Média & $\mathrm{CV}(\%)$ & $\begin{array}{c}\text { médi } \\
\text { a }\end{array}$ & CV(\%) & média & $\mathrm{CV}(\%)$ \\
\hline Controle & \multicolumn{2}{|c|}{0,25} & $10^{\mathrm{a}}$ & 24 & $0,04^{\underline{a}}$ & 113 & $1794^{a}$ & 73 & $0,61^{\mathrm{a}}$ & 67 & $27523^{a}$ & 29 & $0,78^{a}$ & 84 & $0,027^{\mathrm{a}}$ & 66 & $4547^{a}$ & 43 \\
\hline Orgânico & \multicolumn{2}{|c|}{$<$ LID } & $13^{a}$ & 23 & $0,03^{\underline{a}}$ & 90 & $741^{b}$ & 37 & $0,23^{a}$ & 79 & $32614^{a}$ & 14 & $0,37^{\mathrm{a}}$ & 22 & $0,017^{a}$ & 36 & $6173^{\underline{a}}$ & 16 \\
\hline Convencional & \multicolumn{2}{|c|}{$<$ LID } & $10^{\mathrm{a}}$ & 21 & $0,02^{\mathrm{a}}$ & 47 & $1102^{a}$ & 59 & $0,40^{\mathrm{a}}$ & 89 & $27652^{a}$ & 13 & $0,72^{\mathrm{a}}$ & 84 & $0,020^{\underline{a}}$ & 56 & $5563^{a}$ & 16 \\
\hline Sazonalidade & média & $\mathrm{CV}(\%)$ & média & $\mathrm{CV}(\%)$ & média & $\mathrm{CV}(\%)$ & média & $\mathrm{CV}(\%)$ & média & $\mathrm{CV}(\%)$ & média & $\mathrm{CV}(\%)$ & média & CV(\%) & média & $\mathrm{CV}(\%)$ & Média & $\mathrm{CV}(\%)$ \\
\hline Outono & \multicolumn{2}{|c|}{$<$ LID } & $14^{\mathrm{a}}$ & 12 & $0,03^{a}$ & 43 & $2221^{a}$ & 64 & $0,69^{a}$ & 61 & $28697^{a b}$ & 20 & $1,2^{\mathrm{a}}$ & 57 & $0,03^{a}$ & 75 & $4964^{\mathrm{a}}$ & 13 \\
\hline Inverno & \multicolumn{2}{|c|}{$<$ LID } & $10^{a b}$ & 35 & $0,05^{\mathrm{a}}$ & 138 & $905^{b}$ & 20 & $0,39^{a b}$ & 78 & $34901^{a}$ & 11 & $0,4^{b}$ & 23 & $0,02^{a}$ & 96 & $4544^{\mathrm{a}}$ & 49 \\
\hline Primavera & \multicolumn{2}{|c|}{$<$ LID } & $11^{a b b}$ & 10 & $0,03^{\mathbf{a}}$ & 30 & $965^{b}$ & 51 & $0,21^{b}$ & 59 & $29878^{a b}$ & 17 & $0,4^{b}$ & 29 & $0,01^{a}$ & 42 & $5908^{a}$ & 11 \\
\hline Verão & \multicolumn{2}{|c|}{$<$ LID } & $9^{b}$ & 13 & $0,01^{a}$ & 75 & $759^{b}$ & 45 & $0,09^{b}$ & 88 & $23577^{b}$ & 12 & $0,3^{b}$ & 34 & - & - & $6296^{\mathrm{a}}$ & 23 \\
\hline Média total & \multicolumn{2}{|c|}{0,11} & \multicolumn{2}{|c|}{11} & & 03 & & & 0 & & 292 & & & & 0, & 02 & & 28 \\
\hline
\end{tabular}

Médias seguidas por letras distintas diferem entre si pelo teste de Tukey, a 0,05 de significância ${ }^{1} n=8 .{ }^{2} n=6 .{ }^{3}$ Coeficiente de variação. 


\begin{tabular}{|c|c|c|c|c|c|c|c|c|c|c|c|c|c|c|c|c|}
\hline \multirow{2}{*}{ Cultivo } & \multicolumn{2}{|c|}{ Mn } & \multicolumn{2}{|c|}{$\mathrm{Na}$} & \multicolumn{2}{|c|}{$\mathrm{Ni}$} & \multicolumn{2}{|c|}{$\mathbf{P b}$} & \multicolumn{2}{|c|}{$\mathbf{R b}$} & \multicolumn{2}{|c|}{ Sb } & \multicolumn{2}{|c|}{ Sc } & \multicolumn{2}{|c|}{ Sm } \\
\hline & média & $\mathrm{CV}(\%)$ & média & $\mathrm{CV}(\%)$ & média & $\mathrm{CV}(\%)$ & média & $\mathrm{CV}(\%)$ & média & $\mathrm{CV}(\%)$ & média & CV(\%) & média & $\mathrm{CV}(\%)$ & média & $\mathrm{CV}(\%)$ \\
\hline Controle & $22,9^{\underline{a}}$ & 46 & $109^{\underline{a}}$ & 94 & $11^{\underline{a}}$ & 90 & $2,72^{\underline{a}}$ & 53 & $14^{\mathrm{c}}$ & 15 & $0,14^{\underline{a}}$ & 5 & $0,51^{a}$ & 83 & $0,09^{a}$ & 80 \\
\hline Orgânico & $14,9^{\mathrm{a}}$ & 12 & $61^{\mathrm{a}}$ & 88 & $25^{\mathrm{a}}$ & 62 & $3,61^{a}$ & 39 & $23^{a}$ & 14 & $0,25^{\mathrm{a}}$ & 47 & $0,08^{b}$ & 68 & $0,04^{a}$ & 38 \\
\hline Convencional & $20,3^{a}$ & 25 & $75^{\mathrm{a}}$ & 114 & $24^{\underline{a}}$ & 60 & $3,25^{\mathrm{a}}$ & 54 & $18^{b}$ & 11 & $0,23^{\underline{a}}$ & 19 & $0,22^{a b}$ & 103 & $0,08^{\underline{a}}$ & 84 \\
\hline
\end{tabular}

Sazonalidade média $C V(\%)$ média $C V(\%)$ média $C V(\%)$ média $C V(\%)$ média $C V(\%)$ média $C V(\%)$ média $C V(\%)$ média $C V(\%)$

\begin{tabular}{|c|c|c|c|c|c|c|c|c|c|c|c|c|c|c|c|c|}
\hline Outono & $26^{\underline{a}}$ & 38 & $196^{a}$ & 31 & $4^{c}$ & 19 & $3,3^{a}$ & 40 & $20^{\underline{a}}$ & 22 & $0,20^{\underline{a}}$ & 27 & $0,64^{\underline{a}}$ & 71 & $0,14^{\mathrm{a}}$ & 57 \\
\hline Inverno & $19^{a b}$ & 25 & $35^{b}$ & 35 & $41^{\underline{a}}$ & 13 & $3,5^{\mathrm{a}}$ & 58 & $18^{a}$ & 21 & $0,24^{\mathrm{a}}$ & 43 & $0,20^{b}$ & 104 & $0,04^{b}$ & 24 \\
\hline Primavera & $19^{a b}$ & 21 & $39^{b}$ & 24 & $24^{b}$ & 11 & $2,5^{\mathrm{a}}$ & 44 & $18^{a}$ & 29 & $0,25^{\mathrm{a}}$ & 1 & $0,15^{b}$ & 70 & $0,04^{b}$ & 42 \\
\hline Verão & $13^{b}$ & 25 & $32^{b}$ & 24 & $24^{\mathrm{b}}$ & 40 & $3,5^{\mathrm{a}}$ & 47 & $17^{a}$ & 21 & $0,22^{\mathrm{a}}$ & 61 & $0,09^{b}$ & 79 & $0,03^{b}$ & 40 \\
\hline
\end{tabular}

\begin{tabular}{|c|c|c|c|c|c|c|c|c|c|c|c|c|c|c|}
\hline \multirow{2}{*}{ Cultivo } & \multicolumn{2}{|c|}{ Ta } & \multicolumn{2}{|c|}{ Th } & \multicolumn{2}{|c|}{ Ti } & $\mathbf{U}$ & \multicolumn{2}{|c|}{$\mathbf{V}$} & \multicolumn{2}{|c|}{$\mathbf{Y b}$} & \multicolumn{2}{|c|}{ Zn } & $\mathrm{Zr}$ \\
\hline & média & CV(\%) & média & CV(\%) & média & CV $(\%)$ & média $\mathrm{CV}(\%)$ & média & CV(\%) & média & CV $(\%)$ & média & CV(\%) & média $\mathrm{CV}(\%)$ \\
\hline Controle & $0,10^{a}$ & 80 & $0,87^{a}$ & 77 & $218^{a}$ & 76 & $<L Q$ & $2,3^{a}$ & 48 & $0,18^{\underline{a}}$ & 63 & $60^{\underline{a}}$ & 22 & $<L Q$ \\
\hline Orgânico & $0,03^{a}$ & 38 & $0,15^{b}$ & 65 & $78^{\mathrm{a}}$ & 11 & $<L Q$ & $0,8^{\mathrm{a}}$ & 36 & $0,08^{a}$ & 25 & $58^{\mathrm{a}}$ & 28 & $<L Q$ \\
\hline Convencional & $0,08^{a}$ & 84 & $0,37^{a b}$ & 105 & $188^{\underline{a}}$ & 55 & $<L Q$ & $1,9^{a}$ & 90 & $0,13^{a}$ & 62 & $44^{\mathrm{a}}$ & 23 & $<L Q$ \\
\hline
\end{tabular}

Sazonalidade média $C V(\%)$ média $C V(\%)$ média $C V(\%)$ média $C V(\%)$ média CV(\%) média CV(\%) média CV(\%) média CV(\%)

\begin{tabular}{|c|c|c|c|c|c|c|c|c|c|c|c|c|c|c|}
\hline Outono & $0,07^{\mathrm{a}}$ & 56 & $1,04^{\underline{a}}$ & 68 & $258^{\underline{a}}$ & 61 & $<\mathrm{LQ}$ & $3,01^{\mathrm{a}}$ & 59 & $0,17^{a}$ & 57 & $42^{\mathrm{a}}$ & 23 & $<L Q$ \\
\hline Inverno & - & - & $0,41^{a b}$ & 101 & $93^{a}$ & 38 & $<\mathrm{LQ}$ & $1,15^{a b}$ & 38 & 0,03 & - & $56^{a}$ & 30 & $<L Q$ \\
\hline Primavera & $0,07^{\underline{a}}$ & - & $0,25^{\mathrm{b}}$ & 60 & $105^{\underline{a}}$ & 38 & $<\mathrm{LQ}$ & $1,62^{\underline{a b}}$ & 68 & $0,13^{\underline{a}}$ & 59 & $60^{\mathrm{a}}$ & 15 & $<L Q$ \\
\hline Verão & - & - & $0,14^{\mathrm{b}}$ & 68 & $136^{\underline{a}}$ & - & $<L Q$ & $0,85^{b}$ & 37 & - & - & $59^{a}$ & 29 & $<L Q$ \\
\hline Média total & \multicolumn{2}{|c|}{0,07} & \multicolumn{2}{|c|}{0,62} & \multicolumn{2}{|c|}{176} & - & \multicolumn{2}{|c|}{1,72} & \multicolumn{2}{|c|}{0,14} & \multicolumn{2}{|c|}{54,2} & 15,6 \\
\hline
\end{tabular}

Continuação TAB. $4 \cdot 11 .{ }^{1} n=8 .{ }^{2} n=6 .{ }^{3}$ Coeficiente de variação. 
TABELA 4.12 - Resultados das análises elementares para as amostras de planta, $\mathrm{mg} \mathrm{kg}^{-1}$.

\begin{tabular}{|c|c|c|c|c|c|c|c|c|c|c|c|c|c|c|c|c|c|}
\hline \multirow[t]{2}{*}{ Amostras } & \multicolumn{2}{|c|}{ As } & \multicolumn{2}{|c|}{$\mathrm{Ba}$} & \multicolumn{2}{|c|}{$\mathrm{Br}$} & \multicolumn{2}{|c|}{$\mathrm{Ca}$} & \multicolumn{2}{|c|}{ Cd } & $\mathrm{Ce}$ & \multicolumn{2}{|c|}{$\mathrm{Cl}$} & \multicolumn{2}{|c|}{ Co } & \multicolumn{2}{|c|}{$\mathrm{Cr}$} \\
\hline & médian $^{n}$ & $\pm 1 \delta$ & média & $\pm 1 \delta$ & média & $\pm 1 \delta$ & média & $\pm 1 \delta$ & média & $\pm 1 \delta$ & média & média & $\pm 1 \delta$ & média & $\pm 1 \delta$ & média & $\pm 1 \delta$ \\
\hline FLO-1 & 2,01 & $\pm 0,08$ & 102 & \pm 3 & 56,2 & $\pm 0,2$ & 10159 & \pm 409 & 0,096 & $\pm 0,004$ & $3,42 \pm 0,09$ & & 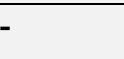 & 0,366 & $\pm 0,008$ & 9,8 & $\pm 0,2$ \\
\hline FLO-2 & 2,3 & $\pm 0,1$ & 86 & \pm 3 & 53,7 & $\pm 0,2$ & 8864 & \pm 337 & 0,093 & $\pm 0,007$ & $2,96 \pm 0,08$ & & - & 0,27 & $\pm 0,01$ & 12,2 & $\pm 0,2$ \\
\hline FLO-3 & 0,32 & $\pm 0,04$ & 51 & \pm 2 & 10,87 & $\pm 0,07$ & 10626 & \pm 908 & 0,059 & $\pm 0,003$ & $<L Q$ & 3138 & \pm 145 & 0,165 & $\pm 0,005$ & 5,1 & $\pm 0,1$ \\
\hline FLO-4 & 0,34 & $\pm 0,05$ & 52 & \pm 2 & 5,29 & $\pm 0,05$ & 8849 & \pm 423 & 0,066 & $\pm 0,007$ & $<L Q$ & 4527 & \pm 308 & 0,167 & $\pm 0,007$ & 6,9 & $\pm 0,1$ \\
\hline FLO-5 & 2,3 & $\pm 0,1$ & 46 & \pm 2 & 65,8 & $\pm 0,3$ & 18456 & \pm 1018 & 0,053 & $\pm 0,004$ & $2,04 \pm 0,05$ & 1350 & \pm 322 & 0,357 & $\pm 0,007$ & 6,2 & $\pm 0,1$ \\
\hline FLO-6 & 0,96 & $\pm 0,04$ & 60 & \pm 3 & 28,2 & $\pm 0,1$ & 10913 & \pm 522 & 0,065 & $\pm 0,001$ & $2,10 \pm 0,06$ & 1972 & \pm 481 & 0,234 & $\pm 0,008$ & 13,7 & $\pm 0,3$ \\
\hline FLI-1 & & 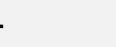 & 73 & & 54,1 & $\pm 0,3$ & 12709 & \pm 551 & 0,057 & $\pm 0,003$ & $<L Q$ & 1985 & \pm 137 & 0,37 & $\pm 0,02$ & & \\
\hline FLI-2 & 0,28 & $\pm 0,08$ & 82 & & 60,8 & $\pm 0,3$ & 11625 & \pm 568 & 0,032 & $\pm 0,007$ & $<L Q$ & 1928 & \pm 156 & 0,57 & $\pm 0,03$ & 42,9 & $\pm 0,9$ \\
\hline FLI-3 & & . & 79 & & 9,3 & $\pm 0,1$ & 24628 & \pm 2225 & 0,060 & $\pm 0,004$ & $<L Q$ & 1263 & \pm 448 & 0,92 & $\pm 0,01$ & 83 & \pm 1 \\
\hline FLI-4 & & . & 68 & & 10,47 & $\pm 0,07$ & 12080 & \pm 600 & 0,068 & $\pm 0,005$ & $<L Q$ & 1047 & \pm 231 & & & & \\
\hline FLI-5 & & - & 52 & \pm 2 & 10,34 & $\pm 0,08$ & 9692 & \pm 299 & 0,123 & $\pm 0,001$ & $<L Q$ & & - & 2,19 & $\pm 0,02$ & 146 & \pm 2 \\
\hline FLI-6 & & 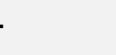 & 52 & & 10,5 & $\pm 0,1$ & 10743 & \pm 628 & 0,061 & $\pm 0,001$ & $<L Q$ & & - & 1,16 & $\pm 0,01$ & 103 & \pm 2 \\
\hline FLP-1 & & 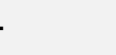 & - & & 24,5 & $\pm 0,4$ & 14273 & \pm 957 & 0,048 & $\pm 0,004$ & $1,3 \pm 0,1$ & & - & 0,80 & $\pm 0,01$ & 66 & \pm 1 \\
\hline FLP-2 & & . & - & & 47,0 & $\pm 0,7$ & 13062 & \pm 881 & 0,044 & $\pm 0,001$ & $1,13 \pm 0,07$ & & - & 1,69 & $\pm 0,02$ & 163 & \pm 3 \\
\hline FLP-3 & & 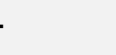 & 58 & \pm 2 & 13,5 & $\pm 0,5$ & 13506 & \pm 798 & 0,030 & $\pm 0,002$ & $<L Q$ & 3900 & \pm 293 & 0,531 & $\pm 0,008$ & 47,9 & $\pm 0,7$ \\
\hline FLP-4 & & . & 54 & & 11,2 & $\pm 0,1$ & 12165 & \pm 498 & 0,038 & $\pm 0,003$ & $<L Q$ & 1554 & \pm 160 & 0,61 & $\pm 0,01$ & 51,9 & $\pm 0,9$ \\
\hline FLP-5 & & . & 60 & \pm 2 & 11,04 & $\pm 0,09$ & 12917 & \pm 763 & 0,035 & $\pm 0,001$ & $<L Q$ & 4785 & \pm 1001 & 0,77 & $\pm 0,01$ & 72 & \pm 1 \\
\hline FLP-6 & & 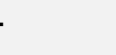 & 69 & \pm 2 & 12,7 & $\pm 0,1$ & 10438 & \pm 473 & 0,060 & $\pm 0,002$ & $<L Q$ & 1957 & \pm 237 & 0,893 & $\pm 0,009$ & 92,2 & $\pm 1,6$ \\
\hline FLV-1 & & 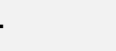 & 70 & \pm 3 & 24,2 & $\pm 0,5$ & 13699 & \pm 1042 & 0,038 & $\pm 0,001$ & $<L Q$ & & & 0,48 & $\pm 0,01$ & 40,1 & $\pm 0,8$ \\
\hline FLV-2 & & . & 82 & \pm 3 & 18,6 & $\pm 0,5$ & 11644 & \pm 872 & 0,021 & $\pm 0,001$ & $<L Q$ & & - & 0,271 & $\pm 0,007$ & 24,1 & $\pm 0,5$ \\
\hline FLV-3 & & . & 63 & \pm 3 & 14,6 & $\pm 0,1$ & 20485 & 1535 & 0,027 & $\pm 0,001$ & $<L Q$ & 2396 & \pm 169 & 2,80 & $\pm 0,03$ & & \\
\hline FLV-4 & & 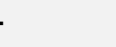 & 60 & \pm 3 & 8,55 & $\pm 0,06$ & 13033 & \pm 456 & 0,030 & $\pm 0,002$ & $<L Q$ & 2570 & \pm 136 & 1,052 & $\pm 0,009$ & 113 & \pm 2 \\
\hline FLV-5 & & - & 64 & \pm 2 & 14,8 & $\pm 0,1$ & 14360 & \pm 467 & 0,035 & $\pm 0,001$ & $<L Q$ & 2649 & \pm 286 & 0,693 & $\pm 0,007$ & 61,0 & $\pm 0,9$ \\
\hline FLV-6 & & 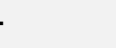 & 60 & \pm 3 & 11,68 & $\pm 0,08$ & 10688 & \pm 531 & 0,028 & $\pm 0,001$ & $<L Q$ & 2946 & \pm 250 & 1,05 & $\pm 0,01$ & 49,7 & $\pm 0,8$ \\
\hline
\end{tabular}

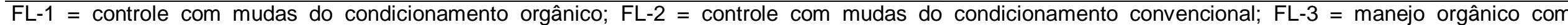

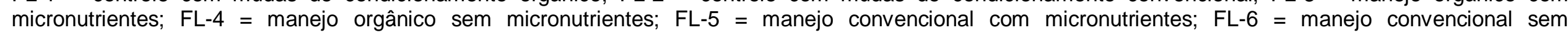

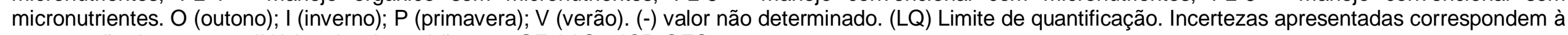
propagação de erro para INAA e desvio padrão para GF AAS e ICP-OES. $n=4$. 


\begin{tabular}{|c|c|c|c|c|c|c|c|c|c|}
\hline Amostras & Cs & $\mathrm{Cu}$ & Eu & $\mathrm{Fe}$ & $\mathrm{Hf}$ & $\mathrm{K}$ & La & Lu & $\mathrm{Mg}$ \\
\hline FLO-1 & $0,26 \pm 0,02$ & $14,7 \pm 0,9$ & $0,039 \pm 0,002$ & $4138 \pm 31$ & $1,15 \pm 0,01$ & $22405 \pm 1160$ & $1,94 \pm 0,03$ & $0,059 \pm 0,002$ & $4639 \pm 437$ \\
\hline FLO-2 & $<L Q$ & $12,18 \pm 0,07$ & $0,038 \pm 0,002$ & $3564 \pm 27$ & $1,17 \pm 0,01$ & $23634 \pm 1224$ & $1,72 \pm 0,03$ & $0,049 \pm 0,002$ & $6056 \pm 397$ \\
\hline FLO-3 & $<L Q$ & $14,7 \pm 0,1$ & $<L Q$ & $697 \pm 5$ & $0,22 \pm 0,006$ & $36013 \pm 826$ & $0,34 \pm 0,01$ & $<L Q$ & $4714 \pm 176$ \\
\hline FLO-4 & $<L Q$ & $15,9 \pm 0,1$ & - & $784 \pm 5$ & $0,260 \pm 0,007$ & $35026 \pm 881$ & $0,424 \pm 0,009$ & $<L Q$ & $5464 \pm 171$ \\
\hline FLO-5 & $<L Q$ & $14,2 \pm 0,2$ & $0,038 \pm 0,002$ & $1911 \pm 12$ & $0,549 \pm 0,008$ & $27858 \pm 780$ & $1,70 \pm 0,03$ & - & $4436 \pm 252$ \\
\hline FLO-6 & $<L Q$ & $11,5 \pm 0,1$ & $<\mathrm{LQ}$ & $2231 \pm 16$ & $0,76 \pm 0,01$ & $27248 \pm 761$ & $1,20 \pm 0,02$ & $0,034 \pm 0,001$ & $4475 \pm 223$ \\
\hline FLI-1 & $<L Q$ & $7,3 \pm 0,1$ & $0,14 \pm 0,04$ & $785 \pm 13$ & $0,72 \pm 0,07$ & $38385 \pm 2863$ & $0,39 \pm 0,02$ & - & $2303 \pm 241$ \\
\hline FLI-2 & $<L Q$ & $7,63 \pm 0,01$ & - & $1104 \pm 15$ & $0,79 \pm 0,07$ & $41139 \pm 3070$ & $0,54 \pm 0,03$ & $0,046 \pm 0,008$ & $1622 \pm 192$ \\
\hline FLI-3 & $<L Q$ & $12,6 \pm 0,1$ & $<L Q$ & $644 \pm 6$ & $0,275 \pm 0,007$ & $32195 \pm 1017$ & $0,21 \pm 0,02$ & - & $5707 \pm 198$ \\
\hline FLI-4 & $<L Q$ & $16,7 \pm \pm 0,1$ & $<L Q$ & $830 \pm 7$ & $<\mathrm{LIQ}$ & $32983 \pm 998$ & $0,23 \pm 0,008$ & - & $7512 \pm 270$ \\
\hline FLI-5 & $<L Q$ & $10,3 \pm 0,1$ & $<\mathrm{LQ}$ & $1022 \pm 7$ & $0,275 \pm 0,007$ & $33017 \pm 995$ & $0,37 \pm 0,01$ & $<L Q$ & $5241 \pm 138$ \\
\hline FLI-6 & $<L Q$ & $8,1 \pm 0,1$ & $<L Q$ & $1043 \pm 7$ & $0,193 \pm 0,006$ & $31686 \pm 944$ & $0,44 \pm 0,02$ & $<L Q$ & $4877 \pm 188$ \\
\hline FLP-1 & $<L Q$ & $10,4 \pm 0,2$ & $<L Q$ & $1439 \pm 15$ & $0,42 \pm 0,01$ & $27775 \pm 1633$ & $0,32 \pm 0,02$ & $<L Q$ & $5920 \pm 393$ \\
\hline FLP-2 & $<L Q$ & $11,5 \pm 0,2$ & - & $1654 \pm 18$ & $0,25 \pm 0,01$ & $24096 \pm 1469$ & $0,51 \pm 0,03$ & $<L Q$ & $4668 \pm 326$ \\
\hline FLP-3 & $<L Q$ & $12,3 \pm 0,1$ & - & $507 \pm 5$ & $0,185 \pm 0,008$ & $36236 \pm 1030$ & $<L Q$ & $<L Q$ & $5944 \pm 176$ \\
\hline FLP-4 & $<L Q$ & $12,30 \pm 0,07$ & $0,034 \pm 0,006$ & $485 \pm 5$ & $<\mathrm{LQ}$ & $36463 \pm 1082$ & $0,28 \pm 0,02$ & - & $5893 \pm 183$ \\
\hline FLP-5 & $<L Q$ & $10,43 \pm 0,05$ & $<L Q$ & $748 \pm 7$ & $<L Q$ & $27520 \pm 859$ & $0,36 \pm 0,01$ & $<L Q$ & $6362 \pm 193$ \\
\hline FLP-6 & $<L Q$ & $9,8 \pm 0,1$ & $<L Q$ & $955 \pm 6$ & $0,208 \pm 0,008$ & $27175 \pm 796$ & $0,49 \pm 0,02$ & - & $6657 \pm 253$ \\
\hline FLV-1 & $<L Q$ & $8,75 \pm 0,08$ & $<L Q$ & $789 \pm 7$ & $0,155 \pm 0,007$ & $20745 \pm 1219$ & $0,32 \pm 0,01$ & - & $7515 \pm 507$ \\
\hline FLV-2 & $<L Q$ & $10,4 \pm 0,2$ & $<\mathrm{LQ}$ & $875 \pm 8$ & $0,188 \pm 0,008$ & $22006 \pm 1265$ & $0,50 \pm 0,02$ & - & $3654 \pm 403$ \\
\hline FLV-3 & $<L Q$ & $10,2 \pm 0,2$ & $<\mathrm{LQ}$ & $1360 \pm 13$ & $<L Q$ & $24633 \pm 809$ & $<\mathrm{LQ}$ & - & $7680 \pm 255$ \\
\hline FLV-4 & $<L Q$ & $7,93 \pm 0,03$ & - & $624 \pm 5$ & $<\mathrm{LQ}$ & $27364 \pm 887$ & $0,40 \pm 0,01$ & - & $6471 \pm 192$ \\
\hline FLV-5 & $<L Q$ & $7,7 \pm 0,1$ & _ & $475 \pm 4$ & $<L Q$ & $20617 \pm 709$ & $<L Q$ & - & $6197 \pm 175$ \\
\hline FLV-6 & $<L Q$ & $8,90 \pm 0,05$ & $<L Q$ & $433 \pm 5$ & $<L Q$ & $26096 \pm 860$ & $<L Q$ & - & $6259 \pm 171$ \\
\hline
\end{tabular}

Continuação TAB. 4.12. 


\begin{tabular}{|c|c|c|c|c|c|c|c|c|c|c|c|c|c|}
\hline Amostras & Mn & $\mathrm{Na}$ & & $\mathrm{Ni}$ & & $\mathrm{b}$ & $\mathbf{R b}$ & & Sb & & Sc & & Sm \\
\hline FLO-1 & $41 \pm 1$ & $239 \pm 4$ & 3,9158 & $\pm 0,0005$ & 2,53 & $\pm 0,06$ & $17,2 \pm 0,5$ & & 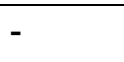 & 1,211 & $\pm 0,005$ & 0,204 & $\pm 0,008$ \\
\hline FLO-2 & $33 \pm 1$ & $245 \pm 4$ & 4,136 & $\pm 0,001$ & 3,73 & $\pm 0,05$ & $16,4 \pm 0,5$ & & - & 1,123 & $\pm 0,004$ & 0,162 & $\pm 0,007$ \\
\hline FLO-3 & $16,4 \pm 0,3$ & $120 \pm 3$ & 5,0434 & $\pm 0,0006$ & 2,37 & $\pm 0,06$ & $22,7 \pm 0,5$ & 0,14 & $\pm 0,03$ & 0,159 & $\pm 0,001$ & 0,045 & $\pm 0,002$ \\
\hline FLO-4 & $15,1 \pm 0,3$ & $170 \pm 3$ & 3,6091 & $\pm 0,0005$ & 7,47 & $\pm 0,07$ & $27,6 \pm 0,6$ & 0,19 & $\pm 0,02$ & 0,171 & $\pm 0,001$ & 0,046 & $\pm 0,003$ \\
\hline FLO-5 & $27,3 \pm 0,4$ & $266 \pm 4$ & 3,9061 & $\pm 0,0004$ & 1,86 & $\pm 0,04$ & $19,5 \pm 0,5$ & & - & 0,508 & $\pm 0,002$ & 0,230 & $\pm 0,006$ \\
\hline FLO-6 & $23,3 \pm 0,4$ & $137 \pm 2$ & 6,5844 & $\pm 0,0007$ & 5,52 & $\pm 0,03$ & $16,6 \pm 0,5$ & 0,25 & $\pm 0,03$ & 0,647 & $\pm 0,003$ & 0,134 & $\pm 0,003$ \\
\hline FLI-1 & $23,5 \pm 0,5$ & $45 \pm 1$ & & - & 5,80 & $\pm 0,07$ & $14,5 \pm 0,8$ & 0,13 & $\pm 0,03$ & 0,62 & $\pm 0,01$ & 0,037 & $\pm 0,003$ \\
\hline FLI-2 & $21,2 \pm 0,7$ & $44 \pm 1$ & & - & 1,642 & $\pm 0,004$ & $16,3 \pm 0,8$ & & & 0,232 & $\pm 0,004$ & 0,045 & $\pm 0,003$ \\
\hline FLI-3 & $14,6 \pm 0,3$ & $23 \pm 3$ & 34,976 & $\pm 0,001$ & 2,54 & $\pm 0,04$ & $19,1 \pm 0,5$ & 0,25 & $\pm 0,03$ & 0,063 & $\pm 0,001$ & & - \\
\hline FLI-4 & $12,4 \pm 0,3$ & $35 \pm 1$ & 35,136 & $\pm 0,002$ & 3,39 & $\pm 0,03$ & $25,2 \pm 0,7$ & 0,33 & $\pm 0,03$ & 0,056 & $\pm 0,001$ & 0,032 & $\pm 0,005$ \\
\hline FLI-5 & $23,8 \pm 0,4$ & $45 \pm 1$ & 50,631 & $\pm 0,001$ & 1,87 & $\pm 0,01$ & $16,2 \pm 0,5$ & & - & 0,107 & $\pm 0,001$ & 0,047 & $\pm 0,005$ \\
\hline FLI-6 & $20,0 \pm 0,4$ & $18 \pm 5$ & 38,699 & $\pm 0,001$ & 2,01 & $\pm 0,06$ & $18,5 \pm 0,5$ & & - & 0,146 & $\pm 0,001$ & 0,059 & $\pm 0,006$ \\
\hline FLP-1 & $21,4 \pm 0,6$ & $28 \pm 7$ & 28,723 & $\pm 0,003$ & 1,4 & $\pm 0,1$ & $13,5 \pm 0,8$ & & - & 0,322 & $\pm 0,002$ & & - \\
\hline FLP-2 & $22,6 \pm 0,7$ & $55 \pm 13$ & & - & 2,448 & $\pm 0,004$ & $10,4 \pm 0,5$ & & - & 0,244 & $\pm 0,002$ & & - \\
\hline FLP-3 & $15,1 \pm 0,3$ & $41 \pm 1$ & 22,056 & $\pm 0,001$ & 4,36 & $\pm 0,02$ & $23,8 \pm 0,7$ & & - & 0,057 & $\pm 0,001$ & 0,026 & $\pm 0,002$ \\
\hline FLP-4 & $13,5 \pm 0,3$ & $35 \pm 7$ & 22,265 & $\pm 0,001$ & 1,69 & $\pm 0,04$ & $22,2 \pm 0,7$ & 0,25 & $\pm 0,02$ & 0,060 & $\pm 0,001$ & 0,038 & $\pm 0,004$ \\
\hline FLP-5 & $22,7 \pm 0,4$ & $45 \pm 4$ & 23,858 & $\pm 0,001$ & 2,00 & $\pm 0,01$ & $21,1 \pm 0,7$ & & - & 0,106 & $\pm 0,001$ & 0,044 & $\pm 0,002$ \\
\hline FLP-6 & $19,1 \pm 0,4$ & $32 \pm 5$ & 23,787 & $\pm 0,001$ & 3,20 & $\pm 0,07$ & $17,4 \pm 0,4$ & 0,25 & $\pm 0,02$ & 0,129 & $\pm 0,001$ & 0,070 & $\pm 0,009$ \\
\hline FLV-1 & $12,0 \pm 0,7$ & - & 15,847 & $\pm 0,002$ & 2,15 & $\pm 0,02$ & $12,9 \pm 0,4$ & 0,14 & $\pm 0,02$ & 0,163 & $\pm 0,001$ & 0,04 & $\pm 0,01$ \\
\hline FLV-2 & $8,2 \pm 0,7$ & - & 10,864 & $\pm 0,002$ & 2,068 & $\pm 0,002$ & $14,1 \pm 0,4$ & 0,14 & $\pm 0,02$ & 0,195 & $\pm 0,001$ & & - \\
\hline FLV-3 & $18,1 \pm 0,5$ & $31 \pm 3$ & 29,421 & $\pm 0,002$ & 4,60 & $\pm 0,02$ & $22,1 \pm 0,8$ & 0,47 & $\pm 0,10$ & 0,034 & $\pm 0,001$ & & - \\
\hline FLV-4 & $14,0 \pm 0,4$ & $34 \pm 1$ & 45,058 & $\pm 0,002$ & 2,77 & $\pm 0,02$ & $17,9 \pm 0,4$ & 0,12 & $\pm 0,01$ & 0,036 & $\pm 0,001$ & 0,027 & $\pm 0,002$ \\
\hline FLV-5 & $13,8 \pm 0,3$ & $21 \pm 1$ & 27,133 & $\pm 0,001$ & 5,32 & $\pm 0,03$ & $21,2 \pm 0,5$ & 0,26 & $\pm 0,05$ & 0,051 & $\pm 0,001$ & 0,033 & $\pm 0,003$ \\
\hline FLV-6 & $12,7 \pm 0,3$ & $39 \pm 2$ & 21,339 & $\pm 0,001$ & 3,18 & $\pm 0,01$ & $16,6 \pm 0,5$ & 0,17 & $\pm 0,02$ & 0,059 & $\pm 0,001$ & 0,035 & $\pm 0,003$ \\
\hline
\end{tabular}

Continuação TAB. 4.12. 


\begin{tabular}{|c|c|c|c|c|c|c|c|c|}
\hline Amostras & $\mathrm{Ta}$ & Th & $\mathbf{T i}$ & $\mathbf{U}$ & $\mathbf{V}$ & $\mathrm{Yb}$ & Zn & $\mathrm{Zr}$ \\
\hline FLO-1 & $0,135 \pm 0,007$ & $1,95 \pm 0,07$ & $341 \pm 68$ & $<L Q$ & $2,9 \pm 0,7$ & $0,32 \pm 0,02$ & $58 \pm 1$ & $<L Q$ \\
\hline FLO-2 & $<\mathrm{LQ}$ & $1,76 \pm 0,07$ & $494 \pm 80$ & $<\mathrm{LQ}$ & $3,9 \pm 0,7$ & $0,22 \pm 0,01$ & $48 \pm 2$ & $<\mathrm{LQ}$ \\
\hline FLO-3 & $<L Q$ & $0,30 \pm 0,01$ & $76 \pm 20$ & - & $0,7 \pm 0,2$ & - & $31 \pm 1$ & - \\
\hline FLO-4 & $<L Q$ & $0,28 \pm 0,01$ & $87 \pm 22$ & - & $1,2 \pm 0,2$ & $<\mathrm{LQ}$ & $40 \pm 1$ & - \\
\hline FLO-5 & $>L Q$ & $0,89 \pm 0,03$ & $279 \pm 19$ & - & $4,1 \pm 0,2$ & $<L Q$ & $34 \pm 1$ & $<L Q$ \\
\hline FLO-6 & $>L Q$ & $1,07 \pm 0,03$ & $274 \pm 22$ & $<\mathrm{LQ}$ & $5,2 \pm 0,3$ & $<L Q$ & 4213 & - \\
\hline FLI-1 & - & $0,80 \pm 0,05$ & - & - & $1,0 \pm 0,3$ & - & $57 \pm 2$ & - \\
\hline FLI-2 & - & $1,03 \pm 0,05$ & $68 \pm 29$ & - & $1,8 \pm 0,4$ & - & $61 \pm 2$ & - \\
\hline FLI-3 & - & $<\mathrm{LQ}$ & - & - & - & - & $64 \pm 2$ & $<L Q$ \\
\hline FLI-4 & - & $<L Q$ & - & - & $0,6 \pm 0,2$ & - & $78 \pm 2$ & - \\
\hline FLI-5 & - & $0,19 \pm 0,01$ & - & - & $1,1 \pm 0,2$ & - & $34 \pm 1$ & - \\
\hline FLI-6 & - & $0,25 \pm 0,01$ & $118 \pm 31$ & $<L Q$ & $1,4 \pm 0,2$ & $<L Q$ & $38 \pm 1$ & - \\
\hline FLP-1 & - & $0,48 \pm 0,02$ & $160 \pm 28$ & - & $3,2 \pm 0,5$ & $<L Q$ & $61 \pm 2$ & $<L Q$ \\
\hline FLP-2 & - & $0,39 \pm 0,02$ & $107 \pm 28$ & - & $2,2 \pm 0,4$ & $<L Q$ & $56 \pm 2$ & $<L Q$ \\
\hline FLP-3 & - & $<L Q$ & $71 \pm 18$ & - & $0,42 \pm 0,08$ & $<L Q$ & $73 \pm 1$ & - \\
\hline FLP-4 & - & $0,17 \pm 0,01$ & - & - & - & - & $67 \pm 2$ & - \\
\hline FLP-5 & - & $0,17 \pm 0,01$ & $82 \pm 24$ & - & $1,0 \pm 0,1$ & $0,24 \pm 0,03$ & $59 \pm 1$ & $<L Q$ \\
\hline FLP-6 & - & $0,22 \pm 0,01$ & - & - & $1,3 \pm 0,2$ & - & $46 \pm 1$ & - \\
\hline FLV-1 & - & $0,23 \pm 0,01$ & $136 \pm 41$ & - & $1,2 \pm 0,3$ & - & $47 \pm 1$ & - \\
\hline FLV-2 & - & $0,28 \pm 0,01$ & - & - & - & - & $89 \pm 3$ & - \\
\hline FLV-3 & - & $<L Q$ & - & - & $1,0 \pm 0,1$ & - & $53 \pm 1$ & - \\
\hline FLV-4 & - & $<L Q$ & - & - & $0,8 \pm 0,2$ & - & $62 \pm 1$ & - \\
\hline FLV-5 & - & $<L Q$ & - & - & $0,4 \pm 0,1$ & - & $41 \pm 1$ & $<L Q$ \\
\hline FLV-6 & - & $<L Q$ & - & - & $0,9 \pm 0,2$ & - & $61 \pm 1$ & - \\
\hline
\end{tabular}

Continuação TAB. 4.12. 
A análise dos nutrientes nas folhas apresentou poucas variações em função do manejo, sendo o bário, bromo, ferro, rubídio, escândio e tório os responsáveis pela maior diferença entre os solos de cultivo (TAB. 4.11).

Entre os elementos determinados nas folhas de Melissa officinalis, os menores coeficientes de variação foram observados para $\mathrm{Ba}, \mathrm{Ca}, \mathrm{Cd}, \mathrm{Cu}, \mathrm{K}, \mathrm{Mg}$, $\mathrm{Mn}, \mathrm{Rb}, \mathrm{Sb}$ e $\mathrm{Zn}$ (faixa de $20 \%$ a $50 \%$ ) e os maiores coeficientes de variação foram observados $\mathrm{Co}, \mathrm{Cr}, \mathrm{Na}$, Sc eTh (faixa de 102 \% a 114 \%). Esta variação observada pode estar relacionada, além do manejo agrícola e época do ano, com a capacidade de acumulação desses elementos pela espécie estudada (KabataPendias e Mukherjee, 2007).

\subsubsection{Análise dos teores dos óleos voláteis de Melissa officinalis}

Na TAB. 4.13 são apresentados os valores médios, desvio padrão (DP) e o teste de Tukey obtidos para os teores dos óleos voláteis (OV) extraídos das folhas de Melissa officinalis considerando os sistemas de cultivo: controle com mudas do condicionamento orgânico (OV-1), controle com mudas do condicionamento convencional (OV-2), orgânico com micronutrientes (OV-3), orgânico sem micronutrientes (OV-4), convencional com micronutrientes (OV-5) e convencional sem micronutrientes (OV-6); e as épocas de colheita. E para melhor visualização, os resultados são apresentados na FIG. 4.7 na forma gráfica. Devido a produção de biomassa insuficiente para os sistemas controles (OV-1 e OV-2), não foi possível extrair os óleos em replicatas para essas amostras.

TABELA 4.13 - Resultados dos teores dos óleos voláteis de Melissa officinalis sobre interação do manejo agrícola e época de colheita, em porcentagem.

\begin{tabular}{|c|c|c|c|c|}
\hline \multirow[t]{2}{*}{ Amostras } & Outono & Inverno & Primavera & Verão \\
\hline & média $^{n} \pm \mathrm{DP}$ & média $\pm \mathrm{DP}$ & média $\pm \mathrm{DP}$ & média $\pm \mathrm{DP}$ \\
\hline OV-1 & $0,01^{\mathrm{a}} \mathrm{AB}$ & $0,001^{\mathrm{a} B}$ & $0,03^{\underline{a} A B}$ & $0,05^{\underline{a} A}$ \\
\hline OV-2 & $0,03^{\mathrm{a} A B}$ & 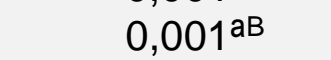 & $0,03^{a} A B$ & $0,06^{\underline{a} A}$ \\
\hline OV-3 & $0,02^{\mathrm{a} A B} \pm 0,01$ & $0,002^{\underline{a} \mathrm{~B}} \pm 0,001$ & $0,01^{a A B} \pm 0,01$ & $0,03^{\mathrm{a} A} \pm 0,03$ \\
\hline OV-4 & $0,01^{a} A B=0,02$ & $0,002^{\mathrm{a} B} \pm 0,001$ & $0,02^{a A B} \pm 0,02$ & $0,04^{\underline{a} A} \pm 0,04$ \\
\hline OV-5 & $0,02^{\underline{a} A B} \pm 0,02$ & $0,008^{\mathrm{a} B} \pm 0,01$ & $0,02^{a A B} \pm 0,02$ & $0,03^{\mathrm{a} A} \pm 0,04$ \\
\hline OV-6 & $0,02^{\underline{a} A B} \pm 0,01$ & $0,006^{\mathrm{aB}} \pm 0,01$ & $0,02^{a A B} \pm 0,02$ & $0,05^{\mathrm{a} A} \pm 0,05$ \\
\hline Média total & 0,02 & 0,004 & 0,02 & 0,04 \\
\hline
\end{tabular}




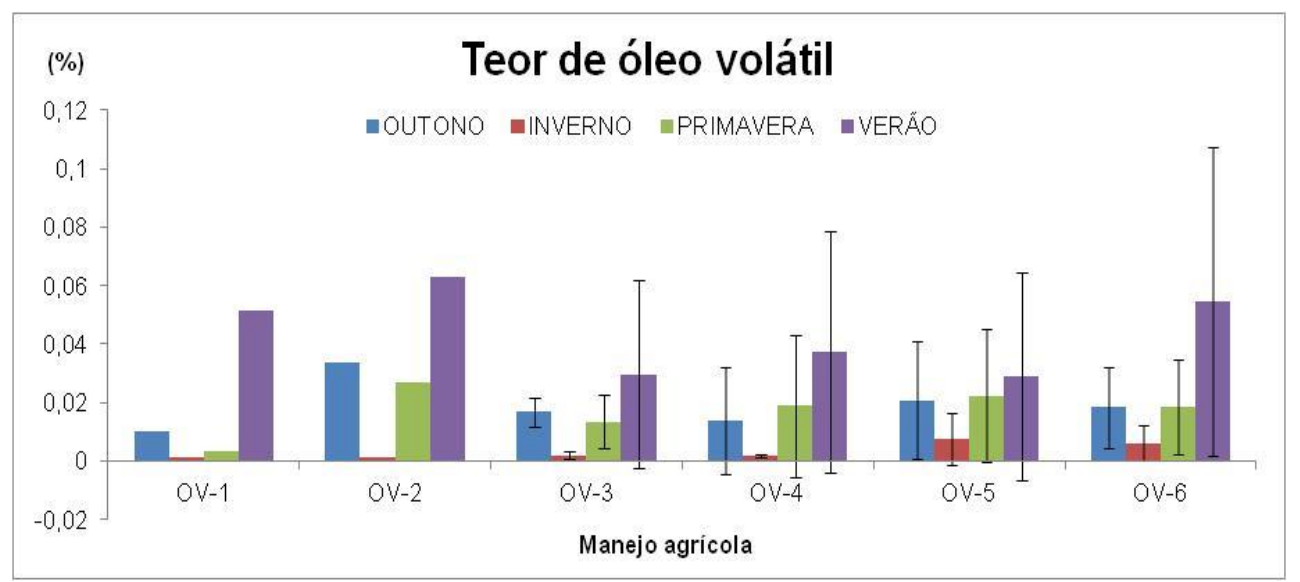

FIGURA 4.7 - Teores dos óleos voláteis extraídos das folhas de Melissa officinalis considerando o manejo agrícola e época de colheita.

Os resultados analíticos foram avaliados pela análise de variância, com o objetivo de se analisar a relevância das análises químicas realizadas na discriminação entre os tipos de manejo aplicados e a sazonalidade. Por meio dessa, é possível verificar que a sazonalidade influencia de forma significativa $(p<0,05)$ na variação do teor do óleo volátil de Melissa officinalis (TAB. 4.14).

TABELA 4.14 - Análise de variância, tendo como efeitos o manejo e a sazonalidade, aplicada ao teor de óleo volátil.

\begin{tabular}{lccccc}
\hline \multicolumn{7}{c}{ Tabela da ANOVA } \\
\hline & G.L. & $\begin{array}{c}\text { Soma de } \\
\text { Quadrados }\end{array}$ & $\begin{array}{c}\text { Quadrado } \\
\text { Médio }\end{array}$ & Estat. F & P-valor \\
\hline Sazonalidade & 3 & 0,005 & 0,002 & 20,5 & 0,0001 \\
Manejo & 2 & 0,0002 & 0,0001 & 1,3 & 0,3 \\
Sazonalidade:Manejo & 6 & 0,0005 & 0,00008 & 0,9 & 0,5 \\
Resíduos & 12 & 0,001 & 0,00008 & & \\
\hline
\end{tabular}

G.L. Grau de liberdade.

Os teores dos óleos voláteis de Melissa officinalis foram diferentes entre as épocas do inverno e do verão $(p<0,05)$. No inverno as amostras de melissa apresentaram os menores teores $(0,003 \%)$ e no verão os maiores teores $(0,04 \%)$. Resultados semelhantes foram apresentados por Silva (2011), que obteve rendimento insuficiente para a época do inverno.

O manejo agrícola não influenciou nos teores dos óleos voláteis extraídos. Resultados semelhantes foram apresentados por Sodré (2007), no qual, o teor de óleo volátil não apresentou diferença significativa entre os sistemas adubados e os controles. Em relação à adubação, algumas espécies da família Lamiaceae 
apresentam variação nos teores dos óleos voláteis, como o manjericão, já outras espécies são indiferentes à adubação, como o tomilho. Esta divergência nas observações reflete a diversidade de fatores que influenciam o metabolismo vegetal, que é resultado da interação de fatores genéticos, bióticos e abióticos, podendo ainda um fator prevalecer sobre o outro (Duarte, 2012).

\subsubsection{Análise dos óleos voláteis de Melissa officinalis por GC/MS}

Para identificação dos constituintes citronelal, neral e geranial, extraídos das folhas de Melissa officinalis por cromatográfica gasosa e espectrometria de massas (GC/MS), primeiramente, foram injetados padrões comerciais do citronelal e do citral (neral e geranial) no equipamento e foram obtidos os cromatogramas, nos quais são perfeitamente identificáveis os picos relativos aos três compostos em análise. Na FIG. 4.8 é apresentado o cromatograma do padrão de citronelal, em que se verifica o pico, cujo tempo de retenção é de 12,62 minutos com $95 \%$ de área percentual.

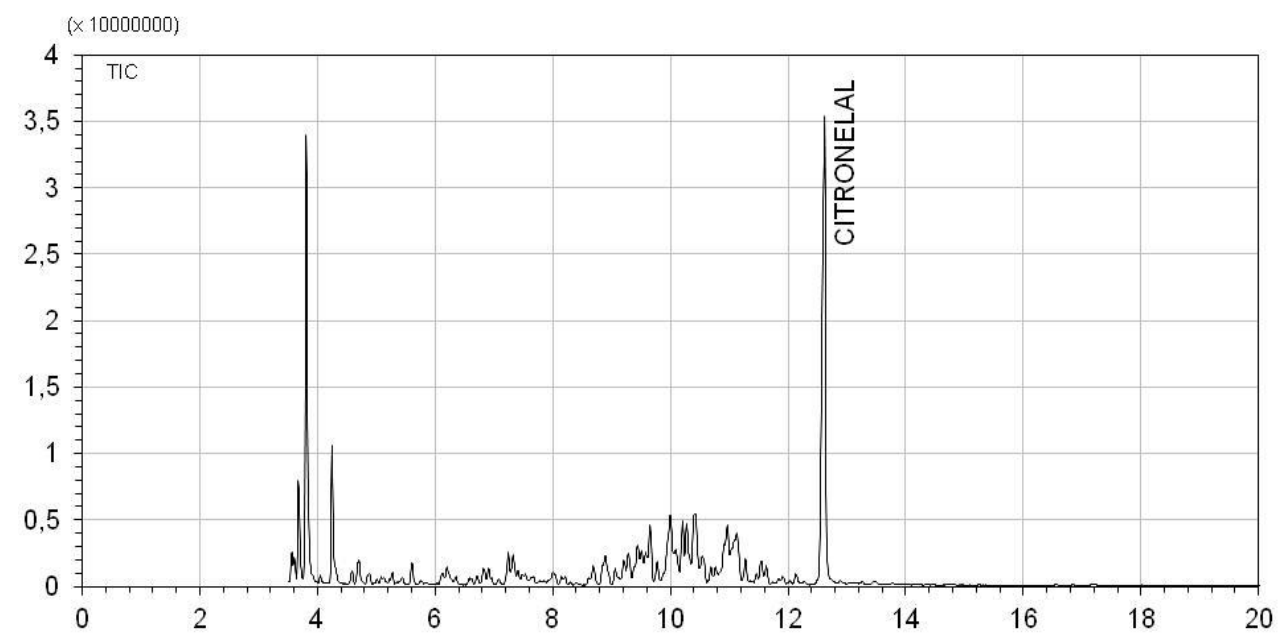

FIGURA 4.8 - Cromatograma do padrão de citronelal em hexano em função do tempo de retenção nas análises de GC/MS.

O cromatograma do padrão de citral é apresentado na FIG. 4.9, na qual se verifica um pico com tempo de retenção de 16,49 minutos com 41,77 \% de área percentual, correspondente ao 3, 7 dimetil, 2,6 octadienal (Z), ou beta citral ou neral; e outro pico com tempo de retenção de 17,82 minutos com 58,23 \% de área percentual, correspondente ao 3,7 dimetil, 2,6 octadienal (E), ou alfa citral ou geranial. 


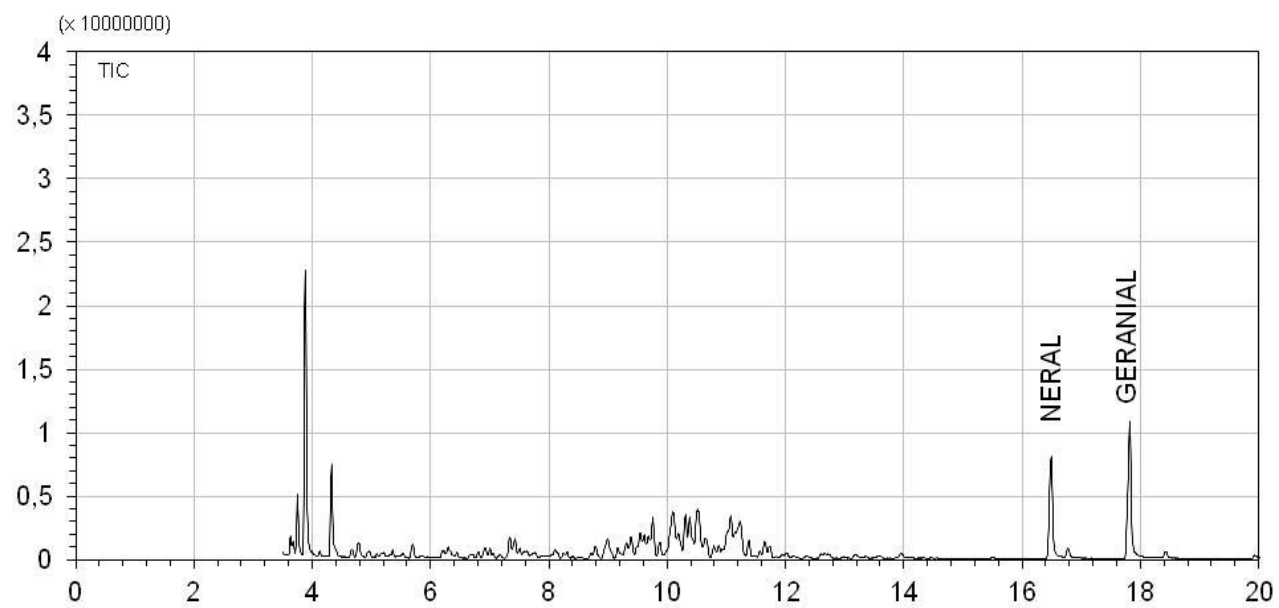

FIGURA 4.9 - Cromatograma do padrão de citral em hexano em função dos tempos de retenção de neral e geranial, respectivamente, nas análises de GC/MS.

Através da sobreposição do cromatograma do branco do solvente (hexano - linha vermelha) com os cromatogramas dos padrões, observa-se a presença de sinais referentes a elementos da coluna do aparelho que não interferem nos tempos de retenção dos padrões analisados (FIG. 4.10). Deste modo, é possível concluir que esta metodologia é adequada para detecção de citronelal, neral e geranial nas folhas de Melissa officinalis.

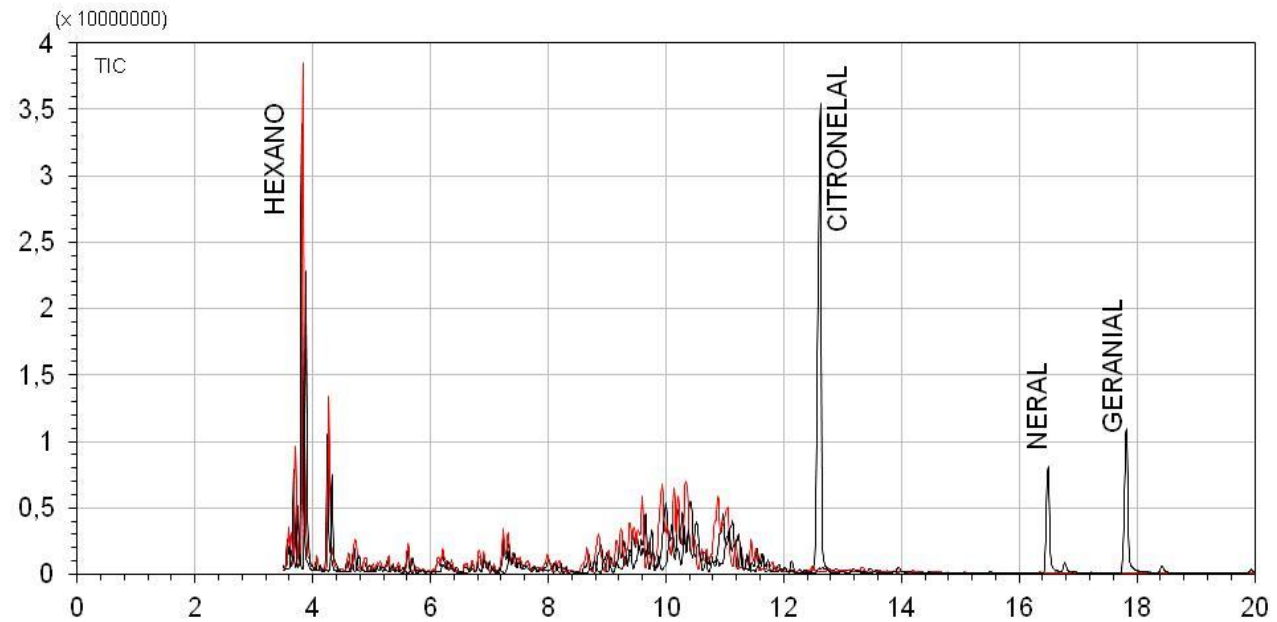

FIGURA 4.10 - Sobreposição do cromatograma do ensaio em branco com os cromatogramas dos padrões comerciais na análise de citronelal, neral e geranial.

Na FIG. 4.11 estão apresentados os cromatogramas dos óleos voláteis de Melissa officinalis. 

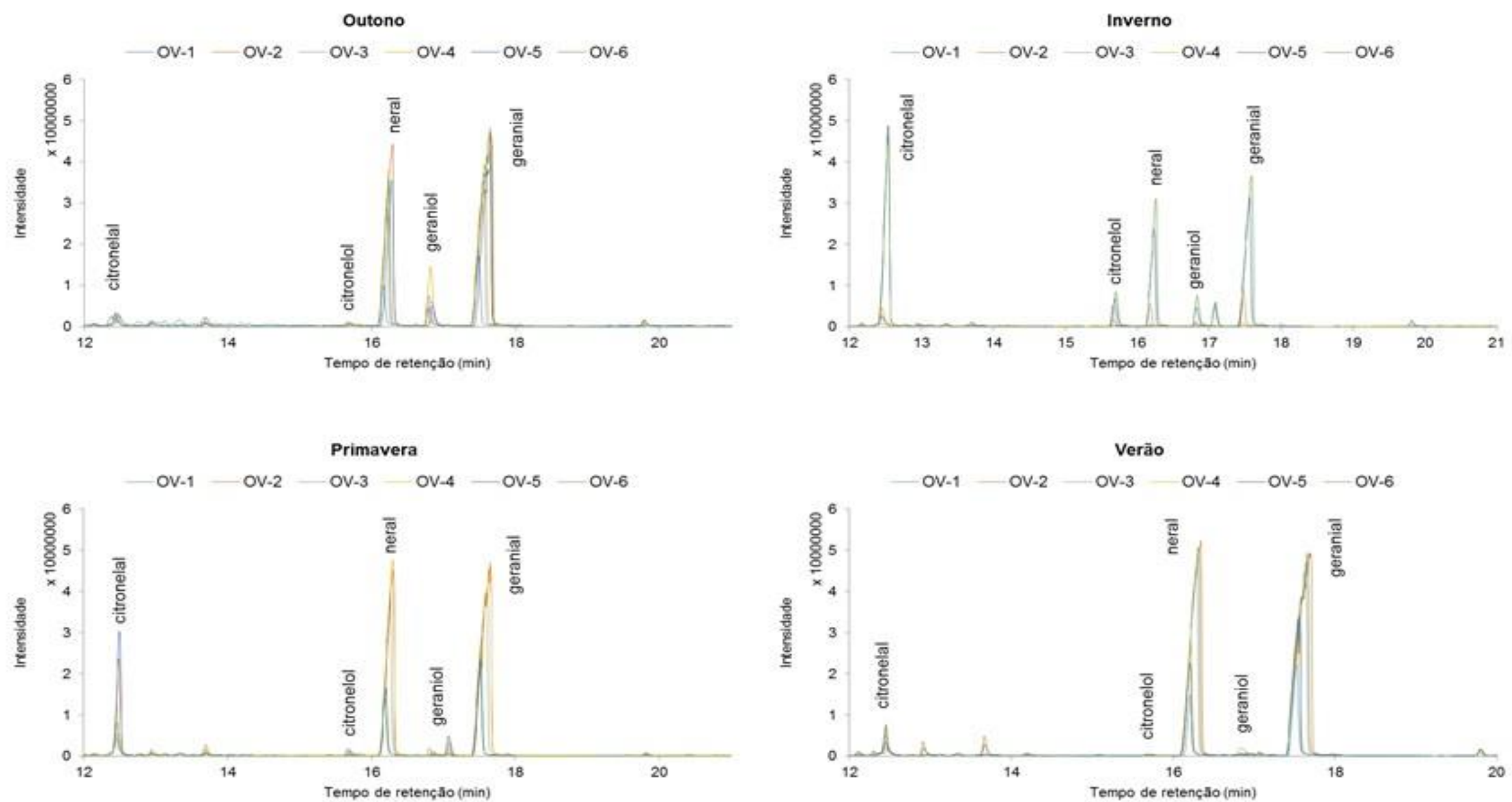

FIGURA 4.11 - Cromatograma dos óleos voláteis de Melissa officinalis extraídos nos diferentes manejos aplicados e nas quatro épocas de colheita. 
$\mathrm{Na}$ TAB. 4.15 estão apresentados os resultados da análise descritiva dos óleos voláteis de Melissa officinalis, obtidos pelas técnicas analíticas GC/MS, determinados nos diferentes sistemas de cultivo e nas diferentes épocas de colheita (sazonalidade) e o teste de Tukey para a comparação das médias. Os dados completos estão apresentados na TAB. 4.16, juntamente com os valores dos índices de retenção linear (Índice de Kovats) e nas FIG. 4.12, 4.13, 4.14 e 4.15 são apresentados os resultados na forma de gráfico.

TABELA 4.15 - Análises descritivas dos óleos voláteis de Melissa officinalis considerando os sistemas de cultivo aplicados e sazonalidade, em porcentagem.

\begin{tabular}{|c|c|c|c|c|c|c|}
\hline \multirow{2}{*}{ Cultivo } & \multicolumn{2}{|c|}{ Citronelal } & \multicolumn{2}{|c|}{ Neral } & \multicolumn{2}{|c|}{ Geranial } \\
\hline & média & $\mathrm{CV}(\%)$ & média & $\mathrm{CV}(\%)$ & média & $\mathrm{CV}(\%)$ \\
\hline Controle & $20^{a}$ & 167 & $33^{a}$ & 20 & $54^{a}$ & 11 \\
\hline Orgânico & $7^{b}$ & 121 & $31^{\mathrm{a}}$ & 42 & $47^{\mathrm{a}}$ & 39 \\
\hline Convencional & $13^{a}$ & 114 & $31^{\mathrm{a}}$ & 23 & $53^{\underline{a}}$ & 20 \\
\hline \multirow{2}{*}{ Sazonalidade } & \multicolumn{2}{|c|}{ Citronelal } & \multicolumn{2}{|c|}{ Neral } & \multicolumn{2}{|c|}{ Geranial } \\
\hline & média & $\mathrm{CV}(\%)$ & média & $\mathrm{CV}(\%)$ & média & $\mathrm{CV}(\%)$ \\
\hline Outono & $1,8^{b}$ & 23 & $34^{\underline{a}}$ & 11 & $58^{a}$ & 7 \\
\hline Inverno & $36^{\mathrm{a}}$ & 86 & $18^{b}$ & 43 & $32^{b}$ & 42 \\
\hline Primavera & $9^{b}$ & 40 & $35^{\underline{a}}$ & 15 & $54^{\mathrm{a}}$ & 5 \\
\hline Verão & $2^{b}$ & 46 & $38^{\underline{a}}$ & 8 & $599^{a}$ & 5 \\
\hline Média total & \multicolumn{2}{|c|}{13} & \multicolumn{2}{|c|}{32} & \multicolumn{2}{|c|}{51} \\
\hline
\end{tabular}

\begin{tabular}{lcccccc}
\hline \multirow{2}{*}{ Cultivo } & \multicolumn{2}{c}{ Citronelol } & \multicolumn{2}{c}{ Nerol } & \multicolumn{2}{c}{ Geraniol } \\
\cline { 2 - 7 } & média & $\mathrm{CV}(\%)$ & média & $\mathrm{CV}(\%)$ & média & $\mathrm{CV}(\%)$ \\
\hline Controle & $4,0^{\mathrm{b}}$ & 86 & $1,8^{\mathrm{a}}$ & 34 & $4,4^{\mathrm{a}}$ & 93 \\
Orgânico & $13,0^{\mathrm{a}}$ & 184 & $2,1^{\mathrm{a}}$ & 150 & $3,7^{\mathrm{a}}$ & 116 \\
Convencional & $4,0^{\mathrm{b}}$ & 118 & - & & $2,6^{\underline{a}}$ & 89
\end{tabular}

\begin{tabular}{lcccccc}
\hline \multirow{2}{*}{ Sazonalidade } & \multicolumn{2}{c}{ Citronelol } & \multicolumn{2}{c}{ Nerol } & \multicolumn{2}{c}{ Geraniol } \\
\cline { 2 - 7 } & média & $\mathrm{CV}(\%)$ & média & $\mathrm{CV}(\%)$ & média & $\mathrm{CV}(\%)$ \\
\hline Outono & $1,7^{\mathrm{b}}$ & 107 & $0,8^{\mathrm{a}}$ & 74 & $5,6^{\mathrm{a}}$ & 63 \\
Inverno & $23^{\mathrm{a}}$ & 100 & $5,4^{\mathrm{a}}$ & 71 & $7,1^{\mathrm{a}}$ & 41 \\
Primavera & $1,1^{\mathrm{b}}$ & 100 & $1,6^{\mathrm{a}}$ & 8 & $0,9^{\mathrm{b}}$ & 133 \\
Verão & $0,3^{\mathrm{b}}$ & 58 & $0,1^{\mathrm{a}}$ & 28 & $1,2^{\mathrm{b}}$ & 24 \\
\hline Média total & & $\mathbf{7}$ & \multicolumn{2}{c}{$\mathbf{2}$} & & $\mathbf{3}$
\end{tabular}

Médias seguidas por letras distintas diferem entre si pelo teste de Tukey, a 0,05 de significância $n=4$. $\mathrm{CV}=$ coeficiente de variação, em porcentagem. 
TABELA 4.16 - Porcentagem dos óleos voláteis de Melissa officinalis (média „DP) considerando o manejo agrícola e época de colheita.

\begin{tabular}{|c|c|c|c|c|c|c|c|c|c|c|c|c|c|c|}
\hline \multirow[t]{2}{*}{ Amostra } & \multicolumn{2}{|c|}{ Citronelal } & \multirow[t]{2}{*}{$\mathbf{n}$} & Neral & $\mathbf{n}$ & Geranial & $\mathbf{n}$ & \multicolumn{2}{|c|}{ Citronelol } & \multirow[t]{2}{*}{$\mathbf{n}$} & Nerol & \multirow[t]{2}{*}{$\mathbf{n}$} & \multirow{2}{*}{$\frac{\text { Geraniol }}{\text { média } \pm \mathrm{DP}}$} & \multirow[t]{2}{*}{$\mathbf{n}$} \\
\hline & Média & $\pm \mathrm{DP}^{\mathrm{a}}$ & & média $\pm \mathrm{DP}$ & & média $\pm \mathrm{DP}$ & & média & $\pm \mathrm{DP}$ & & édia $\pm \mathrm{DP}$ & & & \\
\hline OVO-1 & - & & & $28,8 \pm 0,1$ & 2 & $58 \pm 1$ & 2 & 1,4 & $\pm 0,2$ & 2 & - & & $12 \pm 1$ & 2 \\
\hline OVO-2 & 1,6 & $\pm 0,1$ & 2 & $36,56 \pm 0,03$ & 2 & $57,2 \pm 0,1$ & 2 & 0,51 & $\pm 0,02$ & 2 & - & & $4,16 \pm 0,06$ & 2 \\
\hline OVO-3 & 1 & \pm 1 & 4 & $38 \pm 3$ & 4 & $57 \pm 3$ & 4 & 0,5 & $\pm 0,6$ & 2 & $0,4 \pm 0,2$ & 2 & $3 \pm 3$ & 4 \\
\hline OVO-4 & 2 & \pm 2 & 3 & $36 \pm 6$ & 3 & $52 \pm 3$ & 3 & 0,6 & $\pm 0,2$ & 2 & $1 \pm 1$ & 3 & $8 \pm 3$ & 3 \\
\hline OVO-5 & 2,1 & $\pm 0,1$ & 3 & $34 \pm 3$ & 2 & $58 \pm 1$ & 2 & 5 & \pm 7 & 2 & - & & $3,6 \pm 0,1$ & 2 \\
\hline OVO-6 & 1,5 & $\pm 0,4$ & 3 & $30 \pm 3$ & 4 & $66 \pm 3$ & 4 & 2 & \pm 2 & 3 & - & & $3 \pm 3$ & 3 \\
\hline OVI-1 & 9 & & 1 & - & & - & & 6 & & 1 & - & & - & \\
\hline OVI-2 & 1 & & 1 & 26 & 1 & 43 & 1 & 7 & & 1 & 2,2 & 1 & 6 & 1 \\
\hline OVI-3 & 25 & \pm 9 & 2 & $8 \pm 6$ & 2 & $12 \pm 10$ & 2 & 59 & \pm 28 & 3 & - & & $11 \pm 5$ & 3 \\
\hline OVI-4 & 10 & \pm 6 & 2 & $14 \pm 8$ & 2 & $29 \pm 14$ & 2 & 43 & \pm 34 & 2 & 8,5 & 1 & - & \\
\hline OVI-5 & 33 & \pm 23 & 3 & $18 \pm 4$ & 3 & $33 \pm 11$ & 3 & 9 & \pm 4 & 3 & - & & $7 \pm 5$ & 3 \\
\hline OVI-6 & 36 & \pm 31 & 4 & $22 \pm 6$ & 3 & $42 \pm 13$ & 3 & 13 & \pm 9 & 4 & - & & $5 \pm 4$ & 3 \\
\hline OVP-1 & 9,31 & $\pm 0,03$ & 2 & $26,3 \pm 0,3$ & 2 & $56,3 \pm 0,3$ & 2 & 3,34 & $\pm 0,01$ & 2 & 1,4 & 1 & $3,3 \pm 0,3$ & 2 \\
\hline OVP-2 & 10,94 & $\pm 0,04$ & 2 & $37 \pm 0,2$ & 2 & $50,9 \pm 0,2$ & 2 & 0,73 & $\pm 0,02$ & 2 & - & & $0,454 \pm 0,002$ & 2 \\
\hline OVP-3 & 7 & \pm 5 & 4 & $40 \pm 3$ & 4 & $52 \pm 4$ & 4 & 0,3 & $\pm 0,1$ & 3 & - & & $0,4 \pm 0,2$ & 4 \\
\hline OVP-4 & 4 & \pm 1 & 4 & $39 \pm 5$ & 4 & $57 \pm 5$ & 4 & 0,32 & $\pm 0,01$ & 2 & - & & $0,6 \pm 0,2$ & 3 \\
\hline OVP-5 & 15 & \pm 16 & 4 & $32 \pm 7$ & 4 & $52 \pm 11$ & 4 & 1,3 & $\pm 0,8$ & 4 & - & & 0,2 & 1 \\
\hline OVP-6 & 9 & \pm 5 & 4 & $34 \pm 3$ & 4 & $57 \pm 4$ & 4 & 0,9 & $\pm 0,4$ & 3 & - & & $0,3 \pm 0,1$ & 3 \\
\hline OVV-1 & 4,5 & $\pm 0,1$ & 2 & $35,2 \pm 0,1$ & 2 & $60,261 \pm 0,002$ & 2 & - & & & - & & - & \\
\hline OVV-2 & 1,9 & $\pm 0,1$ & 2 & $43,7 \pm 0,2$ & 2 & $53,2 \pm 0,1$ & 2 & - & & & - & & $1,13 \pm 0,02$ & 2 \\
\hline OVV-3 & 2 & \pm 2 & 4 & $38 \pm 8$ & 4 & $58 \pm 7$ & 4 & 0,385 & $\pm 0,004$ & 2 & 0,2 & 1 & $2 \pm 2$ & 2 \\
\hline OVV-4 & 1 & \pm 1 & 4 & $37 \pm 7$ & 4 & $61 \pm 7$ & 4 & 0,23 & $\pm 0,05$ & 2 & 0,1 & 1 & $1,1 \pm 0,7$ & 2 \\
\hline OVV-5 & 2 & \pm 1 & 4 & $36 \pm 6$ & 4 & $60 \pm 4$ & 4 & 0,6 & $\pm 0,2$ & 2 & - & & $1,5 \pm 1,4$ & 3 \\
\hline OVV-6 & 2 & \pm 1 & 4 & $39 \pm 4$ & 4 & $59 \pm 5$ & 4 & 0,13 & $\pm 0,01$ & 2 & - & & $0,8 \pm 0,1$ & 4 \\
\hline Kl lit. & 11 & & & 1240 & & 1270 & & 12 & & & 1228 & & 1255 & \\
\hline $\mathbf{K} \mathbf{I}^{\mathbf{b}}$ & 11 & & & 1250 & & 1282 & & 12 & & & 1229 & & 1260 & \\
\hline
\end{tabular}

$\mathrm{n}=$ replicatas. $\mathrm{DP}^{\mathrm{a}}$ - Desvio Padrão. Kl ${ }^{\text {lit. }}$ - Indice de Kovats na literatura (Adams, 2007). KI ${ }^{\mathrm{a}}$ - Indice de Kovats calculado. 
Os compostos dos óleos voláteis de interesse neste estudo foram selecionados baseando-se na exigência do mercado consumidor. Para melissa, o óleo volátil mais valorizado deve apresentar em sua composição química o citral (neral e geranial) e citronelal como majoritários, e preferencialmente, a ausência de alcoóis terpênicos, tais com citronelol, nerol e geraniol (Blank et al, 2005).

Em relação ao manejo agrícola, os sistemas orgânico e convencional não influenciaram de forma significativa os teores dos constituintes majoritários, neral e geranial. Assim como, os sistemas adubados não diferenciaram do controle. $\mathrm{O}$ constituinte citronelal apresentou a maior porcentagem média relativa no sistema convencional (13\%). Os constituintes citronelol, nerol e geraniol apresentaram maiores porcentagens médias relativas no sistema orgânico (13,1\%, 2,1 \% e 3,7 $\%$, respectivamente) (TAB. 4.15).

As colheitas no outono, primavera e verão proporcionaram ganho nos teores dos constituintes majoritários, neral (média de 34, 35 e $38 \%$, respectivamente) e o geranial (58, 54 e $59 \%$, respectivamente), fator importante ao se considerar um óleo comercial. Em contrapartida, na colheita do inverno diminuiu o teor dos constituintes majoritários, neral (média de $18 \%$ ) e geranial (média de $32 \%$ ) e houve o aumento da porcentagem relativa dos outros constituintes, como o citronelal (média de $36 \%$ ), citronelol (média de $23 \%$ ), nerol (média de 5,4\%) e geraniol (média de 7,1\%) (TAB. 4.15).

$\mathrm{Na}$ colheita do inverno, as condições do clima não foram tão favoráveis ao cultivo de Melissa officinalis, principalmente para o sistema orgânico. Essas condições se referem a diminuição da temperatura (média de 16,9 ${ }^{\circ} \mathrm{C}$, IAG/USP), diminuição de chuva (média de $253 \mathrm{~mm}$, IAG/USP) e vento frio característico dessa época que, possivelmente, proporcionaram condições desfavoráveis que levaram a redução no teor de citral. Por outro lado, esses fatores contribuíram para o aumento dos teores de citronelal, citronelol, nerol e geraniol (FIG. 4.13).

Estes resultados estão de acordo com aqueles observados por Luz et al. (2014) que verificaram a influência dos fatores climáticos e observaram que as concentrações de neral e geranial cairam no inverno. Silva (2011) verificou a influencia de sistema de adubação orgânica e química e observou um aumento nas concentrações de citronelol no mesmo período. 
Para Furlan et al. (2010) em estudo sobre a influência dos fatores climáticos, "as concentrações de neral e geranial diminuíram em até $40 \%$ no inverno".

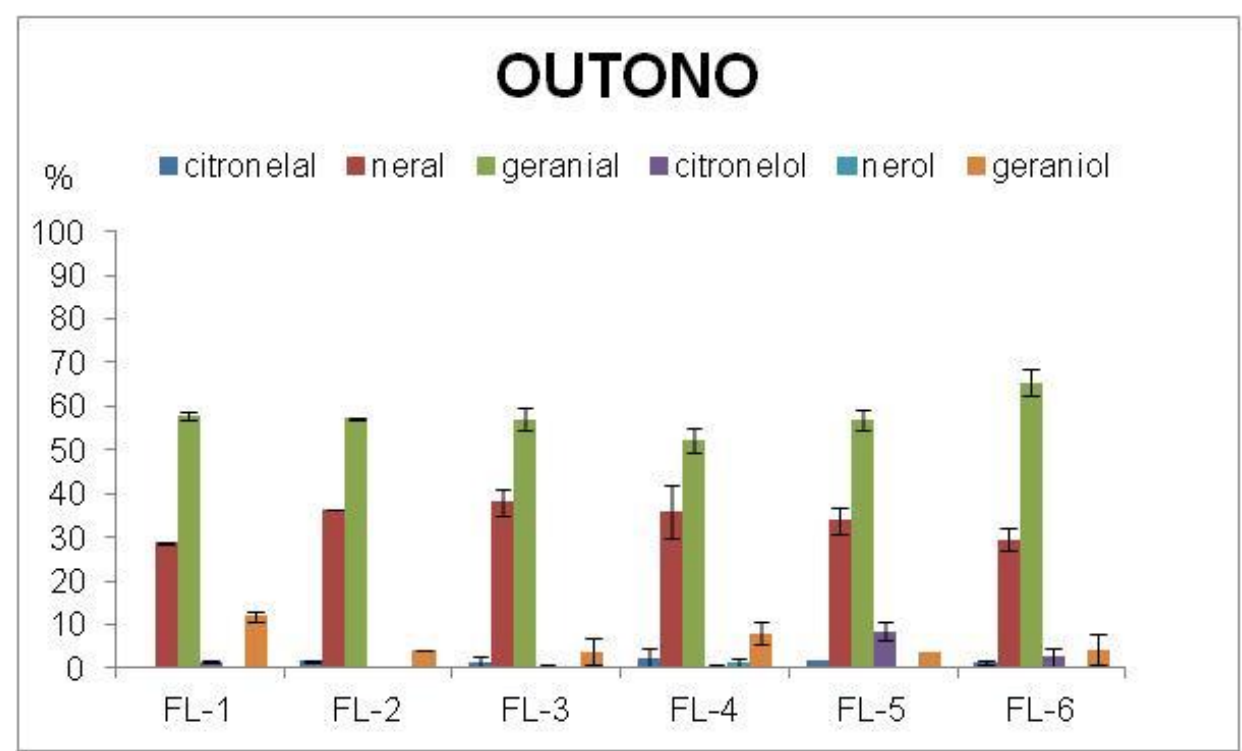

FIGURA 4.12 - Porcentagem relativa média dos óleos voláteis de Melissa officinalis obtidos para a primeira coleta, outono (abril/2013).

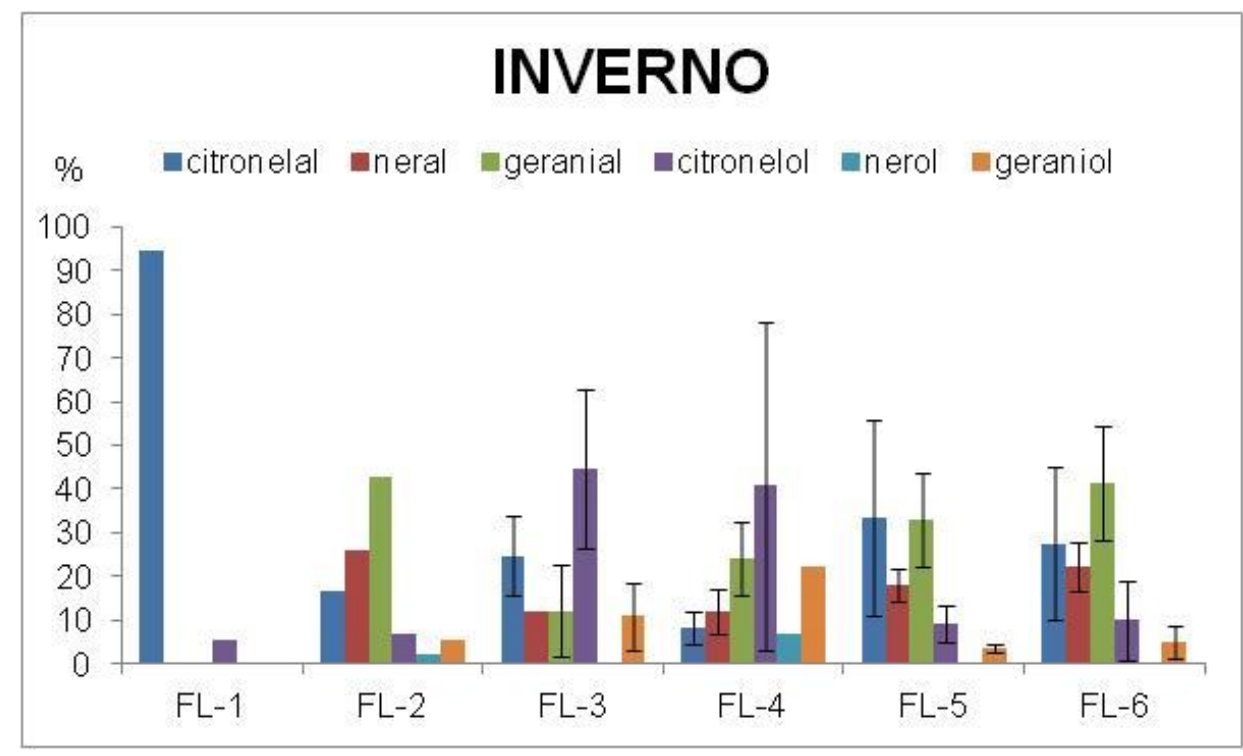

FIGURA 4.13 - Porcentagem relativa média dos óleos voláteis de Melissa officinalis obtidos para a segunda coleta, inverno (julho/2013). 


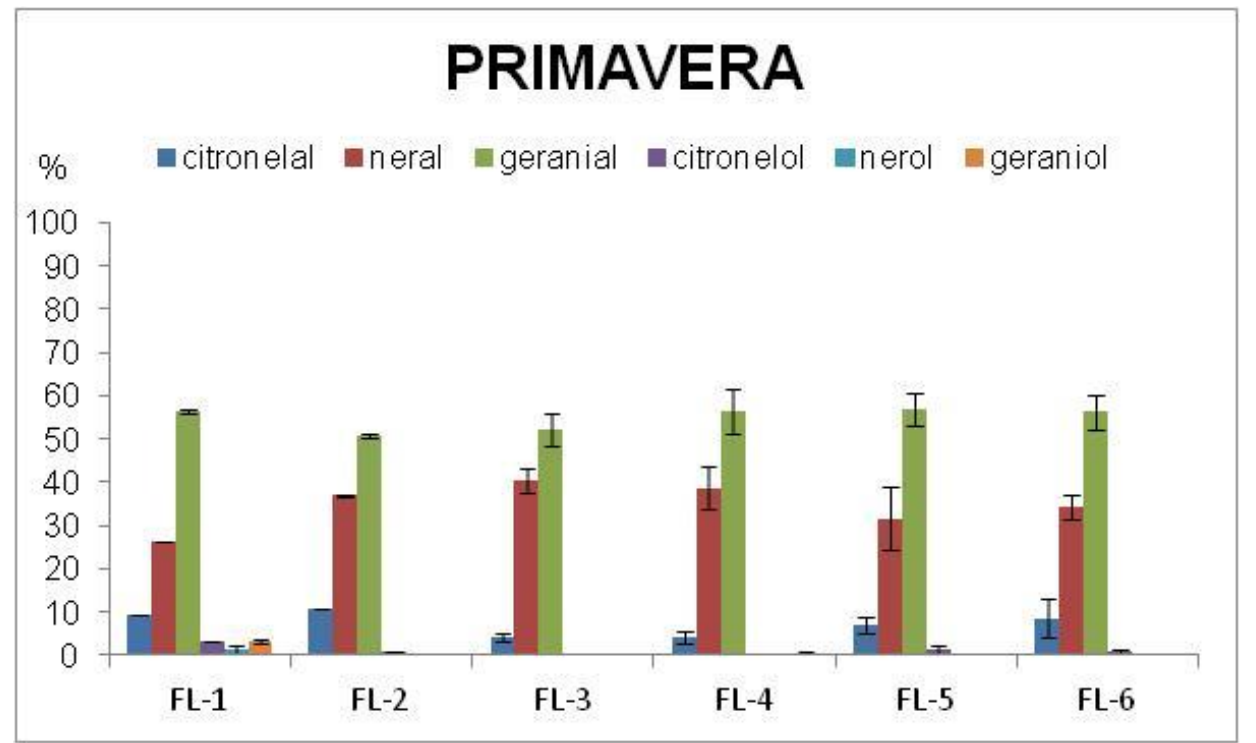

FIGURA 4.14 - Porcentagem relativa média dos óleos voláteis de Melissa officinalis obtidos para a terceira coleta, primavera (outubro/2013).

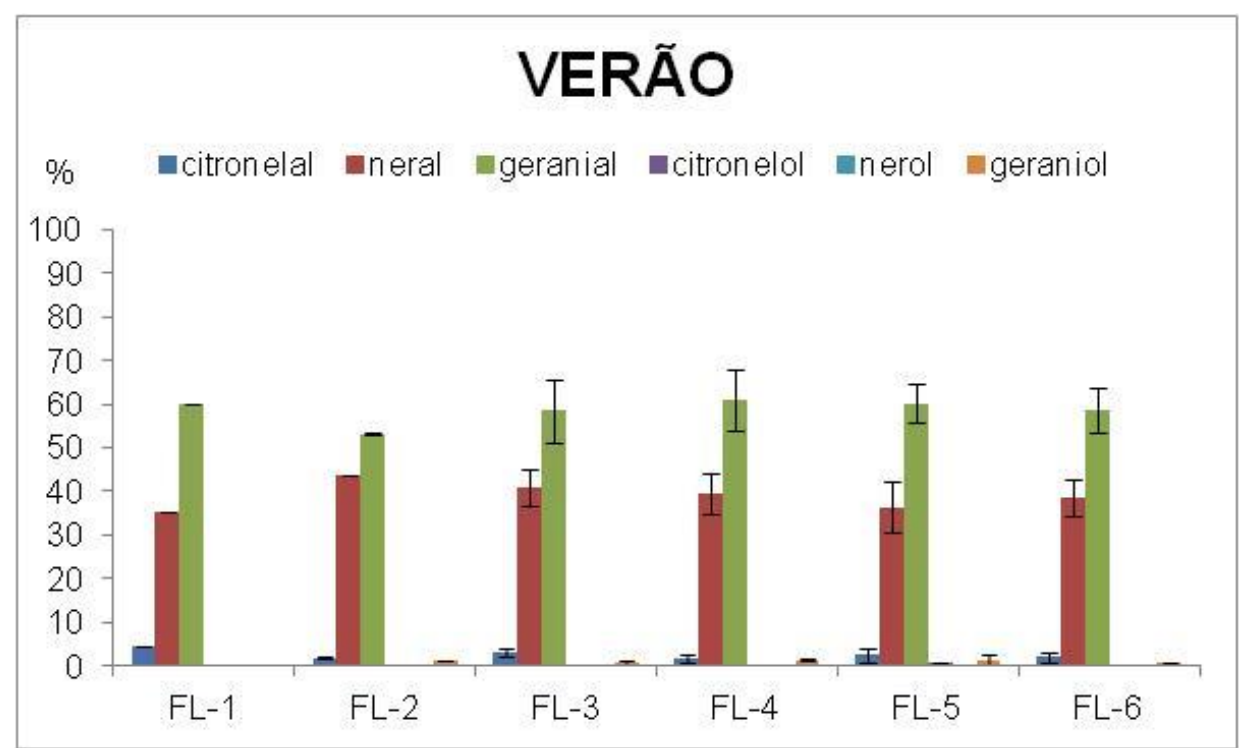

FIGURA 4.15 - Porcentagem relativa média dos óleos voláteis de Melissa officinalis obtidos para a quarta coleta, verão (janeiro/2014).

Os valores das concentrações dos metais nas folhas de Melissa officinalis e dos constituintes químicos dos óleos voláteis, juntamente com os teores dos metais no solo foram analisados por técnicas multivariadas, como a análise de componentes principais (PCA) e a análise de agrupamento hierárquico (AAH). Para a PCA, o comprimento dos vetores, que representam os elementos no solo e nas plantas, é proporcional a sua importância. As variáveis $\mathrm{Ce}, \mathrm{Cs}, \mathrm{Eu}, \mathrm{Lu}, \mathrm{Nd}, \mathrm{U}$ e $\mathrm{Zr}$, nas amostras de planta, apresentaram mais de $80 \%$ dos resultados analíticos abaixo do LQ e, as variáveis $\mathrm{As}, \mathrm{Ta}, \mathrm{Tb}, \mathrm{Ti}, \mathrm{Yb}$ e nerol apresentaram 
menos de $40 \%$ de valores determinados nas amostras, por isso, não foram incluídas nas análises.

Na FIG. 4.16 são apresentados os resultados da análise de componentes principal ( $P C A)$. As tendências entre os óleos voláteis e as variáveis ambientais (teores de metais dos solos e nas folhas) foram maiores para os dois primeiros eixos e explicam 33,7 \% da variância acumulada da relação óleo volátil com os fatores ambientais. Os metais presentes na planta estão apresentados com asterisco $\left({ }^{*}\right)$.

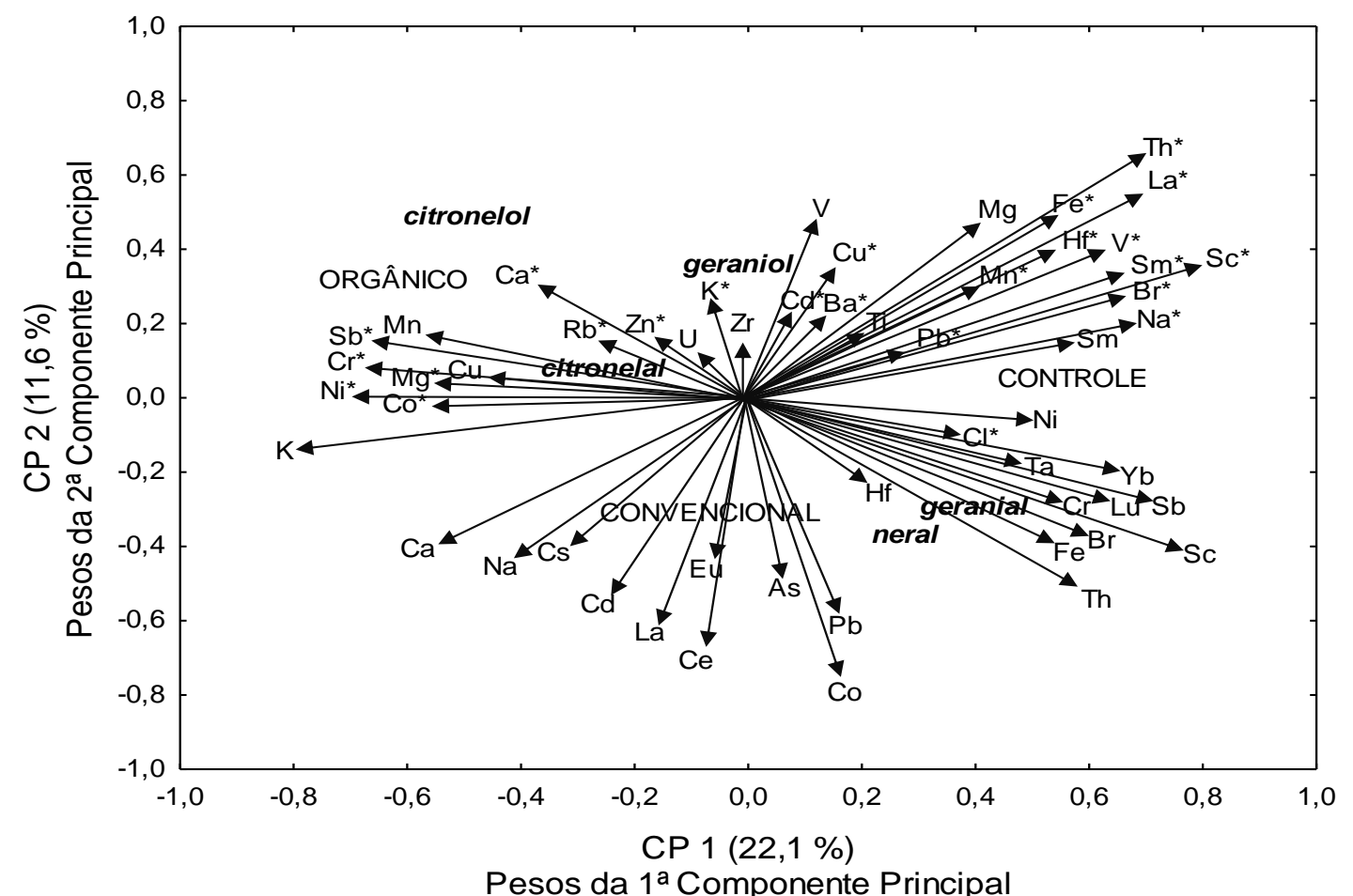

FIGURA 4.16 - Resultado da Análise de Componentes Principais (CP 1 e 2) mostrando o manejo agrícola (controle, orgânico e convencional), metais nos solos, metais nas folhas $\left(^{\star}\right)$ e os óleos voláteis de Melissa officinalis

O gráfico dos pesos (FIG. 4.16) permite a caracterização de tendências entre as variáveis. Observando ao longo do eixo da CP 1 (pesos positivos), as variáveis que influenciaram diretamente os constituintes neral e geranial foram os elementos $\mathrm{Co}, \mathrm{Cr}, \mathrm{Sc}, \mathrm{Th}, \mathrm{Yb}, \mathrm{Ni}, \mathrm{Fe}$, Lu e As. Enquanto que, os metais $\mathrm{K}, \mathrm{Ca}$, $\mathrm{Cu}, \mathrm{Mn}, \mathrm{U}, \mathrm{Zr}, \mathrm{K}^{*}, \mathrm{Ni}^{*}, \mathrm{Co}^{*}, \mathrm{Ca}^{*}$ e $\mathrm{Cd}^{*}$ (pesos negativos, $\mathrm{CP}$ 1) tiveram variação inversamente proporcional a esses constituintes.

Ao longo do eixo $\mathrm{CP}$ 2, pode-se observar que as variáveis que influenciaram diretamente (pesos positivos) os constituintes citronelol e geraniol 
foram $\mathrm{Ba}^{*}, \mathrm{Ca}^{*}, \mathrm{Cd}^{*}, \mathrm{~K}^{*}$ e $\mathrm{Rb}^{*}$, enquanto que as variáveis $\mathrm{As}, \mathrm{Cd}, \mathrm{Co}, \mathrm{Cr}, \mathrm{Fe}, \mathrm{Na}$, $\mathrm{Ni}, \mathrm{Pb}, \mathrm{Th}$ (pesos negativos) apresentaram variação inversamente proporcional à produção desses constituintes. O citronelal apresentou variação com o teor de $\mathrm{Zr}$, $\mathrm{K}^{*}$ e $\mathrm{Zn}^{*}$ (pesos positivos).

As tendências de correlações observadas por meio das PCs foram confirmadas a partir do dendrograma obtido pela análise de agrupamento (FIG. 4.17). Para a $A A H$, adotou-se a distância euclidiana como medida de similaridade e o método de Ward para ligar os casos entre si.

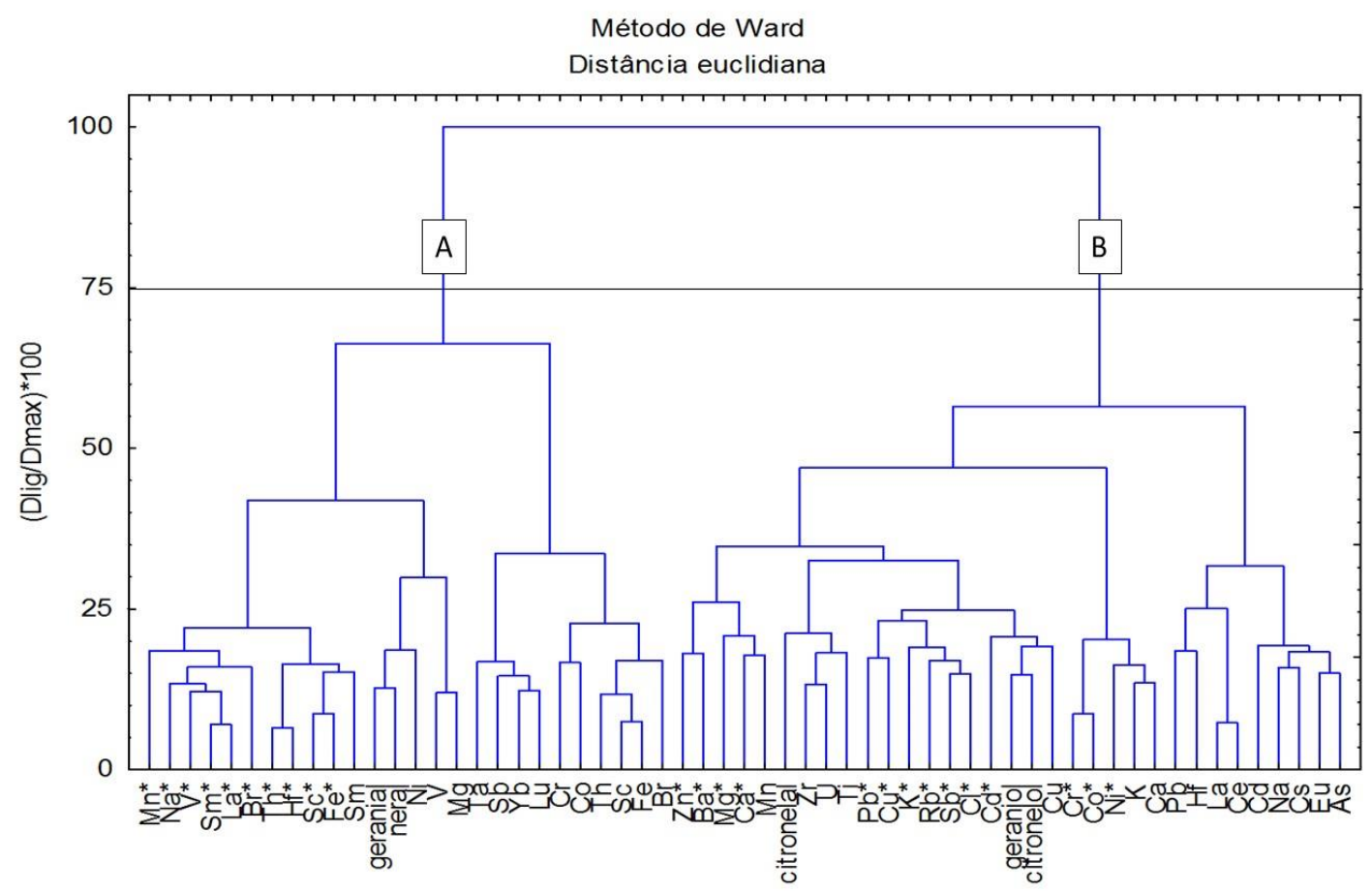

FIGURA 4.17 - Dendrograma obtido entre os metais e os óleos voláteis de Melissa officinalis.

Atribuindo-se o valor 75 para a distância de ligação (Dlig) no dendrograma foi possível identificar a formação de dois grupos distintos (A e B). $O$ grupo A é formado pelas variáveis correlacionadas com neral e geranial. Pode-se observar a correlação de elementos tais como $\mathrm{Ni}, \mathrm{V}, \mathrm{Mg} \mathrm{Fe}^{*}$ e $\mathrm{Mn}^{*}$ com estes constituintes. O grupo B é representado pelas variáveis correlacionadas com citronelal, citronelol e geraniol. Através do agrupamento pode-se visualizar a correlação de elementos tais como, $\mathrm{Cu}, \mathrm{Cl}^{*}, \mathrm{~K}^{*}$ e $\mathrm{Cu}^{*}$ com os constituintes citronelol e geraniol. 


\subsection{Análise de Correlação de Pearson}

Para comparar as correlações entre os diferentes pares de variáveis, foi aplicado o teste de correlação de Pearson, que é tipicamente utilizado para descrever o grau de relação linear entre duas variáveis quantitativas de maneira padronizada (Warner, 2013).

Na TAB. 4.17 são apresentados os resultados das correlações entre as concentrações dos metais nos solos e nas folhas de Melissa officinalis. As concentrações dos elementos determinados nas folhas estão sinalizadas com asterisco (*) para diferenciar das concentrações dos elementos do solo. Os valores em vermelho nas tabelas de correlação indicam correlação significativa com $p<0,05$. Os níveis de correlação estabelecidos foram feitos de acordo Callegari-Jacques (2003), que "considera como fortes correlações acima de 0,6 ( $r$ $\geq 0,6$ ), moderadas, valores entre 0,3 e 0,6 e coeficiente abaixo de $0,3(r<0,3)$ indicam correlação fraca".

Foram verificadas correlações entre os elementos $\mathrm{Br} / \mathrm{Br}^{*}(0,36), \mathrm{Cr} / \mathrm{Cr}^{*}$ $(-0,38), \mathrm{Hf} / \mathrm{Hf}^{*}(0,46), \mathrm{Na} / \mathrm{Na}^{*}(-0,45), \mathrm{Ni} / \mathrm{Ni}^{*}(-0,54), \mathrm{Sc} / \mathrm{Sc}^{*}(0,36)$ e $\mathrm{Sm} / \mathrm{Sm}^{*}(0,40)$ presentes no solo e nas plantas.

Não foi verificada correlação entre as concentrações de $\mathrm{Mn}$ do solo e da planta, possivelmente devido ao fato da absorção deste elemento ser controlada por reações redox. De acordo com Grygo-Szymanko et al. (2016) apenas o Mn(II) é absorvido pela planta. A especiação redox também deve estar relacionada à absorção de outros elementos que apresentam mais de um estado de oxidação, tais como $\mathrm{Cr}$ e $\mathrm{Fe}$, o que pode explicar a falta de correlação ou correlação negativa entre os teores destes elementos encontrados no solo e na planta.

A ausência de correlação ou correlação negativa observada, entre os constituintes do solo e seu teor na planta, para elementos tais como $\mathrm{Ca}, \mathrm{Co}, \mathrm{Mg}$, $\mathrm{Na}, \mathrm{Ni}$ e $\mathrm{Zn}$, que nas condições do solo (por exemplo $\mathrm{pH}$ e potencial redox) encontram-se em seu estado de oxidação mais estável (2+, exceto para o sódio, $1+)$, provavelmente deve estar relacionada a mecanismos seletivos de absorção bem como da dependência da espécie (Ashfaq et al., 2009). Outra possível explicação pode ser o fato de que foram avaliados apenas os teores dos elementos nas folhas de Melissa officinalis. Bakkaus et al. (2005) demonstraram que a concentração de Co na raiz das plantas superiores é maior que a concentração deste elemento nas partes aéreas e sugere que mecanismos 
protetores, em certas plantas, sejam ativados para evitar exposição a altas concentrações. Resultados semelhantes foram observados para os elementos $\mathrm{Cu}, \mathrm{Cr}, \mathrm{Pb}, \mathrm{Zn}, \mathrm{Ni}, \mathrm{Fe}$ e $\mathrm{Mn}$ cujas concentrações foram maiores nas raízes que nas folhas de diversas plantas medicinais (Yoon et al., 2006; Olowoyo et al., 2012).

Dentre os elementos essenciais e benéficos para as plantas, $0 \mathrm{Ca}^{*}$ apresentou moderadas correlações positivas com $\mathrm{Mn}$, $\mathrm{Na}$ e $\mathrm{V}$, correlações negativas com $\mathrm{Cr}, \mathrm{Fe}$ e Ni. $\mathrm{O} \mathrm{Cl}{ }^{*}$ apresentou moderada correlação negativa com o V. O Co* apresentou moderadas correlações positivas com $\mathrm{Ca}, \mathrm{K}$ e $\mathrm{Na}$, e negativas com $\mathrm{Cr}, \mathrm{Fe}, \mathrm{Mg}$ e $\mathrm{Ni}$. O $\mathrm{Cr}^{*}$ apresentou moderadas correlações positivas com $\mathrm{Ca}, \mathrm{K}, \mathrm{Mn}$ e $\mathrm{Na}$, e correlações negativas com $\mathrm{Fe}, \mathrm{Mg}$ e Ni. O Cu* apresentou moderadas correlações negativas com $\mathrm{Ca}$, Co e $\mathrm{Na}$. O Fe* apresentou moderada correlação positiva com o $\mathrm{Mg}$ e fraca correlação positiva com o Ni, moderada correlação negativa com $\mathrm{K}$ e fracas correlações negativas com $\mathrm{Ca}, \mathrm{Mn}$ e $\mathrm{Na}$. O K${ }^{*}$ apresentou moderadas correlações positivas com $\mathrm{Cu}, \mathrm{Fe}$ e negativa com $\mathrm{Na}$. $\mathrm{O} \mathrm{Mg}^{*}$ apresentou moderadas correlações positivas com $\mathrm{Ca}$, $\mathrm{K}, \mathrm{Mn}$ e $\mathrm{Na}$, e negativas com $\mathrm{Cr}$, Fe. O Mn* apresentou moderada correlação negativa com o $\mathrm{Cu}$. $\mathrm{O} \mathrm{Na}{ }^{*}$ apresentou moderadas correlações positivas com o $\mathrm{Cr}$, $\mathrm{Mg}$ e Ni, correlação negativa com o $\mathrm{Ca} e$, forte correlação negativa com o K. O Ni* apresentou fortes correlações positivas com $\circ \mathrm{Ca}$ e $\mathrm{K}$, moderada correlação positiva com o $\mathrm{Na}$, e moderadas correlações negativas com o $\mathrm{Cr}$ e $\mathrm{Mg}$. O V* apresentou moderada correlação positiva com o $\mathrm{Ni}$, e moderadas correlações negativas com $\mathrm{Ca}$, Co, $\mathrm{K}$ e $\mathrm{Mn}$. O Zn* apresentou moderada correlação positiva com o V, e negativa com o $\mathrm{Cr}$.

Embora algumas correlações positivas tenham sido observadas entre as concentrações dos elementos essenciais no solo e nas folhas de melissa, não pode ser observado um padrão para absorção destes elementos. Este fato pode estar relacionado aos diferentes mecanismos de absorção e translocação dos elementos bem como às diferentes fontes de tais elementos conforme mostrado na FIG. 4.16 em que se verificam a associação do $\mathrm{Cu}, \mathrm{Mn}$ e $\mathrm{K}$ com o tratamento orgânico, $\mathrm{Ca}$ e Co com o tratamento convencional enquanto que $\mathrm{Mg}, \mathrm{Ni}, \mathrm{Fe}, \mathrm{e} \mathrm{Cr}$ estão associados ao solo controle. 
TABELA 4.17 - Matriz de correlação de Pearson entre os metais no solo e nas folhas de Melissa officinalis.

\begin{tabular}{|c|c|c|c|c|c|c|c|c|c|c|c|c|}
\hline Variáveis & $\mathrm{Ba}^{*}$ & $\mathrm{Br}^{*}$ & $\mathrm{Ca}^{*}$ & $\mathrm{Cd}^{*}$ & $\mathrm{Cl}^{*}$ & $\mathrm{Co}^{*}$ & $\mathrm{Cr}^{\star}$ & $\mathrm{Cu}^{\star}$ & $\mathrm{Fe}^{*}$ & $H f^{*}$ & $\mathbf{K}^{*}$ & La* $^{*}$ \\
\hline As & 0,25 & 0,19 & 0,00 & $-0,24$ & $-0,11$ & 0,17 & 0,16 & $-0,48$ & 0,10 & 0,47 & $-0,44$ & 0,23 \\
\hline $\mathrm{Br}$ & 0,25 & 0,36 & $-0,39$ & 0,11 & 0,05 & $-0,25$ & $-0,37$ & $-0,21$ & 0,29 & 0,64 & $-0,14$ & 0,36 \\
\hline $\mathrm{Ca}$ & $-0,12$ & $-0,41$ & 0,07 & 0,02 & $-0,17$ & 0,56 & 0,57 & $-0,35$ & $-0,26$ & $-0,55$ & $-0,23$ & $-0,41$ \\
\hline Cd & $-0,14$ & $-0,24$ & 0,09 & $-0,23$ & 0,27 & 0,24 & 0,22 & $-0,17$ & $-0,22$ & $-0,10$ & $-0,20$ & $-0,13$ \\
\hline $\mathrm{Ce}$ & $-0,27$ & $-0,34$ & $-0,05$ & $-0,09$ & 0,24 & 0,04 & $-0,06$ & 0,01 & $-0,34$ & $-0,35$ & 0,02 & $-0,26$ \\
\hline Co & $-0,02$ & $-0,11$ & $-0,15$ & $-0,15$ & 0,17 & 0,00 & $-0,07$ & $-0,30$ & $-0,21$ & $-0,05$ & $-0,13$ & $-0,27$ \\
\hline $\mathrm{Cr}$ & $-0,10$ & 0,19 & $-0,35$ & 0,03 & 0,24 & $-0,33$ & $-0,38$ & 0,17 & 0,08 & $-0,07$ & 0,15 & 0,02 \\
\hline Cs & 0,09 & $-0,32$ & $-0,05$ & $-0,27$ & $-0,08$ & 0,12 & 0,13 & $-0,27$ & $-0,36$ & $-0,04$ & $-0,13$ & $-0,26$ \\
\hline $\mathrm{Cu}$ & $-0,15$ & $-0,51$ & 0,18 & 0,13 & $-0,11$ & 0,17 & 0,15 & 0,22 & $-0,23$ & $-0,34$ & 0,30 & $-0,11$ \\
\hline Eu & 0,00 & 0,02 & 0,15 & $-0,21$ & $-0,04$ & 0,04 & 0,01 & $-0,33$ & $-0,18$ & 0,15 & $-0,44$ & 0,13 \\
\hline $\mathrm{Fe}$ & 0,07 & 0,13 & $-0,58$ & 0,07 & 0,34 & $-0,37$ & $-0,46$ & $-0,03$ & $-0,02$ & 0,14 & 0,27 & $-0,23$ \\
\hline Hf & $-0,16$ & 0,18 & $-0,35$ & 0,09 & 0,11 & $-0,08$ & $-0,18$ & $-0,09$ & 0,12 & 0,46 & 0,19 & 0,27 \\
\hline $\mathrm{K}$ & $-0,13$ & $-0,58$ & 0,04 & 0,02 & 0,16 & 0,53 & 0,57 & $-0,13$ & $-0,33$ & $-0,54$ & $-0,02$ & $-0,60$ \\
\hline La & $-0,15$ & $-0,24$ & 0,07 & $-0,10$ & 0,00 & 0,05 & $-0,03$ & $-0,10$ & $-0,31$ & $-0,23$ & $-0,10$ & $-0,19$ \\
\hline Lu & $-0,25$ & 0,16 & $-0,34$ & $-0,01$ & 0,37 & $-0,39$ & $-0,47$ & 0,11 & 0,10 & 0,08 & 0,05 & 0,15 \\
\hline Mg & 0,18 & 0,39 & 0,03 & $-0,06$ & $-0,10$ & $-0,33$ & $-0,31$ & 0,22 & 0,31 & 0,52 & 0,06 & 0,56 \\
\hline Mn & 0,02 & $-0,33$ & 0,43 & $-0,22$ & $-0,05$ & 0,21 & 0,38 & $-0,05$ & $-0,24$ & $-0,51$ & 0,06 & $-0,37$ \\
\hline $\mathrm{Na}$ & 0,01 & $-0,19$ & 0,34 & $-0,30$ & $-0,22$ & 0,34 & 0,36 & $-0,42$ & $-0,24$ & $-0,13$ & $-0,42$ & $-0,15$ \\
\hline $\mathbf{N i}$ & 0,10 & 0,13 & $-0,25$ & $-0,14$ & 0,11 & $-0,37$ & $-0,32$ & 0,07 & 0,28 & 0,29 & $-0,22$ & 0,30 \\
\hline $\mathrm{Pb}$ & $-0,03$ & $-0,08$ & $-0,21$ & $-0,14$ & 0,03 & $-0,03$ & $-0,13$ & $-0,12$ & $-0,05$ & 0,33 & $-0,19$ & 0,34 \\
\hline $\mathrm{Sb}$ & $-0,16$ & 0,28 & $-0,07$ & 0,00 & 0,32 & $-0,30$ & $-0,49$ & 0,23 & 0,35 & 0,09 & $-0,20$ & 0,51 \\
\hline Sc & $-0,04$ & 0,28 & $-0,60$ & 0,08 & 0,35 & $-0,45$ & $-0,57$ & 0,04 & 0,13 & 0,24 & 0,16 & 0,03 \\
\hline Sm & 0,37 & 0,37 & $-0,29$ & 0,16 & 0,18 & $-0,20$ & $-0,25$ & 0,12 & 0,65 & 0,57 & $-0,07$ & 0,54 \\
\hline $\mathrm{Ta}$ & $-0,23$ & 0,23 & $-0,25$ & 0,04 & 0,33 & $-0,33$ & $-0,41$ & 0,21 & $-0,03$ & $-0,15$ & 0,23 & 0,04 \\
\hline Th & 0,16 & 0,30 & $-0,43$ & $-0,03$ & 0,29 & $-0,30$ & $-0,39$ & $-0,08$ & 0,05 & 0,08 & $-0,04$ & $-0,17$ \\
\hline Ti & $-0,05$ & 0,10 & $-0,05$ & 0,06 & $-0,20$ & $-0,25$ & $-0,21$ & 0,02 & $-0,06$ & 0,06 & 0,24 & $-0,16$ \\
\hline $\mathbf{U}$ & $-0,26$ & $-0,11$ & $-0,08$ & 0,11 & 0,09 & 0,03 & $-0,04$ & 0,08 & $-0,07$ & 0,04 & 0,40 & $-0,03$ \\
\hline V & 0,21 & 0,27 & 0,24 & $-0,03$ & $-0,44$ & $-0,11$ & $-0,09$ & 0,19 & 0,17 & 0,38 & 0,04 & 0,29 \\
\hline Yb & $-0,08$ & 0,33 & $-0,16$ & 0,00 & 0,23 & $-0,37$ & $-0,45$ & 0,10 & 0,17 & 0,12 & $-0,14$ & 0,32 \\
\hline $\mathrm{Zr}$ & $-0,09$ & $-0,04$ & $-0,08$ & 0,11 & $-0,12$ & $-0,11$ & $-0,13$ & $-0,02$ & $-0,10$ & 0,21 & 0,33 & $-0,01$ \\
\hline
\end{tabular}

*metais presentes nas folhas de melissa. 


\begin{tabular}{|c|c|c|c|c|c|c|c|c|c|c|c|c|}
\hline Variáveis & $\mathrm{Mg}^{\star}$ & Mn* & $\mathrm{Na}^{*}$ & $\mathrm{Ni}^{*}$ & $\mathbf{P b}^{*}$ & $\mathbf{R} \mathbf{b}^{*}$ & Sb* $^{*}$ & $\mathrm{Sc}^{\star}$ & $\mathrm{Sm}^{\star}$ & Th* & $\mathbf{V}^{*}$ & $\mathbf{Z n}^{*}$ \\
\hline As & 0,10 & $-0,02$ & $-0,18$ & 0,14 & $-0,17$ & $-0,36$ & $-0,20$ & 0,13 & 0,03 & 0,54 & $-0,08$ & 0,13 \\
\hline $\mathrm{Br}$ & $-0,33$ & 0,24 & 0,23 & $-0,02$ & $-0,10$ & $-0,42$ & $-0,46$ & 0,45 & 0,25 & 0,54 & 0,15 & $-0,03$ \\
\hline $\mathrm{Ca}$ & 0,25 & $-0,17$ & $-0,54$ & 0,63 & $-0,24$ & $-0,24$ & 0,09 & $-0,46$ & $-0,37$ & $-0,48$ & $-0,37$ & 0,05 \\
\hline Cd & 0,20 & $-0,21$ & $-0,28$ & 0,09 & $-0,13$ & 0,18 & 0,06 & $-0,28$ & $-0,29$ & $-0,08$ & $-0,28$ & 0,07 \\
\hline $\mathrm{Ce}$ & $-0,05$ & $-0,17$ & $-0,12$ & $-0,03$ & 0,07 & 0,14 & 0,06 & $-0,30$ & $-0,28$ & $-0,38$ & $-0,31$ & $-0,19$ \\
\hline Co & $-0,14$ & $-0,18$ & $-0,13$ & $-0,09$ & $-0,05$ & $-0,20$ & $-0,49$ & $-0,07$ & $-0,21$ & $-0,17$ & $-0,32$ & $-0,16$ \\
\hline $\mathrm{Cr}$ & $-0,36$ & 0,05 & 0,35 & $-0,49$ & 0,28 & $-0,05$ & $-0,56$ & 0,22 & 0,07 & $-0,05$ & 0,10 & $-0,26$ \\
\hline Cs & 0,45 & $-0,36$ & $-0,45$ & 0,14 & $-0,23$ & 0,15 & 0,32 & $-0,36$ & $-0,21$ & $-0,09$ & $-0,54$ & 0,32 \\
\hline $\mathrm{Cu}$ & 0,13 & $-0,26$ & $-0,20$ & 0,17 & 0,01 & 0,41 & 0,33 & $-0,29$ & $-0,13$ & $-0,17$ & $-0,19$ & $-0,05$ \\
\hline Eu & 0,26 & $-0,08$ & $-0,09$ & $-0,04$ & 0,02 & $-0,05$ & $-0,09$ & $-0,12$ & 0,09 & 0,10 & $-0,09$ & $-0,10$ \\
\hline $\mathrm{Fe}$ & $-0,41$ & 0,05 & 0,10 & $-0,21$ & $-0,02$ & $-0,18$ & $-0,57$ & 0,19 & $-0,14$ & $-0,10$ & $-0,23$ & 0,03 \\
\hline Hf & $-0,32$ & 0,20 & 0,06 & 0,00 & $-0,01$ & 0,00 & 0,00 & 0,24 & 0,04 & 0,31 & 0,15 & $-0,16$ \\
\hline K & 0,41 & $-0,19$ & $-0,65$ & 0,56 & $-0,29$ & 0,12 & 0,32 & $-0,50$ & $-0,66$ & $-0,57$ & $-0,57$ & 0,06 \\
\hline La & $-0,01$ & $-0,12$ & $-0,20$ & 0,08 & 0,09 & $-0,05$ & 0,05 & $-0,27$ & $-0,20$ & $-0,28$ & $-0,20$ & $-0,12$ \\
\hline Lu & $-0,38$ & 0,03 & 0,46 & $-0,42$ & 0,13 & $-0,03$ & $-0,35$ & 0,23 & 0,11 & 0,00 & 0,36 & $-0,25$ \\
\hline Mg & $-0,01$ & 0,15 & 0,38 & $-0,36$ & 0,20 & 0,07 & 0,08 & 0,41 & 0,53 & 0,61 & 0,29 & 0,20 \\
\hline Mn & 0,32 & $-0,22$ & $-0,26$ & 0,20 & $-0,06$ & 0,24 & $-0,03$ & $-0,36$ & $-0,25$ & $-0,47$ & $-0,46$ & 0,15 \\
\hline $\mathrm{Na}$ & 0,30 & $-0,16$ & $-0,45$ & 0,31 & $-0,11$ & $-0,24$ & 0,27 & $-0,34$ & $-0,22$ & $-0,11$ & $-0,15$ & 0,12 \\
\hline $\mathbf{N i}$ & $-0,09$ & $-0,02$ & 0,36 & $-0,54$ & 0,07 & 0,03 & $-0,43$ & 0,42 & 0,27 & 0,34 & 0,36 & $-0,09$ \\
\hline $\mathbf{P b}$ & 0,04 & $-0,13$ & $-0,05$ & $-0,12$ & $-0,07$ & $-0,16$ & 0,16 & 0,01 & $-0,02$ & 0,36 & 0,18 & 0,05 \\
\hline Sb & $-0,28$ & 0,15 & 0,65 & $-0,52$ & 0,29 & 0,14 & 0,00 & 0,39 & 0,40 & 0,28 & 0,41 & $-0,41$ \\
\hline Sc & $-0,51$ & 0,17 & 0,40 & $-0,43$ & 0,09 & $-0,21$ & $-0,54$ & 0,36 & 0,15 & 0,01 & 0,13 & $-0,14$ \\
\hline Sm & $-0,13$ & 0,41 & 0,45 & $-0,30$ & 0,04 & $-0,05$ & $-0,02$ & 0,69 & 0,40 & 0,66 & 0,13 & $-0,09$ \\
\hline Ta & $-0,40$ & 0,03 & 0,43 & $-0,32$ & 0,24 & 0,09 & $-0,30$ & 0,10 & 0,12 & $-0,23$ & 0,06 & $-0,19$ \\
\hline Th & $-0,39$ & 0,06 & 0,14 & $-0,25$ & 0,05 & $-0,42$ & $-0,61$ & 0,24 & $-0,20$ & $-0,08$ & $-0,08$ & $-0,05$ \\
\hline Ti & $-0,23$ & 0,00 & $-0,15$ & 0,16 & 0,10 & $-0,19$ & $-0,36$ & 0,06 & $-0,20$ & $-0,07$ & 0,10 & 0,14 \\
\hline $\mathbf{U}$ & $-0,11$ & 0,12 & $-0,17$ & 0,10 & $-0,08$ & 0,17 & 0,34 & $-0,04$ & $-0,15$ & $-0,02$ & 0,14 & 0,18 \\
\hline V & 0,13 & 0,05 & 0,17 & $-0,10$ & 0,13 & $-0,02$ & 0,04 & 0,20 & 0,30 & 0,40 & 0,23 & 0,29 \\
\hline Yb & $-0,32$ & 0,13 & 0,53 & $-0,41$ & 0,20 & $-0,17$ & $-0,65$ & 0,35 & 0,40 & 0,12 & 0,40 & $-0,13$ \\
\hline $\mathrm{Zr}$ & $-0,15$ & 0,08 & $-0,13$ & 0,23 & $-0,08$ & 0,06 & 0,04 & 0,00 & $-0,03$ & $-0,02$ & $-0,06$ & 0,11 \\
\hline
\end{tabular}


Conclusão semelhante foi obtida por Nordløkken et al. (2015) para a distribuição de elementos em diferentes partes de plantas medicinais e, similarmente, Raguž et al. (2013) concluíram que um modelo de transferência linear solo/planta para 61 elementos investigados é melhor ajustado quando se considera a concentração na planta como um todo em oposição à análise de suas partes, separadamente.

Na FIG. 4.18 são apresentadas as correlações observadas entre os metais presente no solo e suas concentrações nas folhas $\left({ }^{*}\right)$ e as correlações entre os elementos essenciais presentes nas folhas de melissa e no solo na forma gráfica para melhor visualização.
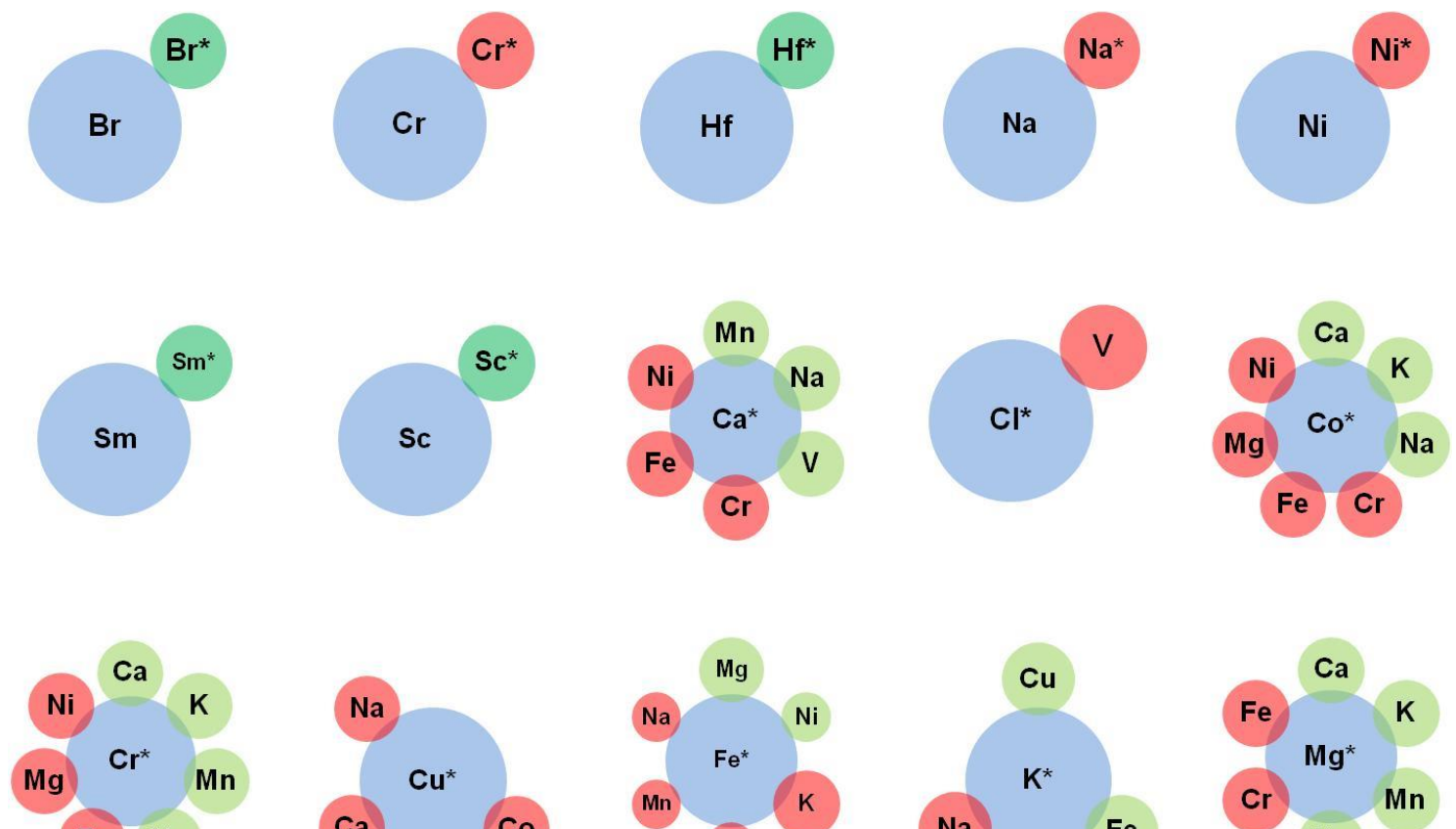

$\mathrm{Fe} \quad \mathrm{Na}$
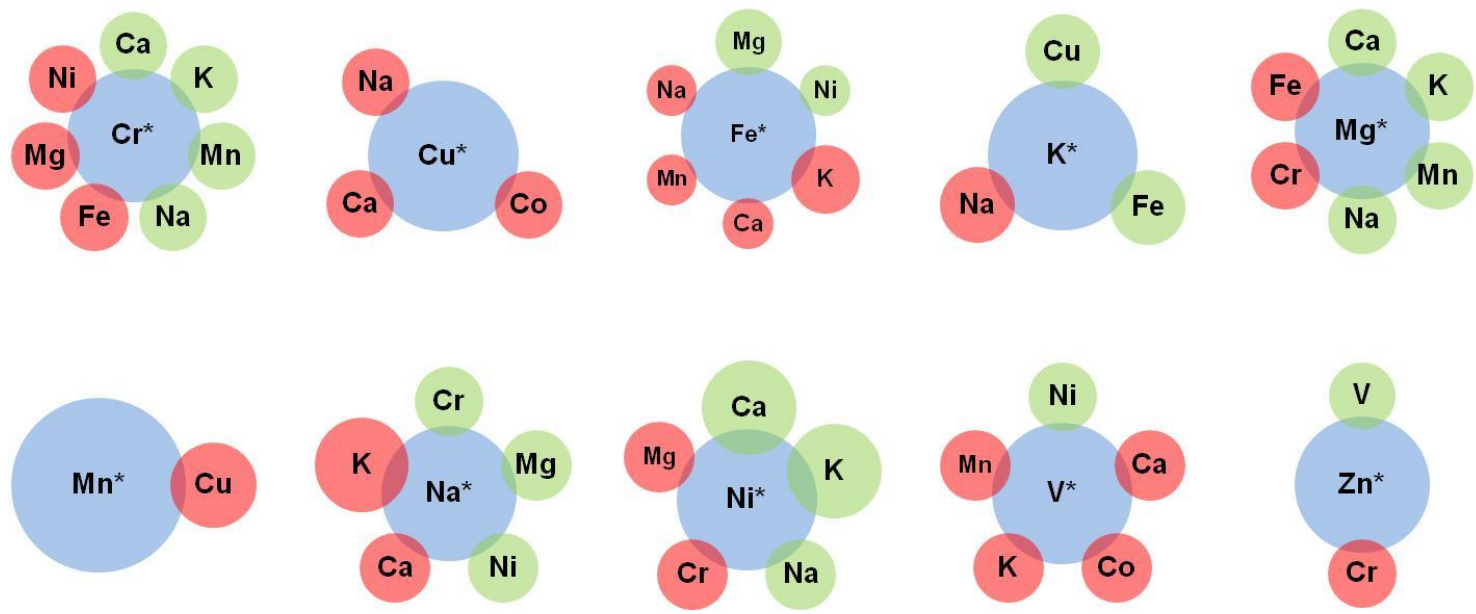

FIGURA 4.18 - Correlações encontradas entre os metais no solo e nas folhas de Melissa officinalis. 
Os círculos azuis, verdes e vermelhos correspondem às variáveis no solo nas folhas de melissa. Os círculos verdes correspondem às correlações positivas e círculos vermelhos correspondem às correlações negativas. Os tamanhos dos círculos representam as correlações observadas: círculos maiores (fortes correlações), médios (moderadas correlações) e menores (fracas correlações).

As análises de matrizes de gráfico de Pearson entre os componentes químicos determinados no óleo volátil das folhas de Melissa officinalis, biomassa, teor de óleo volátil e os elementos químicos caracterizados no solo e nas plantas estão representados nas TAB 4.18 e 4.19, respectivamente. E nas FIG. 4.19 e 4.20 são apresentados os resultados de correlação entre os óleos voláteis e os metais na forma gráfica para melhor visualização.

Considerando as correlações observadas na TAB. 4.17, em relação aos teores dos elementos no solo, o composto citronelal apresentou moderada correlação positiva com os níveis de $\mathrm{Zr}(0,37)$, baixa correlação positiva com o Lu $(0,29)$, moderadas correlações negativas com $\mathrm{Ni}(-0,36)$ e $\mathrm{Sb}(-0,30)$ e baixa correlação negativa com Mg $(-0,28)$ e $\mathrm{V}(-0,27)$.

O composto neral apresentou moderadas correlações positivas com os níveis de $\mathrm{Co}(0,30), \mathrm{Cr}(0,40), \mathrm{Mg}(0,33)$ e $\mathrm{Ni}(0,40)$, baixa correlação positiva com os níveis de Lu $(0,29)$ e moderada correlação negativa com os níveis de $\mathrm{K}(-0,35)$.

O composto geranial apresentou moderadas correlações positivas com os níveis de $\mathrm{Cr}(0,30), \mathrm{Lu}(0,35), \mathrm{Ni}(0,54)$ e Sb $(0,31)$, baixas correlações positivas com Co $(0,26), \mathrm{Mg}(0,27), \mathrm{Yb}(0,26)$, moderadas correlações negativas com os níveis de $\mathrm{Cu}(-0,30), \mathrm{K}(-0,34)$ e $\mathrm{Nd}(-0,45)$ e baixa correlação negativa com o $\mathrm{Zr}$ $(-0,26)$

O composto citronelol apresentou moderadas correlações positivas com os níveis de $\mathrm{Cu}(0,56), \mathrm{K}(0,32)$ e $\mathrm{Mn}(0,34)$ e moderadas correlações negativas com o Cr $(-0,44)$, Fe $(-0,36)$, Lu $(-0,40)$, Ni $(-0,32)$, Sc $(-0,50)$ e Th $(-0,37)$.

O composto geraniol apresentou baixa correlação positiva com o $\mathrm{Cu}(0,29)$ e moderada correlação negativa com o $\mathrm{Na}(-0,41)$.

A biomassa apresentou forte correlação positiva com $\circ \mathrm{Cu}(0,71)$, moderadas correlações positivas com $\mathrm{Ce}(0,45), \mathrm{K}(0,32)$ e $\mathrm{Mn}(0,36)$, baixas correlação positiva com o La $(0,24)$, fortes correlações negativas com o As $(0,41)$, 
$\operatorname{Br}(-0,50)$ e $\operatorname{Th}(-0,32)$ e baixas correlações negativas com o Sc $(-0,23)$ e Yb $(-0,24)$.

O teor dos óleos voláteis apresentou moderadas correlações positivas com os níveis de As $(0,34)$, Co $(0,32)$ e $\mathrm{Pb}(0,32)$; baixas correlações positivas com os níveis de $\mathrm{Cd}(0,25)$, Cs $(0,22)$, Eu $(0,24), \mathrm{Na}(0,29)$ e $\mathrm{Ni}(0,25)$ e moderada correlação negativa com o $\operatorname{Zr}(-0,30)$.

TABELA 4.18 - Matriz de correlação de Pearson entre os compostos do óleo volátil, teor, biomassa e os elementos inorgânicos presentes no solo.

\begin{tabular}{|c|c|c|c|c|c|c|c|}
\hline Variável & Citronelal & Neral & Geranial & Citronelol & Geraniol & Biomassa & Teor \\
\hline As & 0,01 & 0,17 & 0,24 & $-0,18$ & $-0,18$ & $-0,41$ & 0,34 \\
\hline $\mathrm{Br}$ & 0,22 & $-0,06$ & $-0,01$ & $-0,13$ & 0,11 & $-0,50$ & 0,15 \\
\hline $\mathrm{Ca}$ & 0,21 & $-0,11$ & $-0,23$ & 0,15 & $-0,13$ & $-0,02$ & 0,15 \\
\hline Cd & $-0,15$ & 0,16 & 0,10 & $-0,09$ & $-0,07$ & 0,21 & 0,25 \\
\hline $\mathrm{Ce}$ & $-0,04$ & 0,12 & $-0,01$ & 0,02 & $-0,08$ & 0,45 & 0,15 \\
\hline Co & 0,06 & 0,30 & 0,26 & $-0,17$ & $-0,16$ & 0,06 & 0,32 \\
\hline $\mathrm{Cr}$ & $-0,18$ & 0,40 & 0,30 & $-0,44$ & $-0,15$ & 0,13 & 0,16 \\
\hline Cs & $-0,08$ & 0,19 & 0,04 & 0,00 & $-0,21$ & 0,05 & 0,22 \\
\hline $\mathrm{Cu}$ & $-0,01$ & $-0,23$ & $-0,30$ & 0,56 & 0,29 & 0,71 & $-0,21$ \\
\hline Eu & $-0,06$ & 0,04 & 0,18 & $-0,01$ & $-0,09$ & $-0,14$ & 0,24 \\
\hline $\mathrm{Fe}$ & 0,23 & 0,20 & 0,01 & $-0,36$ & $-0,08$ & $-0,17$ & 0,07 \\
\hline Hf & 0,24 & $-0,11$ & 0,03 & $-0,29$ & 0,03 & $-0,03$ & $-0,19$ \\
\hline K & 0,24 & $-0,35$ & $-0,34$ & 0,32 & 0,10 & 0,32 & $-0,12$ \\
\hline La & $-0,01$ & 0,05 & $-0,03$ & 0,11 & $-0,13$ & 0,24 & 0,16 \\
\hline Lu & $-0,24$ & 0,29 & 0,35 & $-0,40$ & $-0,13$ & $-0,03$ & 0,16 \\
\hline Mg & $-0,28$ & 0,33 & 0,27 & $-0,25$ & $-0,13$ & $-0,18$ & 0,02 \\
\hline Mn & 0,04 & $-0,01$ & $-0,11$ & 0,34 & 0,05 & 0,36 & $-0,07$ \\
\hline $\mathrm{Na}$ & $-0,10$ & 0,14 & 0,17 & $-0,05$ & $-0,41$ & $-0,14$ & 0,29 \\
\hline $\mathbf{N i}$ & $-0,36$ & 0,40 & 0,54 & $-0,32$ & $-0,13$ & $-0,03$ & 0,25 \\
\hline $\mathrm{Pb}$ & $-0,17$ & 0,15 & 0,21 & $-0,12$ & $-0,17$ & $-0,06$ & 0,32 \\
\hline Sb & $-0,30$ & 0,17 & 0,31 & $-0,21$ & 0,14 & 0,11 & 0,17 \\
\hline Sc & 0,14 & 0,24 & 0,19 & $-0,50$ & $-0,09$ & $-0,23$ & 0,14 \\
\hline Sm & $-0,11$ & 0,08 & 0,15 & $-0,21$ & 0,20 & $-0,15$ & 0,01 \\
\hline Ta & 0,11 & 0,18 & $-0,03$ & $-0,18$ & 0,02 & 0,03 & 0,00 \\
\hline Th & 0,08 & 0,23 & 0,16 & $-0,37$ & $-0,09$ & $-0,32$ & 0,21 \\
\hline Ti & 0,18 & $-0,07$ & $-0,12$ & 0,14 & $-0,23$ & $-0,18$ & $-0,18$ \\
\hline $\mathbf{U}$ & 0,22 & $-0,11$ & $-0,17$ & $-0,07$ & $-0,08$ & 0,04 & $-0,23$ \\
\hline V & $-0,27$ & 0,14 & 0,11 & 0,01 & $-0,04$ & $-0,10$ & 0,02 \\
\hline $\mathrm{Yb}$ & $-0,08$ & 0,18 & 0,26 & $-0,22$ & 0,02 & $-0,24$ & 0,21 \\
\hline $\mathrm{Zr}$ & 0,37 & $-0,18$ & $-0,26$ & 0,12 & 0,03 & $-0,05$ & $-0,30$ \\
\hline
\end{tabular}




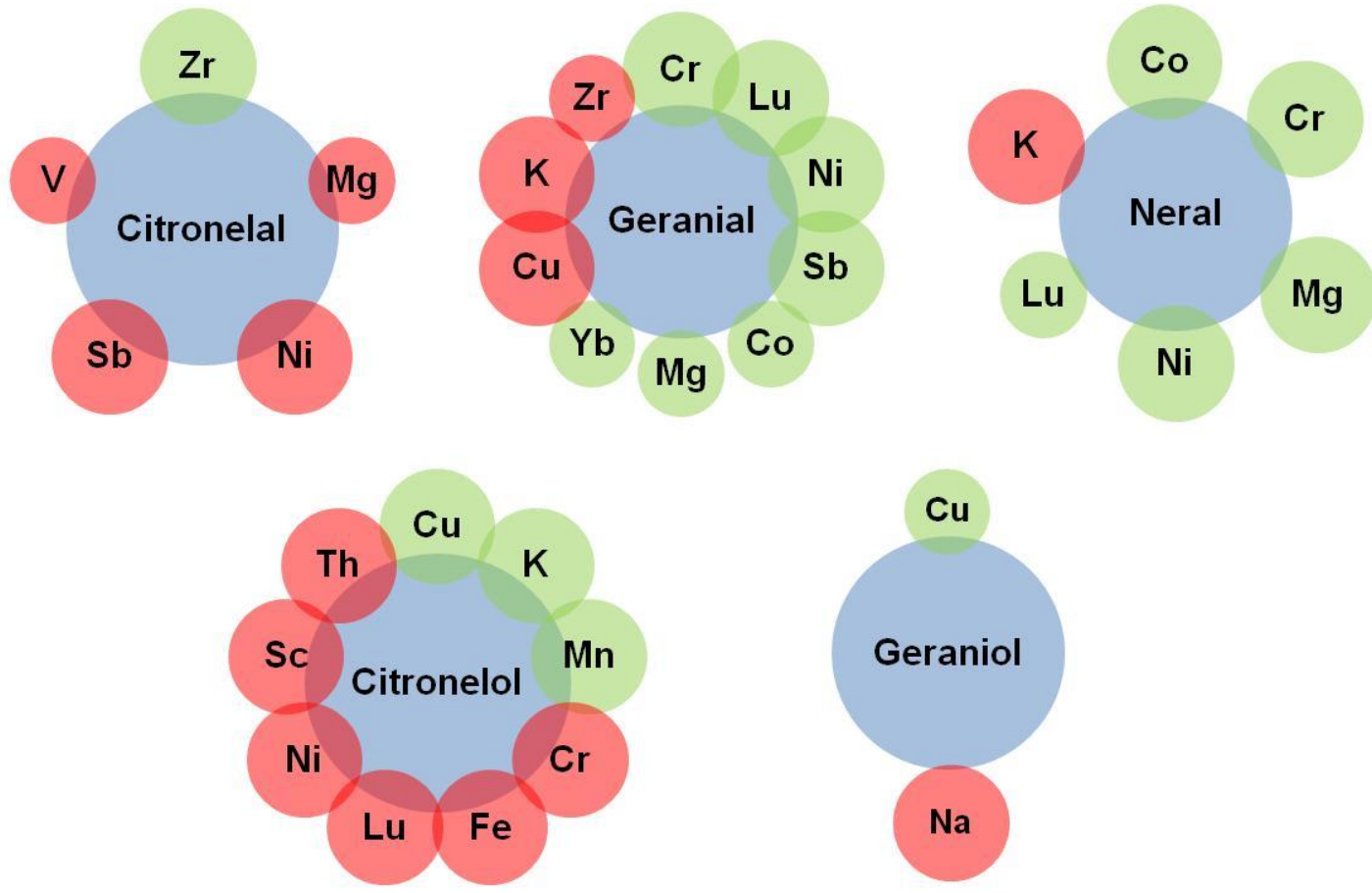

FIGURA 4.19 - Correlação entre os óleos voláteis de Melissa officinalis e os metais presentes no solo.

Correlações entre o teor de elementos essenciais, no solo, tais como Mn, $\mathrm{Cu}, \mathrm{Co}, \mathrm{Fe}$ e $\mathrm{Zn}$ e a produção de compostos voláteis também foram observadas em outros trabalhos encontrados em literatura (Vaičiulytè et al., 2017; Tounekti et al., 2010; Kanias et al., 1998) e estas podem estar relacionadas à processos de biossíntese, estresse oxidativo, produção de compostos que atuem como ligantes favorecendo a sua absorção (Aldrich et al., 2003).

Os resultados do presente estudo concordam com Garlet et al. (2007) e também com Duriyaprapan et al. (1986) e Tuomi et al. (1991) nos quais as concentrações de $\mathrm{K}$ influenciaram significativamente a produção de biomassa fresca de folhas de menta e influenciou negativamente a produção de neral e geranial. Os autores afirmam que a concentração de metabólitos secundários tende a apresentar concentração inversa às taxas de crescimento, havendo então desvio de compostos do metabolismo primário (açúcares, proteínas, lipídios) para produção de metabólitos secundários, tais como os terpenóides. 
Na TAB. 4.18 são apresentados os resultados das análises de correlação de Pearson entre os compostos do óleo volátil, biomassa, teor de óleo e concentração elementar nas folhas de melissa.

O composto citronelal apresentou moderada correlação positiva com o Mn $(0,36)$ e baixa correlação negativa com o $\mathrm{Mg}(-0,26)$.

O composto neral apresentou moderada correlação positiva com $0 \mathrm{Cl}$ $(0,41)$, correlação negativa com o $\mathrm{Cd}(-0,34)$ e baixa correlação negativa com o $\mathrm{Ni}$ $(-0,29)$.

O composto geranial apresentou moderada correlação positiva com os níveis de Hf $(0,39)$, correlações negativas com $\mathrm{K}(-0,35)$ e $\mathrm{Ni}(-0,39)$ e baixa correlação negativa com o $\mathrm{Cd}(-0,26)$.

O citronelol apresentou moderada correlação positiva com os níveis de $\mathrm{Ca}$ $(0,58)$.

O geraniol apresentou moderada correlação positiva com os níveis de $\mathrm{Ba}$ $(0,30)$, Cd $(0,36)$, Hf $(0,42)$, La $(0,37)$, $\mathrm{Na}(0,38)$ e Sm $(0,43)$ e baixa correlação positiva com o $\mathrm{Cu}(0,29)$.

O teor do óleo volátil apresentou baixa correlação positiva apenas com o $\operatorname{Mg}(0,23)$.

Apesar do cádmio não ser um elemento essencial para os processos metabólicos, esse elemento é efetivamente absorvido pelos sistemas radicular e foliar. O cádmio pode competir com o ferro e causar margens marrons nas folhas, pecíolos e veias avermelhadas, folhas enroladas e raiz atrofiada, severa redução no crescimento da raiz, redução da condutividade da haste causada pela deterioração dos tecidos do xilema, clorose, redução do crescimento e da taxa de fotossíntese, e alterações tanto enzimáticas quanto metabólicas (Kabata-pendias e Pendias, 1992; Barceló et al., 1998).

O bário, apesar de estar comumente presente nas plantas, não é um elemento essencial dos tecidos vegetais e em grande quantidade pode inibir 0 crescimento e causar toxicidade no sistema radicular (Merlino, 2013). 
TABELA 4.19 - Matriz de correlação de Pearson entre os compostos do óleo volátil, teor, biomassa e os elementos inorgânicos presentes nas folhas de Melissa officinalis.

\begin{tabular}{|c|c|c|c|c|c|c|}
\hline Variável & Citronelal & Neral & Geranial & Citronelol & Geraniol & Teor \\
\hline $\mathrm{Ba}^{\star}$ & 0,01 & $-0,05$ & 0,01 & 0,20 & 0,30 & $-0,08$ \\
\hline $\mathrm{Br}^{\star}$ & 0,17 & 0,02 & 0,16 & $-0,17$ & 0,12 & $-0,09$ \\
\hline $\mathrm{Ca}^{*}$ & 0,02 & $-0,15$ & $-0,21$ & 0,58 & 0,12 & $-0,10$ \\
\hline $\mathrm{Cd}^{\star}$ & 0,10 & $-0,34$ & $-0,26$ & 0,08 & 0,36 & $-0,20$ \\
\hline $\mathrm{Cl}^{*}$ & $-0,18$ & 0,41 & 0,14 & $-0,29$ & 0,01 & 0,23 \\
\hline Co* & 0,23 & $-0,07$ & $-0,25$ & $-0,03$ & $-0,21$ & 0,07 \\
\hline $\mathrm{Cr}^{*}$ & 0,10 & 0,01 & $-0,12$ & $-0,03$ & $-0,25$ & 0,04 \\
\hline $\mathrm{Cu}^{\star}$ & $-0,23$ & 0,08 & $-0,05$ & $-0,02$ & 0,29 & $-0,17$ \\
\hline $\mathrm{Fe}^{*}$ & $-0,04$ & $-0,05$ & 0,18 & $-0,20$ & 0,19 & $-0,06$ \\
\hline $\mathrm{Hf}^{\star}$ & $-0,20$ & $-0,31$ & 0,39 & $-0,10$ & 0,42 & $-0,19$ \\
\hline $\mathbf{K}^{*}$ & 0,22 & $-0,13$ & $-0,35$ & 0,17 & 0,23 & $-0,23$ \\
\hline $\mathbf{L a}^{*}$ & $-0,14$ & $-0,08$ & 0,29 & $-0,16$ & 0,37 & $-0,08$ \\
\hline $\mathbf{M g}^{*}$ & $-0,26$ & 0,06 & $-0,07$ & 0,14 & 0,01 & 0,23 \\
\hline $\mathrm{Mn}^{\star}$ & 0,36 & $-0,13$ & 0,07 & $-0,27$ & 0,05 & $-0,20$ \\
\hline $\mathrm{Na}^{*}$ & $-0,24$ & 0,02 & 0,23 & $-0,18$ & 0,38 & $-0,02$ \\
\hline $\mathrm{Ni}^{*}$ & 0,24 & $-0,29$ & $-0,39$ & 0,32 & $-0,05$ & $-0,11$ \\
\hline $\mathrm{Pb}^{*}$ & $-0,11$ & 0,10 & 0,13 & 0,05 & $-0,08$ & $-0,07$ \\
\hline $\mathbf{R b} \mathbf{b}^{\star}$ & $-0,16$ & 0,02 & $-0,18$ & 0,15 & 0,20 & $-0,04$ \\
\hline $\mathrm{Sb}^{*}$ & $-0,12$ & 0,08 & $-0,19$ & 0,23 & 0,01 & 0,12 \\
\hline $\mathbf{S c}^{*}$ & $-0,10$ & $-0,07$ & 0,21 & $-0,18$ & 0,24 & $-0,07$ \\
\hline $\mathrm{Sm}^{*}$ & $-0,12$ & $-0,08$ & 0,26 & $-0,09$ & 0,43 & $-0,09$ \\
\hline Th* & $-0,19$ & $-0,09$ & 0,31 & $-0,25$ & 0,32 & $-0,06$ \\
\hline $\mathbf{V}^{*}$ & $-0,16$ & $-0,18$ & 0,32 & $-0,12$ & 0,11 & 0,02 \\
\hline $\mathrm{Zn}^{*}$ & $-0,12$ & 0,21 & $-0,04$ & 0,17 & 0,00 & 0,16 \\
\hline
\end{tabular}

Valores em vermelho são significativos a $5 \%$

Verificou-se um número menor de correlações entre o teor dos elementos presentes nas folhas com os constituintes do que entre o teor de elementos no solo e os compostos orgânicos determinados. Conforme citado anteriormente isto pode estar relacionado ao fato de que as concentrações dos elementos no solo se correlacionam melhor com o teor total na planta do que com suas partes específicas. No entanto, os resultados sugerem que, principalmente, os elementos de transição apresentam alguma correlação direta ou inversa com a produção dos constituintes majoritários do óleo essencial da melissa. De acordo com Nurzynska-Wierdak (2013) a produção de óleos essenciais, bem como diversos processos que ocorrem nas plantas, é dependente de uma série de fatores, entre os quais a presença de diferentes substâncias e enzimas e das 
rotas metabólicas nas quais estes compostos são formados. Entre estas substâncias encontram-se os micronutrientes, incluindo os elementos de transição que podem influenciar não apenas o desenvolvimento nas também a biossíntese dos óleos essenciais (Prasad et al., 2011). Estes metais atuam também como agentes antioxidantes em diversos compostos em reposta a estímulos ou estresse fisiológico (Elzaawely et al., 2007).

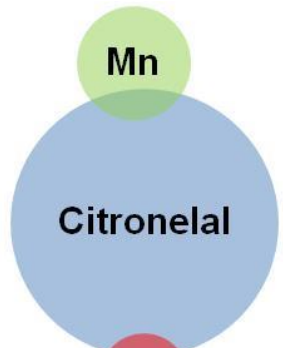

$\mathrm{Mg}$
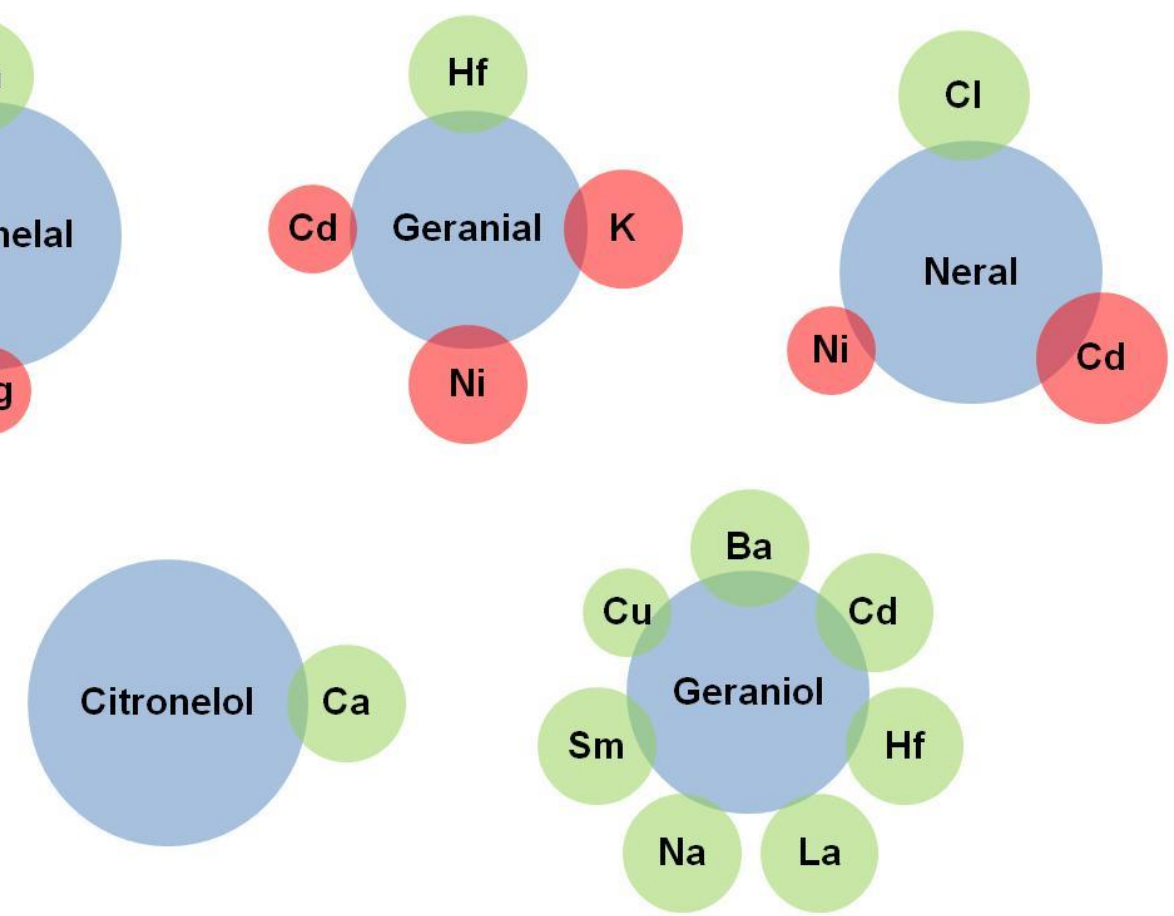

FIGURA 4.20 - Correlação entre os óleos voláteis e os metais presentes nas folhas de Melissa officinalis.

Os resultados aqui obtido indicam que os teores de $\mathrm{Co}, \mathrm{Cr}, \mathrm{Mg}$ e $\mathrm{Ni}$ no solo favorecem a formação de citral (neral e geranial) enquanto que $Z r$, no solo e de $\mathrm{Mn}$ nas folhas podem favorecer a formação de citronelal. Conforme mostrado na FIG. 1.3, as rotas de biossíntese do citronelal e dos alcóis citronelol, nerol e geraniol, a partir do citral, são concorrentes e catalisadas por metais de transição. Desta forma, uma vez que as correlações obtidas entre os teores dos elementos na folha e a formação dos constituintes não foram significativas pode-se inferir que a biossíntese destes óleos é dose-dependente em relação aos teores no solo, mas provavelmente não aos teores presentes na folha de Melissa officinalis. 


\section{CONCLUSÕES}

Os diferentes manejos do solo aplicados no estudo foram satisfatórios, ou seja, resultaram em solos com características suficientemente distintas do solo controle. Com a aplicação da análise de componentes principais (PCA) foi possível distinguir quais variáveis influenciaram nessa separação.

O manejo agrícola influenciou a produção de biomassa fresca e a variabilidade química das amostras de Melissa officinalis.

A sazonalidade influenciou nos teores de óleos voláteis extraídos das folhas de Melissa officinalis e na variabilidade dos constituintes inorgânicos e orgânicos analisados nas folhas de Melissa officinalis.

O período do inverno apresentou os menores teores de óleo volátil e, embora não significativa, o período do verão apresentou uma tendência de aumento nos teores dos óleos voláteis extraídos. Para os teores dos constituintes majoritários, neral e geranial, houve uma diminuição no período do inverno.

As concentrações de arsênio (As), antimônio ( $\mathrm{Sb}$ ) e chumbo (Pb), determinadas nas folhas de Melissa officinalis, ficaram acima dos limites máximo permitidos pela ANVISA.

A análise da variabilidade química nos solos e nas folhas de Melissa officinalis, determinada pela análise de componente principal (PCA), refletiu a influência do ambiente sobre a composição dos óleos voláteis.

Baseando-se nos resultados obtidos neste trabalho, pode-se concluir que os metabólitos de maior interesse, neral e geranial, estão correlacionados positivamente com $\mathrm{Co}, \mathrm{Cr}, \mathrm{Mg}$ e $\mathrm{Ni}$, e negativamente correlacionado com $\mathrm{Cu}$ e $\mathrm{K}$ presentes no solo. No estudo da correlação com os metais presentes nas plantas, o neral e geranial apresentaram correlações positivas com $\mathrm{Cl}$ e correlação negativa com $\mathrm{Cd}$, $\mathrm{K}$ e $\mathrm{Ni}$.

Citronelal apresentou correlação positiva com $\mathrm{Mn}$ e correlação negativa com Mg das folhas. 
Citronelol apresentou correlação positiva com $\mathrm{Cu}, \mathrm{K}$ e $\mathrm{Mn}$ presentes no solo e com $\mathrm{Ca}$ presentes nas folhas; e correlação negativa com $\mathrm{Cr}, \mathrm{Fe}, \mathrm{Ni}$ presentes no solo.

Geraniol apresentou correlação positiva com $\mathrm{Cu}$ presente no solo e na folha e com $\mathrm{Cd}$ e $\mathrm{Na}$ (folha); e correlação negativa com o $\mathrm{Na}$ presente no solo.

As colheitas realizadas na primavera e verão resultaram em um óleo de melhor qualidade, por possuírem os menores teores de citronelol, nerol e geraniol.

Nos resultados são mostrados que a formação de neral e geranial foi favorecida no manejo convencional correlacionado com a presença dos elementos $\mathrm{Co}, \mathrm{Cr}, \mathrm{Mg}$ e $\mathrm{Ni}$ presentes do solo, enquanto que a formação do citronelal foi favorecida no manejo orgânico correlacionado com o $\mathrm{Mn}$ presente nas folhas de Melissa officinalis.

No entanto, os resultados não mostraram diferenças significativas entre os manejos orgânico e convencional nos teores dos principais constituintes de interesse. Desta forma pode-se sugerir que a adubação orgânica é a mais adequada, pois apresenta a vantagem de ser menos agressiva ao meio ambiente e contribui para condições mais favoráveis do solo. Alem disso, os elementos que apresentaram melhor correlação com a produção dos principais componentes do óleo volátil de Melissa officinalis estão associados a este manejo.

Este trabalho contribui para uma forma de recomendação de cultivo de Melissa officinalis para o Estado de São Paulo, visto que não existe recomendação de adubação para esta espécie.

Esta pesquisa colabora com o Programa Nacional de Plantas Medicinais e Fitoterápicos (PNPMF), promovendo o cultivo, manejo e a produção de planta medicinal e, assegurando o acesso e a qualidade da espécie estudada.

A partir deste trabalho é possível sugerir a realização de novas pesquisas em que poderão ser desenvolvidos estudos dos efeitos da especiação destes e de outros metais sobre a produção dos compostos majoritários da espécie; avaliar outros fatores ambientais, como incidência solar, pois este influencia no desenvolvimento vegetal e causa alterações morfofisiológicas; cultivar a espécie com adição dos metais que neste trabalho apresentaram correlações positivas, a fim de aumentar a produção dos compostos de interesse. 


\section{REFERÊNCIAS BIBLIOGRÁFICAS}

ABREU JUNIOR, $\mathrm{H}$. de. Práticas alternativas de controle de pragas e doenças na agricultura: Coletânea de receitas. Campinas, EMOPI, v. 11, p.11, 1998.

\section{ADAMS, R.P. Identification of Essential Oil Components by Gas Cromatography/Mass Spectroscopy. Carol Stream, USA, 2001.}

AGÊNCIA NACIONAL DE VIGILÂNCIA SANITÁRIA. Resolução - RDC no 10, de 9 de março de 2010. Dispõe sobre a notificação de drogas vegetais junto à Agência Nacional de Vigilância Sanitária (ANVISA) e dá outras providências. Diário Oficial da União, Brasília, DF, 10 mar. Seção 1, p. 52-59, 2010.

AGUIAR, J.S.; COSTA, M.C.C.D. Lippia alba (Mill.) N. E. Brown (Verbenaceae): levantamento de publicações nas áreas química, agronômica e farmacológica, no período de 1979 a 2004. Revista. Brasileira de Plantas Medicinais, v. 8, n. 1, p. $79-84,2005$.

ALBRECHT, W.A. Soil reaction ( $\mathrm{pH})$ and balanced plant nutrition, Colorado, USA, 1967.

ALDRICH, M.V.; GARDEA-TORRESDEY, J.L.; PERALTA-VIDEA, J.R.; PARSONS, J.G. Uptake and reduction of $\mathrm{Cr}(\mathrm{VI})$ to $\mathrm{Cr}(\mathrm{III})$ by mesquite (Prosopis spp.): Chromate-plant interaction in hydroponics and solid media studied using XAS. Environmental Science and Technology, v. 37, p. 1859-1864, 2003.

ALLEONI, L.R.F.; BEAUCLAIR, E.G.F. Cana-de-açúcar cultivada após milho e amendoim, com diferentes doses de adubo. Scientia Agricola, v. 52, n. 3, p. 409415, 1995.

ALVARENGA, P.; ARAÚJO, M.F.; DA SILVA, J.A.L. As plantas, os solos, os metais e a vida. Química, v. 71, p. 10-19, 1998.

ANDRADE, M.G. de. Elementos-traço As, Ba, Cd, Cr, Cu, $\mathrm{Hg}$, Mo, $\mathrm{Ni}, \mathrm{Pb}$, Se e Zn em latossolos e plantas de milho após treze aplicações anuais de lodo de esgoto Jaboticabal. 2011. Tese (Doutorado) - Universidade Estadual Paulista, Jaboticabal.

ANDREOLI, C.V.; TAMANINI, C.R.; HOLSBACH, B.; PEGORINI, E.S.; NEVES, P.S. Uso de lodo de esgoto na produção de substrato vegetal. In: ANDREOLI, C.V. (Coord) Alternativas de Uso de Resíduos do Saneamento. Rio de Janeiro, RJ, 2006, p. 87-116. 
ANVISA. Resolução de Diretoria Colegiada no. 42 de 29 de agosto de 2002. Dispõe sobre o Regulamento Técnico MERCOSUL sobre Limites Máximos de Contaminantes Inorgânicos em Alimentos. Diário Oficial da União, 2002.

ARSENIJEVIĆ, J.; MARKOVIC, J.; SOSTARIC, I.; RAZIC, S. A chemometrics as a powerful tool in the elucidation of the role of metals in the biosynthesis of volatile organic compounds in Hungarian thyme samples. Plant Physiology and Biochemistry, v. 71, p. 298-306, 2013.

ARUMUGAM, R.; KANNAN, R.R.R.; JAYALAKSHIMI, J.; MANIVANNAN, K.; DEVI, G. K.; ANANTHARAMAN, P. Determination of element contents in herbal drugs: Chemometric approach. Food Chemistry, v. 135, p. 2372-2377, 2012.

ASHFAQ, M.; ALI, S.; HANIF, M.A. Bioaccumulation of cobalt in silkworm (Bombyx mori L.) in relation to mulberry, soil and wastewater metal concentrations. Process Biochemistry, v. 44, n. 10, p. 1179-1184, 2010.

AYDIN, I.; AYDIN, F.; SAYDUT, A.; BAKIRDERE, E.G.; HAMAMCI, C. Hazardous metal geochemistry of sedimentary phosphate rock used for fertilizer.

Microchemical Journal, v. 96, p. 247-251, 2010.

AOYAMA, E.M.; INDRIUNAS, A.; FURLAN, M.R. Produção de folhas em Melissa officinalis L. (Lamiaceae) em Taubaté, São Paulo. Revista Biociências, v. 17, n. 1, 2011.

BAKKAUS, E.; GOUGET, B.; GALLIEN, J.P.; KHODJA, H.; CARROT, F.; MOREL, J.L.; COLLINS, R. Concentration and distribution of cobalt in higher plants: The use of micro-PIXE spectroscopy, Nuclear Instruments and Methods in Physics Research Section B. Beam Interactions with Materials and Atoms, v. 231, n. 14, p. 350-356, 2005.

BARCELÓ, J.; VASQUES, M.; POSCHENRIEDER, C. Structural and ultrastructural disorders in cadmium treated bush bean plants (Phaseolus vulgaris L.). New Phytologist, v. 108, p. 37-49, 1988.

BLANK, A.F.; FONTES, S.M.; OLIVEIRA, A.S.; MENDONÇA, M.C.; SILVA-MANN, R.; ARRIGONI-BLANK, M.F. Produção de mudas, altura e intervalo de corte em melissa. Horticultura Brasileira, v. 23, n. 3, p. 780-784, 2005.

Boletim Climatológico Anual da Estação Meteorológica do IAG/USP/ Seção Técnica de Serviços Meteorológicos - Instituto de Astronomia, Geofísica e Ciências Atmosféricas da Universidade de São Paulo - v 16, 2013 - São Paulo: IAG/USP, 2013. 
Boletim Climatológico Anual da Estação Meteorológica do IAG/USP/ Seção Técnica de Serviços Meteorológicos - Instituto de Astronomia, Geofísica e Ciências Atmosféricas da Universidade de São Paulo - v 17, 2014 - São Paulo: IAG/USP, 2014.

BOSTELMANN, E. Avaliação da concentração de metais em amostras de sedimento do Reservatório Billings, Braço Rio Grande, São Paulo, Brasil. 2006. Dissertação (Mestrado) - Universidade de São Paulo, São Paulo.

BRASIL. Farmacopeia Brasileira, volume 2 / Agência Nacional de Vigilância Sanitária. Brasília: Anvisa, 5 ed., v. 1, p. 198-199, 2010.

BRASIL. Ministério da Saúde. Agência Nacional de Vigilância Sanitária. Resolução da Diretoria Colegiada - RDC no 42 de 29 de agosto de 2013. Dispõe sobre o Regulamento Técnico MERCOSUL sobre Limites Máximos de Contaminantes Inorgânicos em Alimentos. 2013.

BRASIL. Ministério da Saúde. Secretaria de Ciência, Tecnologia e Insumos Estratégicos. Departamento de Assistência Farmacêutica. Política Nacional de Plantas Medicinais e Fitoterápicos / Ministério da Saúde, Secretaria de Ciência, Tecnologia e Insumos Estratégicos, Departamento de Assistência Farmacêutica. - Brasília: Ministério da Saúde, 2006. 60 p.

BROWN, B.; HART, J.M.; WESCOTT, M.P.; CHRISTENSEN, N.W. The critical role of nutrient management in mint production. Better Crops, n. 4, v. 87, p. 9-11, 2003.

CALLEGARI-JACQUES, S.M. Bioestatística: princípios e aplicações. Porto Alegre: Artmed, 2003.

CARVALHO, C.M.; COSTA, C.P.M.; SOUSA, J.S.; SILVA, R.H.D.; OLIVEIRA, C.L.; PAIXÃO, J.R. Rendimento da produção de óleo essencial de capim-santo submetido a diferentes tipos de adubação. Revista de Biologia e Ciências da Terra, v. 5, n. 2, p. 25-28, 2005.

CARVALHO, M.L.; MAGALHÃES, T.; BECKER, M. Trace elements in human cancerous and healthy tissues: a comparative study by EDXRF, TXRF, synchrotron radiation and PIXE. Spectrochimica Acta, v. 62, p. 1004-1011, 2007.

CASS, H. Herbs for the nervous system: Ginkgo, kava, valerian, passion flower. Seminário de Integração Medicinal. v. 2, p. 82-88, 2004.

CASTRO, H.G.; FERREIRA, F.A.; SILVA, D.J.H.; MOSQUIM, P.R. Contribuição ao estudo das plantas medicinais Metabólitos Secundários. 2. ed. Visconde do Rio Branco: Suprema, p. 113, 2004. 
COBOS, J.Y.G.Fontes nitrogenadas no crescimento e produção de óleo essencial de espécies de capim-limão. 2015. Dissertação (Mestrado) Universidade Federal do Paraná, Curitiba.

COLUSSI, T.C.; DALMOLIN, L.F.; PACHTMANN, M.; FREITAS, G.B.L. Melissa officinalis $L$ : Características gerais e biossíntese dos principais metabólitos secundários. Revista de Biologia e Farmácia, v. 5, n. 2, p. 88-100, 2011.

Committee on toxicity of chemicals in food, consumer products and the environment cot statement on the 2006 uk total diet study of metals and other elements. Disponível em: http://cot.food.gov.uk/pdfs/cotstatementtds200808.pdf. acesso em: 10/2015.

CORREIA, P.R.M.; NOMURA, C.S.; OLIVEIRA, P.V. Espectrometria de Absorção Atômica multielementar: Desafios e perspectivas. Revista Analytica, v. 5, p. 5259, 2003.

COSTA, J.R. Técnicas Experimentais aplicadas às Ciências Agrárias. Seropédica: Embrapa Agrobiologia, 2003. p. 102.

DEON, M.D. Crescimento e nutrição mineral da soja submetida a excesso de $\boldsymbol{P}, \mathbf{S}, \mathbf{K}, \mathrm{Ca}$ e $\mathrm{Mg}$ em solução nutritiva. 2007. Dissertação (Mestrado) Universidade de São Paulo, São Paulo.

DIAS, L.S; DIAS, A.S. Metabolitos secundários como fontes de bioherbicidas: situação atual e perspectivas. Revista de Ciências Agrárias, p. 510-517, 2004.

DIDILLON, L.B.; CANDY, C.; BASSETT, V.; BOURNONVILLE, C. Hydrogenation of citral, n. 578, v. 113, p. 1-6, 1990.

DUARTE, A.R. Variabilidade química dos óleos essenciais e do teor de fenóis em folhas e frutos da jabuticabeira (Myrciaria cauliflora). 2012. Tese (Doutorado) - Universidade Federal de Goiás, Goiânia.

DURIYAPRAPAN, S.; BRITTEN, E.J.; BASFORD, K.E. The effect of temperature on growth, oil yeld and oil quality of Japanese mint. Annals of Botany, v. 58, n. 5, p. 729-736, 1986.

ELZAAWELY, A.E.; XUAN, T.D.; TAWATA, S. Changes in essential oil, kava pyrones and total phenolics of Alpinia zerumbet (Pers.) B.L. Burtt. \& R.M. Sm. leaves exposed to copper sulphate. Environmental and Experimental Botany, v. 59, n. 3, p. 347-353, 2007.

EMBRAPA. Centro Nacional de Pesquisa de Solos. Manual de métodos de análise de solo. 2. ed. Revista Atual, Rio de Janeiro, 1997. 
ERNANI, P.R. Química do solo e disponibilidade de nutrientes. Lages, SC, 2008.

FEI, T.; DEHONG, L.; FENGQUN, Z.; JUNHUA, L.; HUA, T.; XIANGZHONG, K. Determination of trace elements in Chinese medicinal plants by instrumental nêutron activation analysis. Journal of Radioanalytical and Nuclear Chemistry, v. 284, p. 507-511, 2010.

FERRARI, A.P. Caracterização química de tomates (Lycopersicon esculentum Mill.) empregando análise por ativação neutrônica instrumental. 2008. Dissertação (Mestrado) - Química na Agricultura e no Ambiente, Piracicaba.

FERREIRA, M.M.C. Quimiometria - Conceitos, Métodos e Aplicações. Editora da Unicamp, Campinas, SP, 2015.

FLÜCK, $\mathrm{H}$. The influence of the soil on the content of active principles in medicinal plants. The Journal of Pharmacy and Pharmacology, v. 6, p. 153-163, 1954.

FRANCISCONI, L.S. Determinação dos constituintes inorgânicos em plantas medicinais e seus extratos. 2014. Dissertação (Mestrado) - Universidade de São Paulo, SP.

FREITAS, G.A.; RODRIGUES, D.M.; SOUSA, C.R.; CAPONE, A.; AFFÉRRI, F.S.; SILVA, R.R. Parâmetros biométricos de sorgo granífero (Sorghum bicolor (L.) Moench) submetido a diferentes doses de adubação orgânica. Cadernos de Agroecologia, v. 6, n. 2, p. 1-5, 2011.

FREITAS, M.S.M.; MARTINS, M.A. Crescimento e produção de óleo essencial em plantas de Mentha arvensis L. em resposta à inoculação com micorrizas. In: FERTBIO, v. 25, Rio de Janeiro, 2002.

FURLAN, M.R. Cultivo de Plantas Medicinais. SEBRAE, Coleção Agroindústria, Cuiabá, MT, 2005. 140p.

FURLAN, M.R.; MARTINS, R.C.C.; RODRIGUES, E.; SCALCO, N.; NEGRI, G.; LAGO, J.H.G. Variação dos teores de constituintes voláteis de Cymbopogon citratus (DC) Staf, Poaceae, coletados em diferentes regiões do Estado de São Paulo. Revista Brasileira de Farmacognosia, v. 20, n. 5, p. 686-691, 2010.

GARLET, T.M.B.; SANTOS, O.S.; MEDEIROS, S.L.P.; MANFRON, P.A.; GARCIA, D.C.; BORCION, E.; FLEIG, V. Produção e qualidade do óleo essencial de menta em hidroponia com doses de potássio. Ciência Rural, v. 37, n. 4, p. 956-962, 2007 
GERSHENZON, J. Changes in the level of plant secondary metabolites under water and nutrient stress. Recent Advances in: Phytochemistry N.Y. v. 18, p. 273-319, 1984.

GLASCOCK, M.D. An Overview of Neutron Activation Analysis. Archaeometry Laboratory, University of Missouri Research Reactor, Columbia, out. 2010. GOBBO-NETO, L., LOPES, N.P. Plantas medicinais: fatores de influência no conteúdo de metabólitos secundários. Química Nova, v. 30, n. 2, p. 374-381, 2007.

GREENBERG, R.R.; BODE, P.; DE NADAI FERNANDES, E.A. Neutron activation analysis: A primary method of measurement. Spectrochimica Acta, n. 66, p. 193241, 2011.

GRYGO-SZYMANKO, E.; TOBIASZ, A.; WALAS, S. Speciation analysis and fractionation of manganese: A review. Trends in Analytical Chemistry, v. 80, p. 112-124, 2016.

GUIMARÃES, G.M. Avaliação da concentração de metais e elementos traço em amostras de sedimento do Reservatório Guarapiranga, São Paulo, SP, Brasil. 2011. Dissertação (Mestrado) - Universidade de São Paulo, São Paulo.

HABER, L.L.; LUZ, J.M.Q.; ARVATIDÓRO, L.F.; SANTOS, J.E. Diferentes concentrações de solução nutritiva para o cultivo de Mentha piperita e Melissa officinalis. Horticultura Brasileira, v. 23, n. 4, p. 1006-1009, 2005.

HAZENFRATZ-MARKS, R. Nêutrons, radiação e arqueologia: Estudo de caso multianalítico de cerâmicas da tradição borda incisa na Amazônia central. 2014. Tese (Doutorado) - Universidade de São Paulo, São Paulo.

HEWITT, E.J.; SMITH, T.A. Plant Mineral Nutrition, English University Press, London, 1975.

IIJIMA, Y. et al. Analysis of the enzymatic formation of citral in the glands of sweet basil. Archives of Biochemistry and Biophysics, v. 448, n. 1-2, p. 141-149, 2006.

INMETRO, INSTITUTO NACIONAL DE METROLOGIA, QUALIDADE E TECNOLOGIA. Orientação sobre validação de métodos analíticos. Rio de Janeiro, Fev. 2010. Disponível em: $<$ http://www.inmetro.gov.br/Sidoq/Arquivos/CGCRE/DOQ/DOQ-CGCRE-

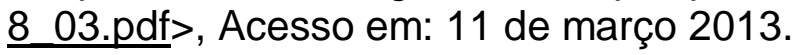


IVYENGAR, G. V.; KOLLMER, W. E.; BROWEN, H. J. M. The elemental composition of human tissues and body fluids. Weinheim: Verlag Chemie, 1970.

KABATA-PENDIAS, A.; MUKHERJEE, A.B. Trace Elements from Soil to Human. 2007. Springer, New York.

KABATA-PENDIAS, A.; PENDIAS, H. Trace Elements in Soil and Plants. 2 ed. Florida: CRC Press, p. 365, 1992.

KANIAS, G.D.; SOULELES, C.; LOUKIS, A.; PHILOTHEOU-PANOU, E. Trace elements and essential oil composition in chemotypes of the aromatic plant Origanum vulgate. Journal of Radioanalytical and Nuclear Chemistry, v. 227, n. 1, p. 23-31, 1998.

KIEHL, E.J. Fertilizantes Orgânicos. São Paulo: Agronômica Ceres, 1985, p. 492.

KIRKBY, E.A.; RöMHELD, V. Micronutrientes na fisiologia de plantas: funções, absorção e mobilidade. The International Fertilizer Society, n. 118, p. 1-24, 2007.

KONIECZKA. P.; NAMIESNICK, J. Quality Assurance and Quality Control in the Analytical Chemical Laboratory. Flórida: CRC Press, 2009.

KOUACHI, K.; LAFAYEA, G.; ESPECEL, C.; CHERIFIB, O.; MARÉCOT, P. Preparation of silica-supported cobalt catalysts from water-in-oil microemulsion for selective hydrogenation of citral. Journal of Molecular Catalysis A: Chemical, v. 308, p. 142-149, 2009.

KRISHNA, R.; RAMAKRISHNA, C.; SONI, K.; GOPI, T.; SWETHA, G.; SAINI, B.; SHEKAR, S.C. Effect of Alkali Carbonate/Bicarbonate on Citral Hydrogenation over Pd/Carbon Molecular Sieves Catalysts in Aqueous Media. Modern Research in Catalysis, v. 5, p. 1-10, 2016.

LORENZI, H.; MATOS, F.J.A. Plantas Medicinais do Brasil: nativas e exóticas. Nova Odesa: Plantarum, 2002, p. 544.

LUZ, J.M.Q.; SILVA, S.M.; HABBER, L.L.; MARQUEZ, M.O.M. Produção de óleo essencial de Melissa officinalis $L$. em diferentes épocas, sistemas de cultivo e adubações. Revista Brasileira de Pantas Medicinais, v. 16, n. 3, p. 552-560, 2014. 
MÄKI-ARVELA, P.; TIAINEN, L.P.; LINDBLAD, M.; DEMIRKAN, K.; KUMAR, N.; SJÖHOLM, R.; OLLONQVIST, T.; VÄYRYNEN, J.; SALMI, T.; MURZIN, D.Y. Liquid-phase hydrogenation of citral for production of citronellol: catalyst selection. Applied Catalysis A: General. v. 241, p. 271-288, 2003.

MALAVOLTA, E. Elementos de Nutrição Mineral de Plantas. São Paulo: Agronômica Ceres, 1980, p. 251.

MALAVOLTA, E. Micronutrientes e Metais Pesados: Mitos, Mistificação e Fatos. São Paulo: Produquímica, 1994, 140p.

MARCHI, G.; GUILHERME, L.R.G.; SILVA, C.A.; GONÇALVES, V.C. Elementostraço e sua relação com qualidade e inocuidade de fertilizantes, corretivos agrícolas e resíduos orgânicos no Brasil. Planaltina, DF, Embrapa Cerrados, 2009.

MARTINS, E.R.; CASTRO, D.M., CASTELLANI, D.C. DIAS, J.E. Plantas Medicinais. Viçosa: UFV, p. 220, 1995.

MARTINS, E.R.; FIGUEIREDO, L.S. Cultivo de plantas medicinais. IN: LEITE, J. P. V. Fitoterapia: bases científicas e tecnológicas. São Paulo: Atheneu, 2009. p. $143-167$.

MAY, A.; BOVI, O.A.; SACCONI, L.V.; SAMRA, A.G.; PINHEIRO, M.Q. Produtividade da biomassa de melissa em função de intervalo de cortes e doses de nitrogênio. Horticultura Brasileira, v. 26, n. 3, p. 312-315, 2008.

MCLAFFERTY, F.W.; STANFFER, D.B. Registry of Mass Spectral Data. WileyInterscience, New York, N.Y, 1989.

MEIRA, M.R.; MANGANOTTI, S.A.; MARTINS, E.R. Crescimento e produção de óleo essencial de Melissa officinalis L. nas condições climáticas de Montes Claros - MG, Biotemas, v. 24, n. 1, p. 1-8, 2011.

MENDES, A.M.S.; OLSZEVSKI, N.; SILVA, F.N.; MENDES, R.L.; BRITO, L.T.L. Impactos ambientais causados pelo uso de fertilizantes agrícolas.

EMBRAPA, p. 55-99, 2010.

MERLINO, L.C.S. Disponibilidade de bário para plantas de sorgo cultivadas em solo contaminado com o elemento. 2013. Tese (Doutorado) - Faculdade de Ciências Agrárias e Veterinárias, Jaboticabal. 
MERTENS, P.G.N.; CUYPERS, F.; VANDEZANDE, P.; YE, X.; VERPOORT, F.; VANKELECOM, I.F.J.; DE VOS, D.E. $\mathrm{Ag}^{0}$ and $\mathrm{Co}^{0}$ nanocolloids as recyclable quasihomogeneous metal catalysts for the hydrogenation of a,b-unsaturated aldehydes to allylic alcohol fragrances. Applied Catalysis A: General. v. 325, p. 130-139, 2007.

MING, L.C.; FERREIRA, M.I.; GONÇALVES, G.G. Pesquisas agronômicas das plantas medicinais da Mata Atlântica regulamentadas pela ANVISA. Revista Brasileira de Plantas Medicinais, vol. 14, p. 131-137, 2012.

MORAIS L. A. S. Influencia dos fatores abióticos na composição química dos óleos essenciais. Horticultura Brasileira, v. 27, p. 4050-4063, 2009.

MOREIRA, H.S.; SAIKI, M.; VASCONCELLOS, M.B.A. Análise por ativação com nêutrons de fitoterápicos obtidos de plantas medicinais. In: International Nuclear Atlantic Conference - INAC 2007, Belo Horizonte, 2007.

MÜZELL, D. P. Propriedades Biológicas de Extratos de Melissa officinalis L. (Lamiaceae) em Ratos Wistar. 2006. Tese (Mestrado em Biologia Celular e Molecular). Porto Alegre: Faculdade de Biociências - Pontifícia Universidade Católica do Rio Grande do Sul, Rio Grande do Sul.

NETO, M.J.L.; NASCIMENTO, E.S.; MAIHARA, V.A.; SILVA, P.S.C. LANDGRAF, $M$. Evaluation of $A s$, Se and $Z n$ in octopus samples in different points of sales of the distribution chain in Brazil. Journal Radioanalytical and Nuclear Chemistry, v. 301, p. 573-579, 2014.

NORDLØKKEN, M.; ERG, T.; FLATEN, T.P.; STEINNES, E. Essential and nonessential elements in natural vegetation in southern Norway: Contribution from different sources. Science of The Total Environment, v. 502, p. 391-399, 2015.

NOVAES, F.R. Fertilidade do Solo. Viçosa, M.G. Sociedade Brasileira de Ciência do Solo. p. 92 -120, 2007.

NURZYNSKA-WIERDAK, R. Does mineral fertilization modify essential oil content and chemical composition in medical plants? Acta Scientiarum Polonorum Hortorum Cultus. v. 12, p. 3-16, 2013.

OLOWOYO, J.O.; OKEDEYI, O.O.; MKOLO, N.M.; LION, G.N.; MDAKANE, S.T.R. Uptake and translocation of heavy metals by medicinal plants growing around a waste dump site in Pretoria, South Africa. South African Journal of Botany, v. 78, p. 116-121, 2012. 
OURIVES, O.E.A.; SOUZA, G.M.; TIRITAN, C.S.; SANTOS, D.H. Fertilizante Orgânico como Fonte de Fósforo no Cultivo Inicial de Brachiaria brizantha cv. Pesquisa Agropecuária Tropical. v. 40. n. 2, p. 126- 132, 2010.

PARREIRA, T.F. Utilização de métodos quimiométricos em dados de natureza multivariada. 2003. Dissertação (Mestrado) - Universidade Estadual de Campinas, Campinas.

PAYE, H.S.; DE MELLO J.W.V.; DE MELO, S.B. Métodos de análise multivariada no estabelecimento de valores de referência de qualidade para elementos-traço em solo. Revista Brasileira de Ciências do Solo, n. 36, p. 1031-1041, 2012.

PETENATTI, M.E,; PETENATTI, E.M,; DEL VITTO, L.A,; TÉVES, M.R,; CAFFINI, N.O,; MARCHEVSKY, E.J,;PELLERANO, R.G. Evaluation of macro and microminerals in crude drugs and infusions of five herbs widely used as sedatives. Revista Brasileira de Farmacognosia. v. 21, n. 6, p. 1144-1149, 2011.

PRADO, G.R. Estudo de contaminação ambiental por urânio no município de Caetité-Ba, utilizando dentes de humanos como bioindicadores. 2007.

Dissertação (Mestrado) - Universidade Estadual de Santa Cruz, Caetité, Bahia.

PRADO, R.M.; NATALE, W. Calagem na nutrição de cálcio e no desenvolvimento do sistema radicular da goiabeira. Pesquisa Agropecuária Brasileira, v. 39, n. 10, p. 1007-1012, 2004

PRASAD A.; KUMAR S.; KHALIQ A. Heavy metals and arbuscular mycorrhizal (AM) fungi can alter the field and chemical composition of volatile oil of sweet basil (Ocimum basilicum L.). Biology and Fertility of Soils, v. 47, p. 853-861, 2011.

RAGUŽ, V.; JARSJÖ, J.; GROLANDER, S.; LINDBORG, R.; AVILA, R. Plant uptake of elements in soil and pore water: Field observations versus model assumptions. Journal of Environmental Management, v. 126, p. 147-156, 2013.

RAIJ, B. van; CANTARELLA, H.; QUAGGIO, J.A.; FURLANI, A.M.C. (Ed.) Recomendações de adubação e calagem para o Estado de São Paulo. 2.ed. Campinas: IAC, 1997. 285p. (Boletim Técnico, 100).

REIS, E.S.; PINTO, J.E.B.P.; ROSADO, L.D.S; CORRÊA, R.M. Teor e composição química do óleo essencial de Melissa officinalis $L$. in vitro sob a influência do meio de cultura. Acta Scientiarium Agronomy, v. 31, n. 2, p. 331 335, 2009.

RIBEIRO, F.C.A. Manejo agrícola e teores de radionuclídeos naturais em vegetais cultivados no Rio de Janeiro. 2004. Dissertação (Mestrado) - Instituto de Radioproteção e Dosimetria, Rio de Janeiro. 
SANTOS, R.I. Metabolismo básico e origem dos metabolitos secundários. In: SIMOES, C. M. O et al.(ed.). Farmacognosia: da planta ao medicamento. 3. ed. Porto Alegre, Ed. UFSC. cap.16, p. 333-364, 2001.

SANTOS, C.C.; BELLINGIERI, P.A.; FREITAS, J.C. Efeito da aplicação de compostos orgânicos de cama de frango nas propriedades químicas de um Latossolo Vermelho Escuro cultivado com sogro granífero [Sorghum bicolor (L.) Moench]. Científica, v. 32, n. 2, p. 134-140, 2008.

SENA, M.M.; POPPI, R.J. Avaliação do uso de métodos quimiométricos em análise de solo. Química Nova, v. 23, n. 4, 2000.

SEVERINO, L.S.; COSTA, F.X.; BELTRÃO, N.E. de; LUCENA, M.A. de; GUIMARÃES, M.M.B. Mineralização da torta de mamona, esterco bovino e bagaço de cana estimada pela respiração microbiana. Revista de Biologia e Ciências da Terra, n. 1, v. 5, 2004.

SHRIVER, D.F.; ATKINS, P.W.; OVERTON, T.L.; ROURKE, J.P.; WELLER, M.T.; ARMSTRONG, F.A. Química Inorgânica, quarta edição. Ed. ARTMED S.A., 2006.

SILVA, M.L.S. Avaliação do comportamento de elementos traço essenciais e não essenciais em solo contaminado sob cultivo de plantas. 2006. Tese (Doutorado) - Escola Superior de Agricultura Luiz de Queiroz, Piracicaba.

SILVA, P.S.C. Determinação de Radionuclídeos Pertencentes às Séries Naturais de Decaimento do U-238 e Th-232 nos Fosfatos de Arquipélago de Abrolhos (BA). 1998. Dissertação (Mestrado) - Instituto Astronômico e Geofísico Universidade de São Paulo, São Paulo.

SILVA, S.M. Sistema e época de cultivo na produção agronômica e de óleo essencial de Melissa officinalis. 2011. Dissertação (Mestrado) - Universidade Federal de Uberlândia, Minas Gerais.

SILVEIRA, P.M.; CUNHA, A.A. Variabilidade de micronutrientes, matéria orgânica e argila de um Latossolo submetido a sistemas de preparo. Pesquisa

Agropecuária Brasileira, v. 37, n. 9, p. 1325-1332, 2002.

SKOOG, D. A.; HOLLER, F. J.; NIEMAN, T. A. Principles of Instrumental Analysis, 5th edition. Saunders College Publishing, EUA. 0-03-002078-6, 1998.

SODRÉ, A.C.B.; LUZ, J.M.Q.; HABER, L.L.; MARQUES, M.O.M.; RODRIGUES, C.R.; BLANK, A.F. Organic and mineral fertilization and chemical composition of lemon balm (Melissa officinalis) essential oil. Revista brasileira de farmacognosia, v. 22, n. 1, p. 40-44, 2012. 
SORENSEN, J. Melissa officinalis. International Journal of Aromatherapy, v. 10, p. $7-17,2000$.

SOUZA, S.N.P. Desenvolvimento de métodos analíticos para determinação de $\mathrm{Cd}, \mathrm{Cu}, \mathrm{Fe}, \mathrm{Pb}$ e $\mathrm{Zn}$ em amostras de patês por espectrometria de absorção atômica. 2014. Tese (Doutorado) - Universidade Federal de Minas Gerais, Belo Horizonte, Minas Gerais.

SOUZA, S.V.C.; JUNQUEIRA, R.G. A procedure to assess linearity by ordinary least squares method. Analytica Chimica Acta, v. 552, p. 25-35, 2005.

SUSSA, F.V.; DAMATTO, S.R.; FÁVARO, D.I.T.; MAZZILLI, B.P.; SILVA, P. S. C. Radioactive and stable elements' concentration in medicinal plants from Brazil. Journal of Radioanalytical and Nuclear Chemistry, v. 281, n. 2, p. 165-170, 2009.

SUSSA, F.V.; DUARTE, C.L.; FURLAN, M.R.; SILVA, P.S.C. Agricultural management, season and trace elements effects on volatile oil production from Melissa officinalis L. (Lemon balm). Journal Radioanalitical and Nuclear Chemistry, v. 307, n. 3, p. 2365-2371, 2016.

TAIZ, L.; ZEIGER, E. Fisiologia Vegetal, 3. ed. Porto Alegre, 719 p. 2004.

TAVARES, I.B.; MOMENTÉ, V.G.; do NASCIMENTO, I.R. Lippia alba: estudos químicos, etnofarmacológicos e agronômicos. Revista Brasileira de Tecnologia Aplicada nas Ciências Agrárias, Guarapuava-PR, v. 4, n. 1, p. 204-220, 2011.

TOUNEKTI, T.; MUNNÉ-BOSCH, S.; VADEL, A.M.; CHTARA, C.; KHEMIRA, H. Influence of ionic interactions on essential oil and phenolic diterpene composition of Dalmatian sage (Salvia officinalis L.). Plant Physiology and Biochemistry, v. 48, p. 813-821, 2010.

TUOMI, J.; FAGERSTRÖM T.; NIEMELÄ, P. Carbon allocation, phenotypic plasticity and induced defences. In: TALLAMY, D.W.; RAUPP, M.J.

Phytochemical Induction by Herbivores. New York: John Wiley, 1991. p. 85104.

VAIČIULYTĖ, V.; LOŽIENĖ, K.; TARAŠKEVIČIUS, R.; BUTKIENĖ, R. Variation of essential oil composition of Thymus pulegioides in relation to soil chemistry. Industrial Crops and Products, v. 95, p. 422-433, 2017.

VALLE, L.A.R. do. Avaliação de elementos-traço em fertilizantes e corretivos. 2012. Dissertação (Mestrado) - Universidade Federal de Lavras, Lavras. 
VIEGAS, M.C.; BASSOLI, D.G. Utilização do Índice de Retenção Linear para caracterização de compostos voláteis em café solúvel utilizando GC-MS e coluna HP-INNOWAX. Química Nova, v. 30, n. 8, p. 2031-2034, 2007.

VULCANO, I.R.C.; SILVEIRA, J.N.; ALVAREZ, E.M.L. Teores de chumbo e cádmio em chás comercializados na região metropolitana de Belo Horizonte. Revista Brasileira de Ciências Farmacêutica, v. 44, n. 3, p. 425- 431, 2008

WARNER, R. Applied Statistics - From Bivariate Through Multivariate Techniques. 2 ed., 1172 p., 2013.

WHO - World Health Organization. Preventing Disease Through Healthy Environments, WHO, 2010. Acesso em fevereiro de 2015. Disponível em: http://www.who.int/quantifying_ehimpacts/publications/preventingdisease/en/

YAMASHITA, C.I.; SAIKI, M.; SERTIÉ, J.A.A. Elemental analysis of leaves and extracts of Casearia medicinal plants by instrumental neutron activation analysis. Journal of Radioanalitical and Nuclear Chemistry, v. 270, n. 1, p. 181-186, 2006.

YILMAZ, S.; UCAR, S.; ARTOK, L.; GULEC, H. The kinetics of citral hydrogenation over Pd supported on clinoptilolite rich natural zeolite. Applied Catalysis A: General. v. 287, p. 261-266, 2005.

YOON, J.; CAO, X.; ZHOU, Q.; MA, L.Q. Accumulation of $\mathrm{Pb}, \mathrm{Cu}$, and $\mathrm{Zn}$ in native plants growing on a contaminated Florida site, Science of The Total Environment, v. 368, n. 2-3, p. 456-464, 2006. 